Universidade de São Paulo

Instituto de Química

\title{
ESTUDO DAS INTERAÇÕES ENTRE VANÁDIO E TERRAS RARAS CONJUGADOS AO CATALISADOR ZEOLÍTICO PARA CRAQUEAMENTO
}

\author{
GUINTAR LUCIANO BAUGIS \\ Prof.a Dr.a Wanda de Oliveira \\ Orientadora
}

\begin{abstract}
Tese apresentada ao Instituto de Química da Universidade de São Paulo para obtenção do título de Doutor em ciências com área de concentração em química inorgânica.
\end{abstract}

São Paulo

2003 
Ficha Catalográfica

Elaborada pela Divisão de Biblioteca e

Documentação do Conjunto das Químicas da USP.

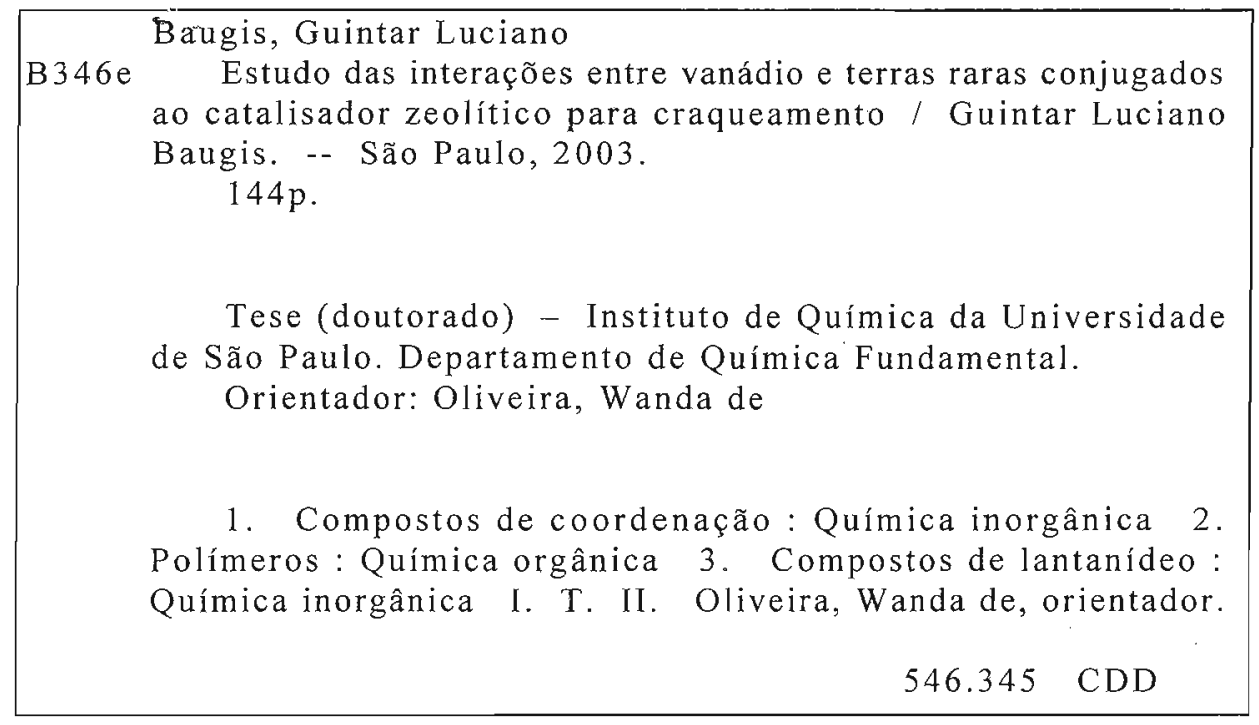




\section{"Estudo das interaçōes entre vanádio e terras raras conjugados ao catalisador zeolítico para craqueamento".}

\section{GUINTAR LUCIANO BAUGIS}

Tese de Doutorado submetida ao Instituto de Química da Universidade de São Paulo como parte dos requisitos necessários à obtenção do grau de Doutor em Química - Área: Química Inorgânica.
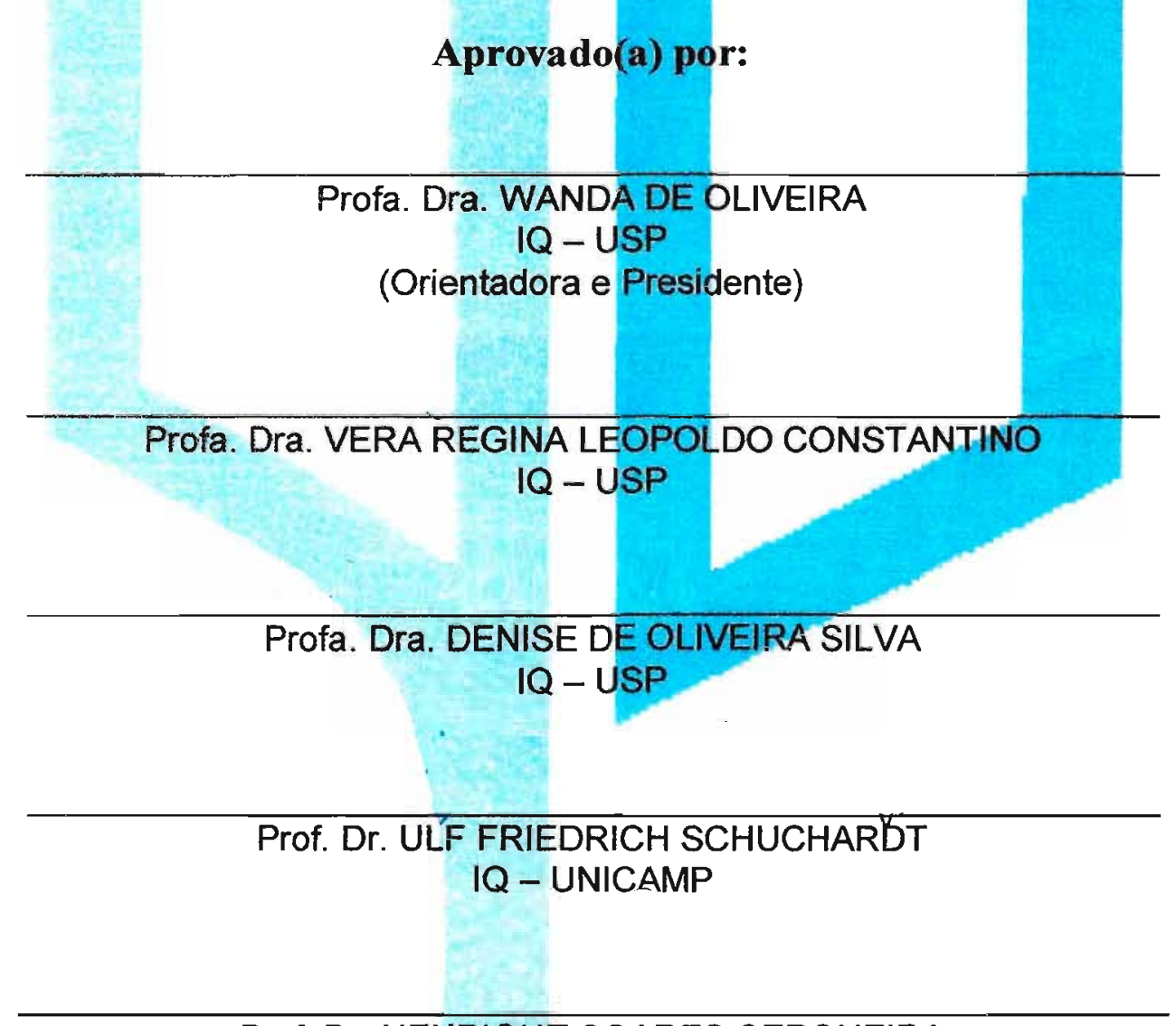

Prof. Dr. HENRIQUE SOARES CERQUEIRA

Petrobrás

SÃo PAULO

02 DE DEZEMBRO 2003. 
"O importante não é o que se conhece, mas sim, aquilo que com o conhecimento se realiza"

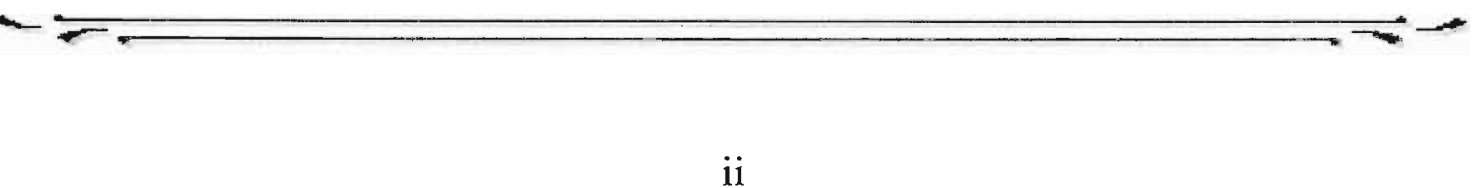


À Gabriela e Heliete, pela compreensão na ausência. 


\section{Agradecimentos}

Ao longo deste trabalho muitos foram aqueles que conosco colaboraram e, infelizmente, a praxe não me permite ir além destes poucos parágrafos. Assim, desejo destacar em agradecimentos, principalmente:

À Profa. Dra. Wanda de Oliveira, não só pela orientação e oportunidade de com ela trabalhar, mas também a todos estes anos de convívio e atenção;

Ao químico Fernando Rabello de Castro, por sua amizade, disposição e confiança no meu trabalho. Tenho certeza de que sem o seu apoio as páginas que seguem a estas não estariam apresentadas da forma como estão;

Reservo especiais agradecimentos aos engenheiros Paulo César Santos de Aguiar, Antônio Ésio Bresciani, Maurício Hoansan Tan e Nelson Hatiro Ueta, pelo apoio, pela oportunidade que me deram de desenvolver este trabalho e, sobretudo, à convicção que me deixam de que a Petrobras se tornou essa grande companhia graças à capacidade dos seus profissionais;

Ao Prof. Dr. Hermi Felinto de Brito, por seus conselhos, pelos momentos de descontração e pela impressão que me deixou de um extraordinário profissional da pesquisa científica;

Aos professores e amigos Alcides Eduardo Jacomassi e Lincoln Gonçalves Couto, pelo companheirismo, pela colaboração e pelo estímulo na obtenção desta conquista;

Aos engenheiros Oscar René Chamberlain de Pravia, Henrique Soares Cerqueira, Alexandre Costa Figueiredo, Eduardo Falabella Sousa-Aguiar, João Adolfo Oderich e José Antonio Moreno Castillero, pelo apoio e disposição que tiveram conosco durante a realização deste trabalho; 
Aos amigos do setor de desenvolvimento de produtos da Refinaria de Capuava, especialmente, a José Carlos Siciliano e Renato Maion;

Aos profissionais Mauri Baldini Cardoso e Sonia Maria Cabral de Menezes, ambos do CENPES, pelo suporte na realização dos experimentos de XPS e NMR;

À Profa Dra Ana Maria Costa Ferreira, pela colaboração com os ensaios de EPR;

À Alessandra Sousa Maia, pelo apoio e grande colaboração que me prestou em todas as etapas dessa jornada;

Ao CNPQ pelo auxílio e suporte concedido durante parte do trabalho. 


\section{Resumo}

No processo de craqueamento catalítico fluidizado do petróleo (FCC) ocorre o envenenamento do catalisador pelo $\mathrm{V}$ presente sob a forma de complexos, que se decompõem na etapa de regeneração resultando espécies que atacam estruturalmente a zeólita - o principal componente do sistema catalítico. O emprego de terras raras (TR) como passivadores do efeito deletério provocado pelo $\mathrm{V}$ neste processo é estudado no presente trabalho.

Sob condições similares àquelas encontradas no processo de regeneração, trisacetilacetonatos TR foram adicionados ao catalisador para craqueamento na presença de $\mathrm{V}$ em proporções estabelecidas. Os resultados da interação entre os componentes deste sistema foram analisados e observou-se que as TR têm razoável capacidade de inibir o ataque do $\mathrm{V}$ ao catalisador desativado, preservando parcialmente a conversão catalítica do material. Análises de propriedades texturais, luminescência e DRX indicaram que a inserção de TR por meio de complexos é mais efetiva que por meio de óxidos no método empregado, além de não influenciarem as propriedades originais do catalisador na ausência de $\mathrm{V}$. Os resultados dos ensaios realizados por RPE, EFX, RMN ${ }^{51} \mathrm{~V}$ e MEV-EED revelaram que a capacidade demonstrada pelas TR em neutralizar o V está associada à formação de $\mathrm{TRVO}_{4}$ termo-quimicamente estáveis nas condições estudadas. Em virtude da reduzida capacidade de permeação das TR através das partículas do catalisador, a interação ocorre preferencialmente na superficie das micro-esferas. Todas as TR foram encontradas no catalisador desativado no estado de oxidação (III) e o V no estado de oxidação (V). As TR estudadas apresentaram desempenhos ligeiramente diferentes, no que concerne à neutralização do V no sistema e o Y apresenta o melhor desempenho. Propôs-se, para este sistema um mecanismo que relaciona a capacidade de passivação da TR às propriedades termodinâmicas da reação com $\mathrm{V}$. 


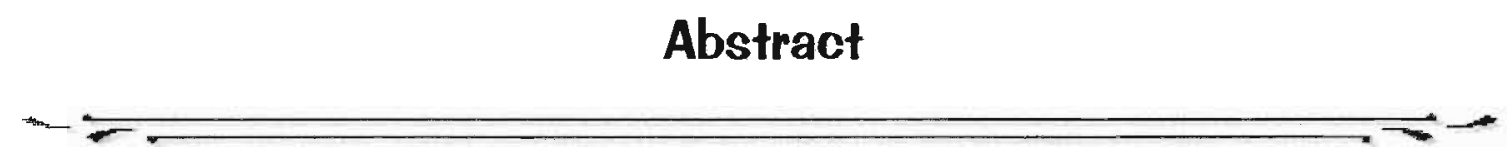

In the fluidized catalytic cracking process (FCC process) of petroleum, vanadium complexes present in the FCC feed cause catalyst poisoning. The decomposition of these complexes in the regeneration step produces species that attack the zeolite structure - the main active component in the catalytic system. This work evaluates the employment of rare earths (RE) as passivators to mitigate the deleterious effects of the V in the FCC feed.

Controlled amounts of tris-acethylacetonate of RE were added to cracking catalyst containing $\mathrm{V}$, under similar conditions to those of the regeneration process. The results of the interaction among the components of this system were analyzed and it was observed that $\mathrm{RE}$ have reasonable capacity to inhibit the $\mathrm{V}$ attack to the disabled catalyst, partially preserving the material catalytic conversion. Analyses of textural properties, luminescence and $\mathrm{XRD}$ indicated that the insertion of RE as complexes is more effective than as oxides in the methods employed. Also, they do not influence the catalyst original properties in the absence of $\mathrm{V}$. The results of the experiments accomplished by EPR, XPS, ${ }^{51} \mathrm{~V}$ NMR and SEM-EDS revealed that the capacity demonstrated by RE to neutralize the $\mathrm{V}$ is associated with the formation of thermo chemically stable $\mathrm{REVO}_{4}$ at the test conditions. Due to the reduced capacity of $\mathrm{RE}$ penetration into the catalyst particles, the interaction happens preferentially in the surface of the micro spheres. All RE found in the catalyst were at the oxidation state (III) and the $\mathrm{V}$ at the oxidation state (V). The RE studied presented approximately the same performance in terms of $\mathrm{V}$ immobilization on the system and $\mathrm{Y}$ presents the best performance. For this system, a mechanism that relates the passivation capacity of RE to the thermodynamic properties of the reaction with $\mathrm{V}$ is proposed. 


\section{Resumen}

En el proceso de craqueo catalítico fluido del petróleo (FCC) ocurre el envenenamiento del catalizador por el Vanadio presente sobre la forma de complejos, que se descomponen en la etapa de regeneración resultando en especies que atacan estructuralmente la zeolita - el componente activo del sistema. El empleo de tierras raras (TR) como pasivadores del efecto perjudicial provocado por el Vanadio en este proceso es estudiado en el presente trabajo.

Sobre condiciones similares a aquellas encontradas en la regeneración del proceso, tris-acetylacetonato de TR fueron adicionados al catalizador para craqueo en la presencia de Vanadio en proporciones establecidas. Los resultados de la interacción entre los componentes de este sistema fueron analizados y se observó que las TR tienen razonable capacidad de inhibir el ataque del Vanadio al catalizador desactivado, preservando parcialmente la conversión catalítica del material. Análisis de propiedades texturales, luminescencia y XRD indicaron que la inserción de TR por medio de complejos es más efectiva que por medio de óxidos en el método empleado, además de que influencía las propiedades originales del catalizador en la ausencia de Vanadio. Los resultados de los ensayos realizados por EPR, XPS, RMN ${ }^{51} \mathrm{~V}$ y SEM-EDS revelaron que la capacidad demostrada por las TR en neutralizar el Vanadio está asociada a la formación de $\mathrm{TRVO}_{4}$ termoquímicamente estable en las condiciones estudiadas. En virtud de la reducida capacidad de permeación de las TR a través de las partículas del catalizador, la interacción entre ocurre pronunciadamente en la superficie de las microesferas. Todas las TR fueron encontrados en el catalizador desactivado en el estado del oxidación (III) y el Vanadio en el estado del oxidación (V). Las TR estudiadas presentaron distintos desempeños, en lo que concierne a la neutralización del Vanadio en el sistema y Y presenta la mejor actuación. Un mecanismo fue posible proponer para el sistema que relaciona la capacidad de pasivación del las TR con las propiedades termodinámicas de la reacción con Vanadio. 


\section{Índice Geral}

Capítulo 1 Introdução

1.1. Visão sobre a indústria do petróleo ……............................................. 1

1.1.1. A composição do petróleo ....................................................... 2

1.1.2. Os processos fundamentais da indústria do petróleo ................. 3

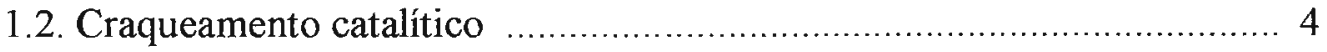

1.2.1. Histórico do processo ................................................................. 4

1.2.2. Descrição sumária do processo de craqueamento catalítico ........... 6

1.3. Catalisadores para craqueamento .................................................... 9

1.3.1. O desenvolvimento dos catalisadores para craqueamento ............. 9

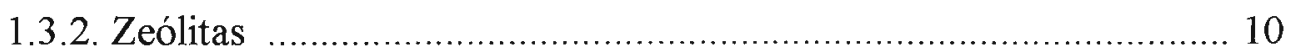

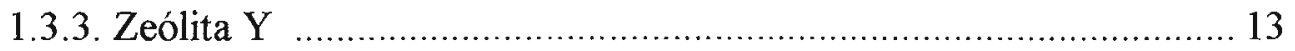

1.3.4. Preparo dos catalisadores para craqueamento ............................ 15

1.3.5. Mecanismos de reação de hidrocarbonetos em zeólitas ................. 18

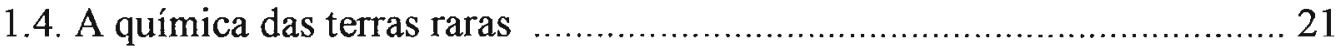

1.4.1. Complexos de terras raras ......................................................... 23

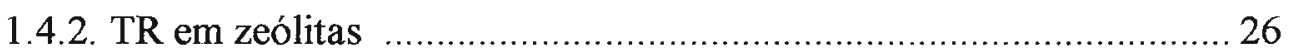

1.5. Desativação dos catalisadores para craqueamento................................. 28

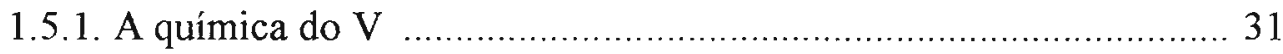

\section{Capítulo 2 Revisão Bibliográfica}

2.1. O efeito da incorporação de $\mathrm{V}$ ao catalisador para craqueamento .......... 37

2.1.1 Métodos para estudo da desativação do catalisador por $\mathrm{V}$............... 37

2.1.2. Mecanismos de ataque do $\mathrm{V}$ ao catalisador para craqueamento ...... 38

2.2 Meios de neutralização do ataque do V ao sistema ............................... 43

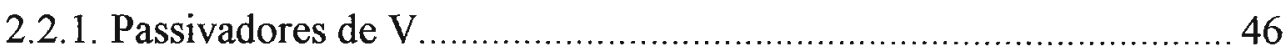

2.2.2. Aplicação de TR como passivadores de V ................................. 48 
Capítulo 3 Objetivos

3.1. Descrição do problema e contexto da tese

Capítulo 4 Materiais e Métodos

4.1. Preparação e caracterização dos sistemas ........................................... 65

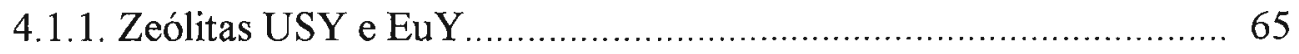

4.1.2. Catalisador para craqueamento................................................... 65

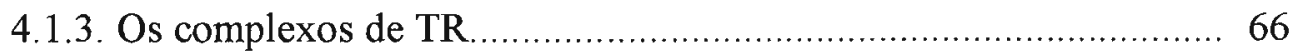

4.1.4. O complexo de V.............................................................. 77

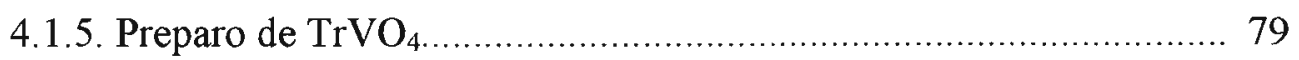

4.1.6. Incorporação dos elementos ao catalisador................................. 80

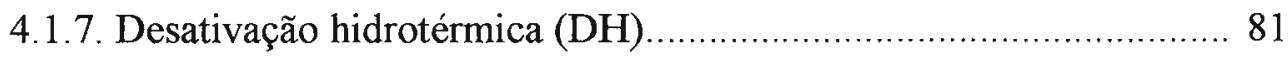

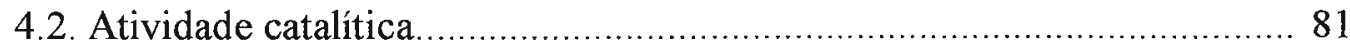

4.3. Escopo das técnicas analíticas empregadas na caracterização dos

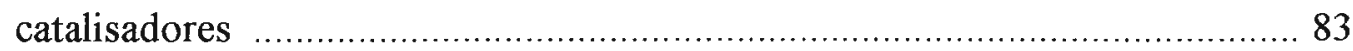

4.3.1. Análise das Propriedades Texturais ............................................ 83

4.3.2. Difração de raios-X (XRD) .................................................. 83

4.3.3. Microscopia Eletrônica de Varredura e espectrometria de energia dispersiva

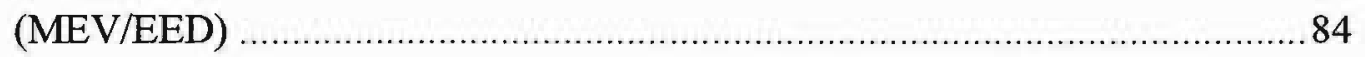

4.3.4. Ressonância Paramagnética Eletrônica .......................................... 84

4.3.5. Ressonância Magnética Nuclear (RMN) de ${ }^{51} \mathrm{~V}$.......................... 84

4.3.6. Espectroscopia foto-eletrônica de raios-X (EFX) ..........................85

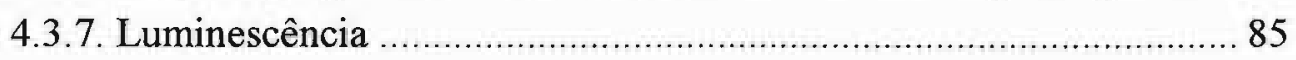

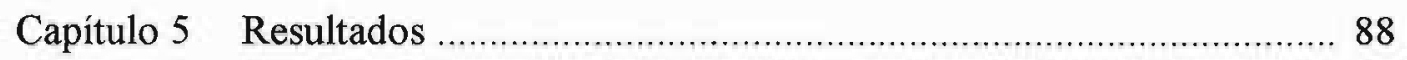

5.1. Fluorescência de Raios-X …........................................................ 88

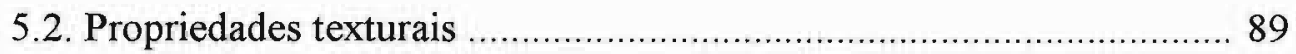

5.3. Difração de raios-X .................................................................... 93

5.4. Microscopia Eletrônica de Varredura .............................................. 96

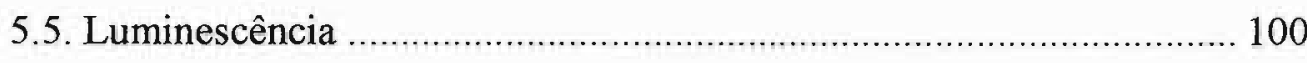

5.6. Ressonância Paramagnética Eletrônica ........................................... 108

5.7. Ressonância Magnética Nuclear ...................................................... 113 
5.8. Espectroscopia de Foto-eletrônica de Raios-X

5.9. Atividade Catalítica

Capítulo 6 Análise e discussão. 128

Capítulo 7 Conclusões 140 


\section{Índice de Figuras}

1.1. Esquema do processo de destilação do petróleo ..................................... 4

1.2. Esquema do processo de craqueamento catalítico .................................. 7

1.3. Construção de diferentes zeólitas a partir da unidade fundamental ........... 11

1.4. Geometria e tamanho das cavidades da zeólita Y ............................... 13

1.5. Formação dos sítios de Brönsted em zeólitas ........................................ 14

1.6. Formação dos sítios de Lewis e desaluminização de zeólitas ..................... 14

1.7. Composição, formato e dimensão das partículas do catalisador para

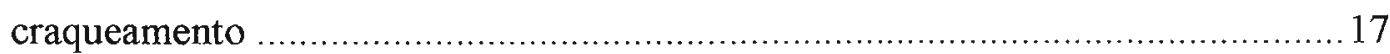

1.8. Processo comercial de fabricação do catalisador para craqueamento ......... 17

1.9. Mecanismos de formação dos carbocátions por meio de zeólitas .............. 19

1.10. Formas tautoméricas das $\beta$-dicetonas .......................................... 25

1.11. Anel quelato dos complexos metálicos com $\beta$-dicetonas …................. 25

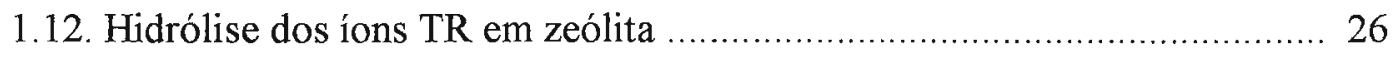

1.13. Complexo de TR coordenado na cavidade $\beta$ da zeólita $Y$................... 27

1.14. Evolução do teor médio de V (em ppm) no catalisador de FCC usado....... 31

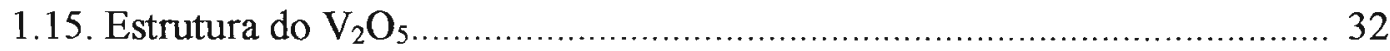

2.1. Métodos de incorporação de trapas metálicas ao catalisador ...................... 44

3.1. Composição dos óxidos de TR presentes em termos de elemento .............. 61

3.2. Elementos selecionados para o estudo ….................................................6. 62

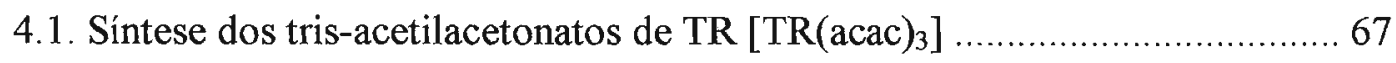

4.2. Curvas de titulação da Hacac e dos íons $\mathrm{La}^{3+} \mathrm{e} \mathrm{Nd}^{3+}$ na presença de excesso de

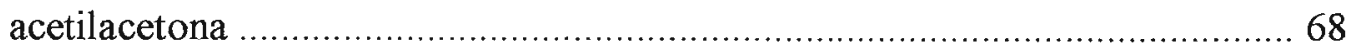

4.3. $1^{\text {a }}$ derivada da curva termogravimétrica do complexo $\mathrm{La}(\mathrm{acac})_{3}$ hidratado e após desidratação .71

4.4. $1^{\text {a }}$ derivada da curva termogravimétrica do complexo Ce(acac) $)_{3}$ hidratado e após desidratação 71

4.5. $1^{\text {a }}$ derivada da curva termogravimétrica do complexo $\mathrm{Nd}(\mathrm{acac})_{3}$ hidratado e após desidratação 72 
4.6. $1^{\text {a }}$ derivada da curva termogravimétrica do complexo Gd(acac) ${ }_{3}$ hidratado e após desidratação

4.7. $1^{\text {a }}$ derivada da curva termogravimétrica do complexo Dy(acac $)_{3}$ hidratado e após desidratação

4.8. $1^{\text {a }}$ derivada da curva termogravimétrica do complexo $\mathrm{Y}(\mathrm{acac})_{3}$ hidratado e após desidratação. 73

4.9. $1^{\text {a }}$ derivada da curva termogravimétrica do complexo $\mathrm{Yb}(\mathrm{acac})_{3}$ hidratado e após desidratação.

4.10. Espectro de transmitância na região do infravermelho do complexo $\mathrm{Yb}(\mathrm{acac})_{3}$ hidratado e após desidratação 75

4.11. Modelos vibracionais do ânion acac76

4.12. Geometria do complexo $\mathrm{La}(\mathrm{acac})_{3} \cdot 2 \mathrm{H}_{2} \mathrm{O}$ 77

4.13. Geometria do complexo trans $\mathrm{VO}(\mathrm{bzac})_{2}$ 78

4.14. $1^{\mathrm{a}}$ derivada da curva termogravimétrica do complexo $\mathrm{VO}(\mathrm{bzac})_{2}$ .79

4.15. Esquema do equipamento empregado na $\mathrm{DH}$ 81

4.16. Esquema típico do equipamento para determinação do ensaio de microatividade catalítica 82

5.1. Análise de área superficial $\mathrm{BET}\left(\mathrm{m}^{2} / \mathrm{g}\right)$ das amostras de catalisador pré-desativado incorporadas com V e TR através dos complexos e óxidos após DH 91

5.2. Análise de área superficial BET $\left(\mathrm{m}^{2} / \mathrm{g}\right)$ das amostras de catalisador pré-desativado incorporadas com $\mathrm{Nd}$ e $\mathrm{V}$ após $\mathrm{DH}$ 92

5.3. Difratogramas de amostras submetidas à $\mathrm{DH}$ 94

5.4. Microscopia eletrônica de varredura da amostra Cd em aproximações de $100 \mu \mathrm{m}$ (a) e $10 \mu \mathrm{m}(\mathrm{b})$ 96

5.5. Microscopia eletrônica de varredura da amostra CdV em aproximações de $100 \mu \mathrm{m}$ (a) e $10 \mu \mathrm{m}(\mathrm{b})$ 97

5.6. Microscopia eletrônica de varredura das amostras $\mathrm{Cd}$ e CdV com aproximação de $2 \mu \mathrm{m}$ 98

5.7. Microscopia eletrônica de varredura de partículas secionadas de CdV secionadas em aproximações de $10 \mu \mathrm{m}$ (elétrons retro-espalhados) 98

5.8. Microscopia eletrônica de varredura da amostra CdVDy em aproximações de $30 \mu \mathrm{m}$ e $2 \mu \mathrm{m}$ 99 
5.9. Microscopia eletrônica de varredura de partículas secionadas de CdVDy secionadas em aproximações de $10 \mu \mathrm{m}$ (elétrons retro-espalhados) 100

5.10. Espectros de excitação das amostras $\mathrm{Y}-\mathrm{V}$ após $\mathrm{DH}, \mathrm{EuVO}_{4} \mathrm{e} \mathrm{GdVO}_{4}$ coletados a $77 \mathrm{~K}\left(\lambda_{\mathrm{em}}=616 \mathrm{~nm}\right)$ 101

5.11. Espectros de excitação das amostras EuY-V e EuY-V/TR após DH coletados a $77 \mathrm{~K}$ $\left(\lambda_{\mathrm{em}}=616 \mathrm{~nm}\right)$ 102

5.12. Valores do parâmetro de intensidade $b$ das amostras após DH a partir dos espectros de excitação a $77 \mathrm{~K}\left(\lambda_{\mathrm{em}}=616 \mathrm{~nm}\right)$ 103

5.13. Espectros de emissão das amostras EuY antes e após DH a $77 \mathrm{~K}$ $\left(\lambda_{\mathrm{ex}}=394 \mathrm{~nm}\right)$ 104

5.14. Espectros de emissão das amostras EuY-V e EuY-V/TR após DH coletados a $77 \mathrm{~K}$ $\left(\lambda_{\text {ex. }}=394 \mathrm{~nm}\right)$ 104

5.15. Espectros de emissão das amostras $\mathrm{Y}-\mathrm{V}$ após $\mathrm{DH}, \mathrm{EuVO}_{4}$ e GdVO $\mathrm{Gd}_{4}$ coletados a $77 \mathrm{~K}\left(\lambda_{\mathrm{ex}}=394 \mathrm{~nm}\right)$ 108

5.16. Espectros de RPE das amostras $\mathrm{V}_{2} \mathrm{O}_{5}, \mathrm{VO}(\mathrm{Bzac})_{2}$ em tolueno e $\mathrm{Cd}$ 110

5.17. Espectros de RPE das amostras $\mathrm{CdV}$ após incorporação com $\mathrm{V}$, antes e após DH 111

5.18. Curva de concentração do teor de $\mathrm{V}^{4+}$ em função do espectro de RPE 112

5.19. Espectro de $\mathrm{RMN}^{51} \mathrm{~V}$ das amostras $\mathrm{CdV}$ após $\mathrm{DH}$ e $\mathrm{V}_{2} \mathrm{O}_{5}$ 114

5.20. Espectro de $\mathrm{RMN}^{51} \mathrm{~V}$ das amostras CdVLaY após $\mathrm{DH}$ e $\mathrm{LaVO}_{4}$ 115

5.21. Espectro de RMN ${ }^{51} \mathrm{~V}$ das amostras CdVY após DH e $\mathrm{YVO}_{4}$ 115

5.22. Espectro de $\mathrm{RMN}{ }^{51} \mathrm{~V}$ das amostras CdVCe após $\mathrm{DH}$ e $\mathrm{CeVO}_{4}$ 116

5.23. Espectro de $\mathrm{RMN}{ }^{51} \mathrm{~V}$ das amostras CdVNd após $\mathrm{DH}$ e $\mathrm{NdVO}_{4}$ 116

5.24. Espectros de EFX da amostra CdV 118

5.25. Espectros de EFX da amostra CdVCe 119

5.26. Limites da análise por EFX 120

6.1. Ataque do $\mathrm{V}$ à zeólita na presença o $\mathrm{Al}$ extra-estrutural gerado na $\mathrm{DH}$ 130

6.2. Permeação dos elementos de TR e V sob a estrutura do catalisador 131

6.3. Resultados de área superficial $\mathrm{BET}$ das amostras submetida à $\mathrm{DH}$ com os respectivos intervalos com $95 \%$ de confiança para a média 132

6.4. Diagramas de fases para o sistema $\mathrm{TR}_{2} \mathrm{O}_{3}-\mathrm{V}_{2} \mathrm{O}_{5}(\mathrm{TR}=\mathrm{La}, \mathrm{Nd})$ 133 6.5. Disposição estrutural do $\mathrm{TRVO}_{4}$ 134 
6.6. $\Delta H f^{\circ}$ de $\mathrm{TRVO}_{4} \mathrm{e} \mathrm{TR}_{2} \mathrm{O}_{3}, \mathrm{em}-\mathrm{kJ} \cdot \mathrm{mol}^{-1}$

6.7. Relação entre a área BET das amostras submetidas à $\mathrm{DH}$ e $\Delta H f^{\circ}$ de $\mathrm{TRVO}_{4}$, em $-\mathrm{kJ} . \mathrm{mol}^{-1}$ 136

6.8. Relação entre parâmetro de intensidade $b$ e $\Delta H f^{0} \mathrm{TRVO}_{4}$, em -kJ.mol ${ }^{-1} \quad \ldots .137$

7.1. Área do catalisador preservada em função da relação mássica de TR/V por elemento nas amostras de catalisador pré-desativado 141 


\section{Índice de Tabelas}

1.1. Perfil de rendimentos típico e composição dos produtos do processo de craqueamento 8

1.2. Caracterização físico-química dos resíduos atmosféricos dos petróleos Marlim e

Nigeriano 30

3.1. Pontos de fusão do $\mathrm{V}$ e seus óxidos em estados de oxidação diferentes ....... 60

3.2. Concentração de TR nos seus principais minérios 62

4.1. Caracterização físico-química da zeólita USY e do catalisador p/ craqueamento 66

4.2. Rendimento, em \%, dos complexos tris-acetilacetonatos obtidos em síntese para diferentes elementos 70

4.3. Caracterização elementar dos complexos por emissão atômica de plasma e análise térmica 70

4.4. Atribuição das bandas presentes no espectro na região do infravermelho de $\operatorname{TR}(\mathrm{acac})_{3}$ .76

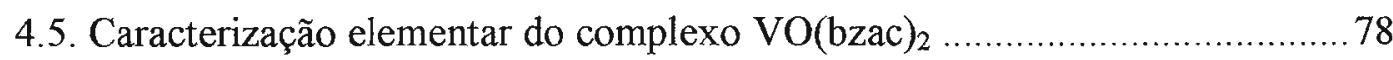

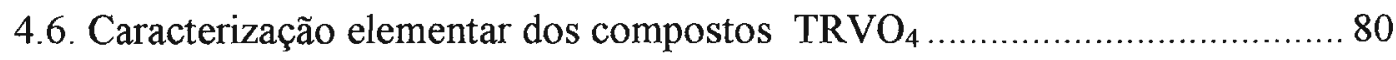

4.7. Técnicas analíticas empregadas na caracterização dos catalisadores 83

5.1. Concentração de V e TR nas amostras de catalisadores fresco (C) e pré-desativado (Cd) e zeólita EuY 88

5.2. Análise de área superficial BET $\left(\mathrm{m}^{2} / \mathrm{g}\right)$ antes e após DH das amostras de catalisador fresco incorporadas por meio dos complexos de $\mathrm{V}$ e TR 89

5.3. Propriedades texturais das amostras de catalisador incorporadas com os complexos de V e TR após DH 90

5.4. Propriedades texturais das amostras de zeólita incorporadas com os complexos de $\mathrm{V}$ e TR após DH 92

5.5. Parâmetro da célula unitária da zeólita e cristalinidade das amostras de catalisador incorporadas com os complexos de V e TR após DH 95

5.6. Parâmetro da célula unitária da zeólita e cristalinidade das amostras de zeólita incorporadas com os complexos de V e TR após DH 96 
5.7. Composição química por EED, em \%, das amostras CdV e CdVDy .99

5.8. Parâmetros de intensidade, razão ${ }^{5} \mathrm{D}_{0} \rightarrow{ }^{7} \mathrm{~F}_{0} / \mathrm{D}_{0} \rightarrow^{7} \mathrm{~F}_{2}$ nos espectros de emissão e medidas do tempo de vida 106

5.9. Razão mássica entre $\mathrm{V}^{4+}$, determinado com RPE, e V total presente nas amostras CdVTR submetidas à $\mathrm{DH}$, em \%

5.10. Deslocamentos químicos das amostras sólidas analisadas por $\mathrm{RMN}$ de ${ }^{51} \mathrm{~V}$, em ppm 117

5.11. Concentrações atômicas (at) e mássicas $(m)$ das superficies das partículas analisadas por EFX 120

5.12. Relações atômicas $\mathrm{Si} / \mathrm{Al}$ da superficie de partículas analisadas por EFX ... 121

5.13. Energia de ligação das amostras de catalisador, em eV 121

5.14. Energia de ligação de espécies de $\mathrm{V}$, em eV 121

5.15. Energia de ligação das linhas respectivas às TR das amostras incorporadas com os passivadores, em eV 122

5.16. Rendimentos no teste de micro atividade das amostras após DH, em \% ... 123

6.1. Tabela de análise de variância (ANOVA) para o ensaio de análise de área superficial com as amostras CdVTR

6.2. $\Delta H f^{\circ}$ de $\mathrm{TRVO}_{4}, \mathrm{em}-\mathrm{kJ} \cdot \mathrm{mol}^{-1}$ 135 


\section{Introdução}

\subsection{Visão sobre a indústria do petróleo}

Conforme dados levantados em 2002 [1], o petróleo ainda contribui com cerca de $40 \%$ da energia primária consumida no mundo. As empresas públicas ou privadas que operam pelo mundo no setor do petróleo envolvem-se em atividades de produção e exploração, refino, transporte, petroquímica e co-geração de energia. Mundialmente, são consumidos 75 milhões de barris por dia, sendo que os países desenvolvidos consomem cerca da metade do petróleo produzido. As maiores reservas conhecidas estão situadas no oriente médio, região de conflitos constantes que transformam este cenário geopolítico em uma combinação explosiva.

Em termos de unidades industriais de refino, há em operação cerca de 740 refinarias pelo mundo com uma capacidade instalada de 80 milhões de barris por dia. No Brasil são produzidos 1,5 milhões de barris por dia de petróleo e o consumo interno está por volta de 1,7 milhões de barris por dia [2]. Estima-se que, com o ritmo de descobrimento de novas reservas e atual nível de consumo, os estoques esgotar-se-ão em prováveis mais 40 anos. Neste cenário, o aumento inevitável e progressivo dos preços do petróleo o fará menos atraente como fonte de energia primária, forçando o emprego em maior escala de energias alternativas. Assim, há como tendência que as empresas de petróleo passem a atuar no campo de provimento de energia no sentido mais amplo. $\mathrm{O}$ perfil de aproveitamento do petróleo, portanto, será alterado, da convencional produção maciça de combustíveis, para fabricação de produtos com maior valor agregado, tais como os produtos petroquímicos mais nobres. 
Diante deste contexto, julga-se que a exploração comercial do petróleo avançará próxima a mais uma centena de anos.

\subsubsection{A composição do petróleo}

O petróleo é uma mistura de substâncias complexa de ocorrência natural, constituída de hidrocarbonetos parafinicos, naftênicos (ciclo-alcanos) e aromáticos, compreendidos em uma ampla faixa de números de carbono. Além dos hidrocarbonetos, o petróleo contém outras substâncias orgânicas consideradas contaminantes: as resinas - que apresentam em sua composição átomos de $\mathrm{S}, \mathrm{N}, \mathrm{O}$ e metais, como $\mathrm{Na}, \mathrm{Ni}, \mathrm{Fe}$ e $\mathrm{V}$; e os asfaltenos - estruturas aromáticas polinucleares de massa molar superior a $4000{\mathrm{~g} . \mathrm{mol}^{-1}}^{-} \mathrm{O}$ petróleo bruto está comumente acompanhado por quantidades variáveis de impurezas, tais como água, matéria inorgânica e gases. As propriedades fisicas do petróleo variam bastante em função da idade de formação, condições geológicas e do estágio de biodegradação alcançado.

Evidências científicas sustentam teoricamente origens diferentes para o petróleo [3], a saber:

- a teoria de origem inorgânica estabelece a formação do petróleo sem qualquer participação de material orgânico e por diferenciação do material que compõe a crosta terrestre, tais como $\mathrm{H}_{2} \mathrm{O}$ e carbonatos, em condições de elevada pressão e temperatura. Esta vertente teórica sustenta-se nas existências de acumulação comerciais de petróleo em rochas cristalinas, ocorrência de hidrocarbonetos em gases vulcânicos e meteoritos e a existência de campos gigantes.

- a teoria de origem orgânica coloca a formação do petróleo a partir da decomposição da matéria orgânica suprida por organismos vegetais ou animais. Segundo esta teoria, em função da deposição da matéria orgânica nos sedimentos os processos bacterianos e químicos durante o soterramento dariam origem ao querogênio - um complexo polimérico. Dada às elevadas temperaturas e pressões nos reservatórios naturais, estes complexos resultariam na formação dos hidrocarbonetos. 
A teoria orgânica é a mais comumente aceita, em função da maior sustentação em evidências científicas. Entre elas, está a presença no petróleo de moléculas consideradas biomarcadores, tais como os isoprenóides e os complexos porfirínicos.

\subsubsection{Os processos fundamentais da indústria do petróleo}

Inúmeras são as aplicações possíveis dos produtos de petróleo. Entretanto, na forma natural como se encontra quando extraído apresenta limitadíssimas utilizações. Os processos de refino foram desenvolvidos anexos ao desenvolvimento tecnológico de outros setores, com objetivo de melhorar o aproveitamento da matéria-prima e agregar valor aos produtos. Basicamente, há dois grupos de operações presentes em uma unidade de refinação de petróleo: separação e conversão [4].

Os processos de separação constituem-se essencialmente em operações de destilação para obtenção de frações ou derivados diretos. Estes processos podem ocorrer em faixas de pressão variável e a qualidade dos derivados obtidos depende diretamente da qualidade do petróleo refinado. A Figura 1.1 apresenta o processo de destilação atmosférica do petróleo. Todas as frações obtidas como produto neste processo possuem aplicação comercial, com exceção ao resíduo atmosférico e aos gasóleos que são normalmente convertidos em outros processos.

O principal processo de conversão primária existente em uma unidade de processamento é o craqueamento de petróleo. Este processo consiste basicamente na quebra (cracking). de estruturas macromoleculares presentes nas cargas resultando fragmentos de hidrocarbonetos de massa molar menor, que possuem maior valor comercial. O craqueamento é responsável pela produção de cerca de $75 \%$ da gasolina automotiva e do gás liquefeito empregado como combustível. Além destes, a obtenção de propeno, usado como monômero para a produção de polipropileno, é quase totalmente realizada por meio do craqueamento de petróleo. 


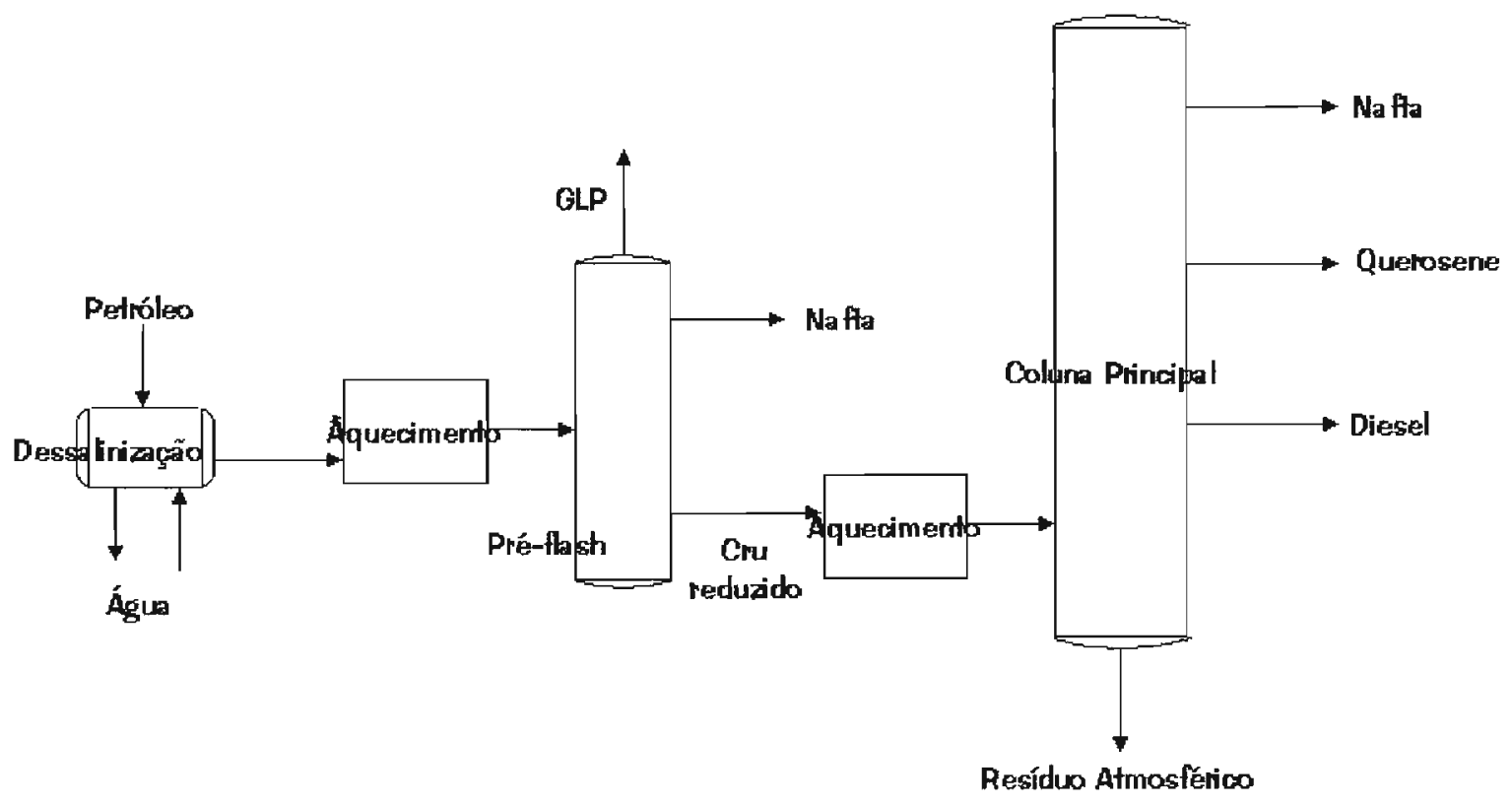

Figura 1.1. Esquema do processo de destilação do petróleo.

\subsection{O craqueamento de petróleo}

Em virtude da rentabilidade e versatilidade operacional, o craqueamento constitui um processo amplamente utilizado em todo o mundo há muitas décadas. Vários fatores colocam o processo de craqueamento em destaque no contexto industrial do processamento de petróleo, entre eles, vale ressaltar a possibilidade de ajuste da produção às necessidades do mercado face à sua grande flexibilidade operacional. Uma unidade de porte médio (50 $\mathrm{mil} \mathrm{barris/d)} \mathrm{em} \mathrm{operação} \mathrm{constante} \mathrm{pode} \mathrm{apresentar} \mathrm{rentabilidade} \mathrm{diária} \mathrm{de} \mathrm{milhões} \mathrm{de}$ dólares [5]

\subsubsection{Histórico do processo}

Os processos de craqueamento surgiram da necessidade de produção de combustíveis em quantidade e qualidade suficiente para atender à crescente demanda [6]. $\mathrm{O}$ crescimento da indústria automobilística dos Estados Unidos no início do século XX foi um importante impulsionador neste aspecto. Até 1913, toda a gasolina produzida era obtida por destilação direta do petróleo. A produtividade e as características do combustível 
dependiam exclusivamente do tipo do petróleo refinado. A grande variedade de petróleos disponíveis resultava também uma grande variação no rendimento e qualidade do produto.

O craqueamento térmico foi o primeiro processo comercial desenvolvido. Até 1943, cerca de metade da gasolina consumida nos Estados Unidos foi obtida por este processo. Apesar do avanço, o processo trazia ainda uma série de desvantagens, tais como baixa conversão, produção de componentes instáveis à oxidação (diolefinas ou alcadienos), condições muito críticas de pressão e temperatura e baixos tempos de campanha devido ao acúmulo acentuado de coque nos reatores.

A viabilidade do emprego de catalisadores no craqueamento foi observada em 1915, em que se percebeu a formação de hidrocarbonetos leves e médios na presença de certas argilas naturais em condições brandas, com formação de uma camada de carbono na superficie [7]. Em 1927, Eugene J. Houdry começou a estudar o emprego contínuo de catalisadores heterogêneos nos processos de craqueamento e notou que a gasolina produzida obtinha qualidade superior em relação ao craqueamento térmico. Em 1936, a primeira unidade industrial empregando o processo Houdry entrava em operação. Era composta por uma série de reatores em leito fixo e o catalisador utilizado era argila bentonítica refinada e ativada com um pré-tratamento ácido. Apesar do sucesso inicial, o processo trazia consigo alguns problemas. As reações de craqueamento (endotérmicas) e regeneração (exotérmicas) ocorriam em um único reator, exigindo muito do material que necessariamente deveria resistir a estas condições extremamente severas.

A separação dos processos de reação e regeneração dentro da mesma unidade foi uma evolução óbvia. Em 1940 a Socony Vaccum desenvolveu um processo de craqueamento catalítico em leito móvel denominado Thermofor. $\mathrm{O}$ catalisador desativado por deposição de coque era elevado entre o forno de regeneração e o reator por meio de dispositivos mecânicos ou pneumáticos. Sem dúvida, um avanço em relação ao Houdry. Contudo, para facilitar o escoamento o catalisador possuía um tamanho granular razoável cerca de $3 \mathrm{~mm}$ de diâmetro - o que trazia algum inconveniente em termos de circulação. Havia também a necessidade do catalisador descer por gravidade, por isso o silo era colocado a grande altura. 
Paralelo ao desenvolvimento do processo Thermofor, a Exxon Research liderando um consórcio de 8 empresas iniciou em 1938 a pesquisa por um processo de craqueamento catalítico heterogêneo em leito fluidizado. Em virtude das necessidades proeminentes da $2^{\mathrm{a}}$ Guerra Mundial, o processo em menos de 3 anos tornou-se comercialmente disponível e foi implementado na Refinaria Bateau Rouge em Lousiana, Estados Unidos. O processo baseia-se no emprego do catalisador finamente dividido em partículas semi-esféricas menores que $150 \mu \mathrm{m}$. Nestas dimensões o catalisador pode ser fluidizado e transferido entre o vaso reator e o regenerador. A carga de hidrocarbonetos entra em contato com o catalisador quente proveniente do regenerador $\mathrm{e}$ as reações do craqueamento são promovidas através da passagem em ascensão por um reator disposto verticalmente. A mistura de catalisador e produtos de reação é separada em um $3^{\circ}$ vaso, por meio de ciclones dispostos internamente.

Desde então, o processo de craqueamento catalítico fluidizado (FCC) é o mais comercialmente empregado na indústria do petróleo. Muitas inovações tecnológicas foram incorporadas desde o primeiro projeto, tais como dispositivos para melhorar a circulação de catalisador, balanço térmico por retirada de calor do conversor e simplifícações estruturais da unidade, otimização dos dispersores de carga, etc. [8]. Contudo, o princípio de funcionamento da unidade continua sendo o mesmo desenvolvido pelo processo original, há mais de 60 anos.

\subsubsection{Descrição sumária do processo de craqueamento catalítico}

Uma unidade industrial típica de craqueamento, conforme apresentada na Figura 1.2 , é composta por 2 seções principais [9]:

- área de conversão - conjunto envolvendo os elementos responsáveis pela reação dos hidrocarbonetos por contato direto com o catalisador, separação do sistema gás-sólido e recuperação da atividade do catalisador;

- área de fracionamento - sistema compreendendo a destilação, para separação dos hidrocarbonetos que atravessam o conversor, e um sistema de recuperação e concentração 
de gases.

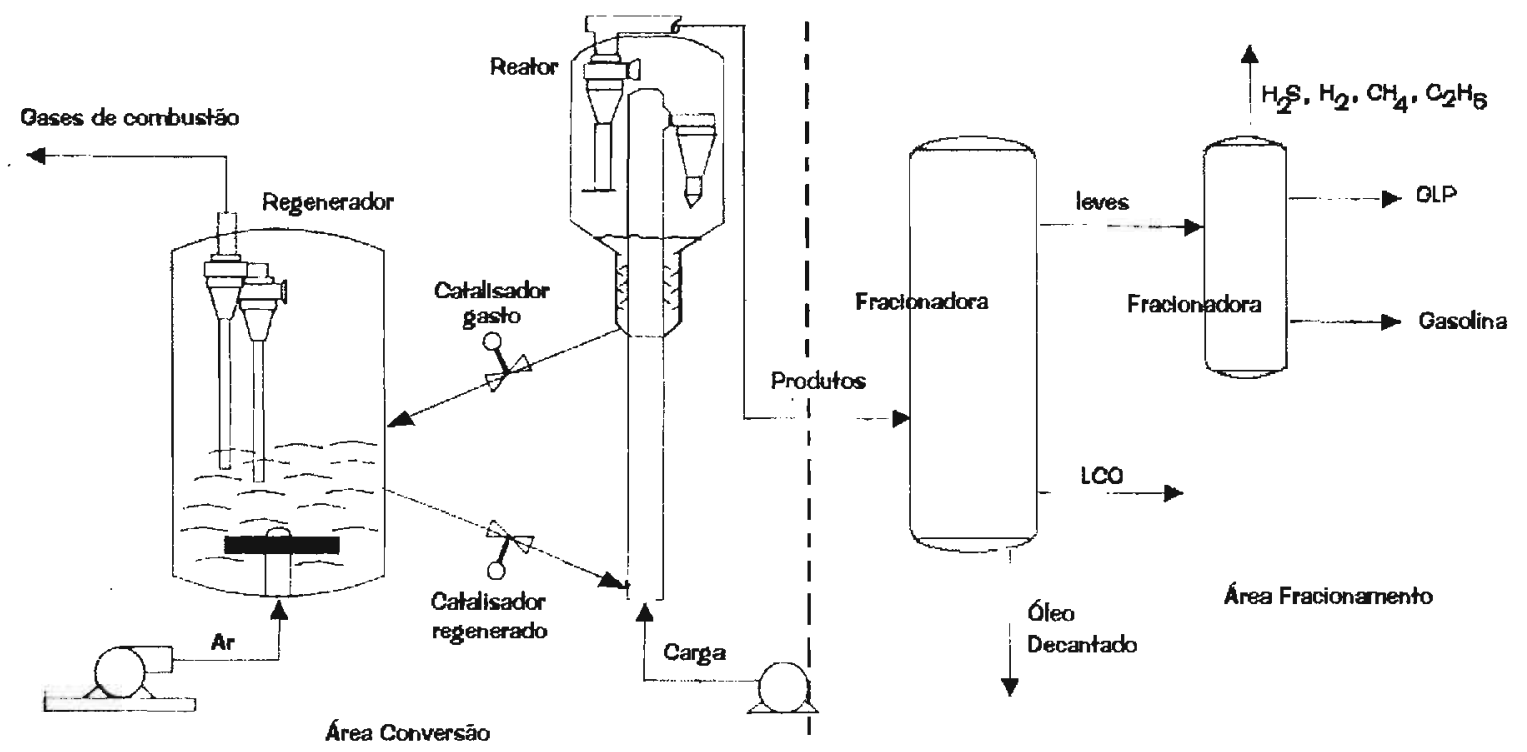

Figura 1.2. Esquema do processo de craqueamento catalitico.

A carga introduzida na unidade pode ser constituída pelo resíduo da destilação atmosférica do petróleo ou uma fração deste obtida por um fracionamento a vácuo. A carga pré-aquecida é dispersa no reator onde entra em contato com o catalisador quente oriundo da seção de regeneração (cerca de $720^{\circ} \mathrm{C}$ ) que supre a energia suficiente para vaporizá-la. A expansão volumétrica desta massa promove o seu deslocamento pelo reator com o auxílio da injeção de vapor de água superaquecido. $\mathrm{O}$ contato entre a carga e o catalisador promoverá a ruptura das ligações $\mathrm{C}-\mathrm{C}$, convertendo parte da carga em hidrocarbonetos de menor tamanho molecular. As características do catalisador empregado, associado a uma série de variáveis operacionais do processo, vão resultar o perfil de produtos obtidos.

Os produtos gerados sob a forma gasosa acompanham o catalisador exausto (desativado) até uma seção de separação, constituída de ciclones em série no interior de um vaso reator. Os gases isentos de sólidos seguem para a seção de fracionamento e recuperação de produtos. Antes da regeneração do catalisador, os hidrocarbonetos residuais arrastados são dessorvidos da sua superfície por meio da retificação com vapor. 
As reações ocorridas no reator provocam também a formação de coque depositado na superfície do catalisador, que é responsável por uma desativação temporária devido à considerável redução do acesso aos sítios ácidos ativos nas reações de craqueamento. Com o objetivo de se restaurar a atividade, o catalisador desativado pelo coque circula entre o vaso de reação e o vaso de regeneração onde por intermédio de uma injeção de ar e por ação da alta temperatura, o coque é eliminado por queima restabelecendo-se parcialmente a atividade catalítica original. Os gases de combustão passam também por uma série de ciclones internos, ficando quase totalmente isentos de sólidos antes de serem lançados à atmosfera.

$\mathrm{Na}$ seção de fracionamento, os gases são submetidos à separação em cortes por faixas de temperatura por intermédio de destilação. Esta seção também dispõe de operações de absorção e recuperação de gases para melhorar o fracionamento. O perfil típico dos produtos obtidos em uma unidade comercial está detalhado na Tabela 1.1. O $\mathrm{H}_{2} \mathrm{~S}$ produzido é convertido em enxofre elementar. O GLP e a gasolina obtida são submetidos a processos específicos para a remoção do teor de S. Parte do GLP pode ser encaminhada à nova seção de fracionamento para a separação do propeno.

Tabela 1.1. Perfil de rendimentos típico e composição dos produtos do processo de craqueamento.

\begin{tabular}{cccc}
\hline Produto & Rendimento (\%) & Composição & Aplicação \\
\hline $\mathrm{H}_{2} \mathrm{~S}$ & 0,5 & & produção de $\mathrm{S}$ \\
$\mathrm{H}_{2}, \mathrm{CH}_{4} \mathrm{e} \mathrm{C}_{2} \mathrm{H}_{6}$ & 4,5 & & combustível, petroquímica \\
GLP & 10,0 & $\mathrm{C}_{3} \mathrm{a} \mathrm{C}_{4}$ & combustível, petroquímica \\
Gasolina & 35,0 & $\mathrm{C}_{5} \mathrm{a} \mathrm{C}_{12}$ & combustível \\
Óleo leve & 12,0 & $\mathrm{C}_{13}-\mathrm{C}_{35}$ & combustível \\
Ó. Aromático & 20,0 & $>\mathrm{C}_{36}$ & combustível, resinas \\
Coque & 8,0 & $(1)$ & combustível \\
\hline
\end{tabular}

(1) aromático polinuclear de composição indefinida. 


\subsection{Catalisadores para craqueamento}

Além de propiciar condições favoráveis para as reações, os catalisadores exercem ainda duas funções fundamentais no processo de craqueamento catalítico fluidizado [6]:

- servir como agente de transporte do coque produzido pelas reações de craqueamento entre o reator e regenerador, possibilitando inclusive o aproveitamento da energia gerada na queima;

- atuar na transferência de calor entre o regenerador e o reator, viabilizando as condições termodinâmicas favoráveis para as reações e energia necessária para a vaporização da carga do processo.

O aprimoramento contínuo dos materiais e processos de fabricação dos catalisadores comerciais tem sido um fator importante para o alcance de melhores resultados e atendimento dos requisitos operacionais necessários, conforme citados acima.

\subsubsection{O desenvolvimento dos catalisadores para craqueamento}

Os primeiros catalisadores comerciais para craqueamento foram produzidos pela Filtrol Inc. e introduzidos com o processo em leito fixo Houdry [10]. Tratavam-se de argilas naturais, do tipo montmorillonitas, submetidas a um tratamento ácido, que era responsável pela formação de grandes poros por desaluminização do material e aumento de acidez, por meio da formação de sítios ácidos. O material apresentava boa resistência hidrotérmica, mas a presença de muitos contaminantes na argila, que não eram removidos pelo ácido, proporcionavam reações indesejáveis como, por exemplo, a desidrogenação dos hidrocarbonetos.

O desenvolvimento do processo catalítico em leito fluidizado impulsionou o desenvolvimento dos primeiros catalisadores sintéticos. Basicamente, eram constituídos de sílica e alumina amorfas agrupadas em partículas de formato semi-esférico [10]. Além de melhorar a qualidade e rendimento dos produtos de maior valor comercial, o catalisador 
ainda incorporava uma série de vantagens em termos operacionais, tais como melhor escoamento e capacidade de fluidização. Nas décadas seguintes, a formulação destes catalisadores foi aprimorada, possibilitando ajustes da atividade catalítica, granulometria, porosidade e área superficial.

A introdução de zeólitas no catalisador de craqueamento comercial no início dos anos 60 foi um dos mais significativos avanços no aprimoramento deste processo. Uma detalhada discussão a respeito deste material está adiante. Em relação aos catalisadores produzidos anteriormente, os catalisadores zeolíticos incorporam uma série de propriedades desejáveis: maior resistência mecânica, maior área superficial disponível, presença de mesoporos, distribuição homogênea de partículas, atividade e seletividade catalítica muito superior [11].

\subsubsection{Zeólitas}

O nome zeólita foi atribuído em 1756 pelo Barão Axel F. Cronsted, um mineralogista sueco, a um extraordinário mineral encontrado que borbulhava quando se aquecia como se estivesse fervendo. O termo é derivado do grego: zeo - ferver, lithos - pedra [12]. As zeólitas naturais são formadas por uma estrutura construída por unidades fundamentais a base de tetraedros de silício $\left(\mathrm{SiO}_{4}\right)^{4-}$ e alumínio $\left(\mathrm{AlO}_{4}\right)^{5-}$. Os tetraedros unem-se pelos vértices onde átomos de oxigênios estão dispostos nas extremidades, contudo, sem compartilhar as faces entre si. Os átomos centrais dos tetraedros nas zeólitas naturais são de $\mathrm{Al}$ e $\mathrm{Si}$, mas têm-se sintetizado outros materiais com a mesma estrutura, compostas de átomos com $\mathrm{Ga}, \mathrm{Ge}, \mathrm{P}, \mathrm{Fe}, \mathrm{B}, \mathrm{Ti}$, entre outros. As unidades tetraédricas são muito regulares, entretanto, a ligação T-O-T (onde T representa o átomo central do tetraedro), pode ter ângulos que variam entre $130^{\circ}$ e $180^{\circ}$, possibilitando um grande número de estruturas combinadas. Ao compartilhar apenas as extremidades, os tetraedros inevitavelmente deixam espaços vazios entre si.

As zeólitas são cristalinas, o que as diferencia da maioria dos materiais, pois possuem canais e espaço interconectados constituindo verdadeiros poros de dimensões moleculares. A Figura 1.3. apresenta o esquema de construção de estruturas zeolíticas a 
partir da unidade tetraédrica fundamental. Em geral, o $\mathrm{O}$ é sempre suprimido das representações gráficas, para efeito de simplificação. Os poros da estrutura têm dimensões específicas e uniformidade ao longo do cristal. Isto permite que moléculas com dimensões compatíveis ao tamanho do poro possam por ele permear, enquanto que moléculas maiores permanecem excluídas. As formas e dimensões dos poros variam de uma estrutura à outra. Algumas zeólitas apresentam cavidades, formadas por grandes espaços vazios de tamanho regular. Na zeólita faujasita, por exemplo, estas cavidades podem alcançar diâmetros de até $11,8 \AA[13]$.

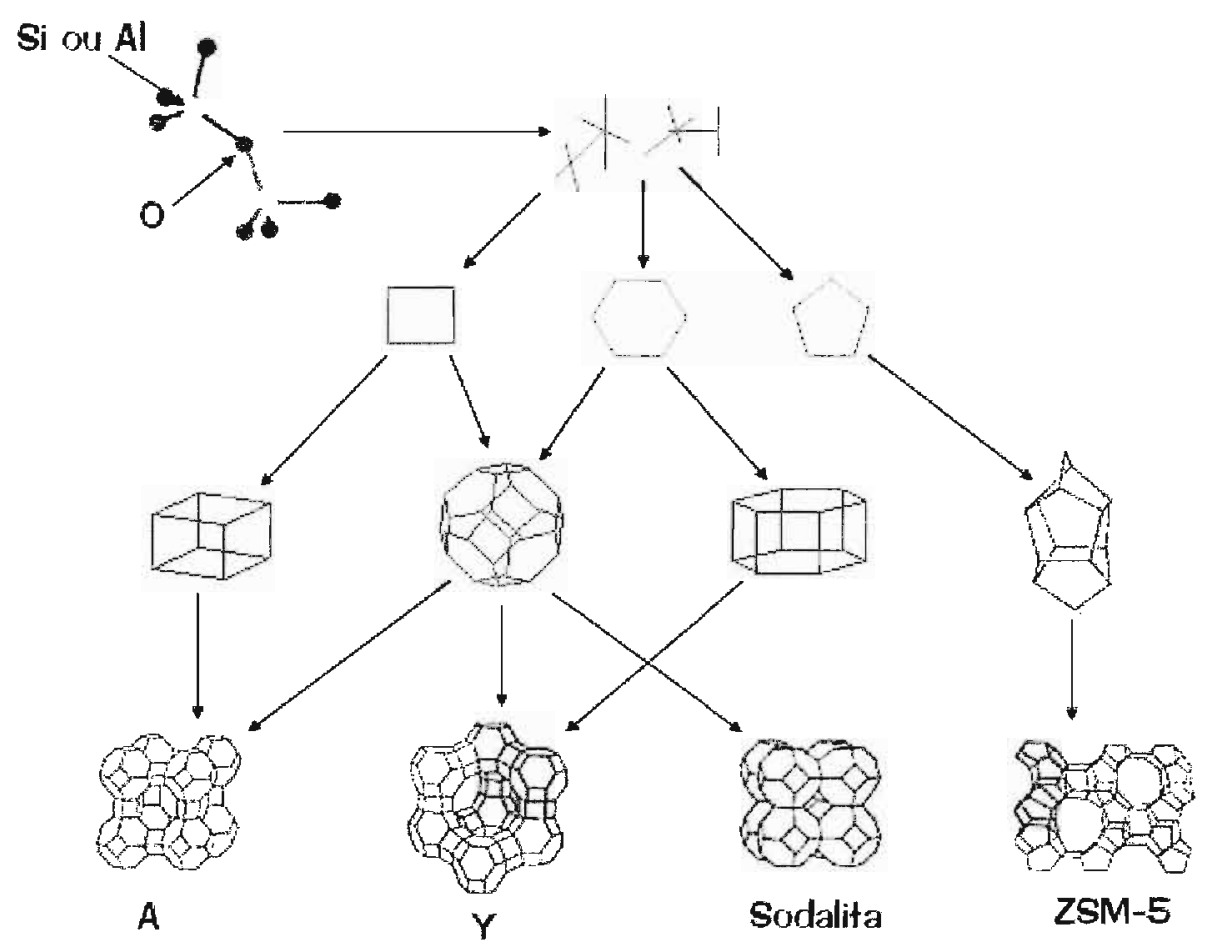

Figura 1.3. Construção de diferentes zeólitas a partir da unidade fundamental.

As unidades tetraédricas contendo Al são carregadas com uma carga negativa, posto que, número de oxidação do $\mathrm{Al}$ é +3 e o mesmo ali se encontra unido a quatro átomos de $\mathrm{O}$ compartilhados por quatro outros tetraedros. Esta carga negativa gerada pela presença do $\mathrm{Al}$ tetraédrico é compensada por contra-íons dispostos na estrutura. Nas zeólitas naturais estes cátions são mono ou bivalentes, tais como $\mathrm{Na}^{+}, \mathrm{K}^{+}, \mathrm{Ca}^{2+}, \mathrm{Mg}^{2+}$, e $\mathrm{Ba}^{2+}$. Contudo, uma ampla variedade de cátions orgânicos e inorgânicos pode ser incorporada nas cavidades das zeólitas. Os cátions que se encontram compensando a carga 
negativa da estrutura, geralmente estão circundados por moléculas de água, cujo número depende das condições de concentração e temperatura [12]. As zeólitas podem ser hidratadas e desidratadas de forma reversível e sua afinidade pela água às fazem excelentes agentes secantes.

A incorporação de cátions diversos nas zeólitas pode ser feita sem comprometimento da estrutura, por meio de processos convencionais de troca iônica em meio aquoso ou no estado sólido. Convém assinalar que o contra-íon na estrutura zeolítica pode ser, inclusive, o $\mathrm{H}^{+}$, o que confere a zeólita o poder de atuar como ácido. Estas propriedades lhes permitem servir como catalisadores em reações catalisadas por ácidos. Talvez, a mais importante delas é a reação de craqueamento de moléculas de hidrocarbonetos. Quando uma molécula de tamanho compatível permea a estrutura cristalina da zeólita se expõe a um grande potencial eletrostático, causado pela alta densidade de carga presente. Isto faz com que a molécula retida sofra polarização em algumas ligações facilitando a sua ruptura [14]. Em outras palavras, o potencial eletrostático presente nas estruturas da zeólita diminui a energia de ativação que algumas reações requerem.

Como cada átomo de $\mathrm{Al}$ induz uma carga negativa dentro da estrutura que precisa ser compensada, a zeólita pode ser vista como um polímero inorgânico com estequiometria definida e a rede de tetraedros como um gigantesco ânion. As propriedades como capacidade de troca iônica, acidez e potencial eletrostático, estão diretamente relacionadas à composição química. Outra propriedade que faz das zeólita sólidos muito especiais é a sua estabilidade térmica. O cristal pode ser aquecido até a desidratação completa sem ser destruído e há estruturas que resistem até $1200^{\circ} \mathrm{C}$ [13].

Basicamente, há dois tipos de zeólitas empregadas como catalisadores para craqueamento: as zeólitas Y e ZSM-5. A zeólita Y é utilizada para promover as reações de craqueamento, favorecendo a formação de compostos na faixa da gasolina (5 a 11 átomos de C). A zeólita ZSM-5, por sua vez, apresenta uma abertura de poro menor e é empregada exclusivamente na conversão de hidrocarbonetos de tamanho intermediário em moléculas com 3 a 4 C. 


\subsubsection{Zeólita $Y$}

A zeólita $\mathrm{Y}$ foi sintetizada por Donald W. Breck na década de 50 [12]. Sua estrutura é análoga a da faujasita (FAU - conforme designação da Associação Internacional de Zeólitas). Possui geometria cúbica e uma célula unitária de aproximadamente $25 \AA$ com 192 tetraedros fundamentais e está formada pela união de sodalitas - um ordenamento de tetraedros em forma de um poliedro de 14 faces, também denominado cavidade $\beta$ - através de prismas hexagonais (Figura 1.4.).

A condensação das unidades da sodalita gera uma estrutura com espaços vazios interconectados. Os espaços maiores são conhecidos como supercavidades ou cavidades $\alpha$, possuem um diâmetro de $12,5 \AA$ e são acessíveis através dos anéis circulares de 12 tetraedros com um diâmetro de $7,4 \AA$.
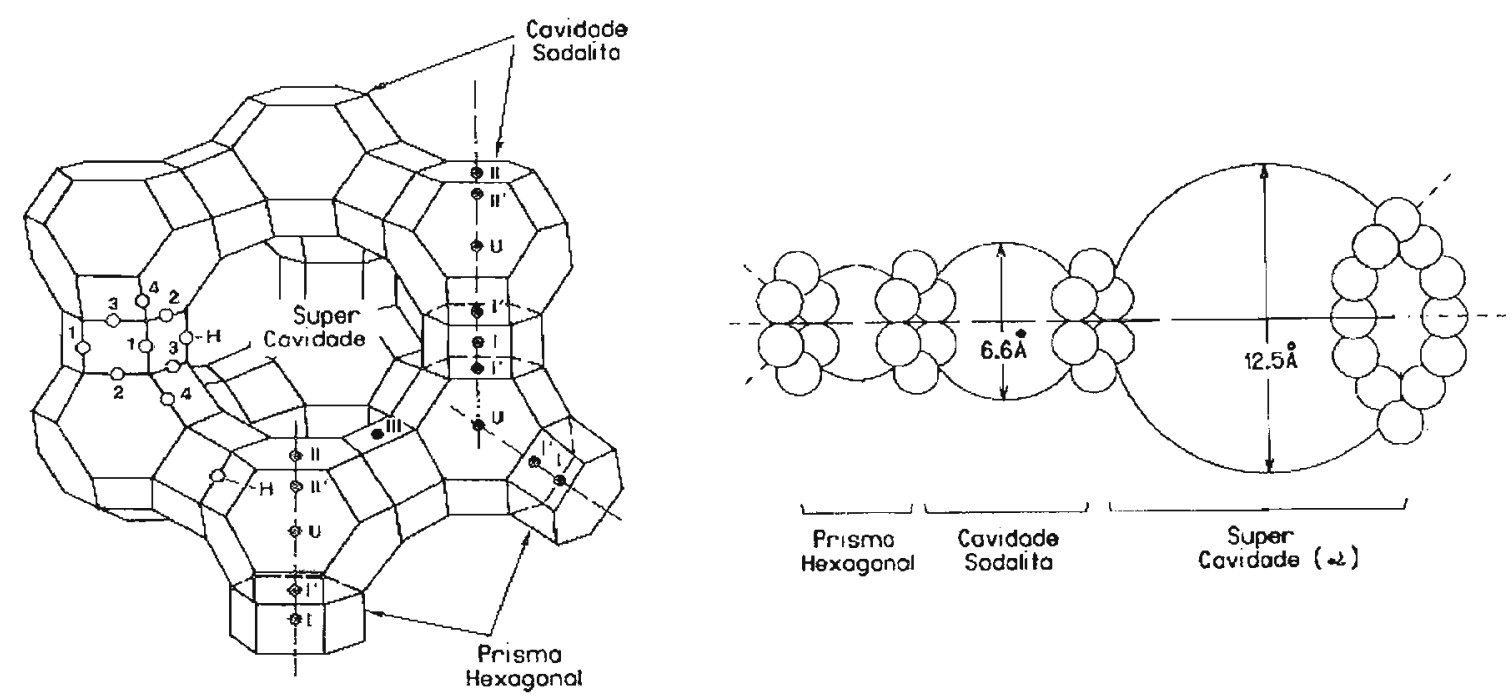

Figura 1.4. Geometria e tamanho das cavidades da zeólita $Y$.

A zeólita $\mathrm{Y}$ se caracteriza por uma relação $\mathrm{Si} / \mathrm{Al}$ entre 1,5 e 6 . É sintetizada inicialmente na forma sódica ( $\mathrm{NaY}$ ) por meio de precursores a base de sais de $\mathrm{Na}$. Entretanto, a forma ativa como catalisador é a forma protonada (HY). Não é possivel realizar a troca dos íons $\mathrm{Na}^{+}$por $\mathrm{H}^{+}$diretamente, porque o $\mathrm{Al}$ da rede cristalina pode ser extraído pelos ácidos levando a estrutura cristalina ao colapso. Para converter a zeólita 
$\mathrm{NaY}$ na forma protonada $\mathrm{HY}$, trocam-se os íons $\mathrm{Na}^{+}$por íons $\mathrm{NH}_{4}^{+}$. Por calcinação a amônia é liberada e o próton se liga à estrutura neutralizando a carga negativa provida pelo $\mathrm{Al}$, dando origem aos sítios de Brönsted (Figura 1.5).

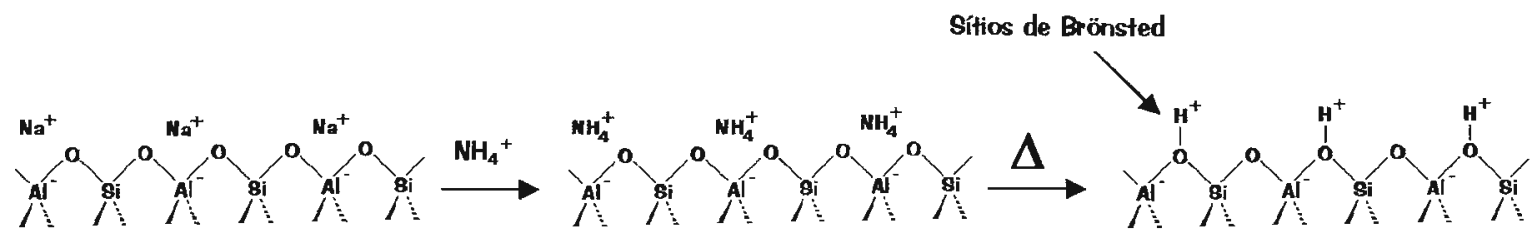

$\mathrm{NaY}$

$\mathrm{NH}_{4} \mathbf{Y}$

HY

Figura 1.5. Formação dos sítios de Brönsted em zeólitas.

A zeólita Y não possui resistência térmica suficiente às temperaturas do processo de regeneração do craqueamento. Para aumentar a estabilidade térmica das zeólitas se promove a desaluminização (retirada dos átomos $\mathrm{Al}$ estruturais da rede) ou se troca com elementos de terras raras (TR), que aumentam a estabilidade térmica e incrementam muito a acidez do material. Os primeiros resultados importantes sobre desaluminização foram obtidos submetendo o material ao tratamento hidrotérmico - calcinação na presença de vapor - sob condições controladas [15]. Esta operação promove a formação dos sítios ácidos de Lewis dada a hidrólise parcial dos átomos de $\mathrm{Al}$ da rede, substituindo-os por $\mathrm{Si}$ de zonas amorfas, mantendo praticamente preservada a estrutura original do material (Figura 1.6). Este material foi denominado de zeólita USY (ultrastable Y) e apresenta estabilidade acima dos $1000^{\circ} \mathrm{C} . \mathrm{O} \mathrm{Al}$ extra-estrutural gerado por tratamento hidrotérmico adquire configuração octaédrica e pode atuar como ácido, da mesma maneira que atua nos catalisadores amorfos.

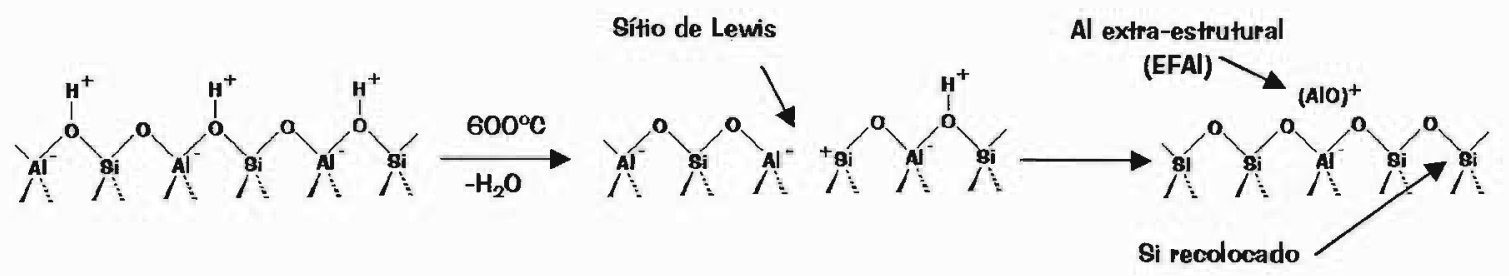

Figura 1.6. Formação dos sítios de Lewis e desaluminização de zeólitas. 
Existe ainda uma série de métodos para desaluminizar zeólitas por modificação química, tais como a complexação do $\mathrm{Al}$, com acetilacetona ou EDTA, e o enriquecimento com $\mathrm{Si}$ através do $\mathrm{SiCl}_{4}$ ou $\left(\mathrm{NH}_{4}\right)_{2} \mathrm{SiF}_{6}$. Os processos de desaluminização podem ser combinados - hidrotérmicos e químicos - com o objetivo de remover os $\mathrm{Al}$ extra-rede gerados que obstruem parcialmente os poros do material, melhorando assim a acessibilidade aos sítios [16].

As zeólitas USY usadas nos catalisadores de craqueamento catalítico são preparadas comercialmente por tratamentos hidrotérmicos em condições controladas. A extração do $\mathrm{Al}$ da rede e a migração do Si fazem com que alguns sítios da estrutura se desfaçam produzindo mesoporos. Caso a velocidade de desaluminização seja muito alta, o processo de reorganização da rede não se dá em tempo suficiente e a estrutura entra em colapso. A ultra-estabilização da estrutura é acompanhada por uma contração da cela unitária da ordem de 1 a $1,5 \%$ comparada com a zeólita original na forma $\mathrm{NaY}$. Isto ocorre pois o comprimento da ligação Si-O é menor que a ligação $\mathrm{Al}-\mathrm{O}$. Os átomos de $\mathrm{Si}$ recolocados aumentam assim a resistência da estrutura. Embora ocorra a redução do número de sítios ácidos com extração do $\mathrm{Al}$, a zeólita preserva ainda seu poder catalítico, pois há aumento da força ácida dos sítios restantes, uma vez que quanto mais afastado se encontram sua força aumenta, devido à possibilidade da carga negativa se distribuir por um maior número de átomos [16].

\subsubsection{Preparo dos catalisadores para craqueamento}

Os cristais de zeólita, tal qual sintetizados, não podem ser empregados diretamente como catalisadores para craqueamento, pois sua atividade é alta e a abertura de poros é relativamente pequena, o que resultaria um perfil inadequado de rendimento de produtos. Além disso, tem alto custo, baixa resistência mecânica e distribuição de tamanho de cristal irregular. Portanto, os catalisadores para craqueamento são preparados com uma mistura de componentes, contendo um ingrediente ativo, no caso a zeólita e uma série de outros com funcionalidades diferentes suportando como matriz os cristais de zeólita [10]. 
O catalisador para craqueamento pode apresentar três diferentes tipos de matriz ativa, inerte e sintética - com características e funções diferentes:

- a matriz ativa, normalmente uma alumina. Além de conter sítios ácidos de Lewis, contribui para o aumento resistência mecânica do conjunto. As aluminas são incorporadas ao catalisador na sua forma hidratada durante a síntese e, após calcinação, encontram-se sob a forma $\gamma-\mathrm{Al}_{2} \mathrm{O}_{3}$. A cristalinidade do hidróxido precursor resultará a cristalinidade e atividade catalítica do material pós-síntese. Em função da cristalinidade resultante, a formulação do catalisador é ajustada em termos de atividade e seletividade a produtos.

- a matriz sintética tem a função principal de aglutinar, como um ligante (termo usual), os componentes do catalisador, podendo ainda interagir com estes modificando parcialmente a sua acidez. A concentração do ligante é fundamental para a estrutura do catalisador, pois pode torná-lo frágil ou bloquear completamente os poros. Em geral, o ligante é constituído de um sol de sílica meta-estável, obtido pela neutralização do ácido sulfúrico com o silicato de sódio. Pode também ser confeccionado por meio do cloreto básico de alumínio.

- a matriz inerte tem especificamente a função de aumentar a resistência do catalisador. Em geral é uma caulinita de pequeno tamanho de partícula.

A Figura 1.7 apresenta a estrutura das partículas do catalisador obtido por síntese. Os componentes são reunidos através da matriz ligante propiciando com isto a formação de mesoporos entre si.

O processo de produção do catalisador para craqueamento, conforme ilustrado na Figura 1.8, envolve uma série de etapas, desde a síntese e troca iônica da zeólita, preparação do gel que serve como matriz, mistura dos componentes e obtenção das partículas por secagem e calcinação [16]. 


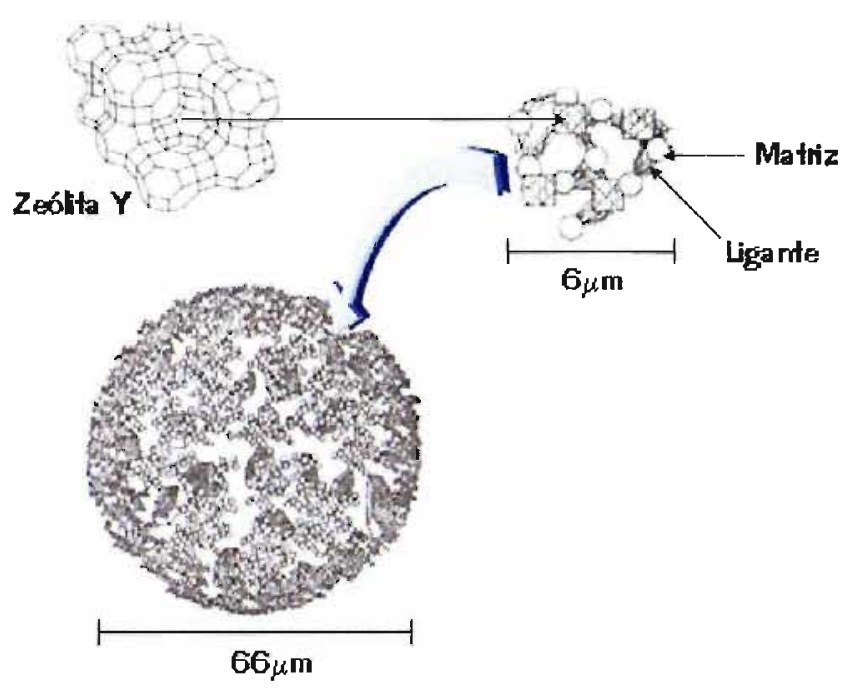

Figura 1.7. Composição, formato e dimensão das partículas do catalisador para craqueamento.

A síntese comercial de zeólitas é realizada com materiais de baixo custo e bastantes disponíveis, incluindo fontes de sílica, alumina e uma base forte, tal como o $\mathrm{NaOH}$. Cristais precursores (sementes) são eventualmente adicionados para servirem como núcleos de cristalização e acelerar o processo. Estes materiais, sob razão estequiométrica e estado adequado (suspensão coloidal ou solução), são aquecidos a uma dada temperatura e por tempo determinado, resultando pureza e estruturas desejadas. Tal como cristalizadas, a maioria das zeólitas estão sob a forma de partículas finamente divididas, na ordem de 1 a $7 \mu \mathrm{m}$.

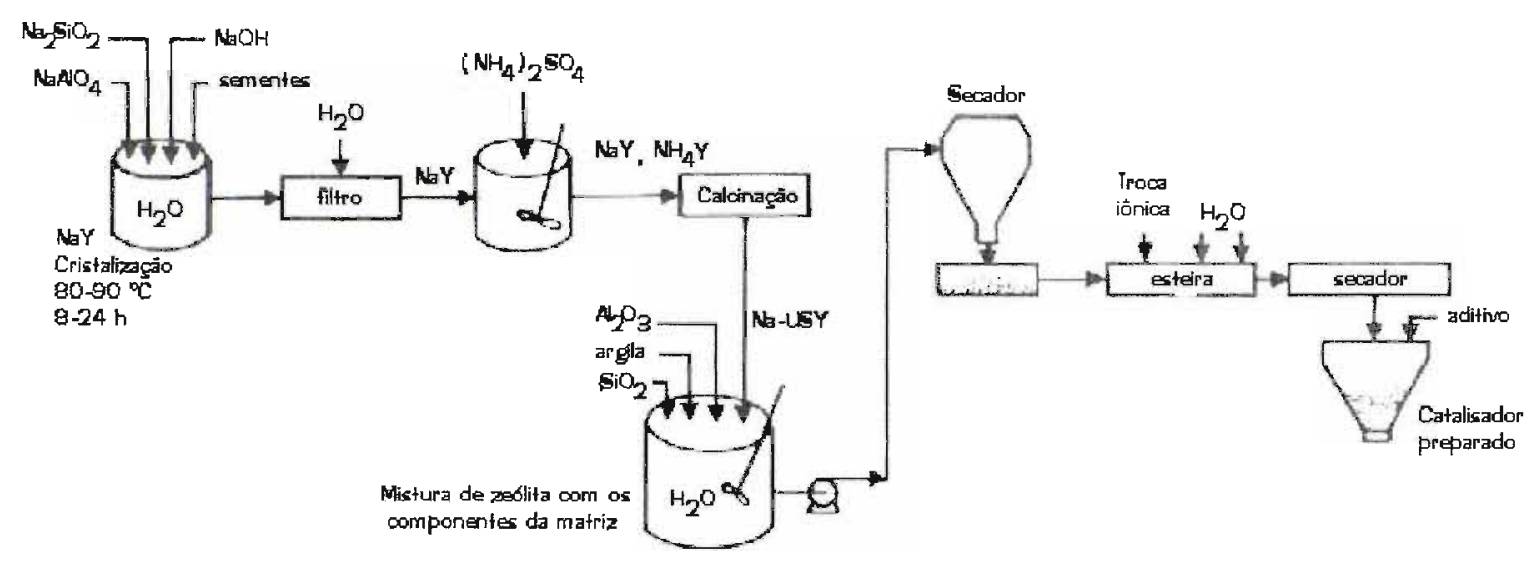

Figura 1.8. Processo comercial de fabricação do catalisador para craqueamento [16]. 
Finalmente, a mistura contendo o sol de sílica, a fonte extra de alumina e a matriz inerte são intimamente misturada com a zeólita e submetida à secagem por pulverização em uma estufa (spray-drying) a $400{ }^{\circ} \mathrm{C}$. A sílica passa ao estado gel e aglutina todos os componentes em uma partícula de formato quase esférico e tamanho regular. Os cristais de zeólitas ficam completamente dispersos sobre a matriz do catalisador. Os espaços existentes entre os componentes constituem verdadeiros macroporos, de utilidade para o acesso de moléculas maiores aos sítios ácidos da alumina.

$\mathrm{Na}$ próxima fase do processo, o excesso de $\mathrm{Na}^{+}$da zeólita é removido por troca iônica com $\mathrm{NH}_{4}^{+}$e, subseqüentemente, pode ser submetida à nova troca iônica com elementos de TR para incremento de certas propriedades do catalisador.

\subsubsection{Mecanismos de reação de hidrocarbonetos em zeólitas}

A carga quando entra em contato com o catalisador na temperatura do processo, é quase completamente vaporizada. A etapa seguinte, fundamental para as reações que ocorrem no craqueamento, consiste na formação dos carbocátions precursores [14].

A formação dos carbocátions ocorre com a interação dos hidrocarbonetos presentes na carga por meio dos sítios ácidos da zeólita ou da matriz. Basicamente, dois tipos de carbocátions são originados nestas condições: a) o íon carbônio $\left(\mathrm{CR}_{5}^{+}\right)$, que é pentacoordenado e pode assumir simetrias diversas $\left(C_{3 \mathrm{~V}}, C_{\mathrm{s}}\right.$ e $D_{3 \mathrm{~h}}$, por exemplo), formadas a partir de uma ligação de 3 centros e 2 elétrons; e b) o íon carbênio $\left(\mathrm{CR}_{3}{ }^{+}\right)$, formado por um carbono tri-coordenado de geometria planar com configuração $s p^{2}$, que é considerado o efetivo precursor das reações de craqueamento

Três mecanismos distintos são descritos na literatura para a formação dos íons carbênios $[14,17]$ :

- (I) o íon carbênio seria gerado por meio da adsorção dos alcanos nos sítios de Lewis disponíveis na superficie; 
- (II) um íon carbônio é formado por protonação direta dos alcanos na superfície do catalisador onde há um sítio de Brönsted. O íon carbônio gerado sofre posteriormente desidrogenação de uma molécula de $\mathrm{H}_{2}$ ou dessorção de um alcano menor, formando o íon carbênio.

- (III) o íon carbênio seria oriundo de traços de hidrocarbonetos insaturados (olefinas) presentes na carga, interagindo diretamente com os sítios de Brönsted.

A Figura 1.9 apresenta os dois primeiros mecanismos de formação dos íons carbênio [17]. Devido à menor força dos sítios de Lewis e à quase inexistência de hidrocarbonetos insaturados nas cargas de processo, o mecanismo II é suposto ocorrer em maior extensão. A proporção em que a formação dos íons carbônio ocorre está associada à força dos sítios presentes na superficie da zeólita. Assim, sítios ácidos fortes são esperados serem proporcionalmente mais ativos. A posição na molécula em que o ataque protolítico ocorre não depende apenas da estabilidade do íon carbônio resultante, mas também de considerações entrópicas ou impedimentos estéricos que determinam os produtos.

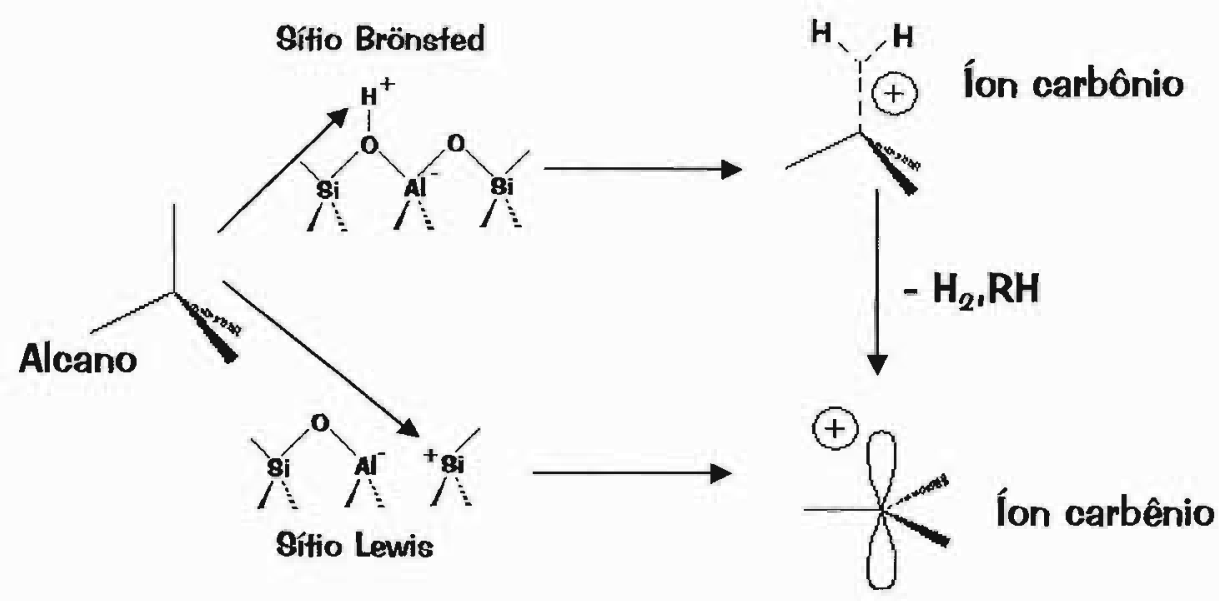

Figura 1.9. Mecanismos de formação dos carbocátions por meio de zeólitas.

O íon carbênio resultante da desidrogenação e/ou craqueamento (eliminação $\beta$ ) permanece adsorvido na superficie do catalisador, tal como um alcoóxido, sendo posteriormente dessorvido na forma de um alceno. Essas reações primárias, descritas entre 
as equações 1.1 a 1.4 , são favorecidas a temperaturas mais altas, baixas conversões e baixas pressões parciais de hidrocarbonetos.

$$
\begin{array}{ll}
\text { Protonação: } & \mathrm{CR}_{2} \mathrm{H}_{2}+\mathrm{H}^{+}-\mathrm{ZO}^{-} \rightarrow\left[\mathrm{CR}_{2} \mathrm{H}_{3}{ }^{+}\right]-\mathrm{ZO}^{-} \\
\text {Desidrogenação: } & {\left[\mathrm{CR}_{2} \mathrm{H}_{3}\right]^{+} \rightarrow \mathrm{CR}_{2} \mathrm{H}^{+}+\mathrm{H}_{2}} \\
\text { Craqueamento: } & {\left[\mathrm{CR}_{2} \mathrm{H}_{3}\right]^{+} \rightarrow \mathrm{CRH}_{2}^{+}+\mathrm{RH}} \\
\text { Dessorção: } & \mathrm{CR}_{2} \mathrm{H}^{+} \rightarrow \text { alceno }+\mathrm{H}^{+} \\
& \mathrm{CRH}_{2}^{+} \rightarrow \text { alceno }+\mathrm{H}^{+}
\end{array}
$$

As reações se propagam com a formação de um novo íon carbênio, por adsorção de um alceno produzido em um sítio de Brönsted, ou pela presença das impurezas mencionadas no mecanismo III. Este caminho reacional ocorre em uma velocidade 800 vezes maior e com muito menor energia que a protonação dos alcanos, sendo favorecido a baixas temperaturas e altas pressões parciais dos alcenos. Os íons carbênio sofrem reações secundárias de eliminação $\beta$, produzindo alcenos menores e íons carbênio adsorvidos. Entre as reações secundárias podem também ocorrer transferência de $\mathrm{H}$ entre um alcano reagente e o ín carbênio adsorvido, isomerizações e cisão $\beta$. As reações secundárias estão apresentadas entre as equações a seguir:

$$
\begin{array}{ll}
\text { Iniciação: } & \text { alceno }+\mathrm{H}^{+} \rightarrow R_{j}^{+} \\
\text {Isomerização: } & R_{i}^{+} \rightarrow R_{i^{+}}^{+} \\
\text {Cisão: } & R_{i}^{+} \rightarrow \text { alceno }+R_{j}^{+} \quad(j<i) \\
\text { Transferência de } \mathrm{H}: & \mathrm{H} R_{i}+R_{j}^{+} \rightarrow R_{i}^{+}+\mathrm{H} R_{j}
\end{array}
$$

O término das reações e a desativação do catalisador se dão pela formação de oligômeros (hidrocarbonetos de maior tamanho molecular), que neutralizam sítios impedindo estericamente a coordenação dos hidrocarbonetos, além de terem força insuficiente para propagar as reações secundárias. Estas reações ocorrem a partir da transferência de $\mathrm{H}$ entre um alcano reagente $\left(\mathrm{H} R_{i}\right)$ e um íon carbênio oligomérico $R_{m}^{+}$ formado pela alquilação de um íon carbênio menor $\left(R_{j}^{+}\right.$ou $\left.R_{n}^{+}\right)$: 


$$
\begin{array}{ll}
\text { Alquilação: } & \text { alceno }+R_{n}^{+} \rightarrow R_{m}^{+} \\
\text {Transferência H: } & \mathrm{H} R_{i}+R_{m}^{+} \rightarrow R_{i}^{+}+\mathrm{H} R_{m} \\
& \mathrm{H} R_{m}+R_{p}^{+} \rightarrow R_{m}^{+}+\mathrm{H} R_{p} \\
\text { Cisão } \beta: & R_{i}^{+} \rightarrow \text { alceno }+R_{j}^{+} \\
& R_{m}^{+} \rightarrow \text { alceno }+R_{n}^{+} \\
\text {Isomerização } & R_{i}^{+} \rightarrow R_{p}^{+}
\end{array}
$$

onde: $j<i, j \leq n<m$.

\subsection{A química das terras raras}

A comissão de nomenclatura em química inorgânica da ILPAC recomenda usar a expressão metais de terras raras para os elementos Sc, Y e os lantanídeos - série de elementos na tabela periódica entre o $\mathrm{La} \mathrm{e} \mathrm{Lu}$, inclusive [18]. Reconhece-se, no entanto, que o termo que denomina estes elementos é um tanto impróprio, uma vez que estes não são a rigor tão raros, com exceção do Pm que é artificial. Os elementos de terras raras (TR) são caracterizados, principalmente, em função da configuração eletrônica que possuem, tanto no estado atômico fundamental como em seus íons. As propriedades características dos íons e compostos de TR, devido a essa configuração eletrônica peculiar, diferem sensivelmente dos demais elementos em termos de estados de oxidação, raios iônicos, comportamentos magnéticos e espectroscópicos, caráter de ligação, número de coordenação e geometria molecular, estabilidade termodinâmica e cinética.

A configuração eletrônica no estado fundamental para os elementos Sc, Y e La é do tipo [gás nobre]nd $d^{1} n s^{2}(\mathrm{n}=3$ para $\mathrm{Sc}, 4$ para $\mathrm{Y}, 5$ para La). Os elementos $\mathrm{Ce}, \mathrm{Gd}$ e Lu apresentam configuração $[\mathrm{Xe}] 4 f^{1} 5 d^{1} 6 s^{2}$ e os demais elementos de TR possuem configuração $[\mathrm{Xe}] 4 f^{\mathrm{n}} 6 s^{2}$, com $\mathrm{n}=1$ a 14 . Os orbitais $4 f$ apresentam pequena extensão radial devido ao seu formato, ficando assim protegidos do ambiente químico em função da sua localização mais interna [19]. A vasta maioria dos compostos de TR apresenta o íon de TR no estado de oxidação (III), devido ao potencial de ionização relativamente baixo e às configurações propícias do elemento no estado fundamental. Os íons $\mathrm{TR}^{2+}$ e $\mathrm{TR}^{4+}$ são 
formados por elementos que podem apresentar as configurações $f^{\theta}, f^{7}$ e $f^{4}$. Assim, o estado de oxidação (II) é notado para alguns compostos de Eu e Yb sob a forma de haletos ou sólidos binários, mas é limitado em soluções e complexos devido à fácil oxidação ao estado (III). O estado de oxidação (IV) é bastante estável para o Ce.

Os elétrons $4 f$ promovem entre si uma blindagem imperfeita, produzindo assim um aumento da carga nuclear efetiva e diminuição do raio iônico com o aumento do número atômico. Tal fenômeno é conhecido como contração lantanídica. Como consequiência, nota-se que o tamanho do raio do $\mathrm{Y}^{3+}$ é próximo ao $\mathrm{Ho}^{3+}$, mas o íon $\mathrm{Sc}^{3+}$ é ainda significantemente menor que o $\mathrm{Lu}^{3+}$. Com a diminuição do raio iônico, os complexos apresentam um aumento da estabilidade termodinâmica e um menor número de coordenação. A proteção efetiva dos elétrons $4 f$ do campo externo pela extensão e arranjo orbitais $5 s^{2} 5 p^{6}$ resulta em efeitos insignificantes nos estados das configurações $4 f^{n}$ pela vizinhança dos íons $\mathrm{TR}^{3+}$. Para um dado íon estes efeitos são essencialmente os mesmos para aproximadamente todos os compostos, tanto em solução como no estado cristalino. Os íons $\mathrm{Sc}^{3+}, \mathrm{Y}^{3+}, \mathrm{La}^{3+}, \mathrm{Ce}^{4+} \mathrm{e} \mathrm{Lu}^{3+}$, são diamagnéticos em função da inexistência de elétrons desemparelhados e todos os outros íons são paramagnéticos. $\mathrm{O}$ momento magnético mensurado em uma série de complexos indica que o grau de covalência da ligação é mínimo, devido à falta da participação dos elétrons $4 f$ nas ligações [19].

Os íons $\mathrm{Sc}^{3+}, \mathrm{Y}^{3+}, \mathrm{La}^{3+}$ e $\mathrm{Lu}^{3+}$ não apresentam bandas de absorção nas regiões do espectro visível, infravermelho ou ultravioleta e são incolores tanto nos cristais como em

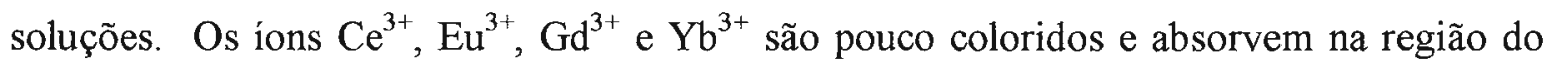
ultravioleta e o último absorve na região do infravermelho. Todos os outros íons absorvem

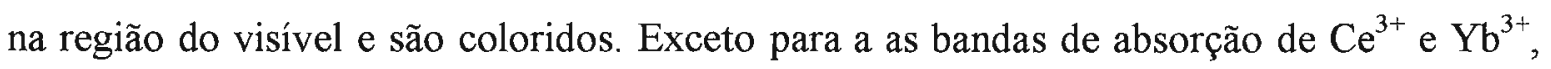
estas absorções são nitidamente definidas e tem comumente a medida de $1 \AA$ de largura. Estas bandas estão associadas às fracas transições do tipo $f-f$ proibidas dentro de uma configuração $4 f$, mas possíveis devido ao efeito do campo cristalino. Excetuando as mudanças de intensidade, poucas são as alterações no comprimento de onda e as bandas para os íons $\mathrm{TR}^{3+}$ são praticamente as mesmas para os complexos ou íons em solução [20].

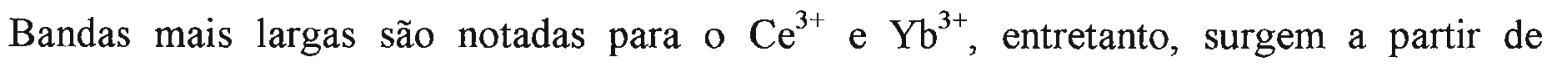
mudanças configuracionais envolvendo os orbitais $5 d$ e são, por conseqüências, mais 
intensas e afetadas pela complexação. Emissão fluorescente é particularmente característica de certos complexos de $\mathrm{Eu}^{3+}$ e úteis para estabelecer a sua estrutura molecular.

\subsubsection{Complexos de TR}

O número total de complexos de TR caracterizados é muito menor que os complexos derivados dos metais de transição $d$ e esta diferença pode ser explicada por uma série de fatores [19].

Os íons $\mathrm{Sc}^{3+}, \mathrm{Y}^{3+} \mathrm{La}^{3+} \mathrm{e} \mathrm{Ce}^{4+}$ apresentam todos configuração de gás nobre, assim

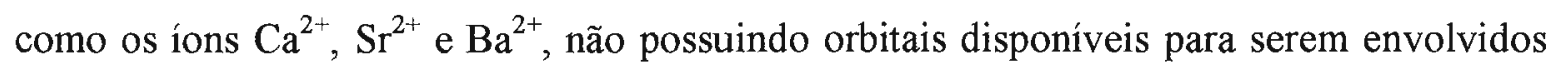
por interações ou hibridizações típicas em ligações covalentes. Da mesma forma, os íons $\mathrm{Yb}^{2+}$ e $\mathrm{Lu}^{3+}$ têm a configuração completa tipo [Xe] $4 f^{4}$ impedindo a covalência. Os íons $\mathrm{Ce}^{3+}-\mathrm{Yb}^{3+}, \mathrm{Sm}^{2+}, \mathrm{Eu}^{2+} \mathrm{e} \mathrm{Tb}^{4+}$ são caracterizados pela configuração $4 f^{44}$ incompleta, mas os orbitais estão muito internamente localizados tais que impedem os tipos de interações que ocorrem com os orbitais $d$ incompletos.

A energia de estabilização do campo ligante no caso dos cátions de metais de TR é pequena comparada aos metais de transição $d$. Os grandes raios iônicos dos cátions de TR permitem minimização das interações eletrostáticas reduzindo a força iônica das ligações.

Reações de substituição de ligantes em meio aquoso ocorrem muito rapidamente. A água é um ligante forte para todos os íons $\mathrm{TR}^{2+}, \mathrm{TR}^{3+} \mathrm{e}^{4+}$, competindo intensamente pelos sítios ligante do cátion ou deslocando outros ligantes previamente coordenados. Em ambiente aquoso neutro e ácido, as moléculas de água podem impedir a formação de complexos por ligantes mais fortes, tais como os quelatos. Em meio alcalino, os íons hidroxila são também fortes competidores pelos sítios ligantes dos cátions, devido a solubilidade reduzida dos hidróxidos dos íons $\mathrm{TR}^{3+}$ e $\mathrm{TR}^{4+}$.

Os cátions dos metais de TR são todos aceitadores do tipo a conforme teoria de Ahrland-Chatt-Davies e são ácidos duros de acordo com a teoria de Pearson [21]. A maior 
parte dos complexos isolados em sistemas aquosos contém ligantes $\mathrm{O}$ doadores. Muitos ligantes são puros $\mathrm{O}$ doadores ou são mistos $\mathrm{O}$ e $\mathrm{N}$ doadores, tais como os poliaminocarboxilatos. Outros elementos coordenam-se exclusivamente na ausência de água, como no caso dos ligantes doadores de $\mathrm{F}^{-}[20]$

Com exceção do $\mathrm{Sc}^{3+}$, os íons de TR apresentam em seus complexos um razoável número de geometrias moleculares em função do seu maior raio iônico. O número de coordenação normalmente encontra-se entre 6 a 12, sendo 8 e 9 os mais comuns. A variação do número de coordenação no complexo para um dado íon depende da acomodação espacial dos ligantes e pouco das propriedades da ligação devido ao caráter eletrostático. A coordenação dos íons em solução difere ligeiramente dos cristais. As posições espaciais prováveis ocupadas pelos átomos doadores em relação ao cátion central $\mathrm{TR}^{\mathrm{n}+}$ são previstas em função das repulsões coloumbicas envolvendo os átomos dos ligantes para alcançar máxima simetria [19].

Comparações para um dado ligante em termos da constante de formação indicam que os complexos de $\mathrm{TR}^{\mathrm{n}+}$ são termodinamicamente menos estáveis que os complexos dos metais de transição $d$. Comparações entre os íons $\mathrm{TR}^{3+}$ para um determinado ligante não demonstram uma tendência uniforme, embora algumas relações considerando a variação no raio solvatado ou do cristal possam ser notadas. Dependendo do ligante, três tendências gerais podem ser descritas para a estabilidade dos complexos: a) aumento da estabilidade com a diminuição do raio iônico; b) aumento até uma constância observada entre o Gd e $\mathrm{Lu}$; e c) aumento até um máximo notado para o íon $\mathrm{Dy}^{3+}$. $\mathrm{Na}$ complexação em meio aquoso, as mudanças entrópicas proporcionam a maior contribuição para a estabilidade. Isto particularmente é observado no caso específico do deslocamento de moléculas de água por ligantes quelatos [22].

Entre os quelatos de TR que proporcionam maior interesses científicos estão os complexos $\beta$-dicetonatos devido às suas inúmeras aplicações, tais como o uso em cromatografia em fase vapor, lasers e espectroscopia por ressonância magnética nuclear [23]. A estabilidade dos complexos, alto rendimento e facilidade em obtenção são outros 
aspectos positivos. As $\beta$-dicetonas são caracterizadas por apresentarem o tautomerismo ceto-enólico, conforme se observa na Figura 1.10.

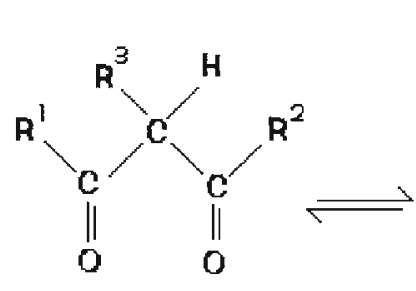

Forma ceto

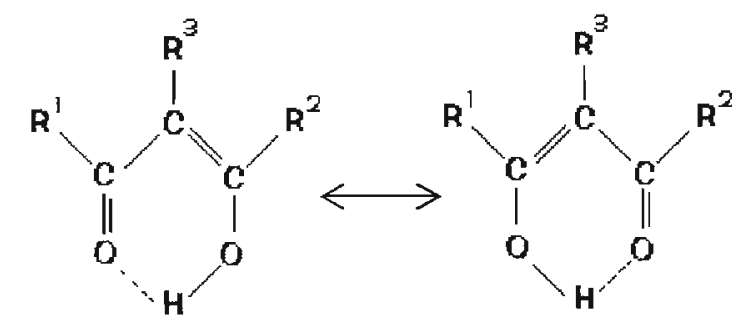

Formas enólicas

Figura 1.10. Formas tautoméricas das $\beta$-dicetonas.

$\mathrm{O}$ átomo de hidrogênio do grupo $\mathrm{CH} R^{3}$ é ativado pelo grupo adjacente $\mathrm{C}=\mathrm{O}$, e o sistema conjugado pode surgir por um deslocamento prototrópico. Estes tautômeros existem entre si em equilíbrio e estruturalmente possuem uma configuração cis. Sob condições apropriadas o átomo de hidrogênio pode ser substituído por um cátion metálico produzindo um anel quelato de seis membros, deslocando o equilíbrio ceto-enólico para a direita e favorecendo a forma enólica conforme Figura 1.11.

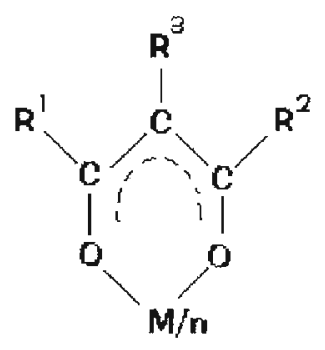

Figura 1.11. Anel quelato dos complexos metálicos com $\beta$-dicetonas.

A forma enólica é geralmente favorecida em solventes apolares, sendo a conjugação simultânea e a quelação através do $H$ responsáveis pela estabilidade do tautomerismo da forma enol. A proporção da forma enólica geralmente aumenta quando um grupo que retira elétrons, como o $\mathrm{Cl}$, substitui o $\mathrm{H}$ em posição $\alpha$ nas $\beta$-dicetonas. $\mathrm{A}$ enolização também cresce quando os ligantes contêm átomos de $\mathrm{F}$ ou um anel aromático. A substituição por um grupo volumoso, como o alquil, em uma posição $\alpha$ tende a produzir 
impedimento estérico entre os grupos $R^{1}$ e $R^{3}$ (ou $R^{2}$ ), particularmente, no tautômero enol, que juntamente com efeitos indutivos dos grupos alquil provoca um grande decréscimo na proporção enólica [23]. Deve-se notar que nenhuma enolização é possível se são substituídos ambos os átomos de $\mathrm{H}$ do átomo do $\mathrm{C} \alpha$, pois a formação de quelatos com íons de metal obviamente não seria possível com tais sistemas.

Um grande número de $\beta$-dicetonatos de TR é reportado na literatura, com diferentes substituintes $R^{1}, R^{2}$ e $R^{3}$ [24]. O tipo mais comum de complexos $\beta$-dicetonatos de TR são os tris-acetilacetonatos, em que os grupos substituintes em $R^{1}, R^{2}$ e $R^{3}$ são constituídos de um agrupamento metil. Normalmente, são obtidos por síntese em meio aquoso e, por isso, sempre apresentam um maior ou menor grau de hidratação da esfera de coordenação associado aos 3 ligantes acetilacetona, dependendo do raio iônico do elemento. Observa-se uma ampla variação dos números de coordenação e estruturas dos tris-acetilacetonatos de TR. Por exemplo, o cátion de $\mathrm{Yb}^{3+}$ forma um complexo hidratado hepta-coordenado com acetilacetona $\left[\mathrm{Yb}(\mathrm{acac})_{3}\left(\mathrm{OH}_{2}\right)\right]$, ao passo que o complexo com $\mathrm{La}^{3+}\left[\mathrm{La}(\mathrm{acac})_{3}\left(\mathrm{OH}_{2}\right)_{2}\right]$, que tem maior raio iônico, é octa-coordenado. As estruturas destes dois complexos são, respectivamente, um prisma e um antiprisma. A estabilidade dos complexos acetilacetonato de TR aumenta a partir da diminuição dos raios iônicos devido à natureza eletrostática das ligações. A solubilidade dos complexos em meio orgânico também aumenta com a diminuição do raio iônico [23].

\subsubsection{TR em zeólitas}

A incorporação de TR em zeólitas tem o propósito de aumentar a estabilidade térmica e a atividade catalítica do material [25]. O tratamento térmico de zeólita $\mathrm{Y}$ incorporada de TR (TR-Y), resulta na formação de sítios ácidos de Brönsted devido à hidrólise dos íons de terras raras hidratados e coordenados aos sítios da zeólita, conforme visto na Figura 1.12.

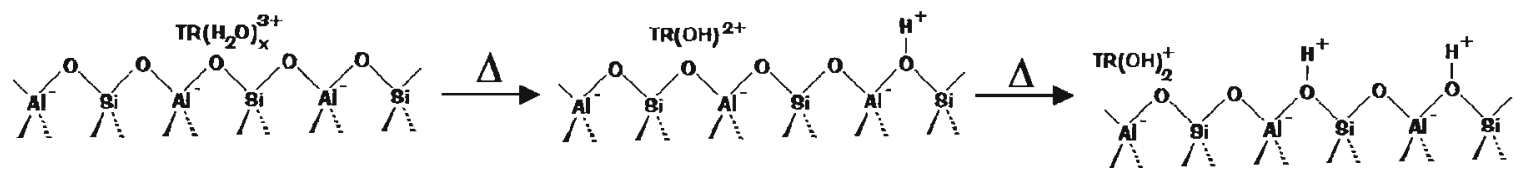

Figura 1.12. Hidrólise dos ions TR em zeólita 
Esta desidratação ocorre em um primeiro instante nas cavidades $\alpha$ da zeólita $\mathrm{Y}$, a seguir os íons TR hidratados migram para as cavidades sodalitas ou $\beta$, e os íons de sódio se movem na direção oposta, o que causa aumento da capacidade de troca iônica da zeólita. Os íons $\mathrm{TR}^{3+}$ apresentam portanto uma dupla função: conferir alta estabilidade térmica e hidrotérmica à estrutura do aluminossilicato e gerar prótons por hidrólise do hidrato de TR. Esta estabilidade térmica tem sido atribuída à presença de cátions nas cavidades sodalitas das cavidades da zeólita contendo íons de oxigênio ligados às TR (Figura 1.13) [26].

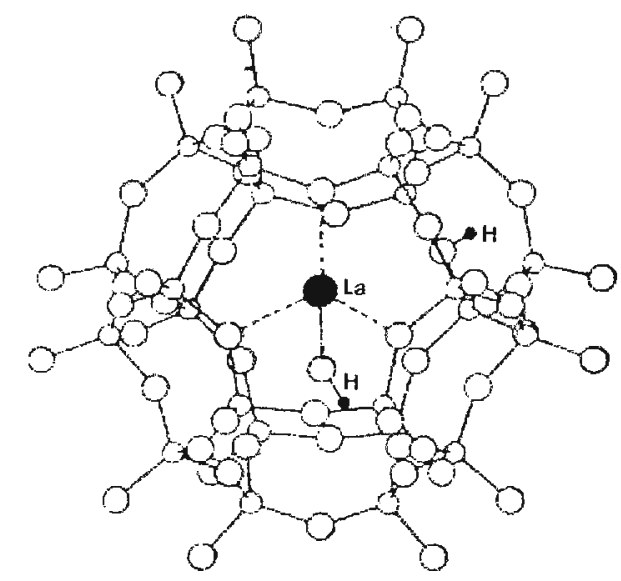

Figura 1.13. Complexo de TR coordenado na cavidade $\beta$ da zeólita Y.

O método mais comum de preparo das zeólita com TR é similar ao da zeólita HY. Consiste na troca iônica da zeólita $\mathrm{NaY}$ com soluções de $\mathrm{NH}_{4}{ }^{+}$e, posteriormente, com cloretos de TR. A troca iônica ocorre primeiramente com o Na presente na supercavidades, uma vez que o cátion hidratado não tem capacidade de permear nas estruturas mais internas.

Quanto maior o raio iônico do cátion de TR presente na zeólita, maior a acidez de Brönsted gerada uma vez que há mais moléculas de água coordenadas e o processo de hidrólise ocorre em maior extensão. Entretanto, poucas mudanças em termos de aumento de atividade catalítica e capacidade de promover as reações de transferência de $H$ são notadas entre os elementos quando empregados nestes sistemas [25]. Outro aspecto importante é que as TR incorporadas à zeólita proporcionam uma maior capacidade de resistir ao ataque de venenos do catalisador presentes no processo. A atividade catalítica depende do nível de troca iônica com o $\mathrm{Na}^{+}$atingindo um máximo em cerca de $40 \%$, 
devido a formações de complexos entre os próprios elementos de TR que suprimem as reações de hidrólise.

\subsection{Desativação dos catalisadores para craqueamento}

Em termos mundiais, o consumo de derivados de petróleo e a capacidade de processamento das unidades de craqueamento têm demonstrado um ligeiro aumento nos últimos 10 anos, com exceção aos países do sudeste asiático que apresentam um considerável crescimento nestes dois aspectos [1,27]. Diferentemente desta tendência, o consumo mundial de catalisadores para craqueamento aumentou cerca de 1,5 vezes no mesmo período [28]. Em 1994 foram consumidas cerca de $170.000 \mathrm{t}$ do produto, ao passo que em 2002 estimou-se um consumo da ordem de $400.000 \mathrm{t}$, com um preço médio da ordem de $2000 \mathrm{US} \$ / \mathrm{t}$.

Estas discrepâncias em relação ao maior consumo de catalisador se devem aos seguintes fatores:

- necessidade de adequar o perfil de produtos em relação à demanda de mercado, através de aumento da reposição do catalisador visando maiores níveis de conversão;

- alteração das características convencionais das unidades de craqueamento para o processamento de cargas parcialmente constituídas de resíduos atmosféricos da destilação do petróleo, requerendo um aumento da severidade de regeneração e elevando assim a taxa de desativação do catalisador;

- piora na qualidade de carga devido à maior incorporação de matérias-primas de menor custo, mas que, ao mesmo tempo, introduzem uma quantidade maior de contaminantes metálicos potencializando a desativação do catalisador durante o processo.

Especialmente no Brasil, há em implementação um intenso programa que associa a adaptação e construção de novas unidades, no escopo da tecnologia de craqueamento catalítico de $100 \%$ de resíduo proveniente da destilação atmosférica, com o aumento da 
participação do petróleo nacional nas refinarias [29]. Este programa tem por objetivo elevar a margem de refino das unidades e diminuir a dependência de petróleo importado no país.

As unidades de craqueamento catalítico de resíduo (RFCC) apresentam um maior consumo de catalisador por massa de carga processada, devido à elevada taxa de desativação, uma vez que reúnem no processo condições muito severas de regeneração e cargas de qualidade inferior. À medida que a carga do craqueamento se concentra em frações residuais da destilação do petróleo, aumentam-se os níveis de contaminantes no catalisador e o processo se torna menos suscetível à conversão. As características das cargas do craqueamento que trazem maiores problemas em termos operacionais estão descritas a seguir, com suas respectivas conseqüências ao processo:

- elevado teor de S: concentra-se nos produtos, sobrecarregando os sistemas secundários de tratamento, e nos gases de combustão do regenerador sob a forma da $\mathrm{SO}_{\mathrm{x}}$;

- elevada massa molar média: a baixa volatilidade da carga causa problemas em termos de vaporização e retificação dos hidrocarbonetos retidos nos poros do catalisador;

- alto teor de $\mathrm{N}$ básico: boa parte dos sítios ácidos do catalisador é neutralizada durante a etapa de reação, diminuindo com isso a conversão dos hidrocarbonetos;

- maior resíduo de carbono: aumenta a formação de coque diminuindo a conversão em produtos nobres e dificultando o equilíbrio térmico da unidade;

- alto teor de asfaltenos: diminui a conversão e eleva a formação de coque;

- elevado teor de Ni: deposita-se nas superfícies das partículas e catalisa as reações de desidrogenação dos hidrocarbonetos, fazendo aumentar a seletividade $\mathrm{H}_{2}$ e coque;

- alto teor de V: promove desativação permanente do catalisador por meio do ataque ao componente zeolítico; 
- alto teor de $\mathrm{Na}$ : neutraliza os sítios ácidos do catalisador e forma liga eutética com $\mathrm{V}$ potencializando a destruição da zeólita.

Os petróleos nacionais produzidos nos campos mais abundantes apresentam a maioria das características descritas acima. A Tabela 1.2. compara a qualidade do resíduo atmosférico de um petróleo nacional típico com um petróleo estrangeiro.

Tabela 1.2. Caracterização físico-química dos resíduos atmosféricos dos petróleos Marlim e Nigeriano [30-31]

\begin{tabular}{ccc}
\hline Propriedade & Marlim (nacional) & Nigeriano \\
\hline Densidade (g/ml a $\left.20^{\circ} \mathrm{C}\right)$ & 1,0253 & 0,9756 \\
$\mathrm{~S}(\%)$ & 1,04 & 0,47 \\
$\mathrm{~V}(\mathrm{ppm})$ & 86,5 & 7,0 \\
$\mathrm{Ni}(\mathrm{ppm})$ & 58,5 & 45,0 \\
Resíduo de carbono (\%) & 21,4 & 14,1 \\
$\mathrm{~N}(\%)$ & 1,10 & 0,76 \\
Asfaltenos (\%) & 10,0 & 5,0 \\
\hline
\end{tabular}

O V presente na carga do craqueamento apresenta os efeitos mais deletérios no que concerne à desativação permanente do catalisador. Uma unidade de RFCC operando com cargas provenientes da destilação de petróleo nacional apresenta consumo relativo extremamente elevado de catalisador devido ao efeito de desativação proporcionado pelo V. O teor de V no catalisador de RFCC é 3 a 5 vezes maior do que em uma unidade convencional, o que eleva exponencialmente a desativação [32]. A Figura 1.14 apresenta o aumento significativo do teor de $\mathrm{V}$ nos catalisadores de equilíbrio das refinarias brasileiras nos últimos anos como tendência.

$\mathrm{O} \mathrm{V}$ está presente no petróleo através de complexos porfirínicos. A ocorrência destas espécies foi atribuída por Treibs à substituição metálica do íon $\mathrm{Mg}$ da estrutura da clorofila por íons de $\mathrm{Fe}$, Ni ou V, seguida de uma etapa de demetilação do anel porfirínico [33]. Estes complexos concentram-se nas frações residuais do petróleo e apresentam alta 
estabilidade química, suportando aos processos de destilação e somente se decompondo nas condições de regeneração do craqueamento sob a superficie do catalisador.

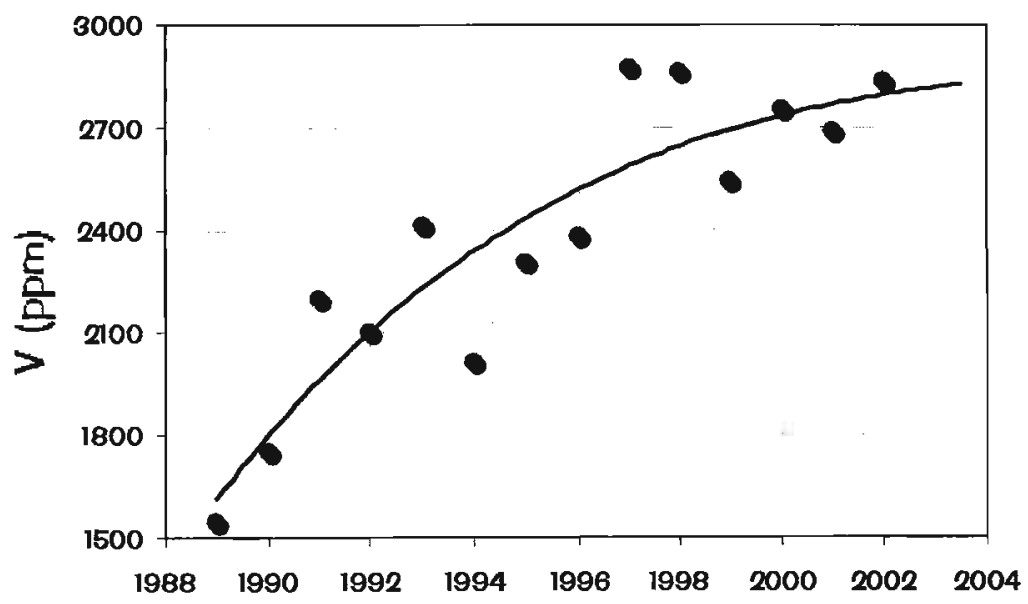

Figura 1.14. Evolução do teor médio de V (em ppm) no catalisador de FCC usado.

\subsubsection{A química do $\mathrm{V}$}

$\mathrm{O}$ elemento $\mathrm{V}$ no estado fundamental apresenta configuração eletrônica [Ar] $3 d^{3} 4 s^{2}$. Os estados de oxidação principais são (II), (III), (IV) e (V). O V (V) $\left(d_{0}\right)$ pode estar presente em um ambiente de coordenação tetraédrica $\left(\mathrm{VO}_{4}\right)$, bipirâmide trigonal $\left(\mathrm{VO}_{5}\right)$ e octaédrica $\left(\mathrm{VO}_{6}\right)$ e tende a formar ânions poliméricos [21]. O V (IV) ( $\left.d^{1}\right)$ também é estável e pode ser encontrado, principalmente, em uma geometria piramidal distorcida ou pseudo-octaédrica como um cátion isolado. Outros estados de oxidação tais como V (III) $\left(d^{2}\right)$ e V (II) $\left(d^{3}\right)$ são menos estáveis e ocorrem apenas sob condições redutoras. Os óxidos de $\mathrm{V}$ apresentam comportamento anfótero: os óxidos de menores estados de oxidação são predominantemente básicos e os óxidos de maiores estados de oxidação são predominantemente ácidos.

Os mais importantes estados de oxidação em solução aquosa são V (V) e V (IV). A existência das espécies em um estado específico depende do $\mathrm{pH}$ e da concentração de $\mathrm{V}$ [21]. O V (V) hidrolisa em uma forma bastante complexa podendo formar até 12 diferentes espécies em solução - monoméricas e/ou poliméricas. O V (IV) é particularmente estabilizado na forma do íon de vanadila $\left(\mathrm{VO}^{2+}\right)$, um dos mais estáveis cátions de elemento 
metálico combinado ao $O$ [34]. Em água, o íon vanadila está sob coordenação bipirâmide tetragonal de $\mathrm{VO}\left(\mathrm{H}_{2} \mathrm{O}\right)_{5}{ }^{2+}$. $\mathrm{O} \mathrm{V}(\mathrm{II})$ e o $\mathrm{V}(\mathrm{III})$ são instáveis em solução aquosa e são oxidados prontamente na presença de ar.

Os óxidos de $\mathrm{V}$ mais importantes são $\mathrm{V}_{2} \mathrm{O}_{5}, \mathrm{VO}_{2}, \mathrm{~V}_{2} \mathrm{O}_{3}$ e VO. Nestes óxidos, o estado de oxidação decresce de V (V) a V (II). Outros óxidos mais incomuns apresentam o $\mathrm{V}$ em um estado de oxidação intermediário, tais como $\mathrm{V}_{3} \mathrm{O}_{5}, \mathrm{~V}_{4} \mathrm{O}_{7}$ e $\mathrm{V}_{7} \mathrm{O}_{13}$, cuja fórmula geral é $\mathrm{V}_{\mathrm{n}} \mathrm{O}_{2 \mathrm{n}-1}[34]$.

$\mathrm{O} \mathrm{V}_{2} \mathrm{O}_{5}$ é um óxido ácido, de cor vermelho laranja, na qual as unidades de $\mathrm{V}$ estão presentes sob a forma de octaedros distorcidos. A estrutura de $\mathrm{V}_{2} \mathrm{O}_{5}$ é formada por lamelas deslocadas de unidades $\mathrm{VO}_{5}$ com geometria piramidal de base quadrada. Cada átomo de $\mathrm{V}$ e seus cinco mais próximos $\mathrm{O}$ formam as unidades $\mathrm{VO}_{5}$ que compartilham as arestas, construindo cadeias duplas ao longo da direção $b$. Estas cadeias estão conectadas pelas extremidades resultando camadas empilhadas ao longo da direção $c$ [35]. $\mathrm{V}_{2} \mathrm{O}_{5}$ é apenas ligeiramente solúvel em água, resultando em uma solução amarela pálida com algum caráter coloidal. Também se dissolve em $\mathrm{NaOH}$ para dar soluções incolores que contêm o íon vanadato $\left(\mathrm{VO}_{4}{ }^{3-}\right)$. Em meio ácido, uma série de reações complexas ocorre envolvendo a formação de estruturas poliméricas, por exemplo o íon decavanadato $\left(\mathrm{V}_{10} \mathrm{O}_{27}(\mathrm{OH})^{5-}\right)$. Em meio ácido forte, o íon pervanadila é formado $\left(\mathrm{VO}_{2}{ }^{+}\right)$.
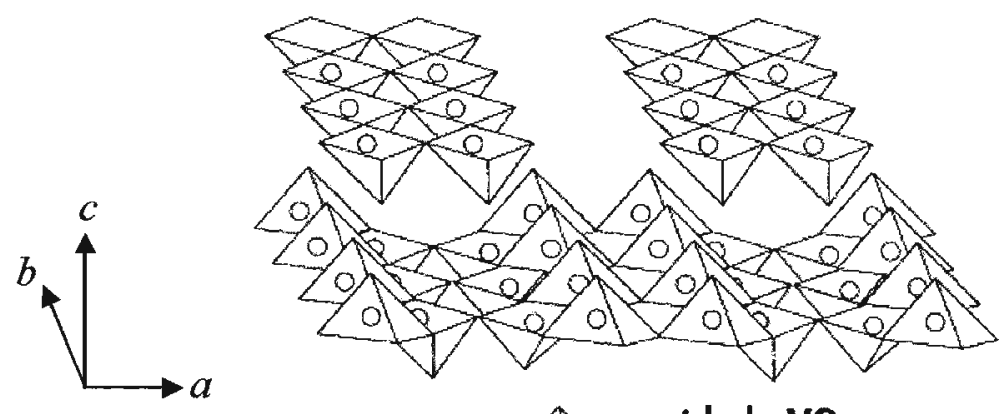

unidade $\mathrm{VO}_{5}$

Figura 1.15. Estrutura do $\mathrm{V}_{2} \mathrm{O}_{5}$.

$\mathrm{O} \mathrm{VO}_{2}$ é um óxido azul escuro, obtido através de redução moderada do $\mathrm{V}_{2} \mathrm{O}_{5}$ e tem a estrutura do tipo rutila distorcida devido a presença de um par átomos de $\mathrm{V}$ unidos. A 
ligação $\mathrm{V}=\mathrm{O}$ é muito menor que as outras na unidade $\mathrm{VO}_{6}$. É um óxido anfótero e dissolve-se em não-oxiácidos resultando soluções coloridas de um azul intenso devido á presença do íon $\mathrm{VO}^{2+}$, que em meio aquoso, está sob a forma de $\mathrm{VO}\left(\mathrm{H}_{2} \mathrm{O}\right)_{5}{ }^{2+}$. Em meio alcalino se transforma em uma solução amarela de íons $\mathrm{V}_{4} \mathrm{O}_{9}{ }^{2-}$, ou em meio muito alcalino de íons $\mathrm{VO}_{4}{ }^{4-}$.

$\mathrm{O} \mathrm{V}_{2} \mathrm{O}_{3}$ é preto e tem uma estrutura do tipo coríndon. É predominantemente básico e obtido por redução de $\mathrm{V}_{2} \mathrm{O}_{5}$ com $\mathrm{H}_{2}$ ou $\mathrm{CO}$. Dissolve-se em ácidos resultando em soluções azuis ou verdes do íon $\mathrm{V}^{3+}$ fortemente redutoras. À adição de íons $\mathrm{OH}^{-}$a estas soluções as tornam facilmente oxidáveis na presença de ar. O VO (ou $\mathrm{V}_{2} \mathrm{O}_{2}$ ) é cinza e apresenta um determinado comportamento metálico. Possui uma estrutura do tipo $\mathrm{NaCl}$ com alguns defeitos e é solúvel em ácidos dando soluções de V (II) violetas e muito sensíveis ao ar [34]. 


\section{Referências Bibliográficas}

[1] British Petroleum, "BP Statiscal Review of World Energy - 2002", website: http://www.bp.com.

[2] Petróleo Brasileiro SA, "Relatório Anual 2002", website: http://www. petrobras.com.br.

[3] I.M.R.A Brüning, "Química do Petróleo", apostila de curso, Petrobras SA, Curitiba, 1998.

[4] E. Abadie, "Processos de Refinação", apostila de curso, Petrobras SA, Rio de Janeiro, 2000

[5] J.A.M. Castillero, G.L. Baugis, "Resultados das Novas Unidades de Craqueamento de Resíduo da Petrobras", in Anales del V Encuentro de Craqueo Catalítico. ed. FCC-SA, Maceió, 2002, p224.

[6] E. Abadie, "Craqueamento Catalítico", apostila de curso, Petrobras SA, Rio de Janeiro, 2000 .

[7] J.A. Montgomery, "Guia para Craqueo Catalitico Fluidizado", Baltimore, Grace Davison Co., 1993, p8.

[8] J.M. Fusco, M. Einsfeldt, J. Medeiros, P.S. Freire, N. Patrício, M.H. Tan, J.G.F. Ramos, M.A. Torem, "PAC ${ }^{R C}$ - Um Marco no Processo de Craqueamento Catalitico Fluido" in Anales del IV Encuentro de Craqueo Catalitico, ed. FCC-SA, Manaus, 2000, p91.

[9] R. Sadeghbeigi, "Fluid Catalytic Cracking Handbook", Houston, Gulf Publishing Company, 1995, p5

[10] P.B. Venuto, T. Habib Jr., "Fluid Catalytic Cracking with Zeolite Catalysts", New York, Marcel Dekker Inc., 1979, p4.

[11] J. Biswas, I.E, Maxwell, "Recent Process and Catalyst-Related Developments in Fluid Catalytic Cracking", Appl. Catal., 63 (1990) 197.

[12] D.W. Breck, "Zeolite Molecular Sieves", New York, Wiley, 1974, p258.

[13] International Zeolite Association, "Atlas of Zeolite Structures", website: http://www.iza-online.org.

[14] B. W. Wojciechowski, A. Corma, "Catalytic Cracking - Catalysts, Chemistry and Kinetics", New York, Marcel Dekker Inc., 1986, p5. 
[15] C.V McDaniel, P.K. Maher, "Molecular Sieves", London, Soc. Chem. Ind., 1967 p186.

[16] J. Scherzer, "Octane-Enhancing, Zeolite FCC Catalysts: Scientific and Technical Aspects", Catal. Rev.-Sci. Eng., 31/3 (1989) 215.

[17] B.A. Williams, S.M. Babitz, J.T. Miller, R.Q. Snurr, H.H. Kung, "The Roles of Acid Strength and Pore Diffusion in the Enhanced Cracking Activity of Steamed Y Zeolites" Appl. Catal. - A, 177 (1999) 161.

[18] A. Abrão, "Química e Tecnologia das Terras-Raras", Rio de Janeiro, Série Tecnologia Mineral 66, CETEM/CNPQ, 1994.

[19] T. Moeller, "Complexes of the Rare Earth Elements", Gmelin Handbook of Inorganic Chemistry, $8^{a}$ ed, Part D1: Sc, Y,La-Lu, Springer Verlag, Berlin, 1980, p1.

[20] Y. Marcus, "Complexes with Water", Gmelin Handbook of Inorganic Chemistry, $8^{\mathrm{a}}$ ed, Part D3: Sc, Y,La-Lu, Springer Verlag, Berlin, 1981, p1.

[21] D.F. Shriver, P.W. Atkins, "Inorganic Chemistry", Oxford, Oxford University Press, $1999, \mathrm{p} 167$.

[22] I. Grenthe, W.C. Fernelius, "Stability Relationships Among the Rare Earth Complexes", J.Phys. Chem., 82 (1960) 6258.

[23] R.C. Mehrotra, B. Bohra, D.P. Gaur, "Metal $\beta$-Diketonates and Allied Derivatives", London, Academic Press Inc., 1978.

[24] J. Forsberg, "Complexes with Diketones and Polydiketones", Gmelin Handbook of Inorganic Chemistry, $8^{\text {a }}$ ed, Part D3: Sc, Y,La-Lu, Springer Verlag, Berlin, 1981, p65.

[25] E.F. Sousa-Aguiar, "El Papel de las Tierras Raras en Zeólitas y Catalizadores de Craqueo" FCC en Revista, 26 (2001).

[26] G.T. Kokotailo, C.A. Fyfe, Y. Feng, H. Grondey, "Characterization of Zeolite Cracking Catalysts" ACS Symp. Series 452 (1991) 27.

[27] H.S. Cerqueira, R. Rawet, A.F. Costa, "FCC Optimizaption Review, Catalyst Impact on the Production Chain", Rio de Janeiro, $17^{\text {th }}$ World Petroleum Congress, 2002.

[28] Solomon Associates, "North and South America Fuels Refineries Performance Analysis for Operating Year 2002", relatório técnico de consultoria, 2003.

[29] A.R. Pinho, E. Morgado Jr., E.F. Sandes, J.G.F. Ramos, O.R.C. Pravia, "Evolução da Tecnologia de FCC na Petrobras" in Anais do $4^{\circ}$ Simpósio de Craqueamento Catalítico, ed. FCC-SA, São Paulo, 2002, 53. 
[30] C.R. Schlosser, J.A.M. Castillero, C.M.L.A. Baptista, "Evaluation of Processing Heavy Brazilian Resides in RDS/RFCC", NPRA Annual Meeting, 1999, paper 99-50.

[31] Refining Process Services Inc., "Fluid Catalytic Cracking Technology", Apostila de curso, Houston, 2001

[32] G.L. Baugis, M.H. Tan, "Efeitos e Moderação de Contaminação Metálica em Catalisador de U-RFCC" in Anales del V Encuentro de Craqueo Catalitico, ed. FCC-SA, Maceió, 2002, p188.

[33] R.H. Filby, G.J. van Berckel, "Geochemistry of Metal Complexes in Petroleum", ACS Symp. Series, 344 (1988) 2.

[34] A.F.Wells, "Structural Inorganic Chemistry", Oxford, 5a ed. Oxford University Press, $1986, \mathrm{p} 565$.

[35] B. M. Weckhuysen, D. E. Keller, "Chemistry, Spectroscopy and the Role of Supported Vanadium Oxides in Heterogeneous Catalysis", Catal Today, 78 (2003) 25. 


\section{Revisão Bibliográfica}

\section{1. $O$ efeito da incorporação de $V$ ao catalisador para craqueamento}

Embora os efeitos da redução da atividade do catalisador por meio da contaminação por $\mathrm{V}$ através da carga fossem há muito tempo conhecidos [1], os mecanismos propostos que explicam este ataque não estavam consensualmente estabelecidos até recentemente. Estes estudos mereceram certa atenção, haja vista que o desenvolvimento dos meios para a minimização dos efeitos deletérios provocados pelo $\mathrm{V}$ passam obrigatoriamente pela compreensão dos mecanismos que envolvem a interação entre o catalisador e o $\mathrm{V}$ quando submetidos às condições do processo.

\subsubsection{Métodos para estudo da desativação do catalisador por $V$}

A simulação experimental das condições encontradas no regenerador consiste-se na maior dificuldade ao estudar os efeitos provocados pelo $\mathrm{V}$ ao catalisador. Em função desta necessidade, uma série de técnicas foi desenvolvida com resultados satisfatórios em determinados aspectos, mas ligeiramente diferentes entre si [2,3].

Um dos primeiros métodos desenvolvidos para o estudo da desativação dos catalisadores foi realizado por Mitchell [4]. O procedimento consiste na deposição de metais comumente presentes na carga das unidades de FCC (Ni e $\mathrm{V}$ ) através de complexos orgânicos ou sais inorgânicos em soluções aquosas com subseqüente calcinação na presença de vapor de água em laboratório. Apesar de fácil execução, o método trás a desvantagem de aumentar o nível de ataque ao catalisador em até 3 vezes quando comparado a uma condição real. Além disso, os metais são quase completamente oxidados na etapa de calcinação, o que eleva muito a atividade desidrogenante do catalisador. 
O método Cyclic Propylene Steaming (CPS), desenvolvido mais recentemente e descrito por Boock et al., emprega o procedimento de impregnação metálica conforme Mitchell precedido de ciclos de oxi-redução combinados com atmosferas de vapor de água [5]. No ciclo redutor emprega-se propeno e no oxidante uma mistura de ar e $\mathrm{SO}_{2}$. Este método apresenta fácil execução e tem a vantagem de manter parcialmente o conteúdo dos metais em baixo estado de oxidação, sendo, portanto, mais representativo às condições do conversor, principalmente, em relação àqueles que operam em processos de combustão parcial no regenerador.

Outra maneira desenvolvida para simular as transformações no conversor é o processo Cyclic Deactivation (CD) [6]. Através desta técnica, a impregnação dos metais é realizada utilizando uma carga de gasóleo real de processo incorporada com uma quantidade adicional de metais para que a concentração no catalisador seja alcançada entre 20 e 50 ciclos. Assim como ocorre na unidade de FCC, após cada etapa de reação ocorre a regeneração sob uma quantidade adicional de vapor injetada. A grande vantagem deste método consiste no estudo da distribuição de idade das partículas, por meio da introdução ou retirada das amostras durante o teste.

\subsubsection{Mecanismos de ataque do $\mathrm{V}$ ao catalisador para craqueamento}

Pompe et al. estudaram a desativação da zeólita TRY na presença de complexos orgânicos e óxidos de $\mathrm{V}$ e $\mathrm{Ni}$ através de uma série de experimentos, empregando atmosferas oxidante e redutora simultaneamente [7]. Concluiu-se que os complexos de $\mathrm{Ni}$ e $\mathrm{V}$ sofrem decomposição e são oxidados aos respectivos óxidos. $\mathrm{O}_{2} \mathrm{O}_{5}$ formado reage com o cátion de TR da zeólita, formando o vanadato de TR. Esta reação ocorreria às expensas dos átomos de $\mathrm{O}$ da rede zeolítica, levando-a para um colapso estrutural.

Wormsbecher et al. demonstraram que o vapor de água é necessário para proporcionar a destruição da rede zeolítica na presença de $\mathrm{V}[8] . \mathrm{O}_{2} \mathrm{O}_{5}$, resultante da oxidação do $\mathrm{V}$, na presença de vapor de água gera o ácido vanádico $\left(\mathrm{H}_{3} \mathrm{VO}_{4}\right)$, que nas condições típicas de temperatura e pressão do regenerador é volátil e pode concentrar-se entre de 1 e 10 ppm na fase diluída ou gasosa. $\mathrm{O} \mathrm{H}_{3} \mathrm{VO}_{4}$ formado é responsável pela 
mobilidade e permeabilidade entre as partículas do catalisador, além de atacar a estrutura cristalina da zeólita. Também como conseqüência, compostos de TR seriam formados. Ainda segundo os autores, o emprego de óxidos de metais alcalinos terrosos poderia ser empregado como passivadores, desde que a reação fosse termodinamicamente controlada no regenerador evitando a competição com os compostos de enxofre que advém dos gases de combustão.

Hettinger sugeriu que a manutenção de uma atmosfera redutora durante a etapa de regeneração é importante para diminuir a desativação catalítica, uma vez que possibilita manter o $\mathrm{V}$ em baixo estado de oxidação no regenerador [9]. $\mathrm{O}$ efeito destrutivo provocado pelo $\mathrm{V}$ à zeólita foi correlacionado com a existência de espécies como o $\mathrm{V}_{2} \mathrm{O}_{5}$.

Chester estudou o efeito da incorporação de metais através da impregnação de gasóleo contaminado com complexos de $\mathrm{Ni}$ e $\mathrm{V}$ seguido de craqueamento e desativação hidrotérmica [10]. O Ni apresentou uma ação desidrogenante 3 a 4 vezes maior que V, conforme demonstrado anteriormente por Cimbalo et al. [11]. Não foi verificado efeito sinérgico quanto à produção de $\mathrm{H}_{2}$ entre os dois elementos. A formação de coque propiciada na presença de V é similar a de Ni. Shubert et al. , por sua vez, demonstraram que os efeitos desidrogenante e de formação de coque do $\mathrm{V}$ podem ser maiores que o $\mathrm{Ni}$ quando associado à superficie do componente não zeolítico do catalisador [12] .

Gallezot et al. demonstraram que o ataque do $\mathrm{V}$ à zeólita $\mathrm{LaY}$ conduz à formação de $\mathrm{LaVO}_{4}$ [13]. A exclusão dos íons $\mathrm{La}^{3+}$ do interior das cavidades sodalitas devido à reação promoveria a desestabilização estrutural e o colapso da zeólita. Quando submetida à desativação hidrotérmica na presença de V, a zeólita USY é convertida em um aluminossilicato amorfo do tipo mulita, e a zeólita USY desaluminizada é transformada em cristobalita. A reação entre $\mathrm{V}_{2} \mathrm{O}_{5}$ e o $\mathrm{Al}$ extra-estrutural gerado no tratamento térmico produz $\mathrm{AlVO}_{4}$, estável termicamente até $650^{\circ} \mathrm{C}[14]$

Anderson et al., utilizando técnicas como luminescência e RPE para monitorar o ataque de $\mathrm{V}$ à zeólita $\mathrm{EuY}$, determinaram que o $\mathrm{V}$ é adsorvido preferencialmente na matriz do catalisador sob a forma de $\mathrm{V}_{2} \mathrm{O}_{5}$ e migra para o componente zeolítico durante a 
desativação hidrotérmica [15-16]. Na zeólita, o V é estabilizado na forma de cátions $\mathrm{VO}^{2+}$ octaédricos. Observou-se também a formação de $\mathrm{EuVO}_{4}$ a partir de da extração dos íons $\mathrm{Eu}^{3+}$ da rede zeolítica. Quando Sn é empregado como imobilizador de V, foi possível notar a presença de espécies do tipo $\mathrm{Sn}^{4+}-\mathrm{O}-\mathrm{V}^{5+}$ na superfície das partículas e a formação surpreendentemente favorecida de $\mathrm{EuVO}_{4}$.

Pine apresentou o mecanismo sob um ponto de vista inusitado, através de uma abordagem cinética da interação entre $\mathrm{V}$ e o catalisador sob condições de desativação hidrotérmica com zeólitas trocadas com $\mathrm{TR}, \mathrm{Na}, \mathrm{K}$ e Li [17]. Concluiu-se que a destruição da zeólita é catalisada por $\mathrm{V}$ e $\mathrm{Na}$ na presença de vapor, sendo constatado um efeito sinérgico entre os dois elementos na reação. A presença das TR não influencia a resistência ao $\mathrm{V}$, mas proporcionam um efeito indireto no aumento da estabilidade da zeólita em virtude da formação de vanadatos. Demonstrou-se também que o ataque do $\mathrm{V}$ se dá nos grupos silanóis $(\mathrm{Si}-\mathrm{OH})$ da zeólita.

Huang et al. demonstraram através de medidas de RPE que o $\mathrm{V}_{2} \mathrm{O}_{5}$ promove troca iônica no estado sólido com a zeólita $\mathrm{Y}$ quando expostos à presença de ar e vapor de água [18]. Como resultado observou-se a formação de íons (VO) ${ }^{3+}$ alocados nas cavidades betas e na supercavidades numa simetria tetraédrica distorcida e/ou piramidal.

Occelli também publicou uma série de trabalhos inerentes ao assunto empregando inúmeras técnicas analíticas [19-20]. Concluiu em seus estudos que as zeólitas HY, USY e TRY quando submetidas à calcinação a $540^{\circ} \mathrm{C}$ na presença de $\mathrm{V}$ sofrem exclusão de $\mathrm{Al}$ da rede sem redução da área superficial ou cristalinidade. A resistência ao ataque de $\mathrm{V}$ nessas condições depende da concentração de $\mathrm{Na}$. Com a presença de vapor a $760^{\circ} \mathrm{C}$, a zeólita $\mathrm{HY}$ é destruída formando mulita, tridimita e uma fase de vanadia. A tolerância ao $\mathrm{V}$ é aumentada em função do maior teor de Si na estrutura, o que sugeriu que o ataque incide sobre as ligações Si-O-Al. Durante a desativação hidrotérmica, o $\mathrm{V}^{5+}$ formado pela decomposição oxidativa dos complexos porfirínicos gera uma série de ácidos, tais como $\mathrm{H}_{4} \mathrm{~V}_{2} \mathrm{O}_{7}$ caracterizados através de ${ }^{51} \mathrm{~V} \mathrm{RMN}$ em meio aquoso, que promovem o ataque à estrutura zeolítica. Observou-se também a formação de vanadatos de $\mathrm{Na}$ que, por exclusão dos cátions da rede zeolítica, promovem o colapso estrutural. $\mathrm{O}$ ataque aos cátions de TR 
dispostos no interior da estrutura zeolítica conduz à formação de $\mathrm{TRVO}_{4}$. Os complexos de $\mathrm{Ce}^{4+}$ localizados nas proximidades das supercavidades são mais suscetíveis ao ataque, conforme reação apresentada:

$$
[\mathrm{Ce}<\underset{\mathrm{O}}{\mathrm{O}}>\mathrm{Ce}]^{4+}+2 \mathrm{VO}^{2+}+4 \mathrm{H}_{2} \mathrm{O} \rightarrow 2 \mathrm{CeVO}_{4}+8 \mathrm{H}^{+}
$$

Torrealba et al. demonstraram que a atividade catalítica da zeólita USHY é diminuída na presença de $\mathrm{V}$, não apenas pelo fato da queda de cristalinidade durante a desativação hidrotérmica, mas também por um efeito de troca iônica entre os cátions de $\mathrm{VO}_{2}{ }^{+} \mathrm{e}$ os sítios protônicos na rede zeolítica [21]. Foi demonstrado também que a desativação causa uma eliminação parcial de $\mathrm{V}$ da superfície das amostras sendo este efeito menos pronunciado no catalisador multicomponente, principalmente, em virtude da migração do V para a matriz.

Suib et al. em uma série de trabalhos empregando medidas de luminescência, RPE e SEM-EDX, demonstraram que a migração de V entre matriz e zeólita depende da característica do ligante no complexo [22-24]. Quando naftenatos ou ftalocianinas são usadas como precursores, ocorre a migração de $\mathrm{V}$ da zeólita para a matriz com maior intensidade. Os complexos porfirínicos, por sua vez, atenuam este efeito migratório e a decomposição oxidativa do complexo é menos pronunciada. Verificou-se que durante a desativação hidrotérmica ocorre formação de compostos voláteis de V que influenciam o estes movimentos migratórios.

Yang et al. estudaram a influência da composição da matriz do catalisador no resultado do ataque promovido pelo $\mathrm{V}$, determinando a seguinte ordem em termos de resistência: $\mathrm{MgO} . \mathrm{Al}_{2} \mathrm{O}_{3}>$ aluminofosfatos de $\mathrm{Mg}$ e $\mathrm{Al}>$ aluminofosfatos de $\mathrm{Al}>\mathrm{Al}_{2} \mathrm{O}_{3}$ [25]. Verificou-se também que o Ni inibe parcialmente a destruição da zeólita causado pelo $\mathrm{V}$, ao passo que os dois elementos não apresentam efeitos sinérgicos na formação de coque. A interação entre $\mathrm{Ni}$ e as matrizes compostas de aluminofosfatos de $\mathrm{Al}$ diminui a habilidade de produção de coque e o efeito destrutivo causado pelo V à zeólita USY. Foi sugerido que a interação entre $\mathrm{V}$ e Ni ocorre durante a desativação hidrotérmica. Isso não 
somente resultaria na diminuição da mobilidade do $\mathrm{V}$, mas também tornaria o $\mathrm{Ni}$ mais difícil de ser reduzido, levando à uma menor produção de coque e $\mathrm{H}_{2}$ [26].

Roncolatto e Lam apresentaram que a migração de $\mathrm{V}$ na unidade de regeneração ocorre por meio de espécies poliméricas de $\mathrm{V}_{2} \mathrm{O}_{5}$, que na presença do vapor são transportadas da fonte até a partícula absorvedora. Foi demonstrado que o $\mathrm{V}$ não sublima do leito de catalisador por meio das espécies voláteis produzidas [27].

Myrstad avaliou que o catalisador submetido à desativação hidrotérmica na presença $\mathrm{V}$ resulta em uma menor conversão e acarreta uma redução no rendimento de gasolina, entretanto, proporciona aumento no número de octano da nafta craqueada [28]. Isto é explicado em função da redução da quantidade de sítios ativos do catalisador por envenenamento de $\mathrm{V}$ e destruição de zeólita que, conseqüentemente, diminui as reações de transferência de hidrogênio (TH). A influência da TH no número de octano da nafta pode ser notada através da reação 2.2 , uma vez que o resultado da soma número de octano dos reagentes é maior que o resultado da soma dos produtos.

$$
\text { Naftênicos }+3 \text { Olefinicos } \stackrel{\text { TH }}{\longrightarrow} 3 \text { Parafinicos }+ \text { Aromáticos }
$$

Talvez, o mais consistente mecanismo até agora proposto tenha sido descrito por Trujillo et al. Além de convergir a maioria das conclusões até então obtidas num postulado único, pôde-se explicar os desvios e as diferentes observações resultantes dos trabalhos anteriores [29]. Através de medidas espectroscópicas, concluiu-se que o V, quando submetido a condições similares àquelas encontradas no conversor, migra para sítios ácidos internos de maior força onde é estabilizado como cátion $\mathrm{VO}_{2}{ }^{+}$por meio de troca iônica. Tal como descrito por Torrealba et al., este fenômeno afeta a atividade catalítica, mas não altera as propriedades texturais do catalisador. $\mathrm{O} \mathrm{Al}$ extra-estrutural gerado durante a desativação hidrotérmica atenua o ataque do $\mathrm{V}$, pois impede parcialmente o movimento migratório. $\mathrm{Na}$ presença de água ocorre a formação de $\mathrm{H}_{3} \mathrm{VO}_{4}$ em regiões internas da estrutura zeolítica. A alta concentração de $\mathrm{H}_{3} \mathrm{VO}_{4}$ nestas localizações acentua a hidrólise do Al levando a estrutura ao colapso. Este efeito é ainda potencializado na presença de $\mathrm{Na}$. 


\subsection{Meios de neutralização do ataque promovido pelo $\mathrm{V}$ ao sistema.}

$\mathrm{O}$ envenenamento provocado pelo $\mathrm{V}$ ao catalisador de craqueamento ainda consiste um problema clássico para os refinadores, e a pesquisa por métodos que objetivam minimizar este efeito têm merecido certo interesse [30]. As novas unidades para craqueamento projetadas visam o aumento de rentabilidade por meio do processamento de cargas com menor custo, mas que, como conseqüência, apresentam maior concentração de contaminantes. Desta forma, novas tecnologias estão sendo incorporadas com escopo de adaptarem o processo ao aumento de severidade exigido, tais como, resfriadores de catalisador, operação em combustão total, melhor dispersão de carga e, sobretudo, o aprimoramento do sistema catalítico empregado com o objetivo de suportar os níveis mais severos de desativação [31].

A despeito da possibilidade de se processar cargas previamente submetidas a hidrotratamento, para diminuir os níveis de contaminantes, uma série de soluções foi desenvolvida e é empregada para minimizar o efeito deletério causado pelo $\mathrm{V}$ no sistema, conforme se enumera a seguir [32]:

- maior reposição de catalisador novo - nesta condição a manutenção da atividade catalítica é facilmente alcançada às expensas do aumento considerável dos custos;

- aumento da reposição com incorporação de catalisador de equilíbrio descartado (flushing) de unidades que operam em condições menos severas, com alguma atividade catalítica e baixo teor de metais, com o objetivo de diluir o $\mathrm{V}$ no inventário das unidades reduzindo a desativação do catalisador. Este processo, no entanto, traz algumas desvantagens, tais como a eventual indisponibilidade de catalisador de flushing e alterações na sua composição;

- emprego de substâncias como passivadores químicos, que são adicionados nas cargas das unidades durante o processo para preservar o catalisador. Estes elementos têm a função de interagir com as espécies envenenadoras no ambiente oxi-redutor do conversor, 
- demetalização do catalisador descartado - consiste em um processo de reciclagem do catalisador através de tratamentos químicos que remove os metais presentes na superficie dos catalisadores [34]. Reduções no catalisador de equilíbrio podem chegar até $95 \%$ para o $\mathrm{Ni}$ e até $85 \%$ de V. A despeito do maior custo do processo, ainda não foi observado resultados comercialmente favoráveis neste processo.

Todas as técnicas apresentadas possuem algum inconveniente em termos de aplicação, e por ora ainda não há uma solução definitiva para a questão da desativação do catalisador por V. O emprego dos passivadores químicos e trapas metálicas consiste na maneira mais explorada em termos de pesquisa e desenvolvimento, pois são as que apresentam os melhores resultados.

$\mathrm{O}$ uso de $\mathrm{Sb}$ através de compostos organometálicos ou óxidos estabilizados em solução aquosa como passivador químico para Ni tem sido empregado há muitas décadas. Além do $\mathrm{Sb}$, o Ce e o $\mathrm{Bi}$ também foram desenvolvidos comercialmente para servirem como passivadores de Ni, porém, são usados em menor extensão [30]. O mecanismo de passivação envolve a interação entre $\mathrm{Ni}$ e $\mathrm{Sb}$, produzindo uma liga que bloqueia os sítios ativos para a desidrogenação. Além disso ocorrem alterações das propriedades eletrônicas do $\mathrm{Ni}$ alterando a atividade catalítica no que diz respeito às condições de promover as reações de desidrogenação. Estudos posteriores demonstraram que a forte interação entre $\mathrm{Ni}$-Sb reduz a capacidade de formar ligações por retrodoação com os hidrocarbonetos, produzindo uma ligação Ni-C enfraquecida por comprimento de ligação, portanto diminuindo a quantidade de $\mathrm{CO}$ adsorvida quimicamente [35]. Testes operacionais têm demonstrado a eficiência do emprego de $\mathrm{Sb}$ na passivação de $\mathrm{Ni}$ e verificou-se que a capacidade de fixação do elemento na superfície do catalisador é diminuída à medida que se aumenta o teor de $\mathrm{Sb}$ dosado. Ocorre na literatura também o fato de que a incorporação de grande quantidade de $\mathrm{Sb}$ pode inibir o efeito dos promotores de combustão a base de Pt, pela passivação da Pt na presença do excesso de Sb [36]. Outra forma empregada para passivação de Ni tem sido também o emprego de alumina de alta cristalinidade, que forma o aluminato de $\mathrm{Ni}$, mantendo-o sob uma forma inócua no que se refere as reações de desidrogenação que promove [37]. 


\subsubsection{Passivadores de $V$}

Enquanto o emprego comercial de $\mathrm{Sb}$ tem demonstrado relativo sucesso para os efeitos provocados pelo $\mathrm{Ni}$, a diminuição dos prejuízos provocados pelo $\mathrm{V}$ ao catalisador através de passivadores químicos ou trapas ainda não atingiu resultados semelhantes. Muito se têm realizado em termos de desenvolvimento e pesquisa nesta área, através de estudos em laboratório e testes comerciais [38].

O Sn foi um dos primeiros passivadores desenvolvidos e testados comercialmente [39]. O uso do elemento como passivador foi protegido através de patentes que estabelecem o uso de $\mathrm{Sn}$ combinado com outros elementos, tais como com $\mathrm{S}$, $\mathrm{Sb}$ e $\mathrm{P}$, por meios de sais inorgânicos ou complexos em diferentes estados de oxidação [40-42]. Tanto Sn elementar como compostos orgânicos e inorgânicos, ou mistura deles, poderiam ser aplicados diretamente ao catalisador ou em determinados pontos do processo. Os mecanismos de interação entre $\mathrm{Sn}$ e $\mathrm{V}$ foram estabelecidos em uma série de trabalhos apresentados por Suib e Occelli empregando medidas de luminescência, ressonância paramagnética eletrônica (RPE), espectroscopia Mössbauer e energia dispersiva de raios-X (EDX) [15-16,43]. Verificou-se que as interações V-Sn ocorrem através da calcinação na presença de vapor, com a formação de espécies do tipo $\mathrm{Sn}^{+4}-\mathrm{O}-\mathrm{V}^{+5}$, inibindo o ataque do $\mathrm{V}$ à zeólita e preservando a cristalinidade e a atividade catalítica do material. Além disso, ocorre a oxidação de $\mathrm{VO}^{2+}$ a $\mathrm{V}^{5+}$ durante a desativação hidrotérmica e o excesso de Sn provocou a formação de $\mathrm{EuVO}_{4}$, acentuando a retirada de cátions da estrutura zeolítica.

Está colocada na literatura sob a forma de patentes uma ampla variedade de substâncias e materiais que servem como passivadores de V. Em geral, descreve-se que os efeitos provocados pelo $\mathrm{V}$ são diminuídos através da formação de compostos ou ligas que são estáveis termicamente nas condições do regenerador. Além de TR, que serão focadas adiante, entre os materiais citados na literatura pode-se destacar em uso:

- Bi e Mn através de compostos orgânicos e inorgânicos [44];

- compostos de Sb com ânions orgânicos e combinados com P e S [45]; 
- dispersões coloidais $\mathrm{Al}_{2} \mathrm{O}_{3}$ ou $\mathrm{SiO}_{2}$ adicionadas à formulação do catalisador ou como partículas discretas [46];

- óxidos, sais e compostos organometálicos dos metais $\mathrm{Mg}, \mathrm{Ca}, \mathrm{Sr}, \mathrm{Ba}, \mathrm{Sc}, \mathrm{Y}, \mathrm{Ti}$, $\mathrm{Zr}$, Hf, $\mathrm{Nb}, \mathrm{Ta}, \mathrm{Mn}, \mathrm{Fe}$, In, Tl, Bi, Te e lantanídeos [47];

- compostos e minérios contendo $\mathrm{Ca}$, tais como: $\mathrm{Ca}_{3} \mathrm{Ti}_{2} \mathrm{O}_{7}, \mathrm{CaTiO}_{3}, \mathrm{CaTi}_{2} \mathrm{O}_{5}$, $\mathrm{CaTi}_{4} \mathrm{O}_{9}, \mathrm{CaZrTi}_{2} \mathrm{O}_{7}, \mathrm{CaZrO}_{3}, \quad \mathrm{Ca}_{0,15} \mathrm{Zr}_{0,85} \mathrm{O}_{1,85}, \quad \mathrm{CaZr}_{4} \mathrm{O}_{9} \quad[48] ; \quad \mathrm{CaO} / \mathrm{TiO}_{2}$, $\mathrm{CaO} / \mathrm{ZrO}_{2}, \mathrm{CaO} / \mathrm{TiO}_{2} / \mathrm{ZrO}_{2}$ [49]; $\mathrm{CaCO}_{3}, \mathrm{CaSi}_{2} \mathrm{O}_{5}$, dolomita, $\mathrm{CaSO}_{4}, \mathrm{CaHPO}_{4}$, $\mathrm{CaCl}_{2}, \mathrm{CaSO}_{3}[50]$;

- Ti na forma de minérios ou como misturas de $\mathrm{TiO}_{2} / \mathrm{P}_{2} \mathrm{O}_{5}, \mathrm{TiO}_{2} / \mathrm{P}_{2} \mathrm{O}_{5}$ e $\mathrm{TiO}_{2} / \mathrm{SO}_{4}{ }^{2-}[51]$;

- compostos organometálicos de P e B [52];

- Sr como carbonato na composição da matriz do catalisador [53-55];

- Silicatos lamelares intercalados com $\gamma-\mathrm{Al}_{2} \mathrm{O}_{3}$ contendo até $10 \%$ de um óxido de metal alcalino-terroso [56];

- incorporação de zeólita ZSM-5 ao catalisador [57];

- Ba na forma de pirofosfatos ou metafosfatos [58];

- adição de minerais $\mathrm{Mg}$ e $\mathrm{Al}$ tais como a hidrotalcita ao catalisador, também com o de reduzir emissões sob a forma de $\mathrm{SO}_{x}[59]$;

- $\mathrm{Al}_{2} \mathrm{O}_{3}$ e coque esponjoso [60-62];

- $\mathrm{MgO}$ adicionado à matriz do catalisador [63-64];

- titanatos, zirconatos e carbonatos de $\mathrm{Ba}, \mathrm{Ce}$ e $\mathrm{Sr}$ incorporados à matriz do catalisador [65-66];

- Ca e Mg em minerais, tais como a sepiolita e a dolomita, adicionados à matriz do catalisador ou na forma de partículas discretas [67-69];

- argilas contendo $\mathrm{Mg}[70]$;

- $\mathrm{Mg}$ e $\mathrm{Al}$ em forma de espinélio [71-72];

- $\mathrm{MgO}$ suportado em alumina [73];

- Ge [74];

- Ga [75] ;

- Te, Cd e Zn [76];

- In [77];

- Ba [78]; 
- B [79];

$-\mathrm{W}[80]$;

- Li [81];

Finalmente, o uso do próprio $\mathrm{V}$ como passivador também foi descrito [82].

\subsubsection{Aplicação de TR como passivadores de $V$}

$\mathrm{Na}$ literatura encontra-se descrito a aplicação de TR como passivadores de $\mathrm{V}$ em FCC, inclusive, com o uso protegido sob determinadas formas em uma série de patentes [47,83-94]. A efetividade dos passivadores de TR foi demonstrada nestes trabalhos, no entanto, o uso comercial ainda é reduzido, em função do custo da aplicação e da neutralização dos passivadores por meio dos compostos de $\mathrm{S}$ que são produzidos no regenerador [58].

Beck et al. patentearam o emprego de TR por meio da incorporação de seus íons na superficie das partículas do catalisador [47]. A incorporação pode ser realizada através de óxidos e sais de TR. O método consiste no enriquecimento das partículas de catalisador através da precipitação dos elementos na forma de hidróxidos ou oxalatos em solução aquosa de $\mathrm{NH}_{4} \mathrm{OH}$ ou ácido oxálico. Foi demonstrado que quanto maior a relação $\mathrm{La} / \mathrm{Ce}$ mais efetiva é a passivação de $\mathrm{V}$, indicando que a maior concentração de La na superfície é relevante para a passivação do $\mathrm{V}$.

Maugé et al. reivindicaram em outra patente o emprego de uma mistura ou um determinado íon lantanídeo adicionados à carga em uma concentração de $5 \%$ em relação à massa total do catalisador, através de compostos orgânicos ou inorgânicos [84]. Explorando melhor os resultados desta invenção, Féron et al. estudaram posteriormente a passivação do $\mathrm{V}$ pela adição à carga de compostos organometálicos de La e Dy [85]. Embora o rendimento de gasolina tivesse se mantido alto nos experimentos catalíticos com os catalisadores envenenados, os resultados obtidos quanto à formação de gás e coque não foram satisfatórios. Por meio de microscopia eletrônica de transmissão (TEM) foram caracterizados compostos de TR e V depositados na superficie do catalisador, e em função 
da alta estabilidade térmica e das proporções estequiométricas mensuradas, concluiu-se por se tratar de vanadatos de TR. Verificou-se, também, que compostos de Sm apresentaram resultado inferior à La e Dy. Atribuiu-se o fato de que o $\mathrm{Sm}$ não possuía capacidade satisfatória de reação com o $\mathrm{V}$ devido ao elemento possuir 2 estados de oxidação estáveis, que o tornaria menos suscetível à reação.

Chao et al. demonstraram, através de medidas de espectrometria de imagens secundárias de elétrons, que o Ce tem menor capacidade que o La de interagir com o V nas condições de regeneração [86]. Segundo os autores, a razão pela qual o Ce foi menos ativo para capturar o $\mathrm{V}$ é devido ao fato do Ce apresentar dois estados de oxidação e, portanto, o vanadato de Ce formado seria menos estável que o vanadato de $\mathrm{La}$.

Mester patenteou o emprego de $\mathrm{Ce}, \mathrm{Nd}$, Pr e $\mathrm{Gd}$ em quantidades maiores que $1 \%$ em massa do catalisador livre de coque e em concentrações relativamente superiores ao La presente, agregados ao catalisador novo através do processo de impregnação por uma solução de nitratos e subseqüente calcinação a $600{ }^{\circ} \mathrm{C}$ [87]. Os passivadores de TR poderiam ser incorporados ao catalisador, também, através de soluções de sais inorgânicos como cloretos, nitratos, sulfatos, acetatos, brometos e iodatos. É referida na patente a possibilidade de emprego de compostos organometálicos de TR adicionados à carga como outra forma de incorporar os passivadores ao catalisador, através de compostos trisciclopentadienilos ou poliéters macrocíclicos. Segundo a patente, alguns elementos de TR não apresentam atividade passivadora efetiva, tais como $\mathrm{Ho}, \mathrm{Yb}$ e La, e portanto devem ser preteridos na aplicação.

Chin et al. protegeram em outra patente o emprego de partículas discretas com tamanho variável de óxidos de $\mathrm{La}, \mathrm{Ce}, \mathrm{Pr}, \mathrm{Nd}, \mathrm{Pm}$ e Sm, em concentrações de até $20 \%$ em massa relativa ao catalisador, combinadas a um material inerte como suporte através de spray-drying ou misturadas apenas fisicamente [88]. O tamanho das partículas discretas deve ter preferencialmente 40 e $150 \mu \mathrm{m}$. O uso de La é colocado como preferencial e foi demonstrada pela patente que o $\mathrm{CeO}_{2}$ tem aproximadamente a metade da efetividade observada com o $\mathrm{La}_{2} \mathrm{O}_{3}$. 
Chu et al. patentearam o recobrimento das micro-esferas do catalisador com uma camada passivadora aplicada por spraying constituída de fosfatos de TR e alumínio neutralizados por uma base orgânica [89]. A camada passivadora que recobre o catalisador pode ser removida ao longo do tempo expondo melhor os poros do catalisador, e o V passivado permaneceria nos fragmentos desprendidos. A camada é sintetizada neutralizando uma solução TR e Al em ácido fosfórico com uma base orgânica, como tetra-alquilamônio ou alquilamina, que é empregada também para regular o tamanho do poro do produto final que recobre as partículas. Resultados foram demonstrados apenas para o La e indicou-se que o V se concentrava de fato nos fragmentos desprendidos.

Hettinger descreveu a adição de sais inorgânicos ao catalisador ou de compostos organometálicos de TR pesadas ( $\mathrm{Gd}, \mathrm{Tb}, \mathrm{Dy}, \mathrm{Ho}, \mathrm{Er}$ e $\mathrm{Tm}$ ) à carga do processo de craqueamento. As TR pesadas teriam a função de realçar as propriedades magnéticas do catalisador, contribuindo posteriormente para a remoção das partículas envelhecidas mais contaminadas por metais através de um campo magnético aplicado [33,90]. As TR apresentariam vantagens sobre Fe ou $\mathrm{Mn}$ normalmente aplicados nesta finalidade, posto que apresentam menor interação com os componentes do catalisador.

Kim patenteou o emprego de uma mistura de óxidos de La e/ou $\mathrm{Nd}$ combinados com um espinélio de $\mathrm{Al}_{2} \mathrm{O}_{3}$ e $\mathrm{MgO}$ para serem usados com o catalisador na forma de partículas discretas [91]. A razão $\mathrm{La} / \mathrm{Nd}$ foi colocada ser preferencialmente a maior possível, indicando mais uma vez a vantagem do La na passivação de V. A inserção de TR no sistema pode ser realizada através de compostos, preferencialmente nitratos, que se convertem em óxidos durante o processo de craqueamento catalítico na etapa de regeneração. A patente demonstrou que as partículas da trapa metálica preparada, após isoladas das partículas do catalisador, tiveram muito maior capacidade de concentrar o $\mathrm{V}$ quando submetidas a um determinado protocolo de desativação.

Kumar [92-94] patenteou o uso de La, preferencialmente, ou de $\mathrm{Nd}$ na forma de óxidos ou oxi-cloretos dispersos na matriz de alumina ou argila do catalisador. A trapa metálica é preparada misturando em suspensão um oxalato de TR com argila e um sol de $\mathrm{Al}_{2}(\mathrm{OH})_{5} \mathrm{Cl}$, submetendo-a posteriormente à secagem por spray. Foi demonstrada na 
patente que o material preparado apresentava excelente resistência ao atrito e boa capacidade de resistir ao ataque promovido pelo $\mathrm{V}$. 


\section{Referências Bibliográficas}

[1] Refining Process Services Inc., "Fluid Catalytic Cracking Technology", Apostila de curso, Houston, 2001.

[2] R. Rawet, R. Pimenta, A. Pinho, W. Gilbert, S. Oliveira, J. Amílcar, "A Predição do Desempenho Catalitico Comercial em Unidades de FCC", in Anais do $3^{\circ}$ Simpósio de Craqueamento Catalítico, FCC SA, São Paulo, 1999.

[3] P. O'Connor, J.P.J. Verlaan, S.J. Yanik, "Challenges, Catalyst Technology and Catalytic Solutions in Resid FCC”, Catalysis Today, 43 (1998) 305.

[4] B. R. Mitchell, "Metal Contamination of Cracking Catalyst. 1. Synthetic Metals Deposition on Fresh Catalyst”, Ind. Chem. Prod. Res. Dev., 19 (1980) 209.

[5] L.T. Boock, T.F. Petti, J.A. Rudesill, "Contaminant-Metal Deactivation and MetalDehydrogenation Effects During Cyclic Propylene Steaming of Fluid Cracking Catalysts", ACS Div. Petr. Chem. 40 (3) (1995) 421.

[6] F. Hernandez, R. García de León, E. Mógica, J.C. Moreno, R. González, E. Garcíafigueroa, "The Mechanism of Metal Poisoning by Cyclic Deactivation in Fluid Cracking Catalysts" Stud. Surf. Sci. Catal., 111 (1997) 455.

[7] R. Pompe, S. Jaras, N.G. Vannenberg, "On the Interaction of Vanadium and Nickel Compounds with Cracking Catalysts" Appl. Catal., 13 (1984) 171.

[8] R.F. Wormsbecher, A. W. Peter, J.M. Maselli, "Vanadium Poisoning of Cracking Catalysts: Mechanism of Poisoning and Design of Tolerant Catalyst System" J. Catal, 100 (1986) 130.

[9] W.P. Hettinger Jr., "Development of a Reduced Crude Cracking Catalyst", ACS Symp. Series, 375 (1988) 308.

[10] A.W. Chester, "Studies on the Metal Poisoning and Metal Resistance of Zeolitic Cracking Catalysts", Ind. Eng. Chem. Res., 26 (1987) 863.

[11] R.N. Cimbalo, R.L. Foster, S.J. Wachtel, "Metal Dehidrogenation Effects in FCC Units", Oil \& Gas Journal, 70 (1972) 112.

[12] P.F. Shubert, C.A. Altomare, "Effects of Ni and V in Catalysts on Contaminant Coke and Hydrogen Yields", ACS Symp. Series, 375 (1988) 182.

[13] F. Maugé, J.C. Courcelle, Ph. Engelhard, P. Gallezot, J. Grosmangin, "Hydrothermal Aging of Cracking Catalysts III. Effect of Vanadium on the Structure of LaY Zeolites", in 
Y. Murakami, A. Iijima and J.W. Ward (eds), Proc. $7^{\text {th }}$ Int. Zeolite Conference, Kodanska Tokyo (1986), p. 803

[14] P. Gallezot, B. Féron, M. Bourgogne, P. Engelhard, "Hydrothermal Aging of Cracking Catalysts IV. Destabilizing Effect of Vanadium on USY Zeolite and FCC Catalysts", Stud. Surf. Sci. Catal., 49 (1989) 1281.

[15] M.W. Anderson, M.L. Occelli, S.L. Suib, "Luminescence Probes of VanadiumContaminated Fluid Cracking Catalysts”, J. Catal., 118 (1989) 31.

[16] M.W. Anderson, M.L. Occelli, S.L. Suib, "Tin Passivation of Metal-Contaminated Fluid Cracking Catalysts: Electron Paramagnetic Resonance Studies”, J. Catal., 122 (1990) 374.

[17] L.A. Pine, "Vanadium-Catalyzed Destruction of USY Zeolites", J. Catal., 125 (1990) 514.

[18] M. Huang, S. Shan, C. Yuan, Y. Li, Q. Wang, "Introduction of Vanadium into Y Zeolite by Solid-State Ion Exchange", Zeolites, 10 (1990) 772.

[19] M.L. Occelli, "Vanadium-Zeolite Interactions in Fluidized Cracking Catalysts", Catal. Rev.-Sci. Eng., 33 (1991) 241.

[20] M.L. Occelli, "Vanadium Resistant Fluid Cracking Catalysts”, Stud. Surf. Sci. Catal, $100(1996) 27$.

[21] M. Torrealba, M.R. Goldwasser, G. Perot, M. Guisnet, "Influence of Vanadium on the Physicochemical Catalytic Properties of USHY Zeolite and FCC Catalyst" Appl. Catal.-A, 90 (1992) 35.

[22] L.K. Kurihara, M.L. Occelli, S.L. Suib, "Luminescence as a Probe of Metal Effects in Fluidized Cracking Catalysts", ACS Symp. Series, 452 (1992) 224.

[23] Y.F. Shen, S.L. Suib, M.L. Occelli, "Vanadium Migration between Model Components of Fluid Cracking Catalysts”, ACS Symp. Series, 517 (1993) 185.

[24] H. Cao, S.L. Suib, "Spectroscopic Studies of the Migration of Vanadium in the Model Fluid Catalytic Cracking Process" Appl. Spec., 49/10 (1995) 1454.

[25] S.J. Yang, Y.W. Chen, C. Li, "Metal-Resistant FCC Catalysts: Effect of Matrix", Appl. Catal. - A, 115 (1994) 59.

[26] S.J. Yang, Y.W. Chen, C. Li, "Vanadium-Nickel Interaction in ReY Zeolite", Appl. Catal. - A, 117 (1994) 109. 
[27] R. E. Roncolatto, Y.L. Lam, "Vanadium Transference Tests as a Tool to Understand V Passivation”, ACS Symp. Series, 517 (1999) 185.

[28] T. Myrstad, "Effect of Vanadium on Octane Numbers in FCC-Naphtha", Appl. Catal. - A, 155 (1997) 87.

[29] C.A. Trujillo, U.N. Uribe, P.P. Knops-Gerrits, L.A. Oviedo, P.A. Jacobs, "The Mechanism of Zeolite Y Destruction by Steam in the Presence of Vanadium", J. Catal., 168 (1997) 1.

[30] R.H. Nielsen, P.K. Doolin, "Metals Passivation", Stud. Surf. Sci. Catal., 76 (1993) 339.

[31] J.M. Fusco, M. Einsfeldt, J. Medeiros, P.S. Freire, N. Patrício, M.H. Tan, J.G.F. Ramos, M.A. Torem, "PAC $C^{R C}$ - Um Marco no Processo de Craqueamento Catalitico Fluido" in Anales del IV Encuentro de Craqueo Catalitico , FCC-SA, Manaus 2000, p91. [32] R. Sadeghbeigi, "Fluid Catalytic Cracking Handbook", Houston, Gulf Publishing Company, 1995, p118.

[33] R.B. Miller, T.L. Goolsby, R.B. Peterson, "Magnacat Technology: A Process and Catalyst Sinergy", in Anais do $4^{\circ}$ Simpósio de Craqueamento Catalítico, FCC-SA, São Paulo, 2001, p109.

[34] S.I. Cho, K.S. Jung, S.I. Woo, "Regeneration of Spent RFCC Catalyst Irreversibly Deactivated by Ni, Fe and V Contained in Heavy OiP', Appl. Catal. - B, 33 (2001) 249.

[35] T.F. Petti, D. Tomczak, C. J. Pereira, W. C. Cheng, "Investigation of Nickel Species on Commercial FCC Equilibrium Catalysts Implications on Catalysts Performance and Laboratory Evaluation" Appl. Catal. - A, 169 (1998) 95.

[36] H.S. Cerqueira, R.D. Pimenta, G.L. Baugis, M.H. Tan, "Avaliação da Efetividade de Sb para Passivação de Ni nas Refinarias da Petrobras", Boletim Técnico da Petrobras, 44 (2001) 29.

[37] M.B. B. de Almeida, E. Morgado Jr., "Conceitos Básicos e Ferramentas para Projeto de Catalisadores de Craqueamento", in Anais do $3^{\circ}$ Simpósio de Craqueamento Catalítico, FCC-SA, São Paulo, 1999.

[38] F.W. Denison, J.F. Hohnholt, A.R. English, "Metals Passivation of Sodium and Vanadium on FCC Catalyst', NPRA Annual Meeting, 1986, paper 86-51.

[39] A.R. English, D.C. Kowalczyck, "Tin Passivates Vanadium on FCC Catalyst", Oil and Gas Journal, July 16 (1984) p 127 
[40] B.R. Mitchell, H.G. Swift, "Method of Negating the Effects of Metals Poisoning on Zeolitic Cracking Catalysts", Gulf Research \& Development Company, U.S. Patent $n^{\circ}$ $4,101,417$.

[41] J.S. Roberts, B. J. Bertus, D.L. McKay, H.W. Mark, "Catalyst Poisons Passivated with Tin Compounds plus both Sulfur and Phosphorus", Phillips Petroleum Company, U.S. Patent $4,397,767$

[42] N. Martinez, J. Lujano, N. Alvarez, J. Lubinkowski, W. McEwen, "Antimony and Tin Containing Compound, Use of Such a Compound as a Passivating Agent, and a Process for Preparing Such a Compound", Intevep SA, U.S. Patent n 5,401,384.

[43] M.L. Occelli, "Metal-Resistant Fluid Cracking Catalysts - Thirty Years of Research", ACS Symp. Series, 452 (1991) 343.

[44] T.C. Readal, J.D. McKinney, R.A. Titmus, "Method of Negating the Effects of Metals Poisoning on Cracking Catalysts", Gulf Research \& Development Company, U.S. Patent $\mathrm{n}^{\circ} 3,977,963$.

[45] D.L. McKay, "Passivating Metals on Cracking Catalysts", Phillips Petroleum Company, U.S. Patent $n^{\circ} 4,025,458$.

[46] A.W. Chester, W.A. Stover, "Cracking Catalyst with Improved Resistance to Poisoning by Metals", Mobil Oil Corporation,U.S. Patent n 4,198,320.

[47] H.W. Beck, J.D. Carruthers, E.B. Cornelius, W.P. Hettinger Jr., S.M. Kovach, J.L. Palmer, O.J. Zandona, "Immobilization of Vanadia Deposited on Catalytic Materials During Carbo-Metallic Oil Conversion", Ashland Oil Inc,U.S. Patent n 4,432,890.

[48] B.R. Mitchell, R.F. Vogel, "Vanadium Passivation in a Hydrocarbon Catalytic Cracking Process", Gulf Research \& Development Company, U.S. Patent nº 4,451,355.

[49] B.R. Mitchell, R.F. Vogel, "Vanadium Passivation in a Hydrocarbon Catalytic Cracking Process", Gulf Research \& Development Company, U.S. Patent n 4,520, 120.

[50] B.R. Mitchell, R.F. Vogel, "Vanadium Passivation in a Hydrocarbon Catalytic Cracking Process", Chevron Research Company, U.S. Patent n ${ }^{\circ} 4,750,988$.

[51] N.P. Martinez, J.R. Velasquez, J.A. Lujano, "Cracking Heavy Hydrocarbon Feedstocks with a Catalyst Comprising an Anatase Vanadium Passivating Agent', Intevep SA, U.S. Patent $n^{\circ} 4,816,135$. 
[52] V.A. Durante, D.J. Olszanski, W.J. Reagan, S.M. Brown, "Passivation of Contaminant Metals on Cracking Catalysts by Phosphorus Addition", Engelhard Corporation, U.S. Patent $n^{\circ} 4,430,199$

[53] E.L. Kugler, "Cracking Catalysts Containing Strontium Carbonate", Exxon Research and Engineering Company, U.S. Patent $n^{\circ} 4,824,815$

[54] E.L. Kugler, "Cracking Catalysts Containing Strontium Carbonate", U.S. Patent $\mathrm{n}^{\circ}$ $4,944,864$

[55] E. Pasek, N.C. Morgan, "Vanadium Passivation in a Hydrocarbon Catalytic Cracking Process", Exxon Research and Engineering Company, U.S. Patent nº4,929,583.

[56] R.J. Lussier, "Catalysts and Catalyst Supports", W. R. Grace \& Co, U.S. Patent n $4,847,225$.

[57] J.A. Herbst, A. Huss Jr., "Resid Catalytic Cracking Process Utilizing ZSM-5 for Increased Gasoline Octane”, Mobil Oil Corporation, U.S. Patent $n^{\circ} 4,867,863$.

[58] C.A.Trujillo, U.N. Uribe, L.A.O. Aguiar, "Vanadium Traps for Catalyst for Catalytic Cracking”, Empresa Colombiana de Petroleos Ecopetrol, U.S. Patent n 6,159,887.

[59] A. Chin, I.D. Johnson, C.T. Kresge, M.S. Sarli, "Additive for Vanadium Capture in Catalytic Cracking", Mobil Oil Corporation, U.S. Patent $n^{\circ} 4,889,615$.

[60] N.Y. Chen; B.K. Huh, T.E. Degnan, "FCC Process with Catalyst Separation”, Mobil Oil Corporation, U.S. Patent $\mathbf{n}^{\circ} 4,895,636$.

[61] N.Y. Chen; B.K. Huh, T.E. Degnan, "Apparatus for FCC Process with Catalyst Separation", Mobil Oil Corporation, U.S. Patent $\mathrm{n}^{\circ} 4,971,766$.

[62] B.K. Huh, T.Y. Yan, "Catalytic Cracking Process with Partial CO Combustion", Mobil Oil Corporation, U.S. Patent n 4,980,050.

[63] R.F. Wormsbecher, "Vanadium Scavenging Compositions", W. R. Grace \& Co, U.S. Patent $\mathrm{n}^{\circ} 4,920,087$.

[64] M.L. Occelli, J.V. Kennedy, "Process for Cracking High Metals Content Feedstocks", Chevron Research Company, U.S. Patent $\mathrm{n}^{\circ} 4,944,865$.

[65] E.A. Pasek, "Vanadium Passivation in a Hydrocarbon Catalytic Cracking Process", Chevron Research Company, U.S. Patent $n^{\circ} 4,990,240$.

[66] E.A. Pasek, "Vanadium Passivation in a Hydrocarbon Catalytic Cracking Process", Chevron Research Company, U.S. Patent $n^{\circ} 4,929,583$. 
[67] J.V. Kennedy, L.W. Jossens, "Dual Component Cracking Catalyst with Vanadium Passivation and Improved Sulfur Tolerance", Chevron Research Company, U.S. Patent $\mathrm{n}^{\circ}$ $4,988,654$.

[68] J.V. Kennedy, L.W. Jossens, "Dual Component Cracking Catalyst with Vanadium Passivation and Improved Sulfur Tolerance", Chevron Research Company, U.S. Patent $\mathrm{n}^{\circ}$ $5,002,653$.

[69] J.V. Kennedy, L.W. Jossens, "Hydrocarbon Processing Composition", Chevron Research Company, U.S. Patent $n^{\circ} 5,071,807$.

[70] T. Pecoraro, "Vanadium Tolerant Cracking Catalyst", Chevron Research Company, U.S. Patent $n^{\circ} 5,071,806$.

[71] A.A. Chin, A.V. Sapre, M.S. Sarli, "Additive for Vanadium and Sulfur Oxide Capture in Catalytic Cracking", Mobil Oil Corporation, U.S. Patent n ${ }^{\circ} 5,057,205$.

[72] W.E. Cormier, G.M. Woltermann, J.S. Magee, F.J. Baars, L.L. Upson, "Increasing Metal-Tolerance of FCC Catalyst by Sulfur Oxide Removal', W. R. Grace Co, U.S. Patent $\mathrm{n}^{\circ} 5,324,416$.

[73] P.C. Liao, D.D. Klendworth, F.M. Lee, "Catalytic Cracking Process", Phillips Petroleum Company, U.S. Patent no 5,141,624.

[74] D. Forester, "Method of Passivating Alkali Metals on Fluid Catalytic Cracking Catalysts Using Aluminum Containing Compounds", Betz Laboratories, Inc., U.S. Patent $\mathrm{n}^{\mathrm{o}} 5,019,241$.

[75] J.S. Roberts, D.L. McKay, B.J. Bertus, “Cracking Catalyst Improvement with Gallium Compounds", Phillips Petroleum Company, U.S. Patent n 4,377,504.

[76] C.F. Bertsch, "Passivation of Cracking Catalysts", Exxon Research \& Engineering Co.,U.S. Patent no 4,522,704.

[77] J.S. Roberts, B.J. Bertus, D.L. McKay, "Cracking Process and Catalyst for Same Containing Indium to Passivate Contaminating Metals", Phillips Petroleum Company, U.S. Patent no 4,256,564.

[78] B.J. Bertus, D.L. McKay, "Cracking Catalysts Passivated by Barium", Phillips Petroleum Company, U.S. Patent nº 4,377,494.

[79] H. Tu, “Attenuation of Metal Contaminants on Cracking Catalyst with a Boron Compound", UOP Inc., U.S. Patent n ${ }^{\circ} 4,295,955$. 
[80] D. L. McKay, B.J. Bertus, H.W. Mark, "Cracking Catalysts Passivated by Tungsten", Phillips Petroleum Co., U.S. Patent n 4,290,919.

[81] H. Tu, "Passivation of Metal Contaminants on Cracking Catalyst with a Lithium Compound', UOP Inc.,U.S. Patent n 4,664,847.

[82] D. Walker, F.M. Lee, “Catalytic Cracking”, Phillips Petroleum Company, U.S. Patent $n^{\circ} 4,846,960$.

[83] H.W. Beck; C.F. Lochow, Jr.; C.W. Nilbert; "Passivation of Vanadium Accumulated on Catalytic Solid Fluidizable Particles", Ashland Oil, Inc., U.S. Patent n 4,515,683.

[84] F.Maugé, P. Gallezot, J.C. Courcelle, "Catalytic Cracking Process", Compagnie Française de Raffinage, European Patent $\mathrm{n}^{\circ}$ 173596B1.

[85] B. Féron, P. Gallezot, M. Bourgogne, "Hydrothermal Aging of Cracking Catalysts", J. Catal., 134 (1992) 469

[86] K.J. Chao, L.H. Lin, Y.C. Ling, J.F. Hwang, L.Y Hou, "Vanadium Passivation of Cracking Catalysts by Imaging Secondary Ion Mass Spectrometry”, Appl. Catal.-A, 121 (1995) 217.

[87] Z. Mester, "Process for the Catalytic Cracking of Vanadium-Containing Feedstocks", Union Oil Company of California, U.S. Patent $n^{\circ} 4,900,428$.

[88] A. A. Chin, M.S. Sarli, "A Metal Passivating Catalyst Composition for Cracking Hydrocarbons", Mobil Oil Corp., U.S. Patent $\mathrm{n}^{\circ} 4,9214,824$.

[89] P. Chu, A. Huss Jr, G.W. Kirker, "Metal Passivating Agents", Mobil Oil Corporation, U.S. Patent $\mathbf{n}^{\circ} 5,001,096$.

[90] W.P. Hettinger Jr., "Magnetic Separation of Old from New Cracking Catalyst by Means of Heavy Rare Earth Magnetic Hooks", Ashland Oil Inc., U.S. Patent n 5,171,424.

[91] G. Kim, "La/Nd-Spinel Compositions for Metals Passivation in FCC Processes", W.

R. Grace \& Co., U.S. Patent $n^{\circ} 5,603,823$.

[92] R. Kumar, "Catalytic Cracking Catalysts and Additives", W. R. Grace \& Co., U.S. Patent $\mathbf{n}^{\circ} 5,194,413$

[93] R. Kumar, "Catalytic Cracking Catalysts and Additives", W. R. Grace \& Co., U.S. Patent $n^{\circ} 5,304,299$

[94] R. Kumar, R.E. Ritter, H.J. Schaeffer, "Catalytic Cracking Catalysts and Additives", W. R. Grace \& Co., U.S. Patent nº 5,364,516. 


\section{Objetivos}

\subsection{Descrição do problema e contexto da tese}

Embora já esteja estabelecido na literatura que as TR possam servir como passivadores de $\mathrm{V}$ em unidades de craqueamento que empregam catalisadores zeolíticos, fica constatado também que há ainda muita controvérsia acerca da diferença de desempenho entre as várias TR. Além disso, poucas são as condições em que estes diferentes desempenhos são justificados.

No trabalho de Féron et al. [1], o menor efeito de passivação do $\mathrm{Sm} \mathrm{em}$ comparação ao La e Dy foi atribuído ao fato do elemento possuir um estado de oxidação (II) razoavelmente estável, e isto resultaria na formação de compostos quimicamente menos estabilizados. Por conseqüência, o $\mathrm{V}$ estaria menos imobilizado e mais disponível a promover o ataque à estrutura zeolítica.

De maneira semelhante, Chao et al. determinaram que o Ce apresentava um menor poder de passivação devido ao elemento apresentar o estado de oxidação (IV) bastante estável e, por isso, a reação com o V seria menos favorável que o La [2]. Nota-se que os resultados são antagônicos ao trabalho de Féron et al. uma vez que, desconsiderando-se os efeitos da contribuição entrópica na formação do cristal, a maior relação carga/raio proporcionada pelo $\mathrm{Ce}^{4+}$ favoreceria a reação com o $\mathrm{V}$.

Um outro aspecto inerente à aplicação de Ce como passivador refere-se ao maior potencial de redução do elemento $\left(\mathrm{Ce}^{4+}+\mathrm{e}^{-} \rightarrow \mathrm{Ce}^{3+}, \mathrm{E}^{\mathrm{o}}=1,61 \mathrm{~V}\right)$. O efeito redutor do $\mathrm{Ce}^{3+}$ poderia ser útil para preservar $\mathrm{V}$ em baixo estado de oxidação. Nesta condição a migração do $\mathrm{V}$ pelo sistema é dificultada, pois em estados mais baixos de oxidação a 
difusão do elemento através da estrutura é pronunciadamente menor devido ao seu maior ponto de fusão, preservando-se sob uma forma inócua à estrutura cristalina do catalisador. A Tabela 3.1 compara o $\mathrm{V}$ em seus estados de oxidação com o ponto de fusão dos respectivos óxidos.

Tabela 3.1. Pontos de fusão do V e seus óxidos em estados de oxidação diferentes [3].

\begin{tabular}{ccc}
\hline Composto & Estado de oxidação & PF $\left({ }^{\circ} \mathrm{C}\right)$ \\
\hline $\mathrm{V}_{2} \mathrm{O}_{5}$ & (V) & 690 \\
$\mathrm{~V}_{2} \mathrm{O}_{4}$ & $(\mathrm{IV})$ & 1.640 \\
$\mathrm{~V}_{2} \mathrm{O}_{3}$ & $(\mathrm{III})$ & 1.970 \\
$\mathrm{~V}_{2} \mathrm{O}_{2}$ & (II) & 950 \\
$\mathrm{~V}$ & 0 & 1.890 \\
\hline
\end{tabular}

Comercialmente se emprega uma solução de cloretos de TR por troca iônica como forma de incluir os cátions na estrutura zeolítica, visando aumentar a acidez e a atividade catalítica do material. Esta troca iônica se dá após redução do teor de $\mathrm{Na}$ da zeólita por meio de uma troca iônica preliminar com solução de amônio, conforme comentado no Capítulo 1. Como o emprego de TR isoladas não se constitui um processo usual e nem comercialmente viável, as eventuais diferenças de desempenho entre os elementos não são consideradas na prática.

No que concerne ao desempenho catalítico, Sousa-Aguiar [4] em seus trabalhos determinou que as diferenças entre TR leves e pesadas não são significativas, embora as TR leves proporcionem mais acidez em função do maior grau de hidrólise da água coordenada na esfera de hidratação do elemento. Hettinger estabeleceu o uso de TR pesadas como aditivos para realçar as propriedades magnéticas do catalisador, visando aplicação na separação magnética da fração mais contaminada com metais, uma vez que Dy, Ho e Er apresentam um alto momento magnético efetivo [5]. 
Sobretudo, o estudo do efeito de passivação do $\mathrm{V}$ proporcionado pelo estudo das TR isoladas pode contribuir para a seleção das mais adequadas, considerando, entre outros aspectos, a subdivisão da série entre leve e pesada ou as características oxi-redutoras dos elementos. Esta abordagem tem consistência com o fato que a aplicação em termos de passivação de $\mathrm{V}$ podem envolver minerais ou matérias-primas não usuais.

As principais fontes comerciais de TR são bastnasita, monazita e xenotima. A composição dos minerais em TR está no gráfico da Figura 3.1, em termos da participação de óxidos de TR leves (La-Eu) e pesadas (Gd-Lu e Y). A Tabela 2 apresenta a concentração mais detalhada do mineral. Verifica-se que a obtenção de TR pesadas é mais conveniente quando se emprega a xenotima, por exemplo.

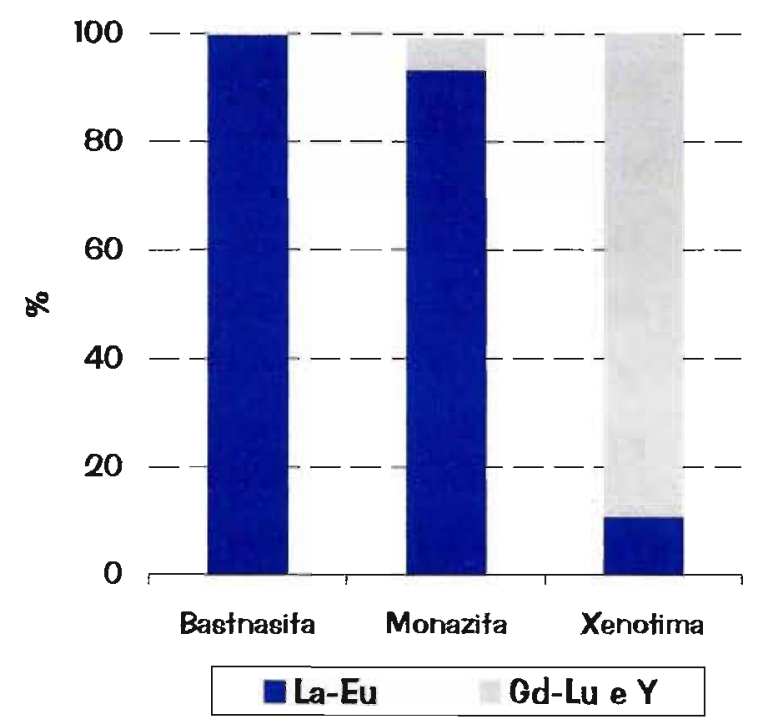

Figura 3.1. Composição dos óxidos de TR presentes em diferentes minerais.

$O$ estudo aqui apresentado se ateve em avaliar o desempenho das TR como passivadores de $\mathrm{V}$, considerando os aspectos discutidos acima. Para tal, foram selecionados os elementos destacados no diagrama da Figura 3.2. Considerou-se, também, natureza do composto. 


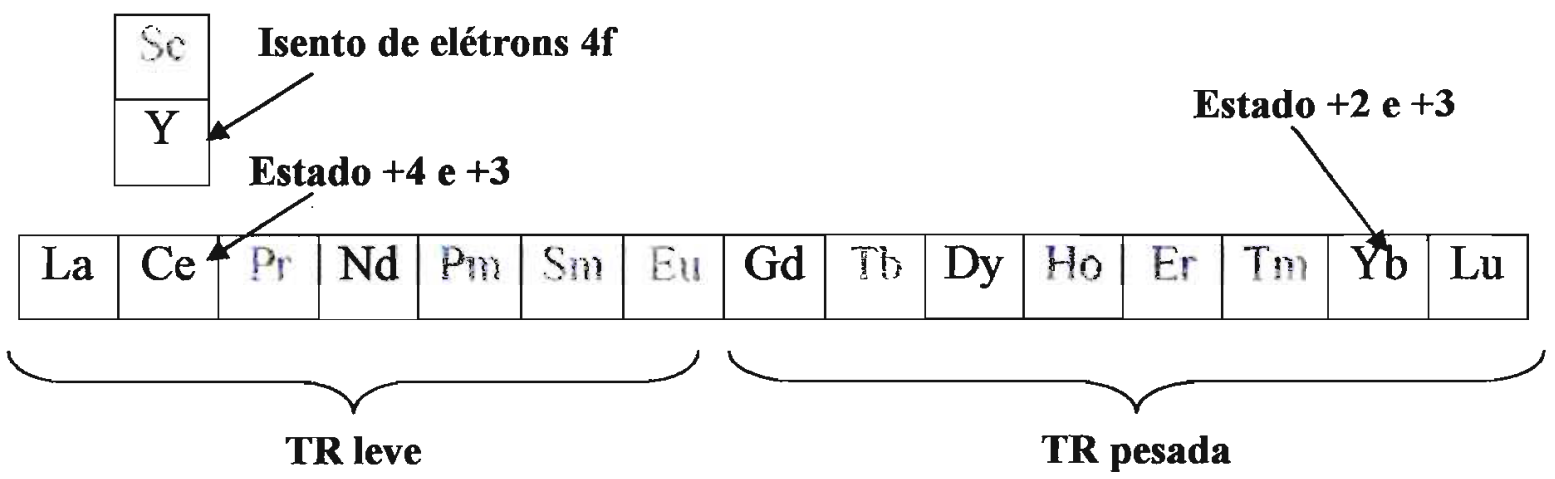

Figura 3.2. Elementos selecionados para o estudo.

Tabela 3.2. Concentração de TR nos seus principais minérios.

\begin{tabular}{cccc} 
& \multicolumn{3}{c}{ Concentração (\%) } \\
\hline Óxido & Bastnasita & Monazita & Xenotima \\
\hline $\mathrm{ThO}_{2}$ & $<0,05$ & $3-9$ & $4-6$ \\
Total em óxidos de TR & $60-70$ & $\approx 60$ & $\approx 60$ \\
\hline $\mathrm{La}_{2} \mathrm{O}_{3}$ & 32 & 22 & 0,5 \\
$\mathrm{CeO}_{2}$ & 49 & 45 & 5 \\
$\mathrm{Pr}_{6} \mathrm{O}_{11}$ & 4,4 & 5 & 0,7 \\
$\mathrm{Nd}_{2} \mathrm{O}_{3}$ & 13,5 & 17 & 2,2 \\
$\mathrm{Sm}_{2} \mathrm{O}_{3}$ & 0,5 & 4 & 1,9 \\
$\mathrm{Eu}_{2} \mathrm{O}_{3}$ & 0,1 & 0,1 & 0,2 \\
$\mathrm{Gd}_{2} \mathrm{O}_{3}$ & 0,3 & 2 & 4 \\
$\mathrm{~Tb}_{4} \mathrm{O}_{7}$ & & 0,2 & 1 \\
$\mathrm{Dy}_{2} \mathrm{O}_{3}$ & & 0,1 & 8,6 \\
$\mathrm{Ho}_{2} \mathrm{O}_{3}$ & & 0,1 & 2 \\
$\mathrm{Er}_{2} \mathrm{O}_{3}$ & 0,1 & 0,4 & 5,4 \\
$\mathrm{Tm}_{2} \mathrm{O}_{3}$ & & traços & 0,9 \\
$\mathrm{Yb}_{2} \mathrm{O}_{3}$ & & 0,2 & 6,2 \\
$\mathrm{Lu}_{2} \mathrm{O}_{3}$ & & traços & 0,4 \\
$\mathrm{Y}_{2} \mathrm{O}_{3}$ & & 3 & 61 \\
\hline
\end{tabular}


A questão sobre o emprego de TR através de compostos orgânicos ou inorgânicos merece também ser discutida. O emprego de compostos solúveis na carga parece ser preferido em função das facilidades de aplicação, melhor controle sobre a concentração de $\mathrm{V}$ presente e melhor dispersão sobre a superficie do catalisador. $\mathrm{O}$ emprego de compostos inorgânicos é menos usual, uma vez que pode aumentar o teor de espécies aniônicas na superficie do catalisador comprometendo em algo a atividade do material. Comercialmente, os passivadores são dosados na forma de óxidos estabilizados em solução aquosa e dispersos através da carga.

Os principais objetivos do trabalho estão sumarizados a seguir:

- (I) Avaliar e justificar as eventuais diferenças de desempenho apresentadas pelas TR no que se refere a passivação de V no sistema estudado. Sobretudo, o trabalho tem propósito de contemplar as diferenças em termos de estados de oxidação, configuração eletrônica e massa atômicas dos elementos. Para tal, foram selecionados as seguintes TR conforme classificação:

- Elementos da série leve: La, Ce e Nd

- Elementos da série pesada: Gd, Dy, Yb e Lu

- Elemento não lantanídico (sem elétrons 4f): Y

- Elemento com estados de oxidação estáveis além do +3: Ce e Yb

- (II) Estudar o efeito da incorporação de complexos de vanádio simulando as condições encontradas nas unidades de FCC empregando um sistema catalítico convencional.

- (III) Propor o mecanismo de interação entre TR e V por meio de uma série de técnicas de caracterização usuais;

- (IV) Verificar as conseqüências da incorporação de complexos de TR na conversão e seletividade original do catalisador.

- (V) Avaliar as diferenças apresentadas pelos precursores de TR empregados (orgânicos ou inorgânicos) para incorporação dos elementos no meio. 


\section{Referências Bibliográficas}

[1] B. Féron, P. Gallezot, M. Bourgogne, "Hydrothermal Aging of Cracking Catalysts", J. Catal., 134 (1992) 469.

[2] K.J. Chao, L.H. Lin, Y.C. Ling, J.F. Hwang, L.Y Hou, "Vanadium Passivation of Cracking Catalysts by Imaging Secondary Ion Mass Spectrometry", Appl. Catal., 121 (1995) 217.

[3] C.A. Trujillo, "Desarrollo de Passivadores de Vanadio para Catalizadores de Ruptura Catalitica", Tese de Doutoramento, Facultad de Ciências, Universidad Nacional de Colombia, Santafé de Bogotá, 1996.

[4] E. F. Sousa-Aguiar, "El Papel de las Tierras Raras em Zeolitas y Catalyzadores de Craqueo", FCC em Revista, 26, 2001.

[5] W.P.Hettinger, “Magnetic Separation of Old from New Cracking Catalyst by means of Heavy Rare Earth Magnetic Hooks", Ashland Oil Inc., US Patent n 5,328, 594. 


\section{4}

\section{Materiais e métodos}

\subsection{Preparação e caracterização dos sistemas}

\subsubsection{Zeólitas USY e EuY}

Para formulação do catalisador empregou-se uma zeólita tipo USY (ultra-stable Y) sintetizada pelo Centro de Pesquisa e Desenvolvimento da Petrobras (CENPES). Este material foi preparado a partir de uma zeólita $\mathrm{NaY}$ obtida através de procedimento industrial [1], submetida à troca iônica com uma solução de $\mathrm{NH}_{4} \mathrm{Cl}$ para redução do teor de Na e calcinada a $760^{\circ} \mathrm{C}$ na presença de vapor durante $5 \mathrm{~h}$. Na verificação da preservação da estrutura cristalina da zeólita frente ao ataque do $\mathrm{V}$, optou-se por empregar um material não incorporado de TR para não influenciar a avaliação do sistema devido à presença dos passivadores. As propriedades da zeólita USY empregada estão sumarizadas na Tabela 4.1.

A zeólita EuY utilizada na série de estudos espectroscópicos por luminescência foi preparada através de sucessivas trocas iônicas da zeólita USY com solução 0,1 mol.L ${ }^{-1}$ de $\mathrm{NH}_{4} \mathrm{Cl}$ para redução ao mínimo do teor de Na. Posteriormente, o material separado da solução foi lavado com água e calcinado a $600^{\circ} \mathrm{C}$ por 5 horas. Em seguida, $10 \mathrm{~g}$ da zeólita foram submetidas à nova troca iônica por agitação em contato com $500 \mathrm{~mL}$ de solução

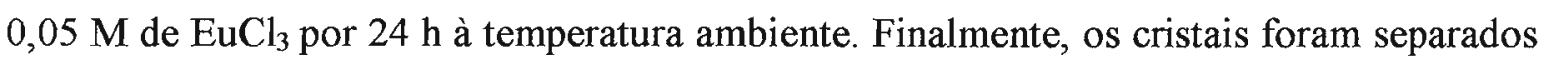
por filtração e submetidos à calcinação a $600^{\circ} \mathrm{C}$. A composição química final da zeólita foi determinada através de difração de raios-X (DRX) e emissão atômica por plasma (ICPOES) conforme método estabelecido [2], apresentando o seguinte resultado: $\mathrm{Eu}_{6} \mathrm{Na}_{3,8}\left(\mathrm{AlO}_{2}\right)_{21,8}\left(\mathrm{SiO}_{2}\right)_{170,2}$.

\subsubsection{Catalisador para craqueamento}


O catalisador para craqueamento foi também preparado pelo CENPES através da mistura dos elementos com um sol de sílica precedido de spray-drying, conforme descrito resumidamente no Capítulo 2 [3]. Incorporou-se caulinita e alumina tipo $\alpha$ (bohemita) à matriz do catalisador, além da zeólita USY, conforme composição típica do produto comercial. A composição final do catalisador, determinada por fluorescência de raios-X, e as propriedades texturais estão apresentadas na Tabela 4.1. A área superficial resultante do catalisador foi reduzida a $40 \%$ da área superficial original da zeólita.

Os ensaios foram realizados com amostras do catalisador tal qual preparado e do catalisador após sofrer desativação hidrotérmica $(\mathrm{DH})$, por calcinação na presença de vapor. Isso foi feito para melhor simular as propriedades do catalisador existente no regenerador. Considerando as condições de reposição do catalisador nas unidades de FCC, ressalta-se que o catalisador virgem quando colocado no regenerador está sujeito à imediata desativação hidrotérmica. Em termos práticos, a quantidade de $\mathrm{V}$ que se deposita sobre o catalisador ainda virgem é desprezível.

Tabela 4.1. Caracterização físico-química da zeólita USY e do catalisador p/ craqueamento.

\begin{tabular}{ccc}
\hline Propriedade & USY & Catalisador \\
\hline $\mathrm{Al}_{2} \mathrm{O}_{3}(\%)$ & 22,5 & 34,7 \\
$\mathrm{SiO}_{2}(\%)$ & 73,4 & 63,2 \\
$\mathrm{razão} \mathrm{Si} / \mathrm{Al}$ & 5,54 & 3,10 \\
$\mathrm{Na}_{2} \mathrm{O}(\%)$ & 4,01 & 0,60 \\
Área específica $\left(\mathrm{m}^{2} / \mathrm{g}\right)$ & 659 & 262 \\
Vol. de microporos $(\mathrm{mL} / \mathrm{g})$ & 0,289 & 0,088 \\
Área externa $\left(\mathrm{m}^{2} / \mathrm{g}\right)$ & 22,4 & 73,5 \\
Tamanho de célula $(\AA)$ & 24,64 & - \\
\hline
\end{tabular}

\subsubsection{Os complexos de TR}

A classe de complexos de TR escolhida para servirem como passivadores de $\mathrm{V}$ neste estudo foi os tris-acetilacetonatos, conforme arrazoado no Capítulo 3. Os aspectos 
referentes às propriedades destes complexos na literatura já foram também abordados no Capítulo 2.

O método utilizado para obtenção dos complexos foi aquele estabelecido por Stites et al. [4] e aprimorado por Mumper e Jay [5]. Basicamente, os maiores rendimentos dos complexos são alcançados em função do ajuste de $\mathrm{pH}$ ótimo, até a precipitação em meio aquoso. A Figura 4.1. ilustra resumidamente o procedimento empregado na obtenção dos complexos. Os óxidos de TR foram obtidos da Aldrich e Baker Reagents e possuíam pureza acima de 99,9\%. A acetilacetona (2, 4 pentanodiona) foi comprada da Carlo Erba, destilada, duas vezes consecutivas e armazenada sob argônio em geladeira antes de ser empregada no procedimento de síntese.

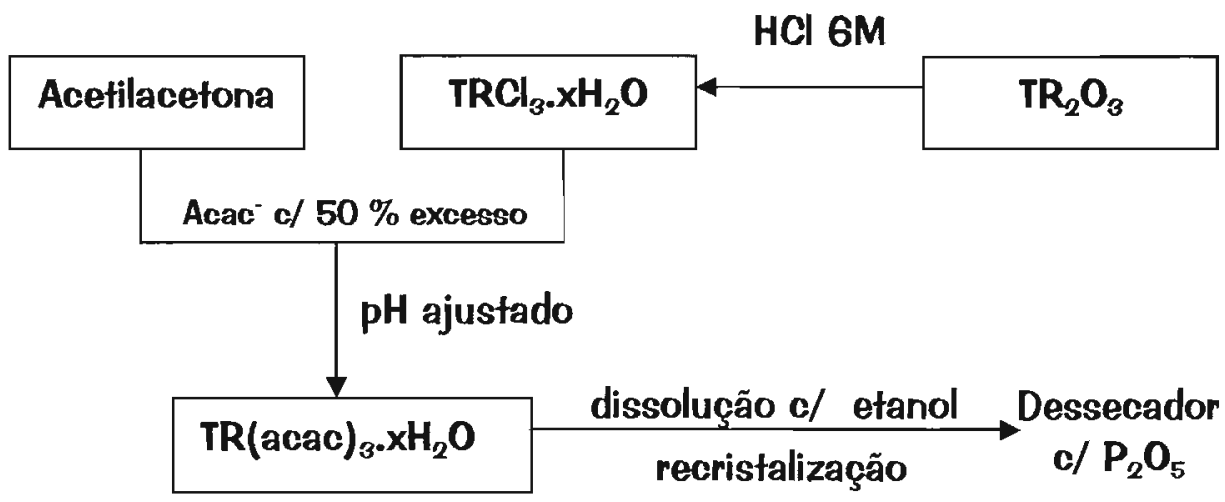

Figura 4.1. Síntese dos tris-acetilacetonatos de $\operatorname{TR}\left[\operatorname{TR}(a c a c)_{3}\right]$.

$\mathrm{O}$ controle do $\mathrm{pH}$ no processo de reação foi monitorado por meio de um titulador automático METROHM modelo 682, com eletrodo combinado de vidro. A temperatura neste processo foi mantida constante a $20^{\circ} \mathrm{C}$. A determinação do $\mathrm{pH}$ para precipitação do complexo com máximo rendimento foi realizada através da titulação do sistema composto por $50 \mathrm{~mL}$ de uma solução com $0,1 \mathrm{~mol} . \mathrm{L}^{-1}$ do íon $\mathrm{TR}^{3+}$ e $0,05 \mathrm{~mol} \cdot \mathrm{L}^{-1}$ de acetilacetona (Hacac). Uma solução de $\mathrm{NaOH} 1 \mathrm{~mol} \cdot \mathrm{L}^{-1}$ foi utilizado como titulante nos ensaios. As curvas de titulação apresentaram perfis semelhantes. $\mathrm{O}$ valor do $\mathrm{pH}$ de máxima complexação variou entre 7,2 e 7,8. Na Figura 4.2 estão apresentadas as curvas de titulação dos ensaios com $\mathrm{La}^{3+}$ e $\mathrm{Nd}^{3+}$. O segundo ponto de inflexão, observado por volta de $\mathrm{pH} 10,5$ nas curvas, refere-se à neutralização do excesso de acetilacetona presente no meio. Os complexos obtidos em $\mathrm{pH}$ acima do ponto de ótimo sofrem a substituição dos ligantes 
acetilacetonatos por grupos hidroxilas, dependendo de quão alto é o $\mathrm{pH}$

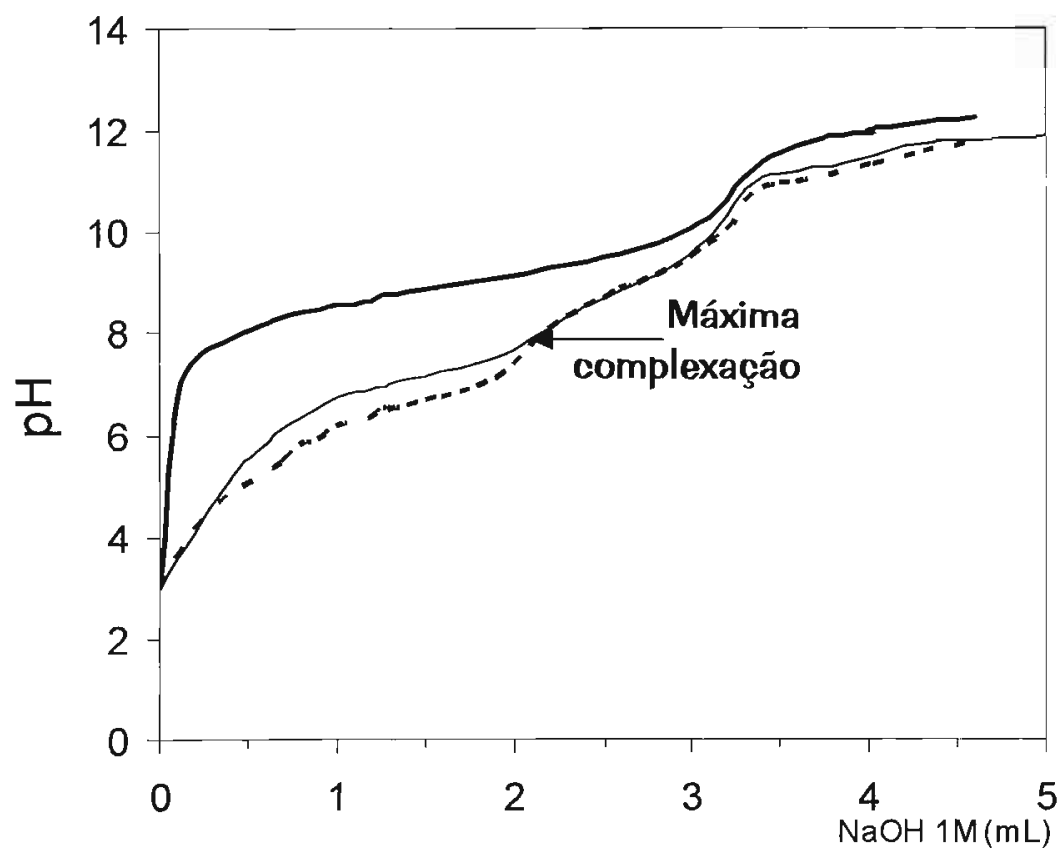

Figura 4.2. Curvas de titulação da Hacac (-) e dos ions $\mathrm{La}^{3+}(-)$ e $\mathrm{Nd}^{3+}$ ('-) na presença de excesso de acetilacetona.

$\mathrm{O}$ íon $\mathrm{La}^{3+}$ apresentou o maior $\mathrm{pH}$ de máxima complexação da série. Como se observa através das curvas, o ponto de equivalência determinado para a complexação $\mathrm{Nd}^{3+}$ ocorre em $\mathrm{pH}$ ligeiramente inferior ao $\mathrm{La}^{3+}$. De fato, os complexos $\beta$-dicetonatos de $\mathrm{La}^{3+}$ apresentam as menores constantes de formação entre os lantanídeos, pois há um aumento na capacidade de complexação pelos ligantes à medida que aumenta o potencial iônico (razão carga/raio). Devido à contração lantanídica, os íons dos elementos mais pesados da série lantanídica são menores que os grupos metilas laterais dos complexos de acetilacetonatos octaédricos e isto resulta um impedimento estérico à coordenação das moléculas do solvente ao íon central, contribuindo assim para a formação de compostos anidros. $\mathrm{O} \mathrm{Y}^{3+}$ apresenta aproximadamente o raio iônico do $\mathrm{Ho}^{3+}$ e ligeiramente menor que o $\mathrm{Dy}^{3+}$ [6], por isso possui características semelhantes a este último em termos de rendimento em síntese. Os complexos dos íons menores apresentam menor solubilidade no meio aquoso, em virtude da maior atração pelos ligantes e, em conseqüência possui maior razão de complexação. As constantes de formação destes complexos estudados foram determinadas anteriormente por Grenthe e Fernelius [7]. 
O precipitado assim obtido foi filtrado e seco ao ar por algumas horas. Em seguida, foi dissolvido em álcool a $60{ }^{0} \mathrm{C}$ com alguns mililitros de acetilacetona adicionados para reprimir hidrólise. Adicionou-se água ao sistema até perfazer uma solução alcoólica a aproximadamente $60 \%$ em volume. Com o resfriamento da solução, lentamente, os cristais formaram-se e depois de $10 \mathrm{~h}$ foram separados por nova filtração. Os complexos de TR da série lantanídica obtidos desta forma apresentam-se trihidratados, com exceção do $\mathrm{La}^{3+}$ que é dihidratado e o $\mathrm{Er}^{3+}$ que é monohidratado [8]. Os cristais então foram submetidos à secagem em dessecador a vácuo contendo $\mathrm{P}_{2} \mathrm{O}_{5}$ por alguns dias. Todos os complexos mostraram-se bastante solúveis em tolueno, com exceção do complexo de $\mathrm{La}^{3+}$, que parcialmente se solubilizava. A cor dos complexos obtidos foi concordante com a descrita na literatura [4]. O complexo de $\mathrm{Ce}^{3+}$ hidratado apresentou a cor verde após cristalização, mas ao longo do tempo armazenado em dessecador, tornou-se devido à desidratação.

Os complexos obtidos eram analisados periodicamente quanto ao teor do íon $\mathrm{TR}^{3+}$ presente e então retirados definitivamente do dessecador quando os valores apresentavamse equivalentes aos calculados para os compostos anidros. $\mathrm{O}$ complexo de $\mathrm{La}^{3+}$ custou mais a alcançar esta condição. Isto pode ser justificado pela maior facilidade de coordenação proporcionada pelo maior raio iônico do $\mathrm{La}^{3+}$, resultando uma maior dificuldade das moléculas água coordenadas desprenderem-se da esfera de saturação [8].

A determinação do rendimento de síntese foi realizada por meio do teor de $\mathrm{TR}^{3+}$ existente em cada complexo através de emissão atômica de plasma. Foi empregado um espectrômetro da marca UNICAM, ajustado com um fluxo de Ar de 1,4 L. $\min ^{-1}$, potência de $1 \mathrm{~kW}$ e freqüência de $27 \mathrm{MHz}$. Os complexos foram solubilizados em solução de $\mathrm{HCl}$ concentrado a quente para a análise em meio aquoso.

O rendimento da síntese para cada elemento foi determinado por meio da seguinte expressão:

$$
\eta(\%)=100 . \mathrm{TR}_{\mathrm{c}} / \mathrm{TR}_{\mathrm{ox}}
$$

onde: $\mathrm{TR}_{\mathrm{c}}$ é a massa do elemento no complexo determinada por plasma e $\mathrm{TR}_{\mathrm{ox}}$ é a massa do elemento no óxido submetido à síntese. Os resultados estão apresentados na Tabela 4.2. 
Tabela 4.2. Rendimento, em \%, dos complexos tris-acetilacetonatos obtidos em sintese para diferentes elementos.

\begin{tabular}{ccccccc}
$\mathrm{Y}$ & $\mathrm{La}$ & $\mathrm{Ce}$ & $\mathrm{Nd}$ & $\mathrm{Gd}$ & $\mathrm{Dy}$ & $\mathrm{Yb}$ \\
\hline 80,2 & 73,2 & 70,5 & 80,1 & 82,3 & 88,3 & 88,2 \\
\hline
\end{tabular}

A caracterização dos complexos por análise térmica foi realizada com equipamento Shimadzu modelo TGA-50. Os ensaios foram realizados em atmosfera de ar sintético com vazão de $50 \mathrm{~mL} / \mathrm{min}$ e taxa de aquecimento de $20{ }^{\circ} \mathrm{C} / \mathrm{min}$ em cadinho de platina. Os resultados da caracterização da composição química dos complexos desidratados por meio desses ensaios estão apresentados na Tabela 4.3. O cálculo baseia-se na redução de massa do quelato ao respectivo óxido na forma mais estável. Os resultados dos ensaios realizados por ICP-OES estão também apresentados na Tabela 4.3 com os respectivos valores calculados para os compostos anidros.

Tabela 4.3. Caracterização elementar dos complexos por emissão atômica de plasma (percentagem de $T R^{3+}$ ) e análise térmica (massa molar).

\begin{tabular}{ccccc}
\hline & \multicolumn{2}{c}{$\mathrm{TR}^{3+}(\%)$} & \multicolumn{2}{c}{ Massa molar $\left(\mathrm{g} \cdot \mathrm{mol}^{-1}\right)$} \\
\cline { 2 - 5 } Composto & Exp. & Calc. & Exp. & Calc. \\
\hline $\mathrm{La}(\mathrm{acac})_{3}$ & 32,0 & 31,8 & 434,0 & 436,2 \\
$\mathrm{Ce}(\mathrm{acac})_{3}$ & 32,3 & 32,0 & 440,0 & 437,4 \\
$\mathrm{Nd}(\mathrm{acac})_{3}$ & 32,5 & 32,7 & 449,1 & 441,5 \\
$\mathrm{Gd}(\mathrm{acac})_{3}$ & 34,2 & 34,6 & 436,1 & 454,6 \\
$\mathrm{Dy}(\mathrm{acac})_{3}$ & 36,0 & 35,3 & 460,0 & 459,8 \\
$\mathrm{Yb}(\mathrm{acac})_{3}$ & 36,3 & 36,8 & 475,0 & 470,3 \\
$\mathrm{Y}(\mathrm{acac})_{3}$ & 24,1 & 23,0 & 379,5 & 386,2 \\
\hline
\end{tabular}

Estão apresentadas nas Figuras 4.3 a 4.9 a $1^{\text {a }}$ derivada das curvas da análise termogravimétrica dos ensaios com os complexos. Para efeito de comparação, em cada gráfico têm-se o ensaio com o quelato hidratado, obtido após síntese, e o ensaio do composto com o mesmo elemento submetido à desidratação em dessecador. Os perfis observados são razoavelmente distintos entre os compostos, mas de forma geral, a perda de massa correspondente às moléculas de hidratação coordenadas ao íon central é verificada pôr volta de $80 \mathrm{a} 100{ }^{\circ} \mathrm{C}$. Isto apenas não foi verificado para o $\mathrm{La}^{3+}$ e para o $\mathrm{Yb}^{3+}$. 


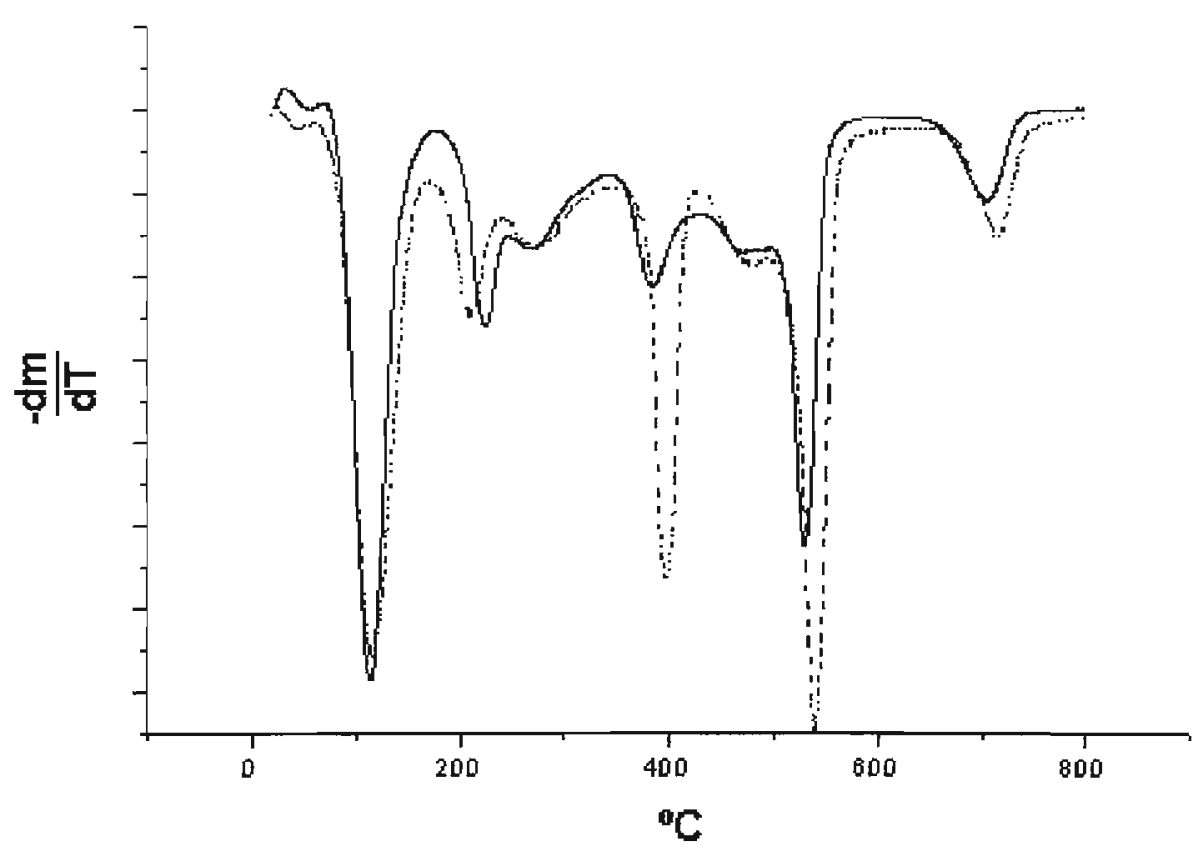

Figura 4.3. $I^{a}$ derivada da curva termogravimétrica do complexo La(acac) ${ }_{3}$ hidratado ( $)$ e após desidratação (').

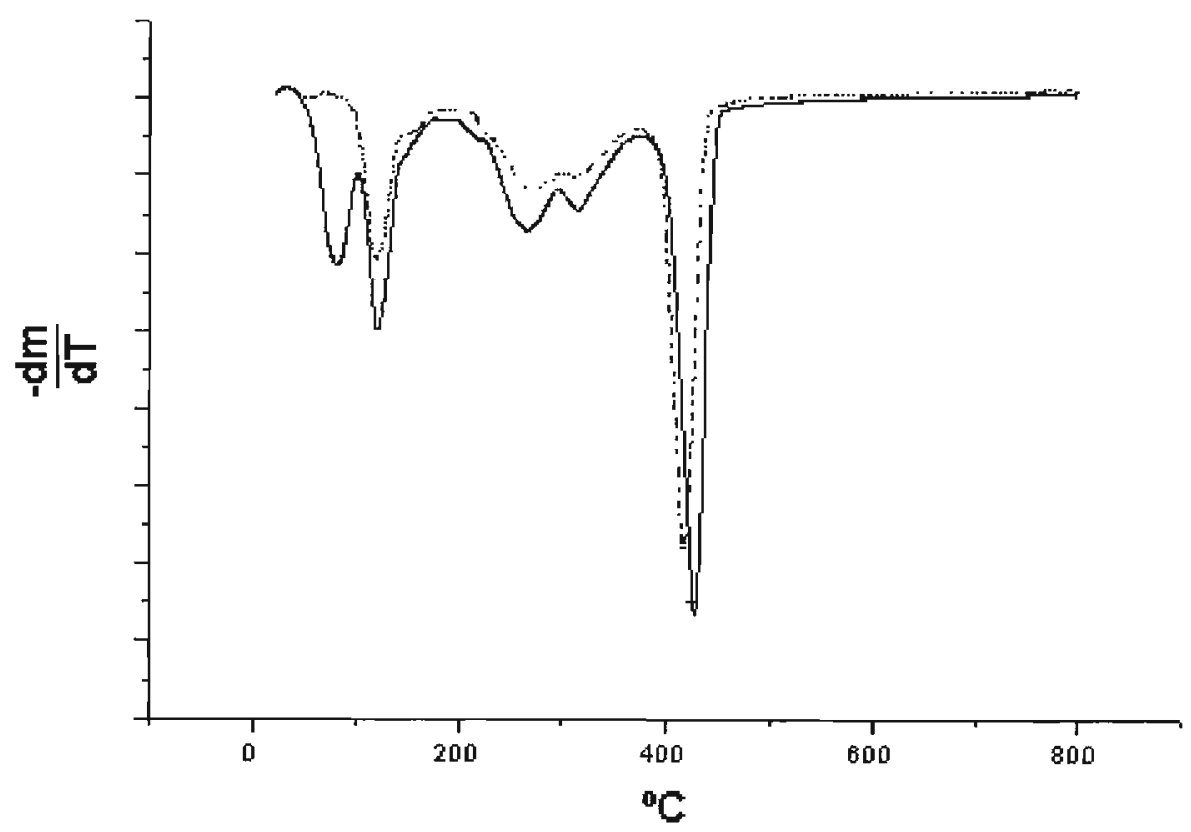

Figura 4.4. $I^{a}$ derivada da curva termogravimétrica do complexo Ce(acac) ${ }_{3}$ hidratado (-) e após desidratação (' ${ }^{\circ}$ ). 


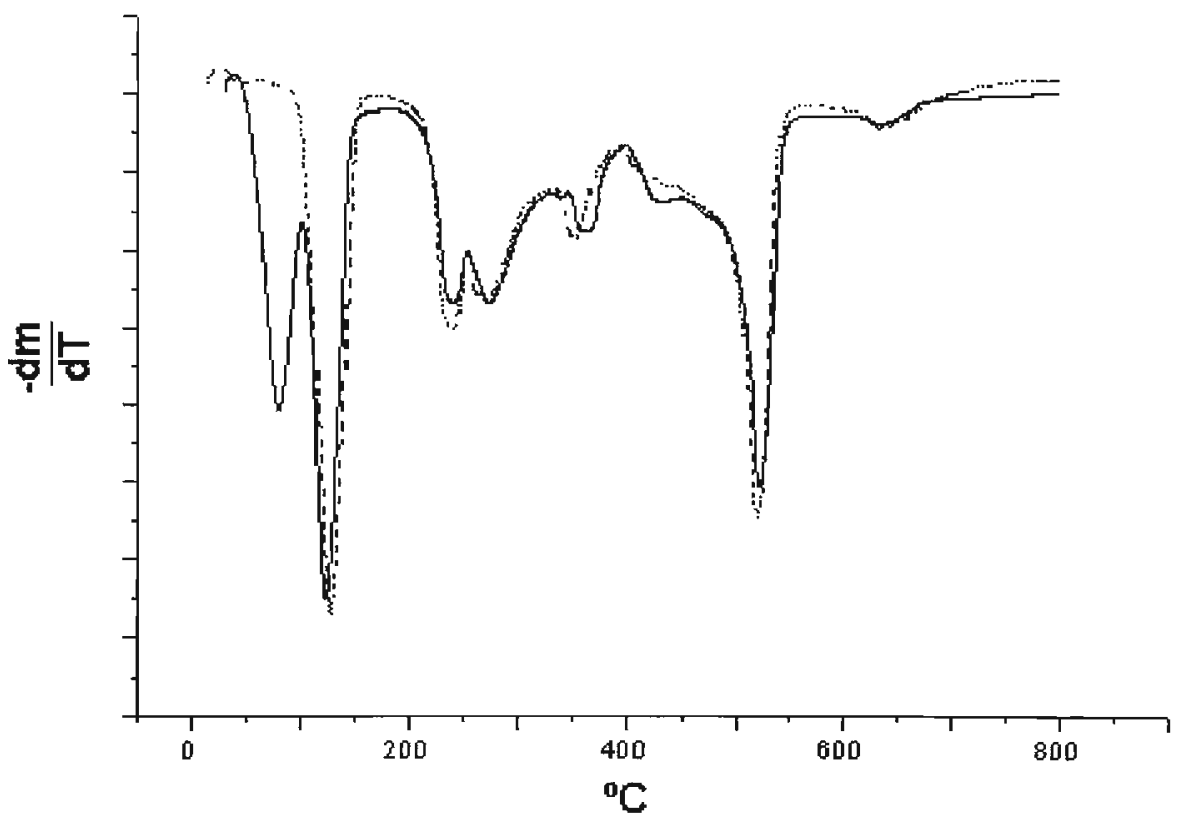

Figura 4.5. $I^{a}$ derivada da curva termogravimétrica do complexo $\mathrm{Nd}$ (acac) ${ }_{3}$ hidratado (-) e após desidratação ('.).

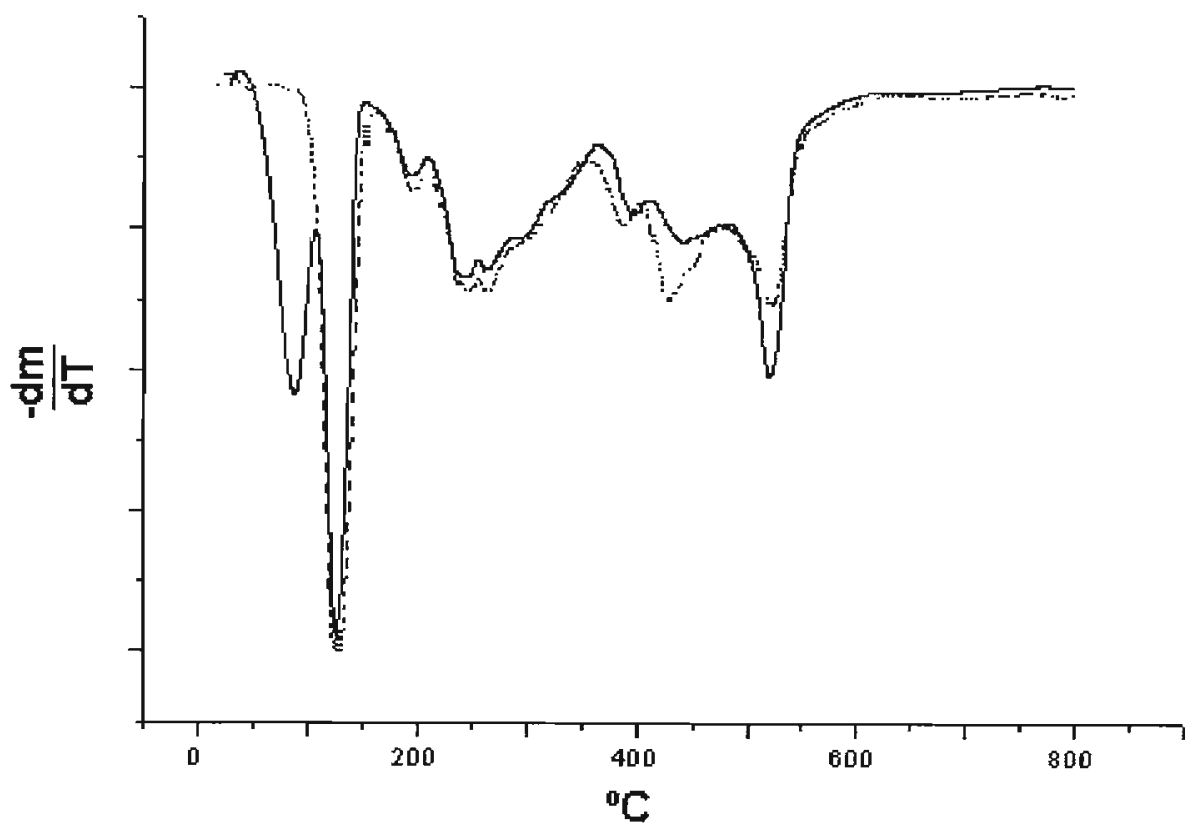

Figura 4.6. $I^{a}$ derivada da curva termogravimétrica do complexo $G d(a c a c)_{3}$ hidratado (-) e após desidratação ('). 


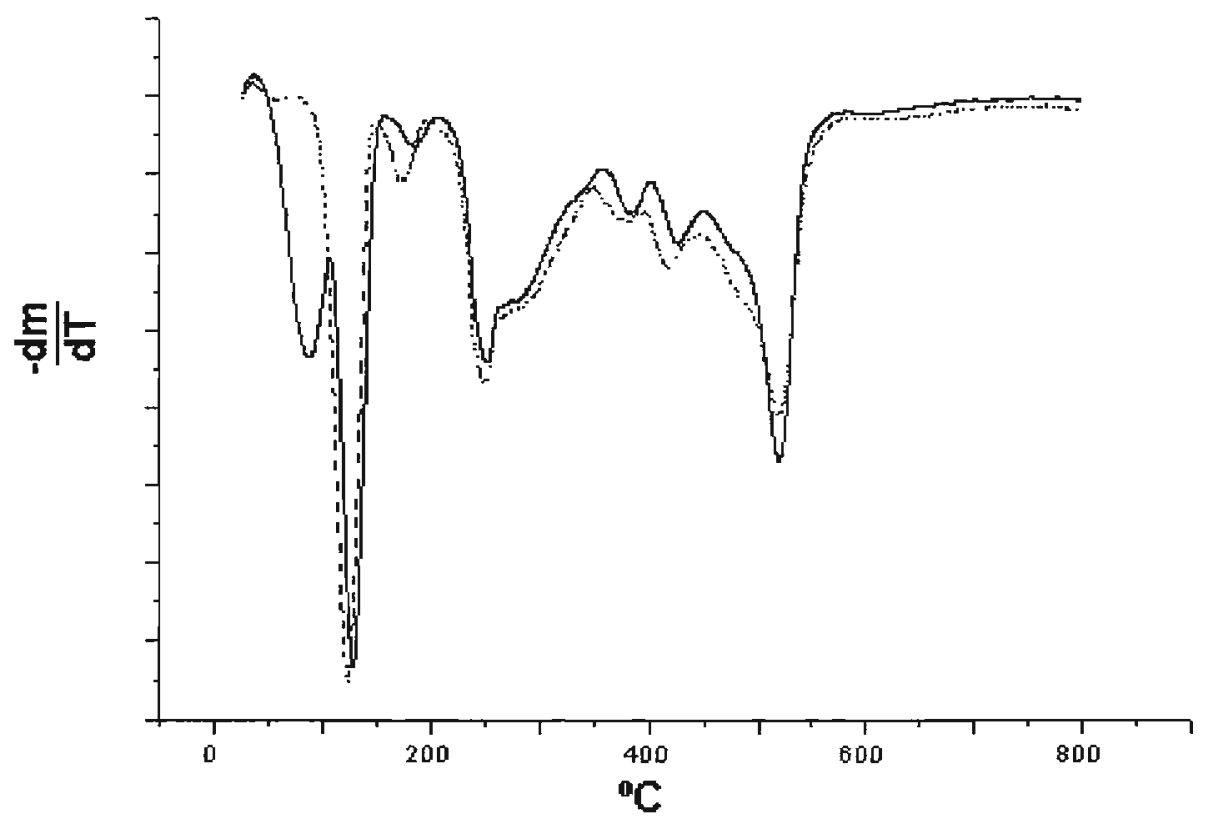

Figura 4.7. $1^{a}$ derivada da curva termogravimétrica do complexo Dy(acac) ${ }_{3}$ hidratado ( $\left.\rightarrow\right)$ e após desidratação (').

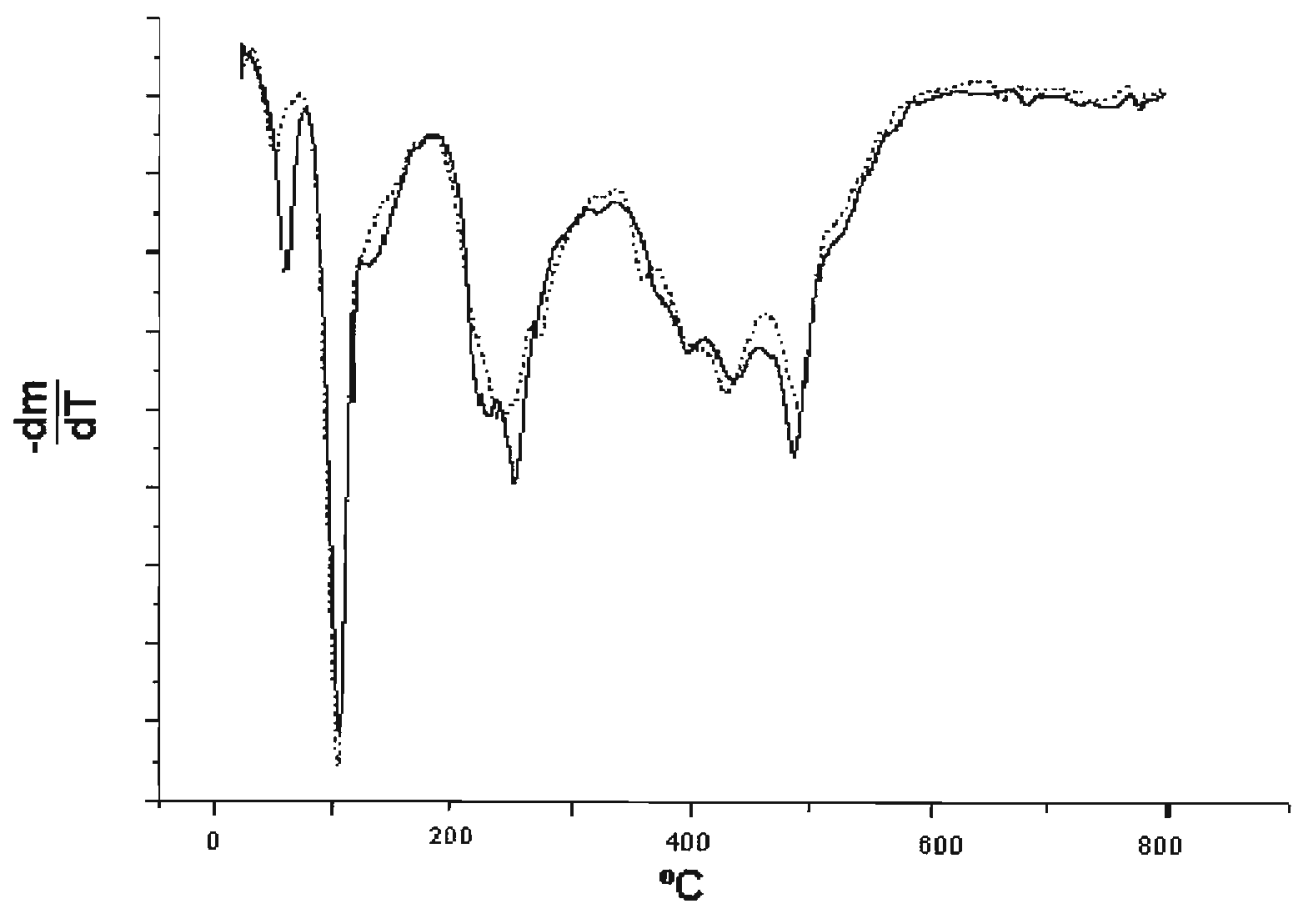

Figura 4.8. $I^{a}$ derivada da curva termogravimétrica do complexo $Y(\text { acac })_{3}$ hidratado (-) e após desidratação ('). 


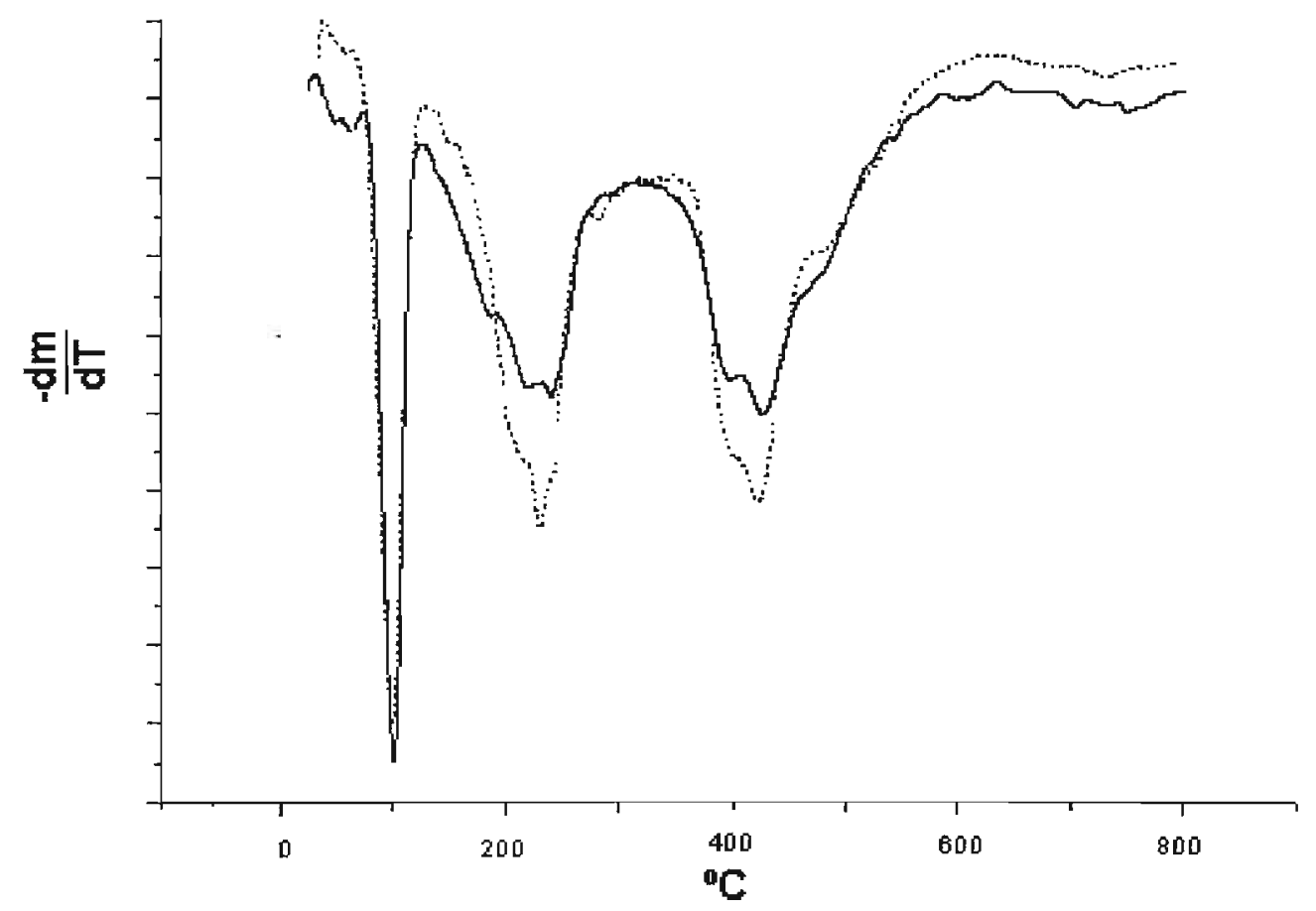

Figura 4.9. $1^{a}$ derivada da curva termogravimétrica do complexo $\mathrm{Yb}(\mathrm{acac})_{3}$ hidratado $(-)$ e após desidratação (').

No caso do $\mathrm{La}^{3+}$, verificou-se que a decomposição do composto ocorre sem perda de massa apreciável acerca de $80^{\circ} \mathrm{C}$. Isto está associado à força que as moléculas de água

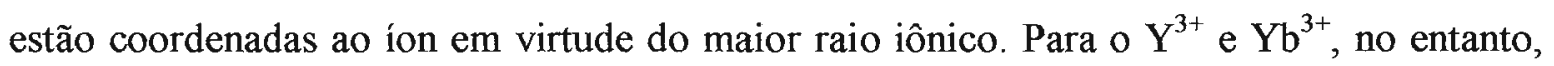
os perfis dos compostos antes e após desidratação são bastante semelhantes. Em virtude do menor raio iônico, há um impedimento estérico em relação à coordenação das moléculas de água ao íon central proporcionado pelos radicais laterais metilas do ligante. Assim,

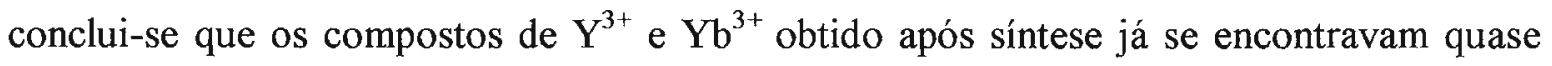
anidros.

Um espectro típico na região do infravermelho dos compostos TR(acac) 3 $(\mathrm{TR}=\mathrm{La}, \mathrm{Ce}, \mathrm{Nd}, \mathrm{Gd}, \mathrm{Dy}, \mathrm{Yb}$ e Y) está apresentado na Figura 4.10. Estes espectros foram registrados no espectrofotômetro Bomen, modelo FTIR-MB 102 com transformada de Fourier. Os ensaios foram realizados com janelas de CsI e dispersando os complexos em óleo Nujol. Na Tabela 4.4 têm-se as atribuições das bandas observadas feita por comparação com dados da literatura [9-11]. Notaram-se diferenças insignificantes em termos de deslocamentos nas bandas relativas ao mesmo modo vibracional entre os 
espectros dos complexos dos elementos da série estudada. Entretanto, observaram-se algumas alterações ao se comparar os espectros IV dos compostos obtidos após cristalização e daqueles obtidos após a desidratação de acordo com a literatura [9]. Como

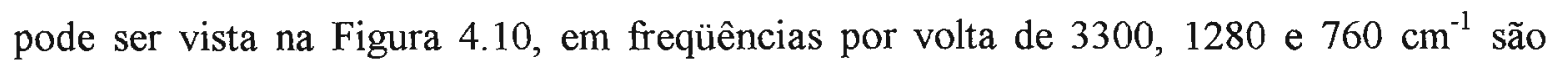
notadas as diferenças das bandas entre os espectros em função dos modos vibracionais atribuídos ao grupo hidroxila $(\mathrm{OH})$. A ilustração dos modos vibracionais do ânion acac ${ }^{-}$ presentes no complexo modelo está apresentada na Figura 4.11.

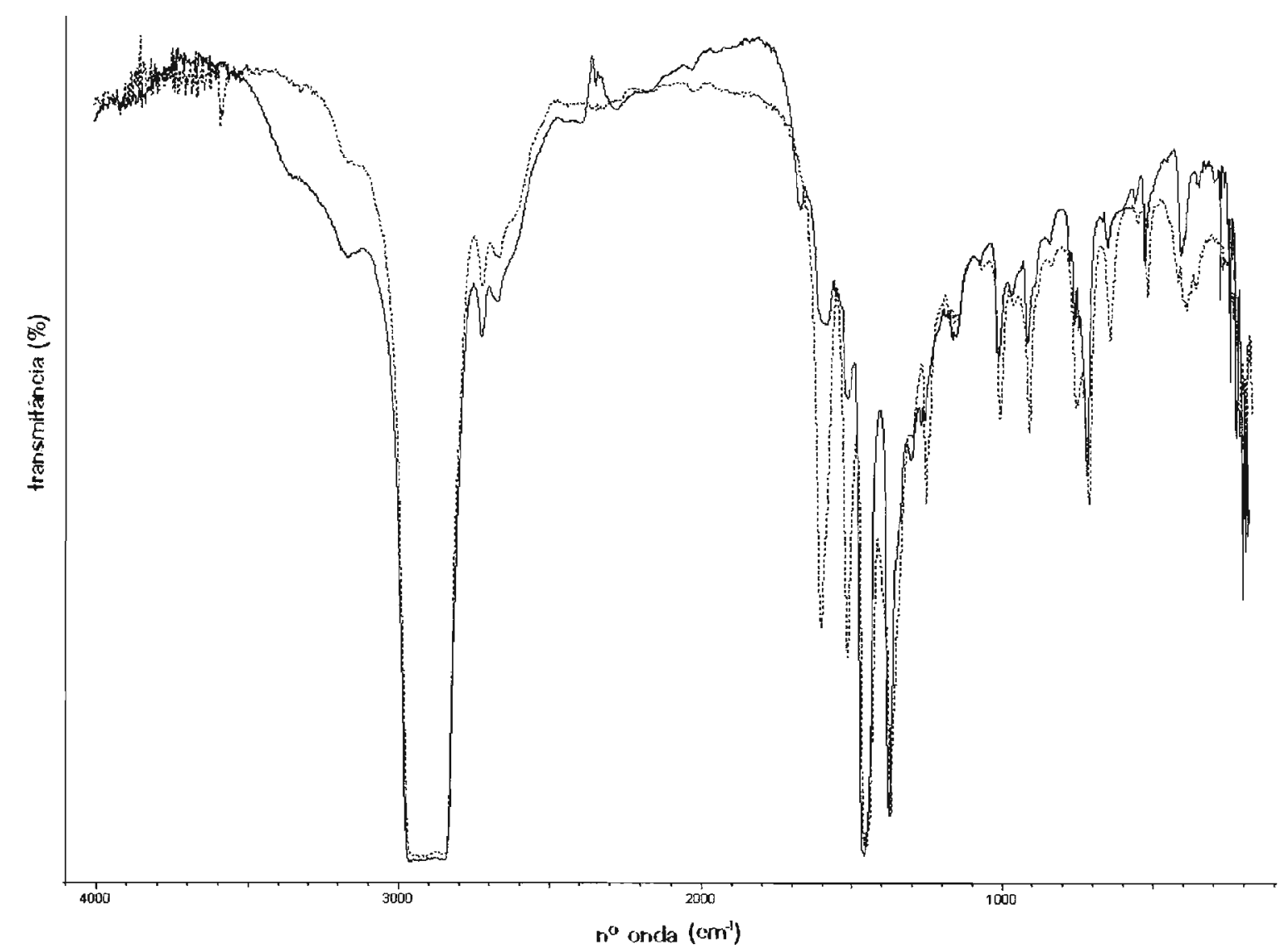

Figura 4.10. Espectro de transmitância na região do infravermelho do complexo $\mathrm{Yb}(\mathrm{acac})_{3}$ hidratado ( $\rightarrow$ ) e após desidratação (...). 
Tabela 4.4. Atribuição das bandas presentes no espectro na região do infravermelho de $\operatorname{TR}(\text { acac })_{3}$.

\begin{tabular}{ccc}
\hline Freqüências* $\left(\mathrm{cm}^{-1}\right)$ & Atribuição & Modo vibracional \\
\hline $3360 \mathrm{sh}$ & $v(\mathrm{O}-\mathrm{H})$ & --- \\
$3174 \mathrm{w}$ & $\omega(\mathrm{C}-\mathrm{H})$ & $v 1$ \\
$1595 \mathrm{~s}$ & $v_{\text {as }}(\mathrm{C}=\mathrm{C})$ & $v 9$ \\
$1513 \mathrm{~s}$ & $v(\mathrm{C}=\mathrm{O})$ & $v 2$ \\
$1170 \mathrm{w}$ & $\gamma(\mathrm{C}-\mathrm{H})$ e $v(\mathrm{C}=\mathrm{C})$ & $v 11$ \\
$1009 \mathrm{~s}$ & $\mathrm{CH}_{3}$ rock & -- \\
$910 \mathrm{~s}$ & $v(\mathrm{C}=\mathrm{O})$ & $v 4$ \\
$729 \mathrm{vs}$ & $\delta(\mathrm{C}-\mathrm{H})$ & --- \\
$645 \mathrm{~s}$ & $\gamma(\mathrm{C}-\mathrm{H})$ & $v 5$ \\
$521 \mathrm{~s}$ & $\delta(\mathrm{C}-\mathrm{CH})$ & $v 13$ \\
$403 \mathrm{~s}$ & $v(\mathrm{Eu}-\mathrm{O})$ & $v 6$
\end{tabular}

* $v, s, m, w, s h$, significam respectivamente, muito, forte, média, fraca, ombro

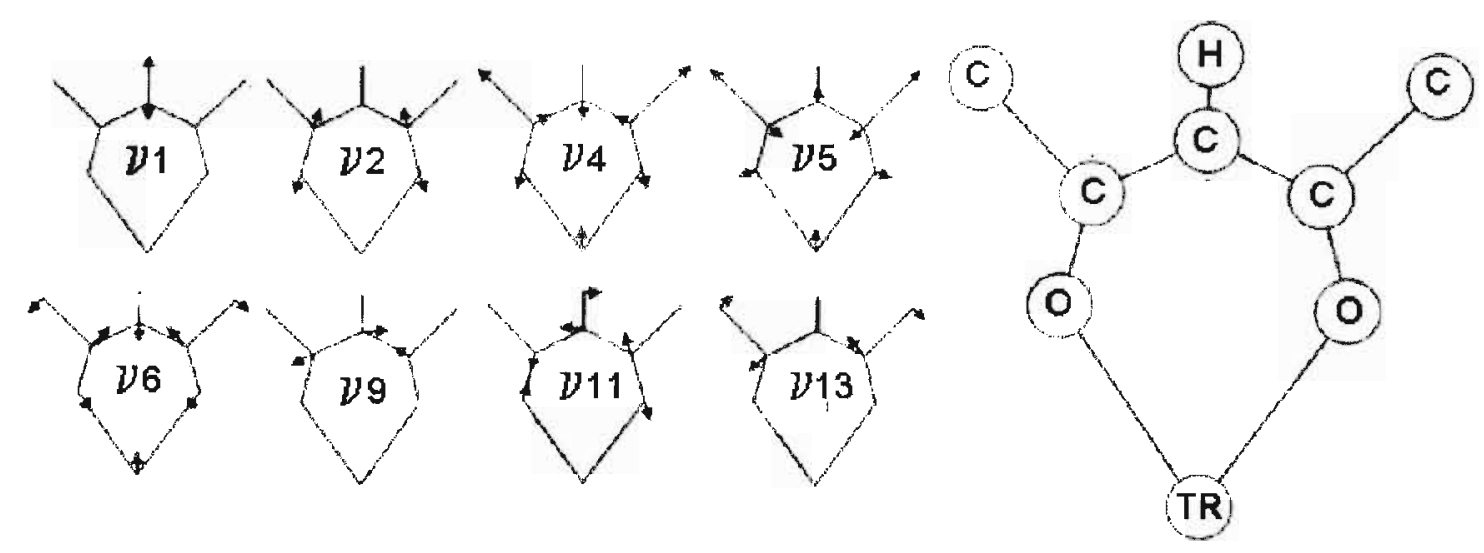

Figura 4.11. Modelos vibracionais do ânion acac [9].

A desidratação em dessecador dos compostos não foi efetiva para obtenção do composto anidro para o $\mathrm{La}^{3+}$, de menor massa molecular e maior raio atômico, mas apresentou resultados satisfatórios para os outros elementos da serie. A Figura 4.12 apresenta a estrutura do complexo $\mathrm{La}(\mathrm{acac})_{3} \cdot 2 \mathrm{H}_{2} \mathrm{O}$ determinada por difração de raios- $\mathrm{X}$ em estudos publicados anteriormente [12]. A desidratação dos compostos também foi 
realizada submetendo os complexos após cristalização ao vácuo sob temperatura de $70^{\circ} \mathrm{C}$. No entanto, verificou-se que nesta condição os compostos degradavam-se.

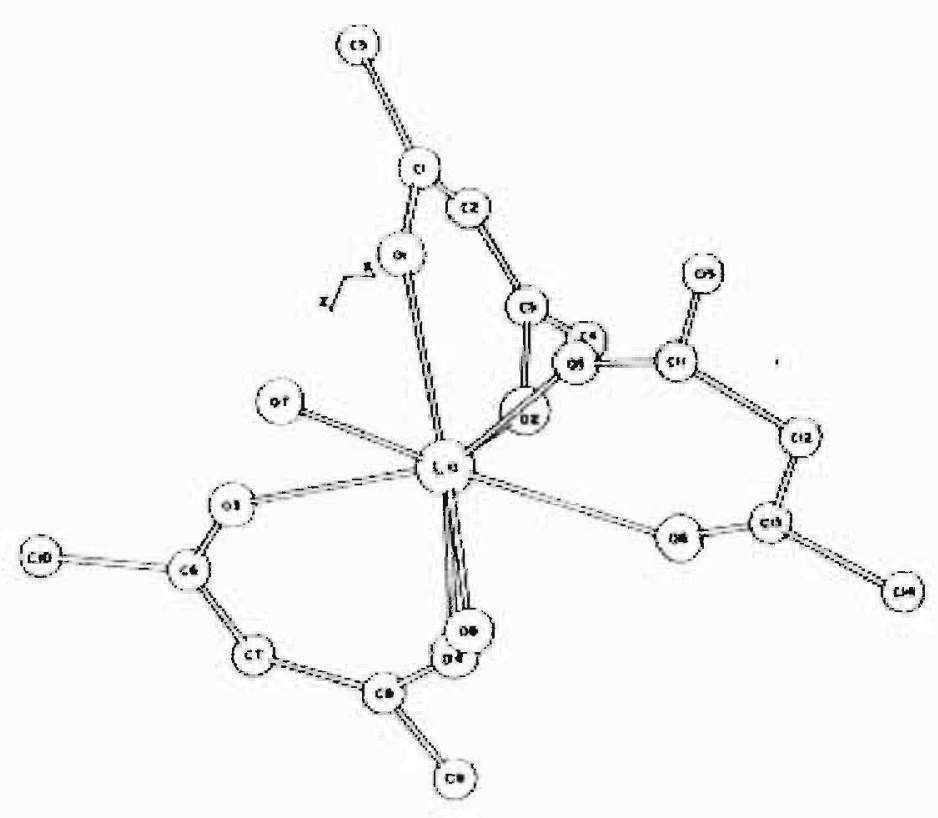

Figura 4.12. Geometria do complexo La(acac) ${ }_{3} .2 \mathrm{H}_{2} \mathrm{O}[12]$.

\subsection{4. $O$ complexo de $V$}

$\mathrm{Na}$ literatura os precursores de $\mathrm{V}$ empregados para incorporação ao catalisador através do método de Mitchell estão compreendidos em uma extensa classe de compostos [13]. Na realidade, os complexos porfirínicos de vanadila são aqueles que predominam no petróleo, entretanto, são indisponíveis e poucos solúveis em meios comuns de laboratório. Assim, a seleção dos precursores pode ter objetivos diversos, tais como a necessária exclusão dos complexos das cavidades zeolíticas na deposição, a mobilidade entre os componentes do catalisador, aestabilidade térmica apresentada durante o processo de desativação e os meios pelos quais serão agregados aos sistemas - aquosos, orgânicos ou fisicamente misturados. O estudo dos efeitos dos passivadores foi realizado através da incorporação dos elementos por meio de soluções orgânicas de maneira a simular de aplicação dos passivadores nos processos. O precursor de $\mathrm{V}$ escolhido neste trabalho foi o bis-benzoilacetonato de vanadila, tal como descrito nos trabalhos de Pine [14] e Trujillo et al. [15]. Entre as vantagens deste complexo está a excelente solubilidade em meio orgânico e o tamanho molecular avantajado beneficiado pela geometria quase totalmente planar (ver 
Figura 4.13), que impede a inclusão direta do composto no interior das cavidades zeolíticas, sendo esta uma condição desejável, diferentemente dos complexos derivados de ácidos naftênicos usualmente mais empregados.

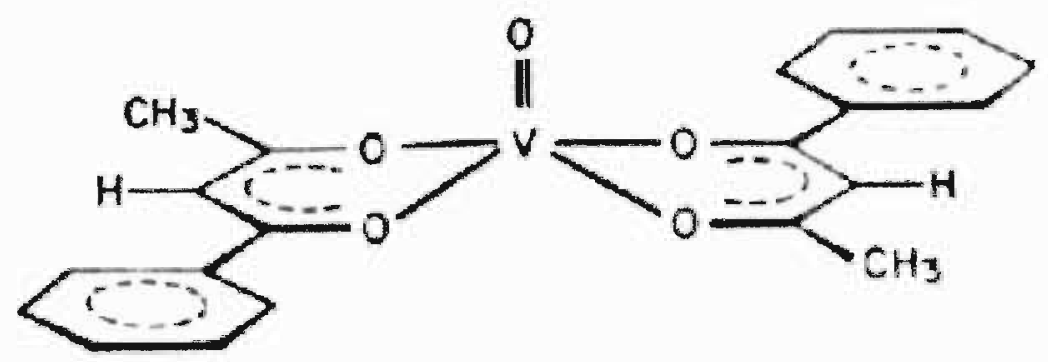

Figura 4.13. Geometria do complexo trans $\mathrm{VO}(b z a c)_{2}$.

O complexo foi sintetizado conforme método descrito por Hon et al. [16]. Uma solução alcoólica com 1 mol. $\mathrm{L}^{-1}$ de benzoilacetona foi vagarosamente adicionada a 0,5 mol. $\mathrm{L}^{-1}$ de $\mathrm{VOSO}_{4}$. A solução resultante foi ajustada a pH 6 com acetato de sódio. O precipitado foi separado por filtração, lavado com água e colocado em dessecador contendo $\mathrm{P}_{2} \mathrm{O}_{5}$ por 2 dias. $\mathrm{O}$ resultado da caracterização do composto de $\mathrm{V}$ está apresentado na Tabela 4.5. $\mathrm{O}$ teor de $\mathrm{C}$ e $\mathrm{H}$ foram determinados por análise elementar e o teor de $\mathrm{V}$ foi determinado por ICP-OES.

Tabela 4.5. Caracterização elementar do complexo $\mathrm{VO}(\mathrm{bzac})_{2}$.

\begin{tabular}{cccccc}
\hline \multicolumn{2}{c}{$\mathrm{C}(\%)$} & \multicolumn{2}{c}{$\mathrm{H}(\%)$} & \multicolumn{2}{c}{$\mathrm{V}(\%)$} \\
\hline Exp. & Calc. & Exp. & Calc. & Exp. & Calc. \\
\hline 61,4 & 61,7 & 4,1 & 4,1 & 13,2 & 13,1 \\
\hline
\end{tabular}

A estabilidade térmica do complexo foi estudada por análise térmica empregando as mesmas condições experimentais que no caso dos TR(acac) $)_{3}$. A Figura 4.14 apresenta a $1^{\text {a }}$ derivada da curva termogravimétrica. A decomposição térmica do composto ocorre em torno de $450^{\circ} \mathrm{C}$, e é menor que a temperatura de decomposição dos complexos porfirínicos [17], não interferindo assim na avaliação dos sistemas quando submetidos aos tratamentos térmicos propostos neste estudo. 


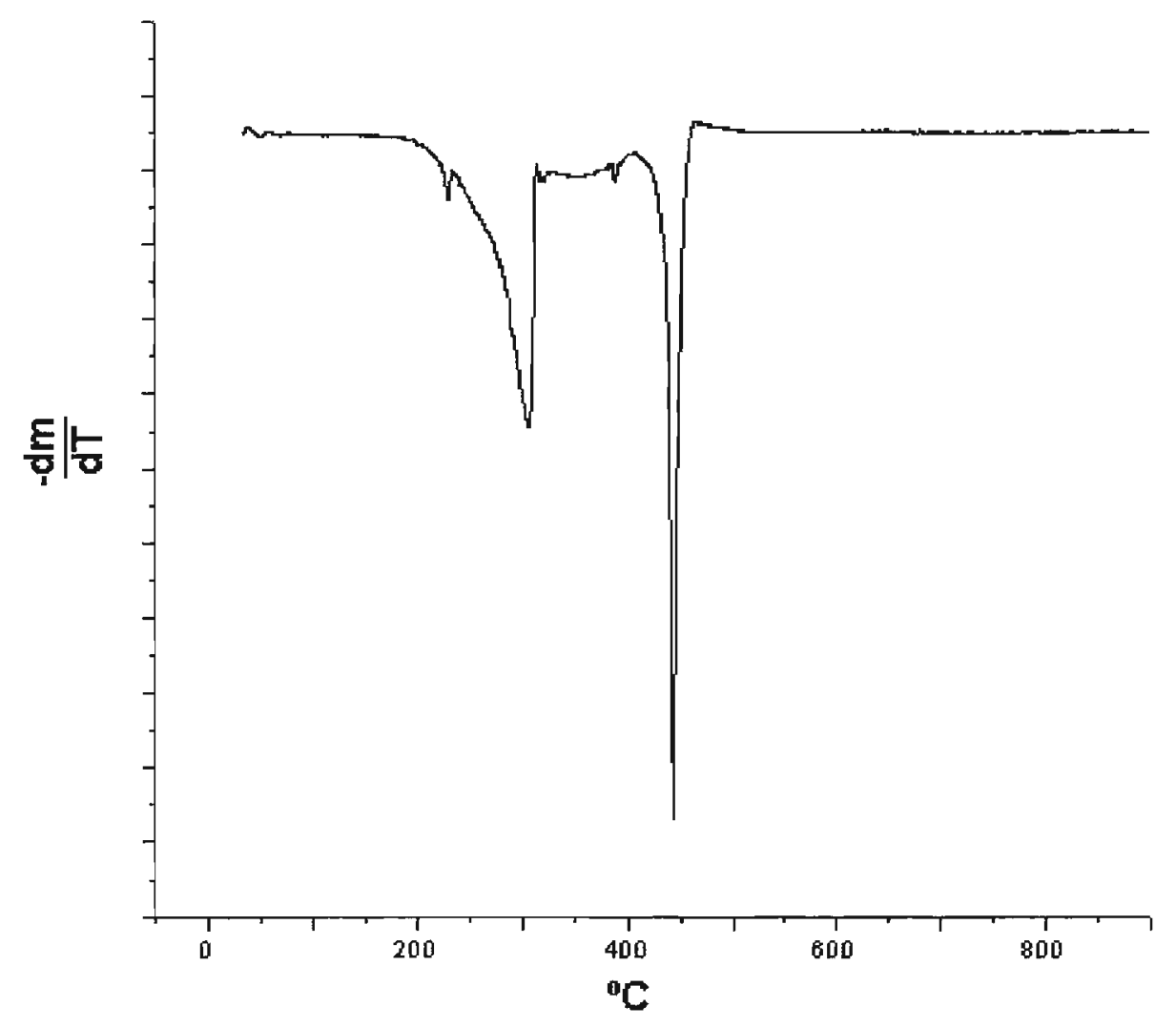

Figura 4.14. $I^{a}$ derivada da curva termogravimétrica do complexo VO(bzac) ${ }_{2}$.

\subsubsection{Preparo dos $\mathrm{TRVO}_{4}$}

Os ortovanadatos da série de TR (estudadas além do de $\mathrm{Eu}^{3+}$ ) foram sintetizados para utilização como referência em algumas técnicas de caracterização, como será abordado adiante. Estes compostos foram preparados conforme método reportado por Milligan e Vernon [18]. A mistura física entre os óxidos de TR e $\mathrm{V}_{2} \mathrm{O}_{5}$ (com $10 \%$ em excesso estequiométrico de $\mathrm{V}_{2} \mathrm{O}_{5}$ ) foi levada a $950{ }^{\circ} \mathrm{C}$ por $10 \mathrm{~h}$. Periodicamente, o material era retirado da mufla e macerado para aumentar o contato. Após este tratamento o excesso de $\mathrm{V}_{2} \mathrm{O}_{5}$ foi removido por rinsagem com solução de $\mathrm{NH}_{4} \mathrm{OH}(10 \%)$. A composição dos compostos foi comparada por caracterização elementar de TR e V através de ICP-OES, conforme descrito no item 4.1.3, e está apresentada na Tabela 4.6. Pode-se observar que o teor de TR é praticamente o mesmo em todas as amostras. 
Tabela 4.6. Caracterização elementar dos compostos $T R V O_{4}$.

\begin{tabular}{ccccc}
\hline & \multicolumn{2}{c}{$\mathrm{TR}(\%)$} & \multicolumn{2}{c}{$\mathrm{V}(\%)$} \\
\cline { 2 - 5 } Composto & Exp. & Calc. & Exp. & Calc. \\
\hline $\mathrm{LaVO}_{4}$ & 55,0 & 54,7 & 19,8 & 20,1 \\
$\mathrm{CeVO}_{4}$ & 55,0 & 54,9 & 19,9 & 20,0 \\
$\mathrm{NdVO}_{4}$ & 55,4 & 55,7 & 19,3 & 19,6 \\
$\mathrm{GdVO}_{4}$ & 57,5 & 57,8 & 18,5 & 18,7 \\
$\mathrm{DyVO}_{4}$ & 58,5 & 58,6 & 18,0 & 18,3 \\
$\mathrm{YbVO}_{4}$ & 60,3 & 60,1 & 17,3 & 17,7 \\
$\mathrm{YVO}_{4}$ & 44,2 & 43,6 & 24,6 & 25,0 \\
\hline
\end{tabular}

\subsubsection{Incorporação dos elementos ao catalisador}

A incorporação dos elementos ao catalisador desativado ou virgem deu-se através do método de Mitchell [19] de duas formas distintas:

- (I) por meio de uma solução dos complexos de V e TR em tolueno;

- (II) por meio dos respectivos óxidos de terras raras misturados fisicamente ao catalisador com os passivadores e incorporando o $\mathrm{V}$ posteriormente por meio da solução do complexo em tolueno.

A zeólita EuY foi incorporada apenas com os complexos conforme descrito acima em (I). As amostras de catalisador foram peneiradas em malha de 325 mesh antes de serem submetidas à incorporação dos elementos.

$\mathrm{O}$ solvente foi eliminado em um roto-evaporador sob fluxo de $\mathrm{N}_{2}$. A concentração proporcional entre os passivadores e $\mathrm{V}$ foi ajustada para razão molar $\mathrm{TR} / \mathrm{V}=1$. Optou-se por incorporar ao catalisador cerca de $8000 \mathrm{ppm}$ de V. Estudos demonstram que em termos equivalentes este conteúdo corresponderia empiricamente a algo em torno de 24000 ppm 
de $\mathrm{V}$ depositado sobre um catalisador de equilíbrio da unidade de FCC [20]. Na zeólita EuY incorporou-se 1000 ppm de V.

\subsubsection{Desativação hidrotérmica (DH)}

Todas as amostras de catalisador e zeólita EuY incorporadas com os elementos foram calcinadas a $540^{\circ} \mathrm{C}$, por cerca de $10 \mathrm{~h}$, sob fluxo de ar sintético. Cerca de $50 \mathrm{~g}$ do catalisador peneirado foram submetidos à $\mathrm{DH}$ (calcinação na presença de vapor de água) a $788^{\circ} \mathrm{C}$, por cerca de $5 \mathrm{~h}$. A DH da zeólita EuY foi realizada a $760^{\circ} \mathrm{C}$, por $1 \mathrm{~h}$, com $3 \mathrm{~g}$ de amostra. O equipamento empregado na $\mathrm{DH}$ das amostras está simplificadamente apresentado na Figura 4.15. Basicamente, o dispositivo consiste de um tubo de quartzo ou aço inox disposto verticalmente em cilindro termicamente condicionado por meio de aquecimento elétrico. A amostra foi suportada em um disco de quartzo sinterizado localizado no interior do tubo. Pela extremidade inferior do tubo foi introduzido um fluxo de $\mathrm{N}_{2}$, medido através de um rotâmetro a $4 \mathrm{~mL} / \mathrm{h}$, que atravessa um leito com água mantido a $90{ }^{\circ} \mathrm{C}$. Estas condições proporcionam uma atmosfera com aproximadamente $95 \%$ de $\mathrm{H}_{2} \mathrm{O}$.

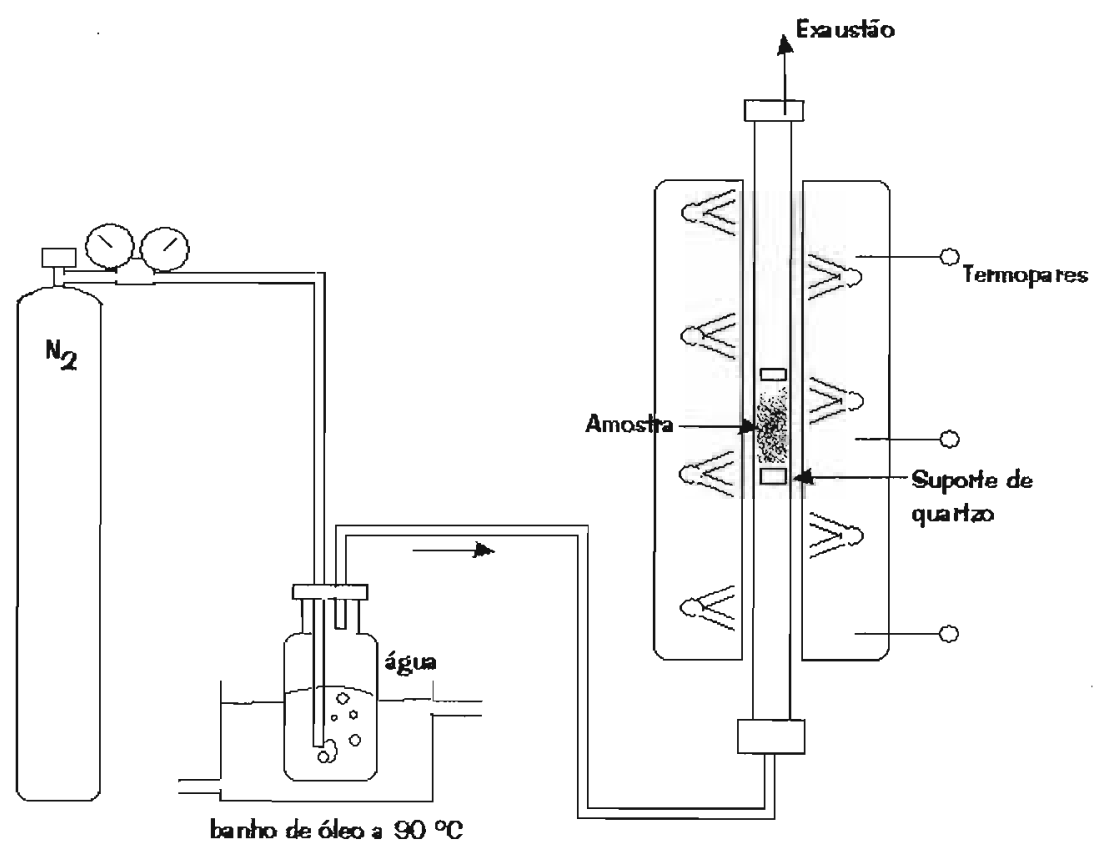

Figura 4.15. Esquema do equipamento empregados na DH. 


\subsection{Atividade Catalítica}

O desempenho do catalisador após tratamento com método de Mitchell foi caracterizado através do ensaio MAT proposto pela American Standards of Testing and Materials - ASTM [21-22]. Os experimentos foram conduzidos na divisão de catalisadores do CENPES. Utilizou-se como carga do reator um gasóleo de petróleo padrão nas seguintes condições operacionais: razão catalisador/óleo $=5$, tempo de injeção de carga $=$ $30 \mathrm{~s}$ e temperatura do reator $=520^{\circ} \mathrm{C}$. A distribuição dos produtos foi estabelecida através de cromatografia gasosa e a conversão foi definida pela soma dos produtos obtidos. Após a reação, recuperou-se o catalisador coqueado e o coque gerado na reação foi determinado por análise termogravimétrica por meio de um analisador da LECO Instruments. A Figura 4.16 apresenta a configuração do aparato utilizado.

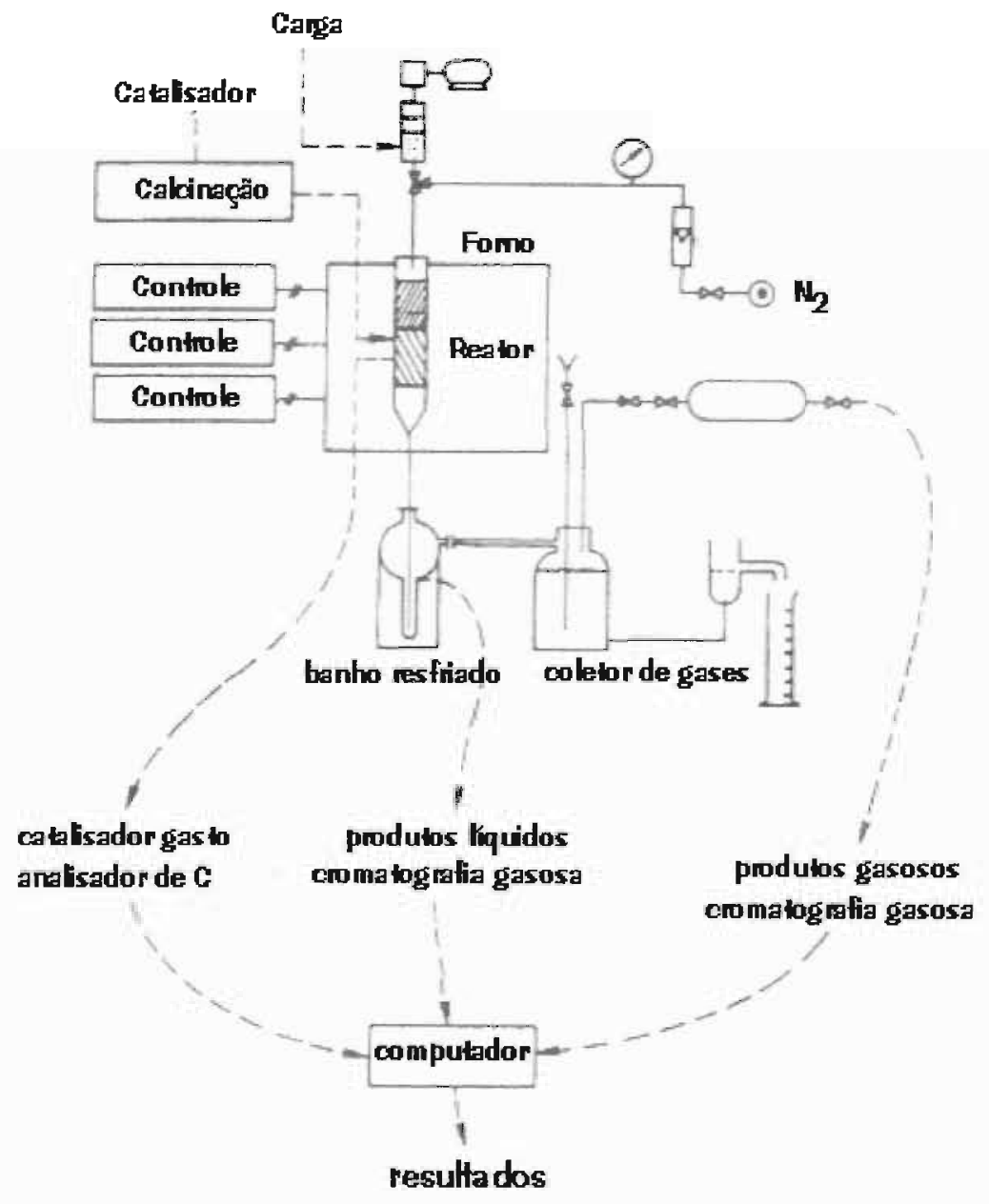

Figura 4.16. Esquema típico do equipamento para determinação do ensaio de microatividade catalítica [22]. 


\subsection{Escopo das técnicas analíticas empregadas na caracterização dos} catalisadores

Uma série de técnicas foi selecionada para a caracterização dos catalisadores após etapas de impregnação e desativação hidrotérmica. A Tabela 4.7 sumariza as técnicas empregadas e apresenta os objetivos associados à avaliação.

Tabela 4.7. Técnicas analíticas empregadas na caracterização dos catalisadores

Ensaio $---O b j$ Obivo

Análise de propriedades texturais

Fluorescência de raios-X (FRX)

Difração de raios-X (DRX)

Microscopia eletrônica de varredura (MEV)

Espectrometria de energia dispersiva (EED)

Ressonância paramagnética eletrônica (RPE)

Ressonância magnética nuclear (RMN) de ${ }^{51} \mathrm{~V}$

Luminescência

Espectroscopia foto-eletrônica de raios-X (EFX)
Volume de poros e área superficial Composição química

Cristalinidade e tamanho de célula unitária Morfologia das partículas Composição química localizada Estado de oxidação do V

Espécies de $\mathrm{V}$ formadas após tratamento térmico Coordenação dos cátions após ataque pelo $\mathrm{V}$ Composição e estado de oxidação de V e TR

\subsubsection{Análise das Propriedades Texturais}

As propriedades texturais das amostras foram determinadas na divisão de química do CENPES, através das isotermas de adsorção de $\mathrm{N}_{2}$ com um equipamento Gremini 2360 . As amostras foram submetidas ao vácuo a $300^{\circ} \mathrm{C}$ por 1 hora antes da adsorção. $\mathrm{A}$ área específica foi calculada no intervalo $0,05<\mathrm{P} / \mathrm{P}_{0}<0,35$ e o volume de microporos foi calculado na camada entre 3 e $6 \AA$ estabelecido pelo método t-plot, conforme equação de Harkins e Juras [23].

\subsubsection{Difração de raios-X (DRX)}

Através dos ensaios de difração de raios-X, determinou-se o tamanho da célula unitária e a cristalinidade relativa das amostras, conforme padrão ASTM [24-25] 
empregando-se um difratômetro Philips $\mathrm{PW}-1710$ com radiação $\mathrm{K} \alpha \mathrm{Cu}(1,541 \AA)$. Si foi utilizado como padrão interno para corrigir os planos de reflexão das amostras. Os ensaios também foram realizados na divisão de química do CENPES.

\subsubsection{Microscopia Eletrônica de Varredura e Espectrometria de Energia Dispersiva (MEV/EED)}

Caracterizou-se a morfologia das partículas por microscopia eletrônica de varredura (MEV) com um Leo $440 I$ no Instituto de Geologia da USP. Em outra série de ensaios, as partículas foram fixadas numa lâmina de vidro, através de uma resina e, depois polidas com material abrasivo para secionar as micro-esferas. A análise elementar, em regiões selecionadas, foi avaliada por energia de espectrometria dispersiva (EED) com um detector de $\mathrm{Si} / \mathrm{Li}$ Oxford, no mesmo instituto.

\subsubsection{Ressonância Paramagnética Eletrônica (RPE)}

O estado de oxidação do $\mathrm{V}$ nas amostras foi monitorado por RPE em um espectrômetro Bruker ESP300E. Os experimentos foram realizados pelo grupo de pesquisa da Profa Dra Ana Maria Costa Ferreira do Instituto de Química da USP. O equipamento foi calibrado com DPPH e operou em uma banda X a 9,6 GHz. Os espectros coletados, à temperatura ambiente, foram normalizados com o ganho no ensaio e a massa da amostra $\mathrm{e}$ os valores comparados à curva de calibração realizada com soluções padrão do complexo $\mathrm{VO}(\mathrm{bzac})_{2}$ em tolueno sob concentrações determinadas. Os ensaios foram realizados em tubos de quartzo de $2 \mathrm{~mm}$ de diâmetro e a massa das amostras normalizadas em $20 \pm 1 \mathrm{mg}$. Este procedimento diminui sensivelmente o erro quando os teores de $\mathrm{V}^{4+}$ são pequenos e também minimiza o efeito de interferência causado pelas impurezas de Fe presentes nas amostras de catalisador.

\subsubsection{Ressonância Magnética Nuclear (RMN) de ${ }^{51} \mathrm{~V}$}

As análises foram realizadas no equipamento Varian Inova-300, equipado com sonda Doty VT CP/MAS $5 \mathrm{~mm}$ SS, específica para amostras sólidas. Nos ensaios utilizou-se uma 
freqüência de $78,7 \mathrm{MHz}$ e largura espectral de $480 \mathrm{kHz}$. Os experimentos foram conduzidos no modo estático e a referência empregada foi o $\mathrm{VOCl}_{3}$. $\mathrm{O}$ ensaio foi realizado também em amostras dos respectivos $\mathrm{TRVO}_{4}$ dos elementos estudados. Os ensaios foram realizados na divisão de química do CENPES.

\subsubsection{Espectroscopia foto-eletrônica de raios-X (EFX)}

As amostras foram analisadas em um espectrômetro de fotoelétrons ESCALAB Mk II da VG Scientific da divisão de catalisadores do CENPES. Todas as amostras foram analisadas como pó aderido à fita dupla face sobre a porta-amostras do equipamento. As amostras foram introduzidas na câmara de ultra alto vácuo e os espectros EFX foram obtidos à temperatura ambiente com vácuo de $10^{-9} \mathrm{mbar}$. As amostras foram excitadas com radiação $\mathrm{Al} \mathrm{K} \alpha$ de $10 \mathrm{kV}$ de energia, com o anodo de raios $\mathrm{X}$ operado a $1,85 \mathrm{kV}$ e $10 \mathrm{~mA}$ Foram registradas seqüencialmente as linhas $\mathrm{Al} 2 p, \mathrm{Si} 2 s, \mathrm{C} 1 s, \mathrm{O} 1 s-\mathrm{V} 2 p$ e La3 $d$ e, além delas, um espectro geral para controle. As concentrações ou razões atômicas dos elementos foram determinadas a partir da área dos picos de fotoelétrons corrigidos pelos fatores de sensibilidade adequados. A análise quantitativa foi efetuada a partir da área de cada um dos picos, após extração de linhas satélites e correção da linha de base.

\subsubsection{Luminescência}

Os espectros de emissão e excitação foram obtidos em um espetrofluorímetro SPEX-Fluorlog 2 com monocromador duplo de 0,22 mm SPEX 1680 e lâmpada de Xe como fonte de excitação. O equipamento foi controlado pelo software DM3000F Spectroscopic. Os ensaios foram realizados em tubos de quartzo de $2 \mathrm{~mm}$ de diâmetro sendo que a massa das amostras foi normalizada em todos os ensaios em $30 \pm 0,1 \mathrm{mg}$. Os ensaios também foram realizados em temperatura de $\mathrm{N}_{2}$ líquido $(77 \mathrm{~K}$ ). As medidas de tempos de vida foram realizadas a temperatura ambiente usando um fosforímetro acessório SPEX 1934D acoplado ao espetrofluorímetro. Os experimentos foram realizados com a colaboração do Prof. Dr. Hermi F. de Brito, do Instituto de Química da USP. 


\section{Referências Bibliográficas}

[1] H. Miyazaki, J. Arika, M Aimoto, "Process for Preparation of Faujasite Zeolite", Toyo Soda Manufacturing Co, U.S Patent $n^{\circ} 4,678,651$.

[2] J.R. Sohn, S.J. Decanio, J.H. Lunsford, D.J. O’Donnel, "Determination of Framework Aluminium Content in Dealuminated Y-type Zeolites - A Comparision Based on Unit-Cell Size and Wave Number of IR Bands", Zeolites, 6/3 (1986) 225.

[3] J. Scherzer, "Octane-Enhancing, Zeolite FCC Catalysts: Scientific and Technical Aspects”, Catal. Rev.-Sci. Eng., 31/3 (1989) 215.

[4] J.G. Sites, C.N. McCarty, L.L. Quill, "The Rare Earth Metals and their Compounds An Improved Method for the Synthesis of Some Rare Earth Acetylacetonates", J. Am. Chem. Soc., 70 (1948) 3142.

[5] R.J. Mumper, M. Jay, "Formation and Stability of Lanthanide Complexes and their" Encapsulation into Polymeric Microspheres", J. Phys. Chem., 96 (1992) 8626.

[6] D.G. Karraker, "Coordination of Trivalent Lanthanides Ions", J. Chem. Educ., 47/6 (1970) 424.

[7] I. Grenthe, W.C. Fernelius, "Stability Relationships Among Rare Earth Acetylacetonates", J. Phys. Chem., 59 (1955) 170.

[8] G.W. Pope, J.F. Steinbach, W.F. Wagner, "Characteristcs of Solvates of the Rare Earth Acetylacetonates", J. Inorg. Nucl. Chem., 20 (1961) 304.

[9] C.Y. Liang, E.J. Schimitschek, D.H. Stephens, J.A Trias, "Infrared of Europium Acetylacetonate”, J. Chem. Phys., 46 (1967) 1588.

[10] I.B. Liss, W.G. Bos, "Rare Earth Acetylacetonate: New Preparative Methods and New Complexes", J. Inorg. Nucl. Chem., 39 (1977) 443.

[11] M.F. Richardson, W.F. Wagner, D.E. Sands, “Anhydrous and Hydrated Rare Earth Acetylacetonates and Their Infrared Spectra”, Inorg. Chem., 7 (1968) 2495.

[12] T. Phillips, D.E. Sands, W.F. Wagner, "The Crystal and Molecular Structure of Diaquotris(acetylacetonato)lanthanum(III)”, Inorg. Chem., 7 (1968) 2295.

[13] L.K. Kurihara, M.L. Occelli, A.L. Suib, "Luminescence as a probe of Metal Effects in Fluidized Cracking Catalysts", ACS Symp. Series, 452 (1992) 224.

[14] L.A. Pine, "Vanadium-Catalyzed Destruction of USY Zeolites”, J. Catal., 125 (1990) 514. 
[15] C.A. Trujillo, U.N. Uribe, P.P. Knops-Gerrits, L.A. Oviedo, P.A. Jacobs, "The Mechanism of Zeolite Y Destruction by Steam in the Presence of Vanadium", J. Catal., 168 (1997) 1.

[16] P.K. Hon, R.L. Belford, C.E Pfluger, "Bis(1-Phenyl-1,3-Butanedionato) Vanadyl. I. Molecular and Crystal Structure of the Cis Form”, J. Chem. Phys., 43 (1965) 1323.

[17] R. Pompe, S. Jaras, N.G. Vannenberg, "On the Interaction of Vanadium and Nickel Compounds with Cracking Catalysts", Appl. Catal., 13 (1984) 171.

[18] O.W. Millligan, W. L. Vernon, "Crystal and Structure of Heavy Metal Orthovanadates", J. Phys. Chem., 56 (1952) 145.

[19] B. R. Mitchell, "Metal Contamination of Cracking Catalyst. 1. Synthetic Metals Deposition on Fresh Catalyst”, Ind. Chem. Prod. Res. Dev., 19 (1980) 209.

[20] R. Rawet, R. Pimenta, A. Pinho, W. Gilbert, S. Oliveira, J. Amílcar, "A Predição do Desempenho Catalítico Comercial em Unidades de FCC”, in Anais do $3^{\circ}$ Simpósio de Craqueamento Catalítico, São Paulo (1999), ed. FCC SA.

[21] ASTM D3907-97, “Determination of Microactivity of Cracking Catalyst”, Annual Book of ASTM Standards, v14.02.

[22] R. Sadeghbeigi, "Fluid Catalytic Cracking Handbook", Gulf Publishing Company, Houston, Texas (1995), p. 100.

[23] W.D. Harkins, G. Jura, J. Am. Chem. Soc., 66 (1944) 1366.

[24] ASTM D3906-97, "Determination of Unit Cell Dimension of Faujasite-Type Zeolite”, Annual Book of ASTM Standards, v14.02.

[25] ASTM D3942-91, "Determination of Relative X-ray Diffraction Intensities of Faujasite-Type Zeolite Containing Materials", Annual Book of ASTM Standards, v14.02. 


\section{Resultados}

Os resultados da avaliação catalítica e da caracterização físico-química das amostras estão demonstrados a seguir. No Capítulo 6 discute-se os resultados aqui obtidos, conforme objetivos estabelecidos.

\subsection{Fluorescência de Raios-X}

A quantidade dos elementos incorporados nas amostras foi verificada por meio de FRX. Os resultados apresentados na Tabela 5.1 indicam que a concentração final dos elementos nas amostras foi obtida conforme previsto.

Tabela 5.1. Concentração de $V$ e TR nas amostras de catalisadores fresco (C) e prédesativado (Cd) e zeólita EuY.

\begin{tabular}{ccccccc}
\hline & \multicolumn{2}{c}{$\mathrm{C}$} & \multicolumn{3}{c}{$\mathrm{Cd}$} & \multicolumn{3}{c}{ EuY } \\
\hline Elementos & $\mathrm{V}$ & $\mathrm{TR}$ & $\mathrm{V}$ & $\mathrm{TR}$ & $\mathrm{V}$ & $\mathrm{TR}$ \\
incorporados & $(\%)$ & $(\%)$ & $(\%)$ & $(\%)$ & $(\%)$ & $(\%)$ \\
\hline V & 0,81 & - & 0,81 & - & 0,10 & - \\
VY & 0,81 & 1,39 & 0,81 & 1,41 & - & - \\
VLa & 0,80 & 2,18 & 0,81 & 2,21 & 0,11 & 0,27 \\
VCe & 0,81 & 2,21 & 0,80 & 2,20 & - & - \\
VNd & 0,80 & 2,27 & 0,80 & 2,28 & - & - \\
VGd & 0,80 & 2,48 & 0,81 & 2,50 & 0,11 & 0,31 \\
VDy & 0,81 & 2,58 & 0,81 & 2,53 & - & - \\
VYb & 0,80 & 2,72 & 0,81 & 2,74 & - & - \\
VLu & - & - & - & - & 0,11 & 0,34 \\
\hline
\end{tabular}




\subsection{Propriedades Texturais}

A área superficial das amostras de catalisador fresco incorporadas com $\mathrm{V}$ e os passivadores foi ensaiada antes e após a desativação hidrotérmica $(\mathrm{DH})$ por calcinação com vapor a $788{ }^{\circ} \mathrm{C}$, conforme descrito em 4.3.1. Os resultados estão apresentados na Tabela 5.2.

Tabela 5.2. Análise de área superficial BET $\left(\mathrm{m}^{2} / g\right)$ antes e após $D H$ das amostras de catalisador fresco incorporadas por meio dos complexos de $V$ e TR.

\begin{tabular}{ccc}
\hline Amostra & Calcinado a $540^{\circ} \mathrm{C}$ & Após DH \\
\hline $\mathrm{C}$ & 258 & 144 \\
$\mathrm{CV}$ & 254 & 11 \\
$\mathrm{CVY}$ & 242 & 24 \\
$\mathrm{CVLa}$ & 250 & 21 \\
$\mathrm{CVCe}$ & 249 & 25 \\
$\mathrm{CVNd}$ & 252 & 30 \\
$\mathrm{CVGd}$ & 245 & 25 \\
$\mathrm{CVDy}$ & 245 & 29 \\
$\mathrm{CVYb}$ & 241 & 22
\end{tabular}

$\mathrm{C}=$ catalisador fresco, $\mathrm{CV}=$ catalisador incorporado com $\mathrm{V}$ e CVTR $=$ catalisador incorporado com $\mathrm{TR}$, $\mathrm{TR}=\mathrm{La}, \mathrm{Ce}, \mathrm{Nd}, \mathrm{Gd}, \mathrm{Dy}, \mathrm{Yb}$ e Y.

A área específica original do catalisador depois da síntese foi de $262 \mathrm{~m}^{2} / \mathrm{g}$. O catalisador fresco (C) apresentou redução de área e volume de microporos após DH mesmo sem a incorporação dos elementos, devido ao efeito conhecido da exclusão de $\mathrm{Al}$ da rede zeolítica por hidrólise durante a desativação hidrotérmica [1]. Todas as amostras incorporadas com V apresentaram alteração significativa das propriedades texturais somente após a desativação na presença de vapor. A queda de área e volume de microporos das amostras está associada ao ataque de espécies de $\mathrm{V}$ conjugadas ao vapor sobre a estrutura cristalina da zeólita, uma vez que a cristalinidade do catalisador é devida majoritariamente ao componente zeolítico do catalisador. 
A Tabela 5.3 apresenta os resultados de área superficial e volume de microporos das amostras de catalisador fresco e pré-desativado incorporadas com os complexos de $\mathrm{V}$ e TR após DH. O catalisador pré-desativado $(\mathrm{Cd})$ conservou uma área maior que o catalisador fresco (C) em relação ao ataque por $\mathrm{V}$, como se pode observar através da relação entre as áreas das amostras .

Tabela 5.3. Propriedades texturais das amostras de catalisador incorporadas com os complexos de V e TR após DH.

\begin{tabular}{ccc}
\hline Amostra & $\begin{array}{c}\text { Área BET } \\
\left(\mathrm{m}^{2} / \mathrm{g}\right)\end{array}$ & $\begin{array}{c}\text { Vol. microporos } \\
(\mathrm{mL} / \mathrm{g})\end{array}$ \\
\hline $\mathrm{C}$ & 262 & 0,083 \\
$\mathrm{Cd}$ & 144 & 0,049 \\
$\mathrm{CV}$ & 11 & 0,004 \\
$\mathrm{CdV}$ & 42 & 0,016 \\
$\mathrm{CVLa}$ & 21 & 0,006 \\
$\mathrm{CdVLa}$ & 80 & 0,027 \\
$\mathrm{CVCe}$ & 25 & 0,008 \\
$\mathrm{CdVCe}$ & 89 & 0,030 \\
$\mathrm{CVNd}$ & 30 & 0,010 \\
$\mathrm{CdVNd}$ & 89 & 0,032 \\
$\mathrm{CVGd}$ & 25 & 0,008 \\
$\mathrm{CdVGd}$ & 90 & 0,034 \\
$\mathrm{CVDy}$ & 29 & 0,012 \\
$\mathrm{CdVDy}$ & 94 & 0,034 \\
$\mathrm{CVYb}$ & 22 & 0,009 \\
$\mathrm{CdVYb}$ & 68 & 0,027 \\
$\mathrm{CVY}$ & 24 & 0,007 \\
$\mathrm{CdVY}$ & 105 & 0,037
\end{tabular}

$\mathrm{Cd}=$ catalisador pré-desativado, $\mathrm{CdV}=$ catalisador pré-desativado incorporado com $\mathrm{V}$ e CdVTR = catalisador pré-desativado incorporado com TR, TR = La, Ce, Nd, Gd, Dy, Yb e Y. 
A incorporação dos passivadores por meio dos óxidos também preservou a área do catalisador em relação ao ataque do V. Entretanto, como pode ser verificado na Figura 5.1, os óxidos foram menos efetivos que os complexos no que diz respeito à conservação da área do catalisador.

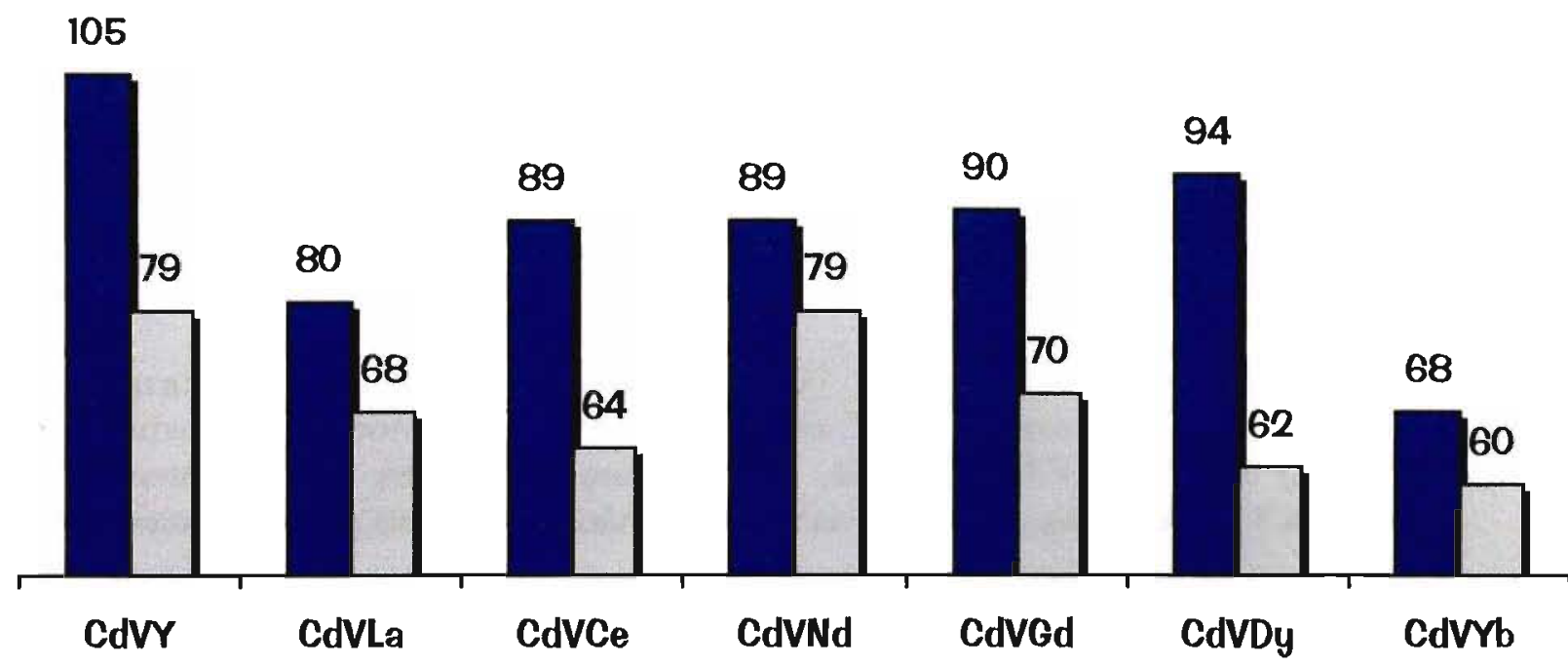

Figura 5.1. Análise de área superficial BET $\left(\mathrm{m}^{2} / \mathrm{g}\right)$ das amostras de catalisador prédesativado incorporadas com $V$ e TR atrovés dos complexos (

Karasev et al. demonstraram através de estudos termogravimétricos que o $\mathrm{Eu}(\mathrm{acac})_{3} \cdot \mathrm{H}_{2} \mathrm{O}$ se decompõe liberando ácido acético [2]. A formação do ácido durante o tratamento térmico poderia atacar a zeólita resultando decréscimo de área e cristalinidade do catalisador mesmo na ausência de V. Para avaliar este efeito, foi realizada uma série de incorporações com o $\mathrm{Nd}^{3+}$ como passivador através do complexo tris-acetilacetonato em concentrações diferentes e na ausência de V precedida da DH. A Figura 5.2 apresenta os resultados da análise de área superficial BET das amostras de catalisador pré-desativado incorporadas com $\mathrm{Nd}$ e $\mathrm{V}$ após $\mathrm{DH}$. Constata-se que a incorporação do complexo de $\mathrm{Nd}^{3+}$ promoveu apenas uma ligeira diminuição da área superficial do catalisador. 


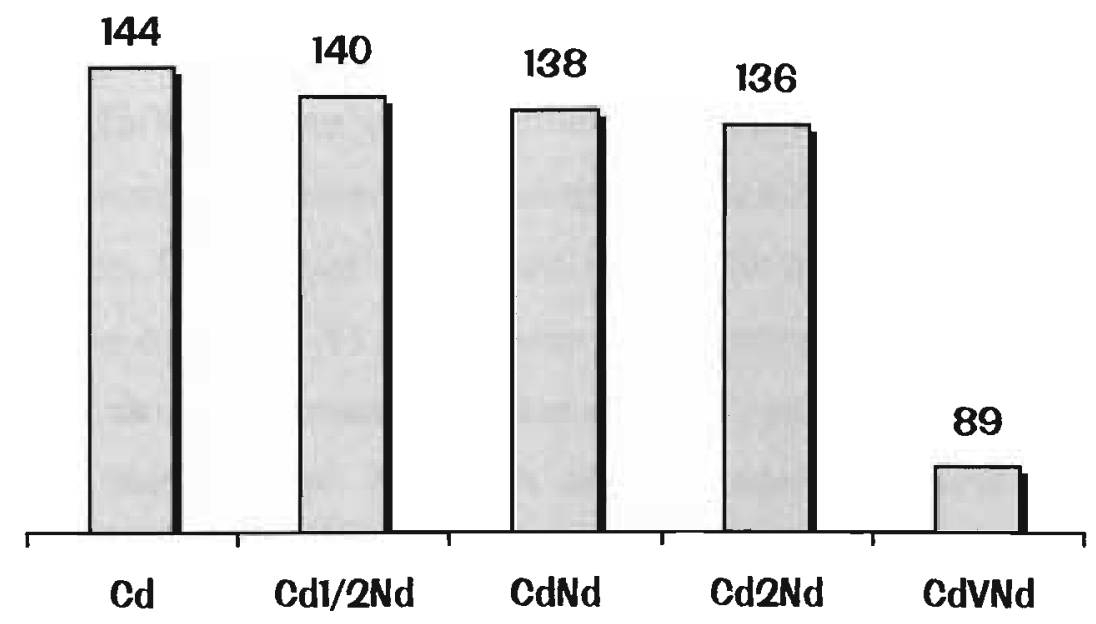

Figura5.2. Análise de área superficial BET $\left(\mathrm{m}^{2} / \mathrm{g}\right)$ das amostras de catalisador prédesativado incorporadas com $N d$ e $V$ após DH. A amostra CdNd contém a mesma concentração do passivador que CdVNd. As amostras Cd1/2Nd e Cd2Nd possuem respectivamente a metade e o dobro da concentração do passivador que CdVNd.

Na Tabela 5.4 estão apresentadas as propriedades texturais das amostras de zeólita EuY incorporadas com V e TR por meio dos complexos após $\mathrm{DH}$ (calcinação a $760^{\circ} \mathrm{C}$, por $1 \mathrm{~h}$ sob fluxo de vapor). Convém ressaltar que o tempo do tratamento térmico empregado nesta série de experimentos foi menor para não comprometer muito a cristalinidade das amostras visando conduzir melhor a avaliação espectroscópica.

Tabela 5.4. Propriedades texturais das amostras de zeólita incorporadas com os complexos de $V$ e TR após DH.

\begin{tabular}{ccc}
\hline Amostra & $\begin{array}{c}\text { Área BET } \\
\left(\mathrm{m}^{2} / \mathrm{g}\right)\end{array}$ & $\begin{array}{c}\text { Vol. microporos } \\
(\mathrm{mL} / \mathrm{g})\end{array}$ \\
\hline Y-V & 397 & 0,150 \\
EuY & 538 & 0,212 \\
EuY-V & 468 & 0,182 \\
EuY-V/La & 478 & 0,188 \\
EuY-V/Gd & 485 & 0,191 \\
EuY-V/Lu & 491 & 0,192 \\
\hline
\end{tabular}


Entre as amostras de zeólita trocadas com $\mathrm{Eu}^{3+}$, a amostra EuY-V apresentou a maior redução da área superficial. A incorporação dos passivadores de TR (TR=La, Gd ou Lu) ao sistema EuY-V inibiu parcialmente o decréscimo de área e do volume de microporos. A amostra incorporada com Lu apresentou a melhor resistência ao ataque do $\mathrm{V}$, e a amostra com $\mathrm{Gd}$, por sua vez, foi mais resistente que La. A amostra de zeólita $\mathrm{Y}$ (USY) incorporada com V (Y-V) sofreu maior dano à estrutura que o EuY. Pine observou que zeólitas REY são de fato mais resistentes que USY, para o mesmo teor de $\mathrm{Na}$ [3]. Em geral, a seguinte tendência foi observada nos resultados, em relação à capacidade do passivador de TR neutralizar o efeito deletério do V: EuY-V/Lu $>$ EuY-V/Gd $>$ EuY-V/La $>$ EuY-V $>$ Y-V.

\subsection{Difração de Raios-X}

A Figura 5.3 apresenta os difratogramas de raios-X de algumas amostras. O parâmetro da célula unitária e a cristalinidade das amostras ensaiadas por XRD, conforme descrito no item 4.3.2, mostraram tendência semelhante àquela observada com as propriedades texturais em termos da queda da área específica das amostras, dependendo dos elementos incorporados e do tratamento térmico submetido. Os resultados estão apresentados na Tabela 5.5. A cristalinidade das amostras foi calculada por meio da comparação dos padrões de difração das amostras e uma zeólita $\mathrm{NaY}$ como padrão, conforme equação:

$$
\text { Cristalinidade }(\%)=\frac{H_{i}}{H_{p}} \times 100
$$

onde $H_{i}$ e $H_{p}$ são as alturas do pico referente à reflexão do plano 533 das amostras e do padrão, respectivamente. Para as zeólitas do tipo faujasita, em que o sistema é cúbico $(a=b=c)$, o grupo espacial é $F d 3$ e o parâmetro de célula varia entre 24,2 e $25 \AA$. O tamanho da célula unitária foi determinado utilizando os ângulos de Bragg calculados nas reflexões selecionadas através da seguinte expressão: 


$$
a=\left\{\left(\mathrm{d}_{h k l}\right)^{2}\left(h^{2}+k^{2}+l^{2}\right)\right\}^{1 / 2}
$$

onde $a$ é o parâmetro de célula, $h, k$ e $l$ são os índices de Miller no ângulo determinado e $d$ é a distância interplanar calculada de acordo equação de Bragg.

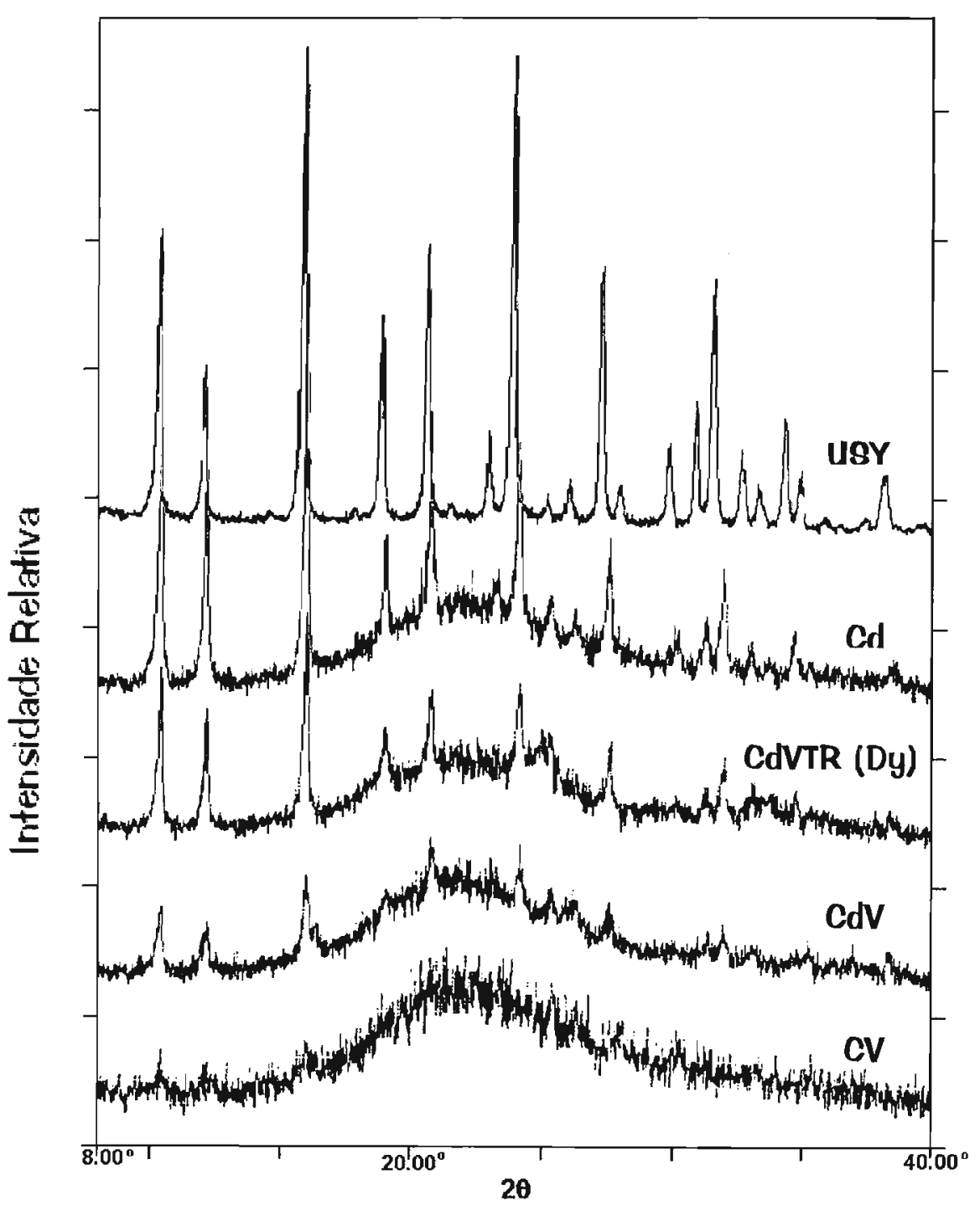

Figura 5.3. Difratogramas das amostras submetidas à $D H$. 
Tabela 5.5. Parâmetro da célula unitória da zeólita e cristalinidade das amostras de catalisador incorporadas com os complexos de Ve TR após DH.

\begin{tabular}{ccc}
\hline Amostra & Parâmetro de célula $(\AA)$ & Cristalinidade (\%) \\
\cline { 2 - 3 } C & 24,57 & 40 \\
$\mathrm{Cd}$ & 24,27 & 33 \\
$\mathrm{CV}$ & - & $<5$ \\
$\mathrm{CdV}$ & 24,24 & 12 \\
$\mathrm{CVLa}$ & - & $<5$ \\
$\mathrm{CdVLa}$ & 24,23 & 21 \\
$\mathrm{CVCe}$ & - & $<5$ \\
$\mathrm{CdVCe}$ & 24,21 & 19 \\
$\mathrm{CVNd}$ & - & $<5$ \\
$\mathrm{CdVNd}$ & 24,23 & 20 \\
$\mathrm{CVGd}$ & - & $<5$ \\
$\mathrm{CdVGd}$ & 24,23 & 19 \\
$\mathrm{CVDy}$ & - & $<5$ \\
$\mathrm{CdVDy}$ & 24,25 & 21 \\
$\mathrm{CVYb}$ & - & $<5$ \\
$\mathrm{CdVYb}$ & 24,23 & 20 \\
$\mathrm{CVY}$ & - & $<5$ \\
$\mathrm{CdVY}$ & 24,24 & 20 \\
\hline & &
\end{tabular}

As amostras que apresentaram baixa cristalinidade, apresentaram um halo entre 15 e $30^{\circ}(2 \theta)$ nos difratogramas. As amostras do catalisador fresco, incorporadas de V e TR apresentaram-se quase completamente amorfas após a DH. As amostras preparadas com o catalisador pré-desativado com TR apresentaram aproximadamente a mesma cristalinidade. Os resultados dos ensaios não foram corrigidos em referência à radiação absorvida pela TR presente. Assim, a comparação entre os desempenhos não pôde ser feita com acurácia por este método.

Os dados de cristalinidade e tamanho de célula das amostras de zeólitas incorporadas com os complexos de V e TR após DH estão apresentados na Tabela 5.6. 
Estes dados confirmam a tendência observada nos resultados de propriedades texturais em termos de resistência ao $\mathrm{V}$ proporcionada pelas amostras incorporadas com os passivadores.

Tabela 5.6. Parâmetro da célula unitária da zeólita e cristalinidade das amostras de zeólita incorporadas com os complexos de Ve TR após DH.

\begin{tabular}{ccc}
\hline Amostra & Parâmetro de célula $(\AA)$ & Cristalinidade (\%) \\
\hline Y-V & - & - \\
EuY & 24,42 & 46 \\
EuY-V & 24,37 & 36 \\
EuY-V/La & 24,40 & 39 \\
EuY-V/Gd & 24,41 & 37 \\
EuY-V/Lu & 24,42 & 41 \\
\hline
\end{tabular}

\subsection{Microscopia Eletrônica de Varredura e Espectrometria de Energia} Dispersiva

A Figura 5.4 apresenta a morfologia das partículas de catalisador pré-desativado (Cd) obtidas por microscopia eletrônica de varredura com feixe de elétrons secundários, conforme descrito no item 4.3.3. Este método é mais apropriado para avaliação de superfícies e estudo de morfologia uma vez que a penetração do feixe de elétrons é baixa.

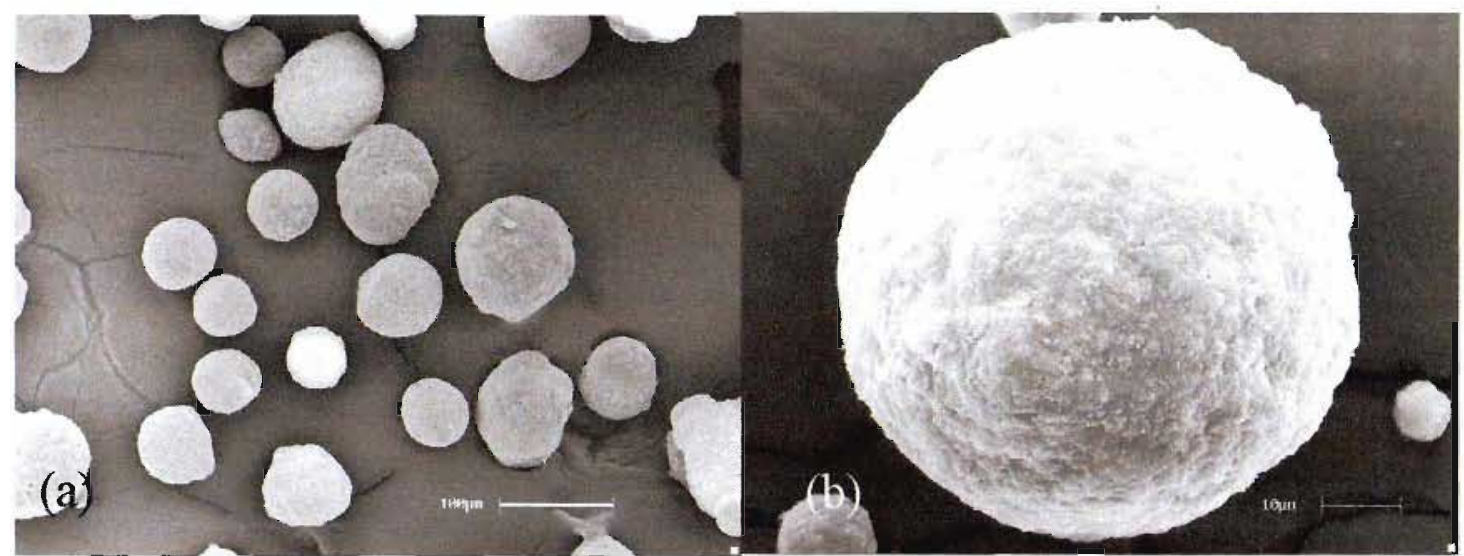

Figura 5.4. Microscopia eletrônica de varredura da amostra $\mathrm{Cd}$ em aproximações de $100 \mu m$ (a) e $10 \mu m(b)$. 
O catalisador pré-desativado apresenta uma morfologia aproximadamente esférica em virtude do processo de fabricação. Podem ser notadas, entretanto, algumas arestas nas partículas. Estas pequenas arestas não existem normalmente em um catalisador de equilíbrio, pois são aparadas em função do atrito que ocorre no reator em condições de trabalhos normais.

A Figura 5.5 apresenta as micrografias do catalisador $\mathrm{CdV}$ submetido à $\mathrm{DH}$. Observou-se que o tratamento térmico com vapor na presença de $\mathrm{V}$ promoveu alterações na textura superficial e, principalmente, na morfologia semi-esférica original devido à sinterização superficial e entre as partículas.

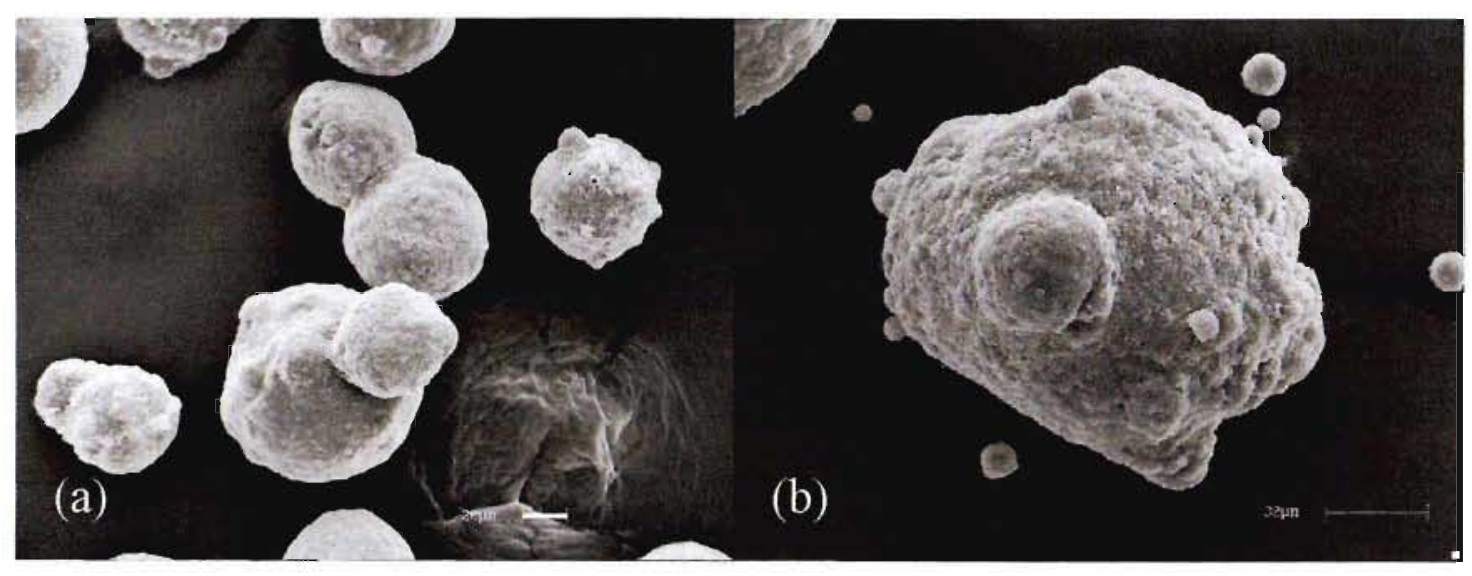

Figura 5.5. Microscopia eletrônica de varredura da amostra CdV após DH em aproximações de $100 \mu \mathrm{m}$ (a) e $10 \mu \mathrm{m}$ (b).

A sinterização interparticular ocorre em virtude da aproximação em um leito estático. Isto não é verificado em uma unidade comercial devido ao efeito de fluidização do leito. A modificação na textura superficial das partículas pode ser vista na Figura 5.6. 


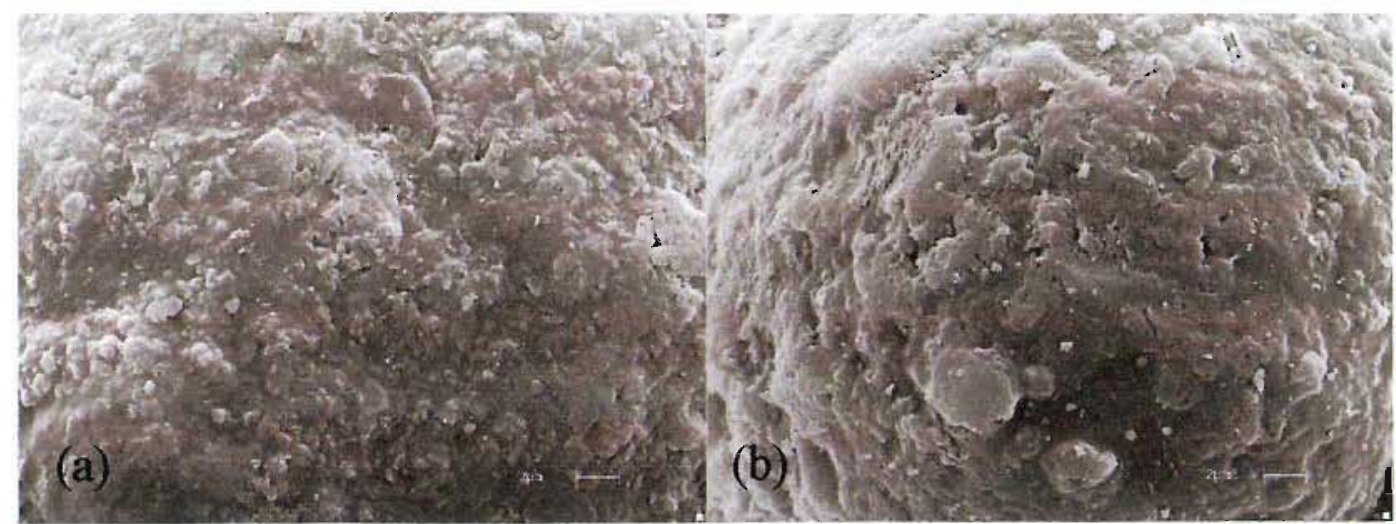

Figura 5.6. Microscopia eletrônica de varredura das amostras $C d(a)$ e $C d V$ (b) após $D H$ com aproximações de $2 \mu m$.

Para análise do interior das partículas, uma fração da amostra $\mathrm{CdV}$ foi suportada $\mathrm{e}$ em lâmina de vidro e fixadas com resina. A superficie das lâminas cobertas com a resina foi polida com carbeto de silício de baixa granulometria para secionar as esferas. As amostras então foram analisadas por microscopia com o módulo de feixe de elétrons retroespalhados. Algumas regiões na superficie foram selecionadas para análise de composição química através de espectrometria de energia dispersiva (EED), conforme apresenta a Figura 5.7. Nitidamente, pode ser observado que ocorreu uma aglutinação de partículas na DH através dos contornos mais claros destacados.

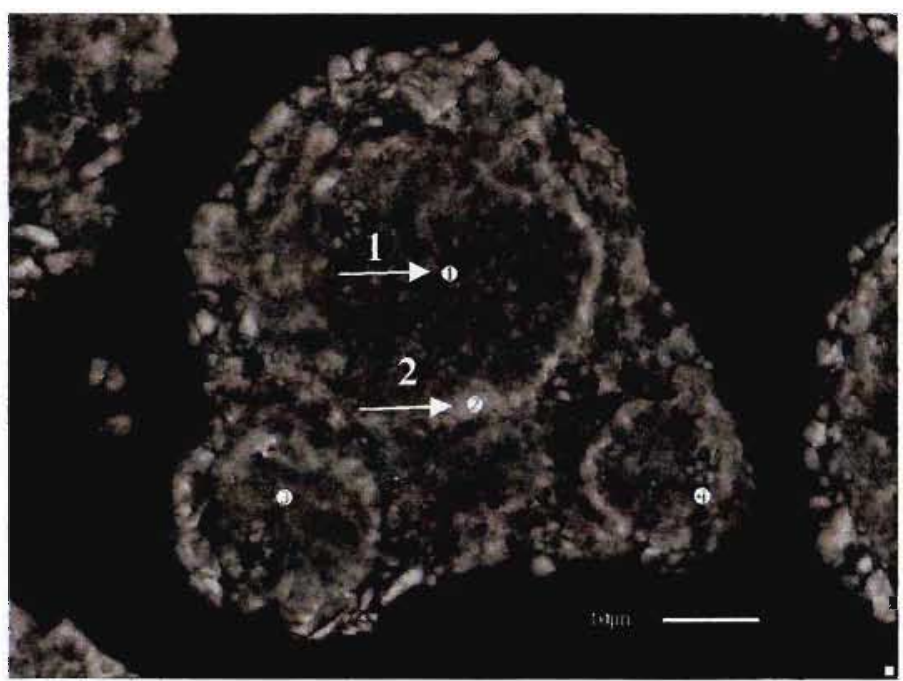

Figura 5.7. Microscopia eletrônica de varredura de partículas secionadas de CdV após DH em aproximações de $10 \mu \mathrm{m}$ (elétrons retro-espalhados). 
A Tabela 5.7 apresenta o resultado da composição química nas regiões 1 e 2 indicadas na micrografia da Figura 5.7. Nota-se que a distribuição de $\mathrm{V}$ é aproximadamente regular entre o centro e a periferia das partículas. Entretanto, os teores de $\mathrm{Si}$ e $\mathrm{Al}$ variaram nas duas regiões. $\mathrm{O} \mathrm{Al}$ concentrou-se na superficie e o conteúdo de $\mathrm{Si}$ no interior das partículas era equivalente ao catalisador original.

Tabela 5.7. Composição química por EED, em \%, das amostras CdVe CdVDy.

\begin{tabular}{ccccc}
\hline & \multicolumn{2}{c}{ CdV } & \multicolumn{2}{c}{ CdVDy } \\
\cline { 2 - 5 } & Região 1 & Região 2 & Região 1 & Região 2 \\
\hline V & 0,9 & 1,1 & 0,7 & 1,6 \\
$\mathrm{Al}$ & 26 & 34 & 26 & 27 \\
$\mathrm{Si}$ & 73 & 65 & 73 & 65 \\
$\mathrm{Dy}$ & - & - & 0,8 & 6,1 \\
\hline
\end{tabular}

A Figura 5.8 apresenta as micrografias do catalisador incorporado com $\mathrm{V}$ e passivadores de TR através dos complexos e submetido à $\mathrm{DH}$. Em contraste ao $\mathrm{CdV}$ (Figura 5.5), observa-se que a morfologia e textura original das amostras foram parcialmente preservadas. Verifica-se, também, que as partículas apresentam-se aglutinadas e com material agregado à superfície do catalisador.

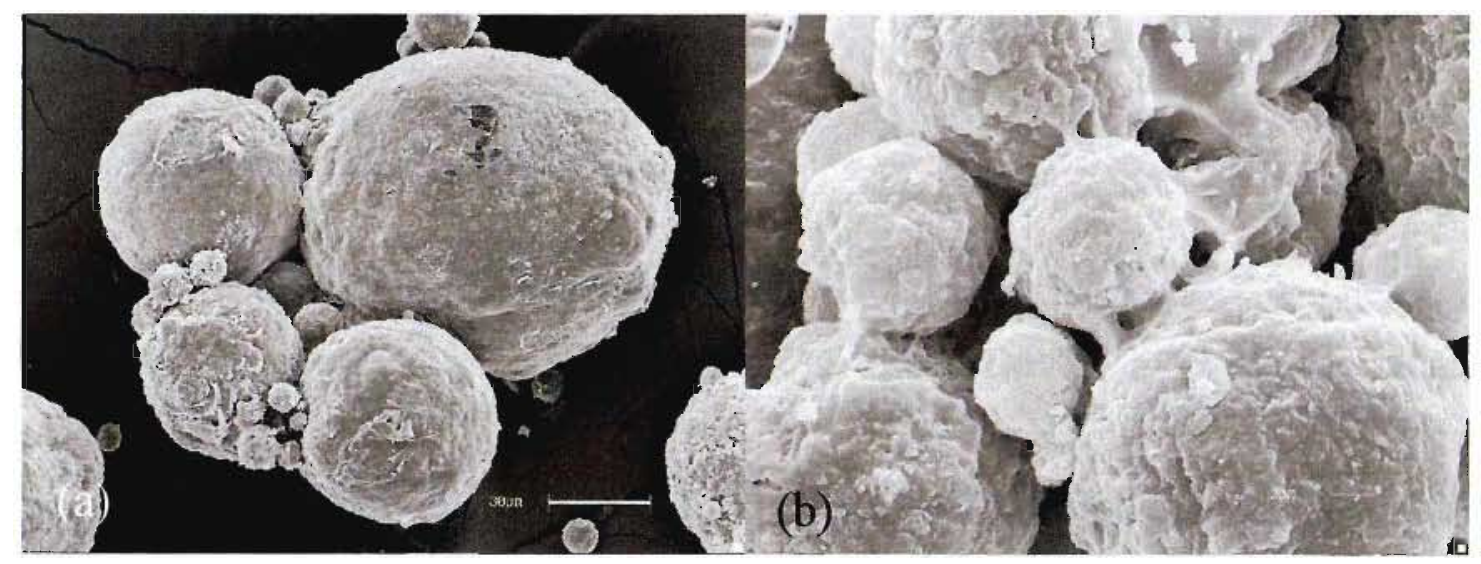

Figura 5.8. Microscopia eletrônica de varredura da amostra CaVDy após DH em aproximações de $30 \mu \mathrm{m}$ (a) e $2 \mu \mathrm{m}$ (b). 
A Figura 5.9 apresenta a micrografia obtida no módulo de elétrons retro-espalhados com a amostra CdVDy. A Tabela 5.6 mostra as composições químicas obtidas por EED nas regiões 1 e 2 indicadas na figura. A concentração de $\mathrm{Dy}^{3+}$ na superfície do catalisador foi muito maior que no interior. Ao contrário da amostra CdV (Figura 5.8) verifica-se que os teores de V são ligeiramente maiores na superfície que no interior da partícula.

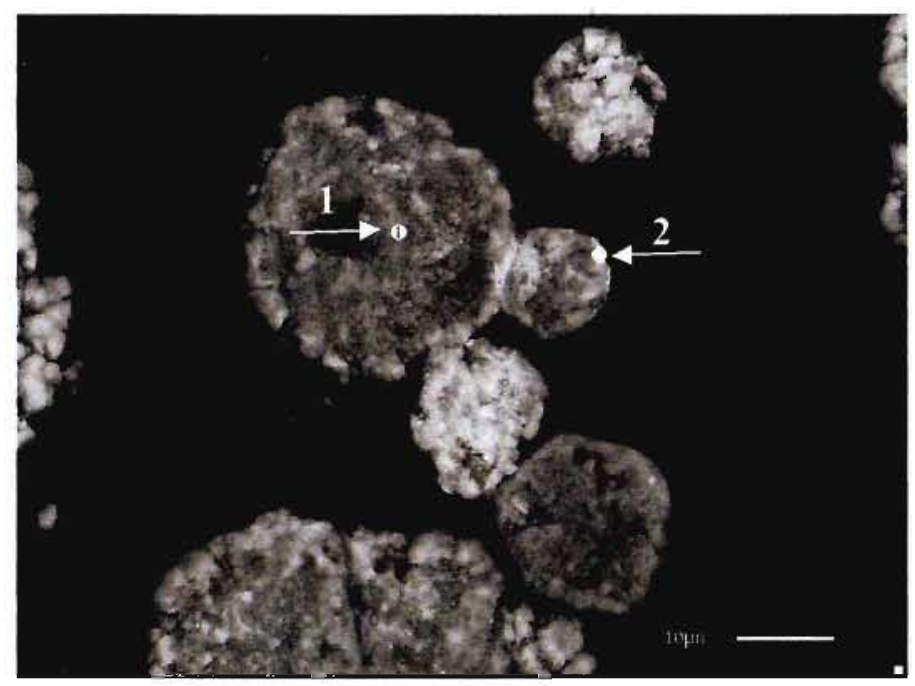

Figura 5.9. Microscopia eletrônica de varredura de particulas secionadas de CdVDy após DH em aproximações de $10 \mu \mathrm{m}$ (elétrons retro-espalhados).

A razão $\mathrm{Si} / \mathrm{Al}$ no interior das partículas é equivalente nas duas amostras. Contudo, $\mathrm{CdV}$ possui menor razão $\mathrm{Si} / \mathrm{Al}$ na superfície que $\mathrm{CdVDy}$, indicando que o ataque do $\mathrm{V}$ ao Al da matriz ou zeólita ocorreu em menor extensão na presença do passivador de TR. A mobilidade do $\mathrm{V}$ foi menor no sistema contendo $\mathrm{Dy}^{3+}$. $\mathrm{Na}$ amostra $\mathrm{CdV}$ o teor de $\mathrm{V}$ na superficie foi menor que CdVDy.

\subsection{Luminescência}

Na Figura 5.10 são apresentados os espectros de excitação de Y-V (amostra de zeólita USY incorporada com V) após $\mathrm{DH}, \mathrm{EuVO}_{4}$ e $\mathrm{GdVO}_{4}$ a $77 \mathrm{~K}$, com emissão monitorada em $616 \mathrm{~nm}$. $\mathrm{O} \mathrm{EuVO}_{4}$ apresenta uma banda larga ao redor $315 \mathrm{~nm}$, devido à transferência de carga ligante-metal $\left(\mathrm{LMCT}, \mathrm{O}^{2-} \rightarrow \mathrm{V}^{5+}\right.$ ) proporcionada pelo íon de ortovanadato $\left(\mathrm{VO}_{4}{ }^{3-}\right)$, e bandas estreitas que ocorrem devido às transições intraconfiguracionais $4 \mathrm{f}$ - proibidas de acordo com a regra de Laporte - características do 
ion de $\mathrm{Eu}^{3+}\left({ }^{7} \mathrm{~F}_{0} \rightarrow{ }^{5} \mathrm{H}_{4},{ }^{7} \mathrm{~F}_{0} \rightarrow{ }^{5} \mathrm{G}_{6},{ }^{7} \mathrm{~F}_{0} \rightarrow{ }^{5} \mathrm{~L}_{6}\right.$ e $\left.{ }^{7} \mathrm{~F}_{0} \rightarrow{ }^{5} \mathrm{D}_{2}\right)$. No espectro de excitação do $\mathrm{GdVO}_{4}$ foi observado apenas as bandas devido ao íon ortovanadato com menor intensidade que nos espectros de $\mathrm{EuVO}_{4}$ e Y-V. O espectro de Y-V apresenta uma banda larga entre 250 e $350 \mathrm{~nm}$ devido à LMCT, similar às espécies tetraédricas monoméricas de vanadila $\left(\mathrm{V}=\mathrm{O}^{2+}\right)$ suportadas em $\mathrm{Al}_{2} \mathrm{O}_{3}$ depois de calcinação a $525^{\circ} \mathrm{C}[4]$.

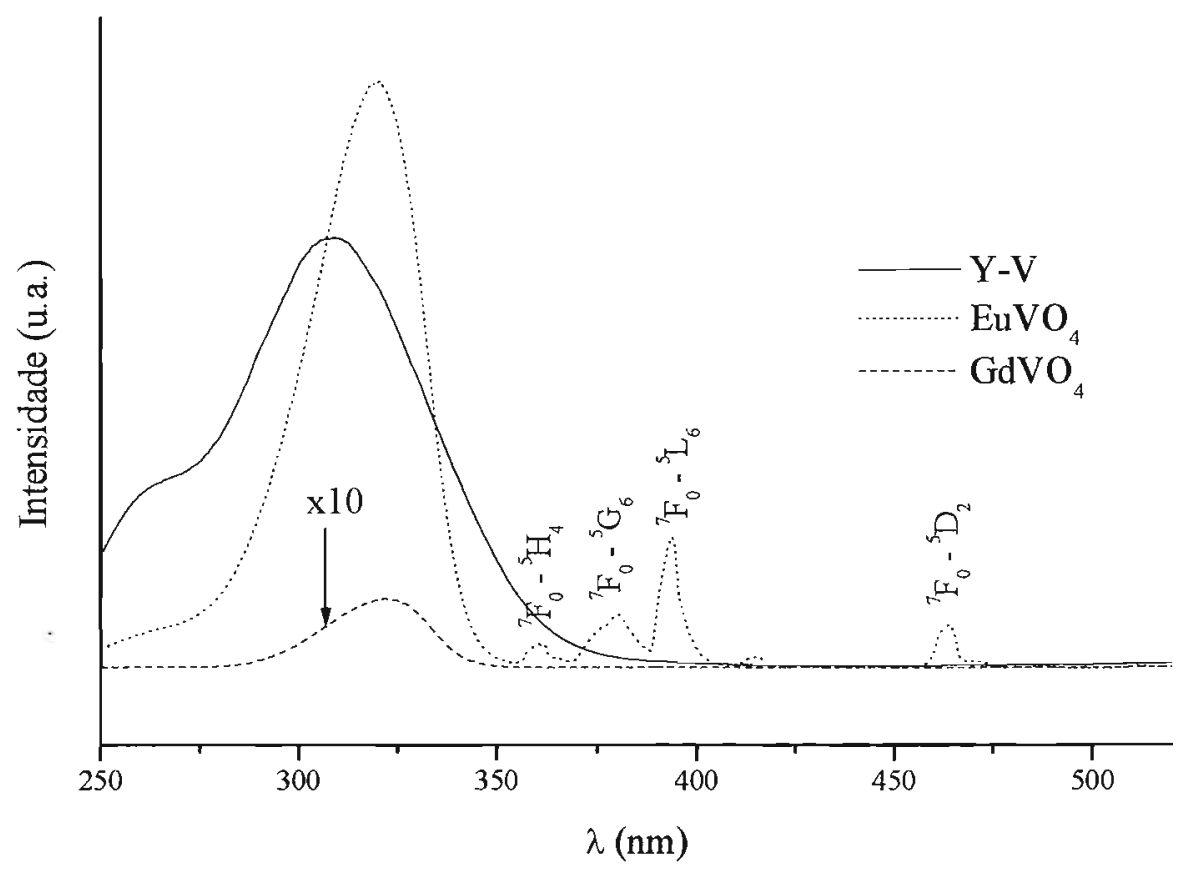

Figura 5.10. Espectros de excitação das amostras $Y-V$ após $D H, E u V O_{4}$ e $G d V O_{4}$ coletados a $77 \mathrm{~K}\left(\lambda_{e m}=616 \mathrm{~nm}\right)$.

A Figura 5.11 apresenta os espectros de excitação de EuY-V e EuY-V/TR $(\mathrm{TR}=\mathrm{La}, \mathrm{Gd}$ ou $\mathrm{Lu})$ a $77 \mathrm{~K}$ com emissão monitorada a $616 \mathrm{~nm}$. Em todos os espectros é observada uma banda larga ao redor $315 \mathrm{~nm}$ devida ao efeito de transferência de carga. A ocorrência desta transição está associada à presença de $\mathrm{EuVO}_{4} \mathrm{e}$ às espécies observadas no espectro de Y-V. Considerando a redução de cristalinidade e a deterioração das propriedades texturais da amostra exibidas nas Tabelas 5.3 e 5.5, pode-se inferir que o $\mathrm{V}$ ataca o $\mathrm{Al}$ e os contra-íons de $\mathrm{Eu}^{3+}$ da estrutura zeolítica durante a etapa de calcinação na presença de vapor. 


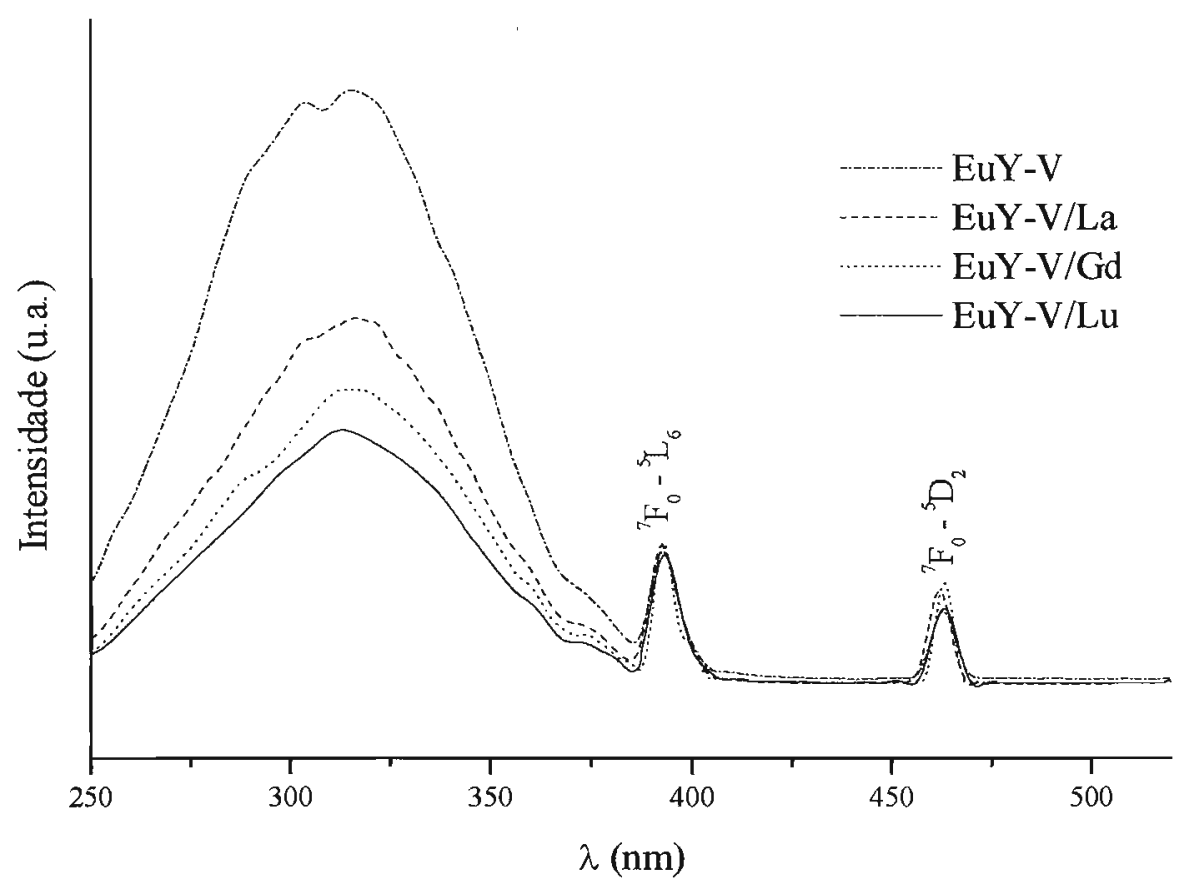

Figura 5.11. Espectros de excitação das amostras EuY-V e EuY-V/TR após DH coletados a $77 \mathrm{~K}\left(\lambda_{e m}=616 \mathrm{~nm}\right)$.

Para ilustrar as relações entre as intensidades da absorção dos íons $\mathrm{VO}_{4}{ }^{3-} \mathrm{e} \mathrm{Eu}^{3++}$, denominamos por " $b$ " o parâmetro de intensidade experimental relativa à razão entre as intensidades da banda larga do íon $\mathrm{VO}_{4}{ }^{3-}$ (considerando a faixa entre 250 e $380 \mathrm{~nm}$ ) e a banda estreita referente a transição ${ }^{7} \mathrm{~F}_{0} \rightarrow{ }^{5} \mathrm{~L}_{6}$ do íon $\mathrm{Eu}^{3+}$ [5]. A intensidade da transição do $\mathrm{Eu}^{3+}$ foi tomada como referência, pois permanece praticamente inalterada em todos os espectros. Os valores de $b$ estão apresentados na Figura 5.12 e seguem a ordem: EuY-V > EuY-V/La $>$ EuY-V/Gd $>$ EuY-V/Lu. Esta ordem está inversamente correlacionada com a capacidade do passivador empregado em minimizar o efeito deletério do V. Observa-se que as relações entre as intensidades das bandas de transição do íon $\mathrm{Eu}^{3+}$ e da LMCT do íon $\mathrm{VO}_{4}^{3-}$ fornecem outro meio de avaliação da capacidade dos passivadores em neutralizar $\mathrm{V}$. 


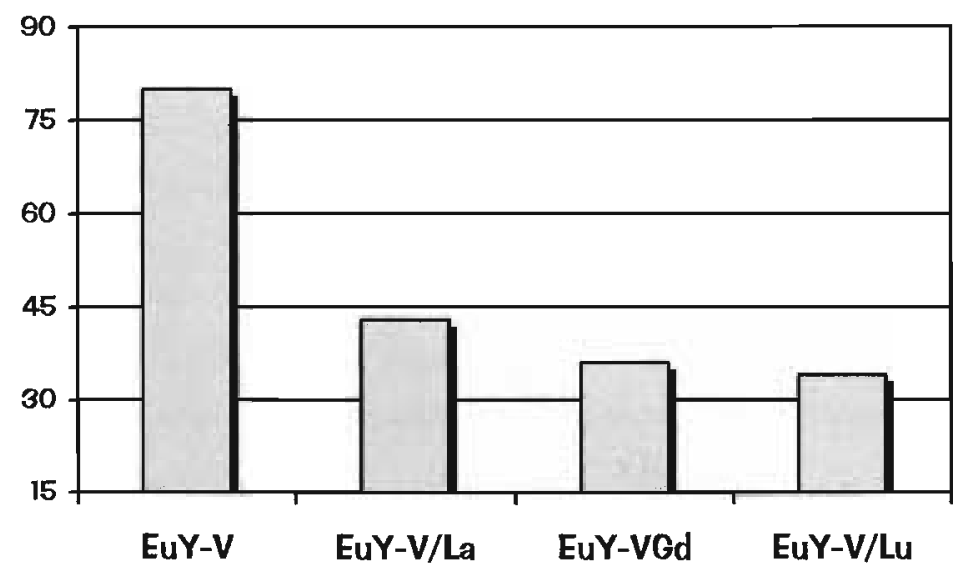

Figura 5.12. Valores do parâmetro de intensidade $b$ das amostras após $D H$ a partir dos espectros de excitação a $77 \mathrm{~K}\left(\lambda_{e m}=616 \mathrm{~nm}\right)$.

Os espectros de emissão da zeólita EuY antes e após DH estão apresentados na Figura 5.13. Observa-se que o íon de $\mathrm{Eu}^{3+}$ após DH encontra-se em um sítio de simetria menor, provavelmente dos tipos $C_{n \nu}, C_{n}$ e $C_{s}$. Isto é corroborado pela diminuição de intensidade da transição ${ }^{5} \mathrm{D}_{0} \rightarrow{ }^{7} \mathrm{~F}_{2}$ comparada com a transição ${ }^{5} \mathrm{D}_{0} \rightarrow{ }^{7} \mathrm{~F}_{1}$ permitida por dipolo magnético. A presença de ambientes químicos diferentes em tal sistema está relacionada à perda de moléculas de água coordenada aos íons $\mathrm{Eu}^{3+}$ localizados nas cavidades maiores da zeólita. Por conseguinte, os íons $\mathrm{Eu}^{3+}$ migram das supercavidades para o interior de cavidades menores com subseqüente coordenação aos átomos de oxigênio da estrutura [6].

A Figura 5.14 apresenta os espectros de emissão do EuY-V e EuY-V/TR depois de $\mathrm{DH}$ registrados a $77 \mathrm{~K}$ com excitação a $394 \mathrm{~nm}$, na região espectral que contém as transições ${ }^{5} \mathrm{D}_{0} \rightarrow{ }^{7} \mathrm{~F}_{J}$ (onde $J=0,1,2,3$ e 4). É observado que o $\mathrm{V}$ provocou uma supressão da luminescência do íon de $\mathrm{Eu}^{3+}$ no ambiente. Por outro lado, o sistema EuY-V incorporado com os passivadores $\mathrm{La}, \mathrm{Gd}$ ou Lu preservou parcialmente a intensidade de luminescência quando comparado com a amostra de EuY-V. As intensidades de luminescência das amostras seguem a ordem: EuY-V $<$ EuY-V/La $<$ EuY-V/Gd $<$ EuY-V/Lu. Correlacionando os dados das Tabelas 5.3 e 5.5 com os valores do parâmetro experimental $b$, pode ser assumido que a supressão da luminescência do íon de $\mathrm{Eu}^{3+}$ está relacionada à quantidade de zeólita preservada do ataque por $\mathrm{V}$ e, por conseguinte, à habilidade do passivador de TR em interagir com V sob as condições de DH. 


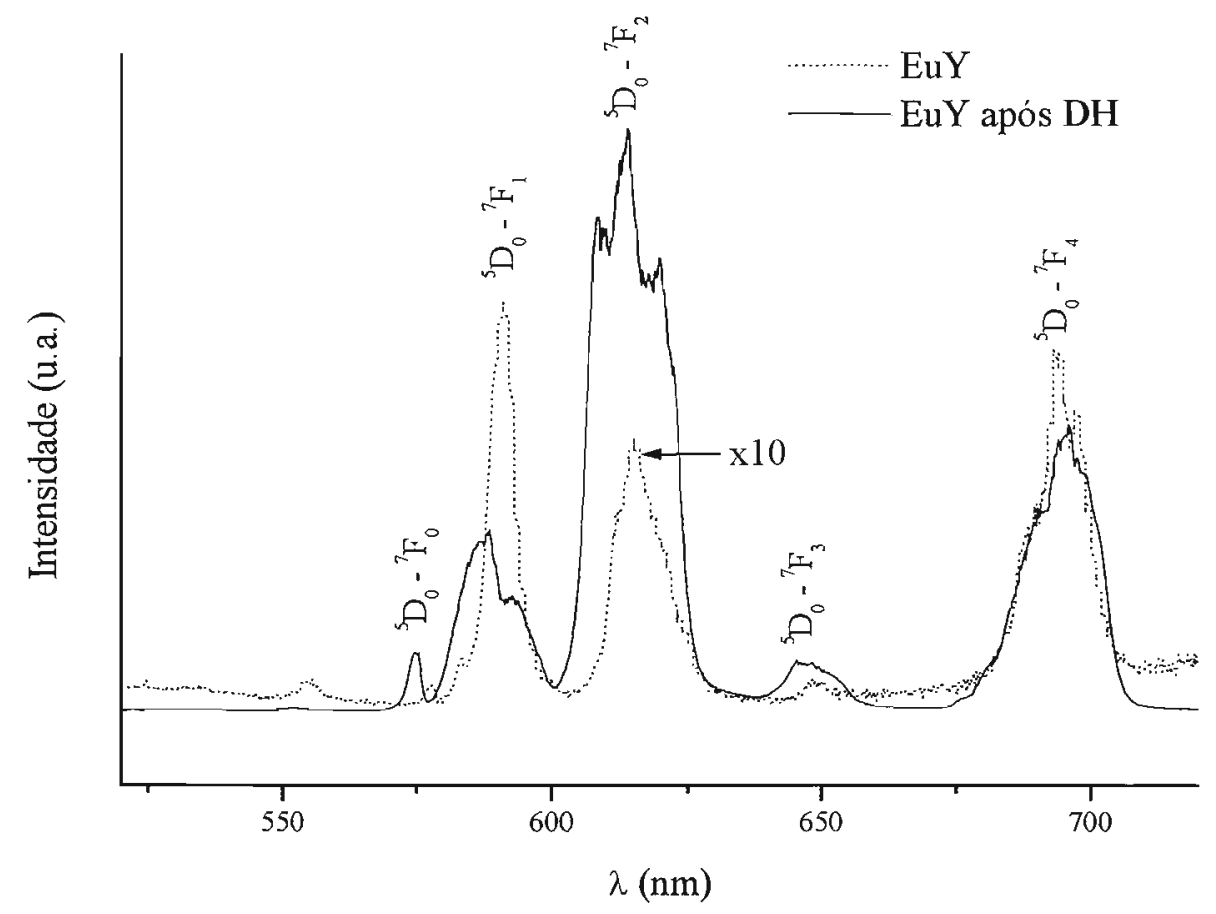

Figura 5.13. Espectros de emissão das amostras EuY antes e após DH a $77 \mathrm{~K}$ $\left(\lambda_{e x}=394 \mathrm{~nm}\right)$.

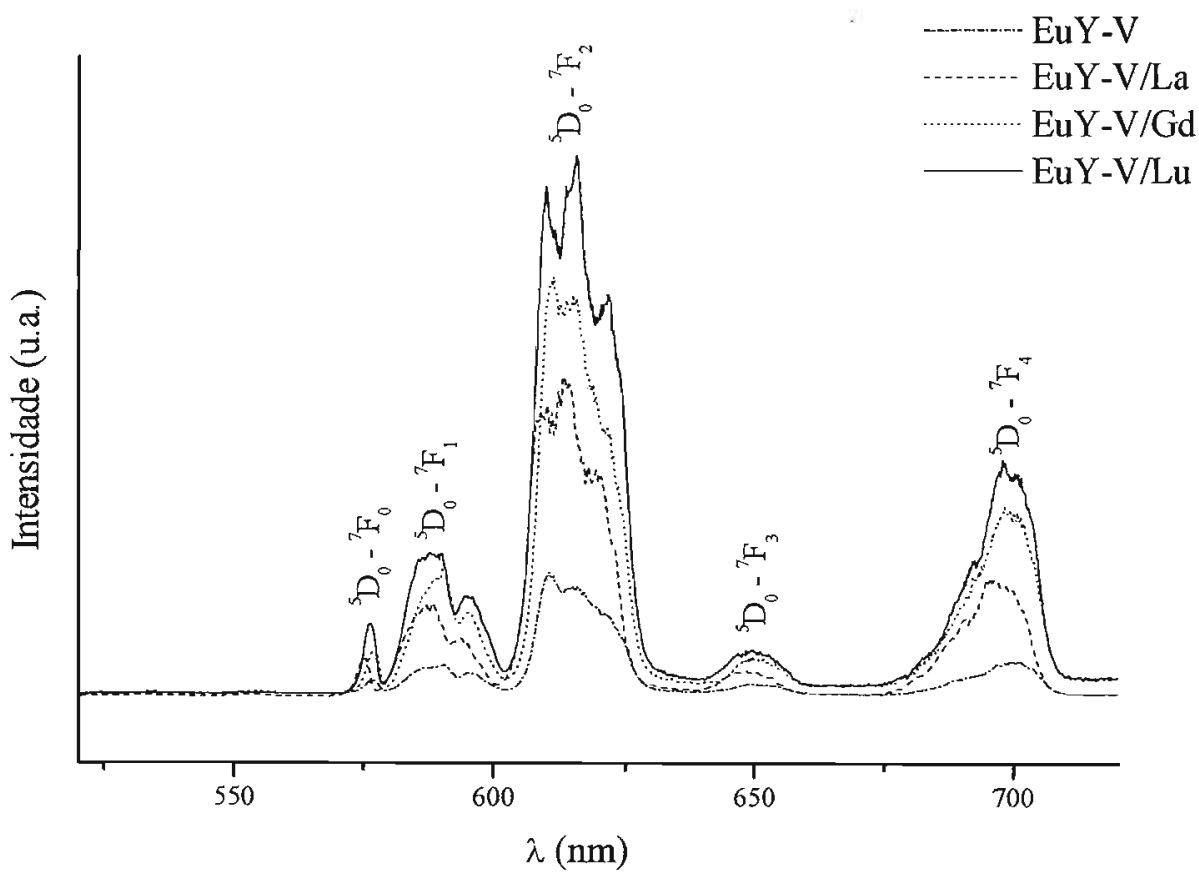

Figura 5.14. Espectros de emissão das amostras EuY-V e EuY-V/TR após DH coletados a $77 \mathrm{~K}\left(\lambda_{\mathrm{ex}}=394 \mathrm{~nm}\right)$. 
A escolha dos passivadores de TR, empregados nos experimentos por luminescência ( $\mathrm{La}, \mathrm{Gd} \mathrm{e} \mathrm{Lu}$ ), foi devido às propriedades eletrônicas específícas destes, que apresentam orbitais $4 f$ vazios, semicheios e cheios, respectivamente [7]. Como conseqüência, não há elétrons opticamente ativos para os íons $\mathrm{La}^{3+} \mathrm{e} \mathrm{Lu}^{3+}$. O íon $\mathrm{Gd}^{3+}$, por sua vez, apresenta um gap muito alto de energia entre o estado fundamental $\left({ }^{8} \mathrm{~S}_{7 / 2}\right)$ e o primeiro estado excitado $\left({ }^{6} \mathrm{P}_{7 / 2}\right)$ na ordem de $32000 \mathrm{~cm}^{-1}$ [8]. Assim, os dados espectrais de emissão podem ser obtidos na região entre 350 a $720 \mathrm{~nm}$ sem qualquer interferência das transições eletrônicas dos passivadores.

Considerando as transições ${ }^{5} \mathrm{D}_{0} \rightarrow{ }^{7} \mathrm{~F}_{J}\left(J=1,2\right.$ e 4) do íon de $\mathrm{Eu}^{3+}$ no ambiente zeolítico, foi possível determinar os parâmetros de intensidade experimentais $\Omega_{\lambda}(\lambda=2$ e 4$)$. No cálculo, a transição por dipolo magnético permitido ${ }^{5} \mathrm{D}_{0} \rightarrow{ }^{7} \mathrm{~F}_{1}$ foi usada como referência para expressar a intensidade de emissão conforme expressão:

$$
I=\eta \omega A N
$$

onde $I$ é a intensidade em termos da superficie sob a curva de emissão, $\eta \omega$ é a energia de transição, $N$ é a população do nível emissor $\left({ }^{5} \mathrm{D}_{0}\right)$ e $A$ é o coeficiente de emissão espontânea de Einstein [9], que para este caso é dado por:

$$
A_{0-\lambda}=\frac{4 e^{2} \omega^{3}}{3 \eta c^{3}} \chi \Omega_{\lambda}\left\langle{ }^{5} D_{0}\left\|U^{(\lambda)}\right\|^{7} F_{\lambda}\right\rangle^{2}
$$

onde $\chi=n_{0}\left(n_{0}^{2}+2\right)^{2} / 9$ é a correção de campo local de Lorentz, $n_{0}$ é o índice de refração do meio. O quadrado dos elementos de matriz reduzida para $U^{2}=0,0032$ e $U^{4}=0,0023$ na equação acima foi tomado da referência [10] e um índice de refração médio igual a 1,5 foi usado. Neste caso os valores de $A_{0-\lambda}$ foram obtidos usando a seguinte relação:

$$
\frac{A_{0-\lambda}}{A_{0-1}}=\frac{S_{0-\lambda}}{S_{0-1}} \frac{\sigma_{\lambda}}{\sigma_{1}}
$$


onde $S_{0-\lambda}$ é a área sob a curva relacionada à transição ${ }^{5} \mathrm{D}_{0} \rightarrow{ }^{7} \mathrm{~F}_{\lambda}$ transição obtida a partir dos dados espectrais, $\sigma_{\lambda}$ é a energia do baricentro da transição $0-\lambda$ e $A_{0-1}$ é o coeficiente do Einstein para a transição dipolo magnético $\left({ }^{5} \mathrm{D}_{0} \rightarrow{ }^{7} \mathrm{~F}_{1}\right)$ que é dada por $A_{0-1}=0,31 \times 10^{-11} n_{0}^{3} \sigma_{1}^{3}$.

Na Tabela 5.8 os valores dos parâmetros de intensidade experimentais $\Omega_{\lambda}(\lambda=2$ e 4$)$ são apresentados para as amostras EuY, EuY-V e EuY-V/TR.

Tabela 5.8. Parâmetros de intensidade, razão ${ }^{5} D_{0} \rightarrow{ }^{7} F_{0} \delta D_{0} \rightarrow{ }^{7} F_{2}$ nos espectros de emissão e medidas do tempo de vida.

\section{Parâmetro}

\begin{tabular}{ccccc} 
Amostra & $\Omega_{2}\left(10^{-20} \mathrm{~cm}^{2}\right)$ & $\Omega_{4}\left(10^{-20} \mathrm{~cm}^{2}\right)$ & $R_{0-2}$ & $\tau_{1}-\tau_{2}(\mathrm{~ms})$ \\
\hline EuY & 8,1 & 9,4 & 23 & $0,29-4,7$ \\
EuY-V & 9,5 & 6,4 & 19 & $0,47-4,7$ \\
$\mathrm{EuY}-\mathrm{V} / \mathrm{La}$ & 7,9 & 8,2 & 19 & $0,43-3,5$ \\
$\mathrm{EuY}-\mathrm{V} / \mathrm{Gd}$ & 8,0 & 8,3 & 20 & $0,42-4,5$ \\
$\mathrm{EuY}-\mathrm{V} / \mathrm{Lu}$ & 7,8 & 8,2 & 22 & $0,41-4,5$ \\
\hline
\end{tabular}

Comparando-se o parâmetro $\Omega_{2}$ em todas as amostras, verifica-se que a amostra EuY-V apresenta o maior valor evidenciando o comportamento hipersensitivo da transição ${ }^{5} \mathrm{D}_{0} \rightarrow{ }^{7} \mathrm{~F}_{2}$. Este fato sugere que os íons de $\mathrm{Eu}^{3+}$ nesta amostra estão em um ambiente mais facilmente polarizável que nas amostras EuY e EuY-V/TR. Também se pode notar que $\mathrm{Eu}^{3+}$ na zeólita não se encontra em um ambiente tão polarizável como observado em certos complexos $\beta$-dicetonatos, em que o parâmetro $\Omega_{2}$ é da ordem de $30 \times 10^{-20} \mathrm{~cm}^{2}$ [9]. Isto é caracterizado pela menor transição por dipolo elétrico ${ }^{5} \mathrm{D}_{0} \rightarrow{ }^{7} \mathrm{~F}_{2}$ no sistema zeolítico. A Tabela 5.7 apresenta também os valores do parâmetro $\Omega_{4}$ das amostras, onde é observado o mais alto resultado para amostra de EuY. Além disto, é notado que o parâmetro $\Omega_{4}$ é mais alto que $\Omega_{2}$ para todas as amostras, com exceção do EuY-V. Com base na teoria das intensidades das transições $4 f$ [11-12], o parâmetro $\Omega_{2}$ depende muito dos componentes em níveis mais baixos do campo cristalino e interações de acoplamento dinâmico, enquanto o 
parâmetro $\Omega_{4}$ depende dos correspondentes componentes mais altos. Assim, em sistemas zeolíticos onde $\Omega_{4}>\Omega_{2}$, a geometria de coordenação é tal que os componentes mais altos nas interações tem valores maiores que os componentes mais baixos. É possível sugerir, portanto, que o sítio de simetria ocupado pelo íon $\mathrm{Eu}^{3+}$ está aproximadamente em um ambiente químico centrossimétrico, considerando que a transição ${ }^{5} \mathrm{D}_{0} \rightarrow{ }^{7} \mathrm{~F}_{2}$ é formalmente proibida por regra de seleção devido ao dipolo elétrico nos grupos pontuais contendo centro de inversão.

O parâmetro intensidade $R_{02}$, mostrado na Tabela 5.8, é a razão entre as intensidades das transições ${ }^{5} \mathrm{D}_{0} \rightarrow{ }^{7} \mathrm{~F}_{0}$ e ${ }^{5} \mathrm{D}_{0} \rightarrow{ }^{7} \mathrm{~F}_{2}$. O parâmetro de $R_{02}$ proporciona informação sobre o efeito $J$-mixing associado com transição ${ }^{5} \mathrm{D}_{0} \rightarrow{ }^{7} \mathrm{~F}_{0}$ como descrito em detalhe em ref. [13]. Neste caso, este efeito é devido principalmente à combinação entre o múltiplo ${ }^{7} \mathrm{~F}_{2}$ e o nivel ${ }^{7} \mathrm{~F}_{0}$ pelos dois componentes no campo ligante. Foi observado que o valor de $R_{02}$ para o íon de $\mathrm{Eu}^{3+}$ na amostra de EuY-V é um dos menores entre as amostras de zeólita.

Os tempos de vida $(\tau)$ do nível emissor ${ }^{5} \mathrm{D}_{0}$ no íon de $E u^{3+}$ foram determinados $\mathrm{e}$ também são apresentados na Tabela 5.8. A curva de decaimento das amostras de zeólita mostram um comportamento bi-exponencial, indicando que há mais de um tipo de ambiente ao redor do íon de $\mathrm{Eu}^{3+}$. Isto sugere que há outro canal de despopulação para o nível ${ }^{5} \mathrm{D}_{0}$.

Os espectros de emissão de $\mathrm{EuVO}_{4}, \mathrm{GdVO}_{4}$ e $\mathrm{Y}-\mathrm{V}$ a $77 \mathrm{~K}$, com excitação monitorada a 394 nm, estão apresentados na Figura 5.15. São observadas bandas muito nítidas no espectro da amostra de $\mathrm{EuVO}_{4}$ entre 450 e $720 \mathrm{~nm}$ devido às transições ${ }^{5} \mathrm{D}_{J} \rightarrow{ }^{7} \mathrm{~F}_{J^{\prime}}$ (onde $J=0-3$ e $J^{\prime}=0-4$ ) características do íon $\mathrm{Eu}^{3+}$. A amostra $\mathrm{Y}-\mathrm{V}$, por sua vez, apresenta na região espectral uma banda larga atribuída a LMCT do grupo vanadila $(\mathrm{O}=\mathrm{V})$ dos tetraedros unitários de $\mathrm{VO}_{4}$ também observado no trabalho de Hazenkamp e Blasse [4]. $\mathrm{O}$ espectro da amostra de $\mathrm{GdVO}_{4}$ apresentou praticamente nenhuma emissão. A comparação entre os perfis dos espectros de emissão do $\mathrm{EuVO}_{4}$ e zeólitas $\mathrm{EuY}$ contendo $\mathrm{V}$ e TR na Figura 5.14, comprovam que o ambiente e a geometria de coordenação de íons de $\mathrm{Eu}^{3+}$ são diferentes na zeólita. 


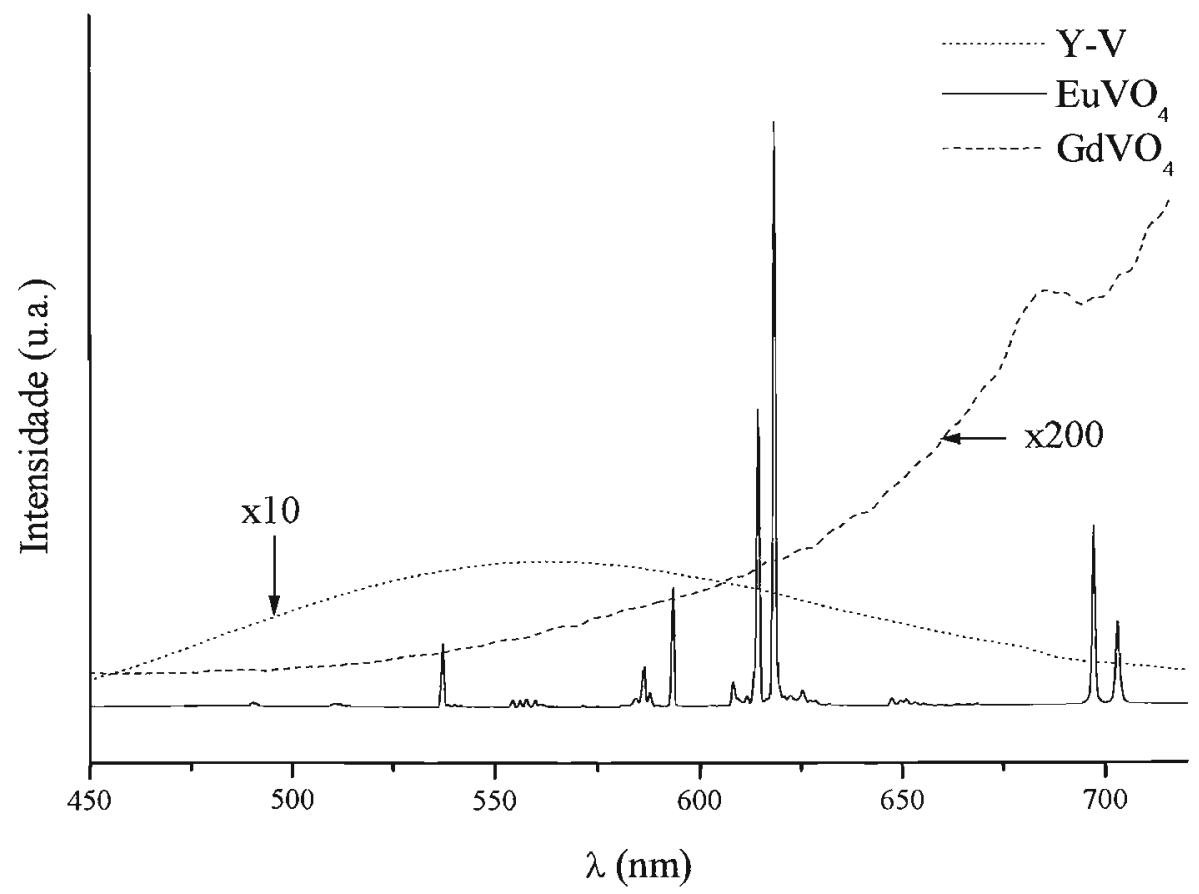

Figura 5.15. Espectros de emissão das amostras $Y-V$ após $D H$, EuVO $_{4}$ e $G d V O_{4}$ coletados a $77 \mathrm{~K}\left(\lambda_{\text {ex }}=394 \mathrm{~nm}\right)$.

\subsection{Ressonância Paramagnética Eletrônica}

$\mathrm{O}$ processo de oxidação do $\mathrm{V}\left(\mathrm{V}^{4+} \rightarrow \mathrm{V}^{5+}+\mathrm{e}^{-}\right)$quando incorporado ao catalisador e submetido à DH pôde ser monitorado por RPE, uma vez que o $\mathrm{V}^{5+}$ é invisível a esta técnica. A oxidação das espécies de V conjugadas ao catalisador para craqueamento ocorre quando o catalisador é submetido à regeneração nas unidades comerciais, especialmente naquelas que procedem com combustão total do coque formado das reações de craqueamento. Conforme descrito no Capítulo 3, quanto maior o estado de oxidação dos compostos de $\mathrm{V}$, maior será a mobilidade e, por conseguinte, a capacidade de ataque do $\mathrm{V}$ à estrutura cristalina do catalisador. $O$ estado de oxidação V (IV) é o mais fácil de ser caracterizado por RPE, por apresentar apenas 1 elétron desemparelhado no subnível $d\left(d^{1}\right)$ 
e spin nuclear $\mathrm{I}_{7 / 2}$, resultando um complexo espectro com 8 linhas hiperfinas, conforme regra de seleção $(2 J+1)$.

A Figura 5.16 apresenta os espectros de $\mathrm{VO}(\text { bzac })_{2}$ em solução de tolueno e das amostras $\mathrm{Cd} \mathrm{e} \mathrm{V}_{2} \mathrm{O}_{5}$ no estado sólido. $\mathrm{O}$ sinal da amostra de $\mathrm{V}_{2} \mathrm{O}_{5}$ foi muito ampliado para ser apresentado, em função da insensibilidade do $\mathrm{V}(\mathrm{V})$ à técnica. A amostra de $\mathrm{VO}(\mathrm{bzac})_{2}$ apresentou transições hiperfinas características da existências de íons $\mathrm{VO}^{2+}$ de geometria octaédrica isolados em um ambiente de simetria axial [14]. A amostra de Cd apresentou uma linha no espectro possivelmente em decorrência de $\mathrm{Ti}$, presente como contaminante na matriz de caulinita do catalisador.

A Figura 5.17 apresenta os espectros das amostras CdV antes e após calcinação e após DH. Comparando os resultados da literatura com os espectros obtidos das amostras submetidas à $\mathrm{DH}$, pode-se concluir que íon $\mathrm{V}^{4+}$ apresenta-se em uma geometria octaédrica distorcida com estrutura ligeiramente rômbica [15-16]. Esta geometria é resultado da interação entre o $\mathrm{V}^{4+}$ e a superficie do catalisador onde, preferencialmente, se coordena às regiões em que o $\mathrm{Al}$ se localiza. A distorção tetragonal do íon se dá em função da dupla ligação com o oxigênio axial do cátion vanadila $\left(\mathrm{O}=\mathrm{V}^{2+}\right)$, resultando uma compressão no sentido do eixo perpendicular $z$. À medida que as amostras são submetidas ao tratamento térmico (calcinação, seguida de $\mathrm{DH}$ ), o sinal do espectro vai se tornando menos intenso, resultado do processo de oxidação e conseqüente redução do teor relativo de $\mathrm{V}^{4+}$.

Os espectros das amostras contendo os passivadores - CdVTR - foram semelhantes à amostra $\mathrm{CdV}$ após $\mathrm{DH}$, conforme demonstrada na Figura 5.17. 


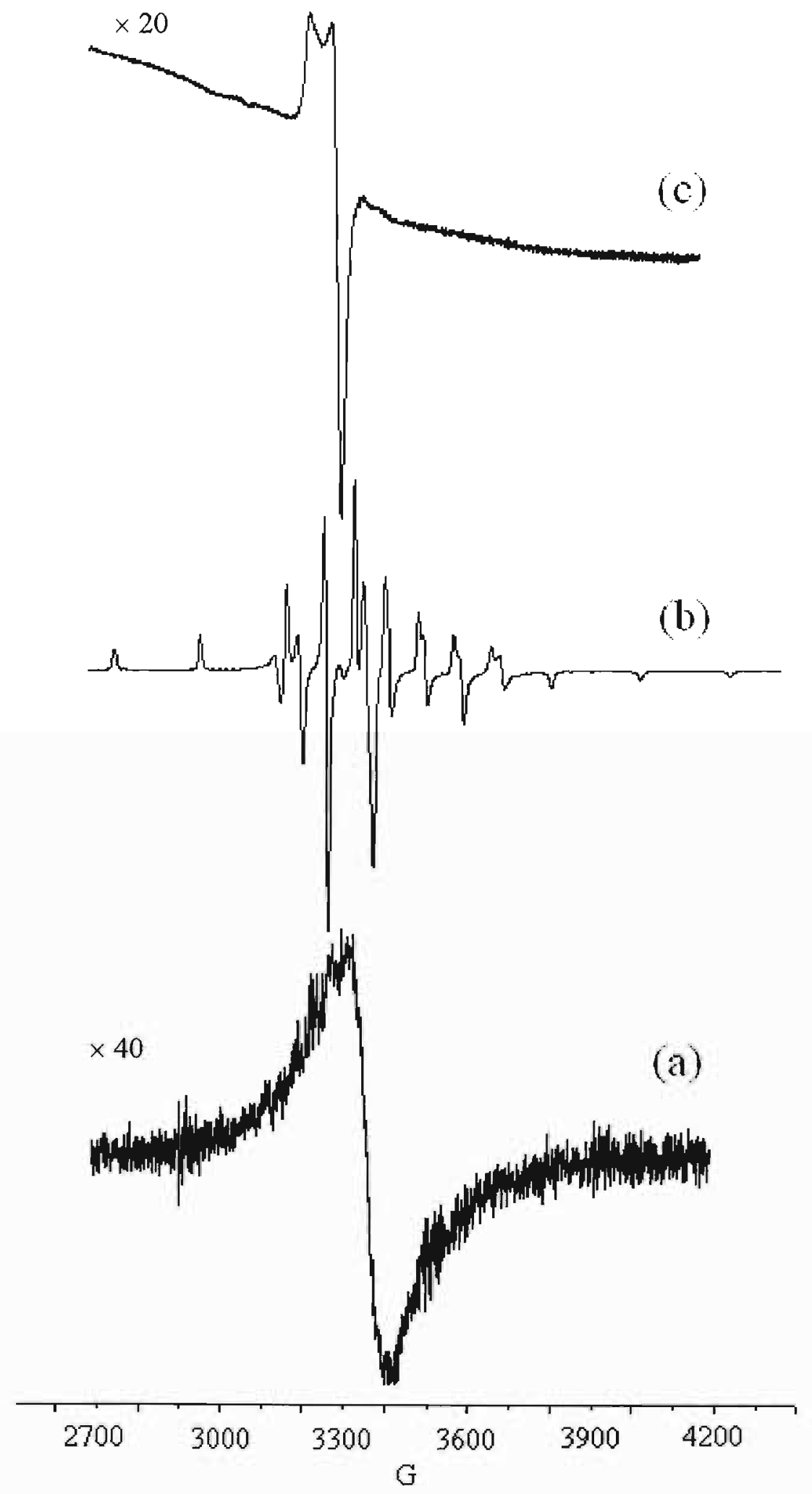

Figura 5.16. Espectro de RPE das amostras (a) $\mathrm{V}_{2} \mathrm{O}_{5}$, (b) $\mathrm{VO}(\mathrm{Bzac})_{2}$ em tolueno e (c) $\mathrm{Cd}$. 


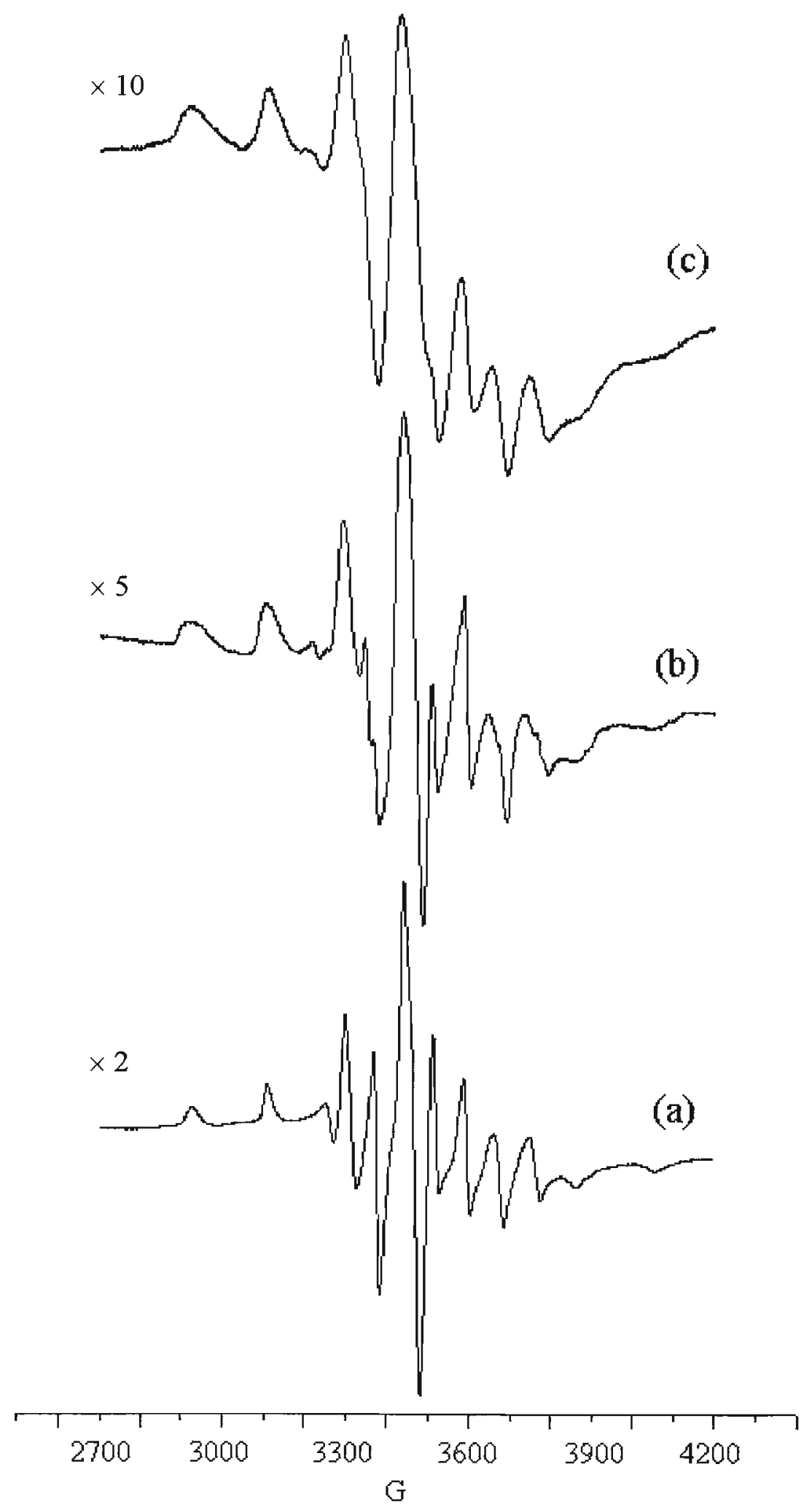

Figura 5.17. Espectro de RPE das amostras $C d V(a)$ após incorporação com $V$, (b) antes $e$ (c) após $D H$. 
Conforme apresentado no Capítulo 4, o método empregado para determinar a razão entre as espécies de V presentes nas amostras consistiu na comparação do teor de V (IV) com a área obtida por integração dupla dos espectros de RPE corrigidos. O gráfíco disposto na Figura 5.18 apresenta a curva elaborada com a solução padrão em tolueno contendo concentrações definidas de V (IV), por meio do complexo VO(bzac) ${ }_{2}$, em função do espectro de RPE. A correlação entre a área dos espectros integrados e a concentração de $\mathrm{V}$ é satisfatória, o que proporciona uma maneira adequada de comparar o teor de V (IV) nas amostras após DH. Considerando todas as amostras de catalisador, cerca de $95 \%$ do V (IV) incorporado foi oxidado a V (V) após DH.

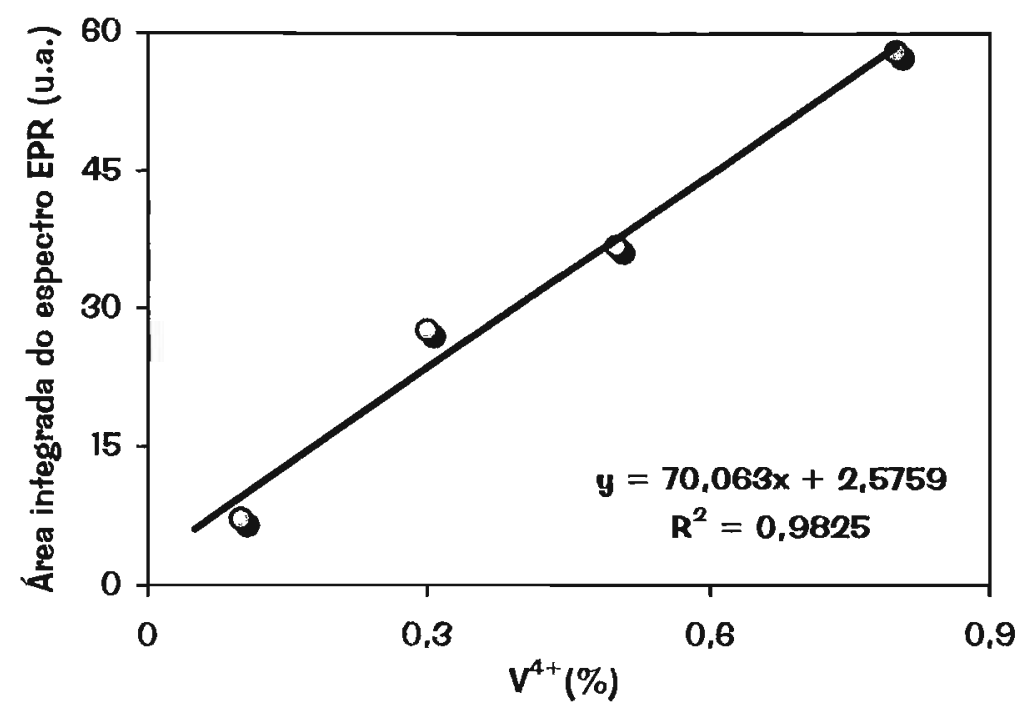

Figura 5.18. Curva de concentração do teor de $V^{4+}$ em função do espectro de RPE.

O teor de V (IV) nas amostras mensuradas através deste ensaio está demonstrado na Tabela 5.9. Devido ao baixo teor de $\mathrm{V}^{4+}$, não foi possível obter com precisão os parâmetros dos espectros de RPE ( $g$ e $A$ ) com as amostras ensaiadas. Contudo, comparando os resultados obtidos com trabalhos anteriores, pôde-se observar que, além de sofrer oxidação, a geometria do cátion vanadila se alterou ligeiramente com o tratamento térmico. Nota-se que à medida que ocorrem os tratamentos térmicos, a componente perpendicular nos espectros se torna menos resolvida, conforme se observa na Figura 5.17. Isto sugere a mudança para uma geometria aproximadamente tetraédrica. 
Tabela 5.9. Razão mássica entre $V^{4+}$, determinado com RPE, e $V$ total presente nas amostras CdVTR submetidas à DH, em \%.

Amostras

\begin{tabular}{ccccccccc} 
& $\mathrm{CdV}$ & CdVLa & $\overline{\mathrm{CdVDy}}$ & $\mathrm{CdVY}$ & $\mathrm{CdVCe}$ & $\overline{C d V Y b}$ & $\overline{C d V G d}$ & $\mathrm{CdVNd}$ \\
\hline $\mathrm{V}^{4+} / \mathrm{V}(\%)$ & 1,3 & 1,5 & 1,6 & 1,3 & 1,5 & 1,6 & 1,5 & 1,6 \\
\hline
\end{tabular}

Embora reduzida durante os tratamentos térmicos, a concentração de V (IV) não foi levada à completa depleção. Isto pode ter ocorrido devido à coordenação do íon vanadila em cavidades zeolíticas mais internas. Trujillo descreveu que uma fração de V (IV) incorporado à zeólita por meio do método de Mitchell, tal como realizado neste trabalho, encontra-se estabilizado nos sítios de Brönsted mais internos e fortes por troca iônica no estado sólido [17].

\subsection{Ressonância Magnética Nuclear de ${ }^{51} \mathrm{~V}$}

$\mathrm{O}$ isótopo ${ }^{51} \mathrm{~V}$ tem spin nuclear $\mathrm{I}_{7 / 2}$ e abundância natural de $99,76 \%$. A espectroscopia de $\mathrm{RMN}$ de ${ }^{51} \mathrm{~V}$ tem se mostrado uma ferramenta adequada na caracterização dos catalisadores à base de $\mathrm{V}$ ou suportados [18]. A comparação entre os espectros de RMN dos catalisadores com compostos referências de estrutura conhecida proporciona informações sobre o ambiente químico e a simetria de coordenação. ${ }^{51} \mathrm{~V}$ tem um momento elétrico quadrupolar moderadamente grande. Assim, a forma do espectro devido à transição de núcleo $+1 / 2 \rightarrow-1 / 2$ pode se tornar muito complexa devido às contribuições quadrupolar de $2^{\mathrm{a}}$ ordem e o deslocamento químico anisotrópico. Estudos anteriores mostraram que a forma das linhas dos espectros em módulo estático em RMN é mais dependente destes deslocamentos anisotrópicos [19].

Foram analisadas por RMN de ${ }^{51} \mathrm{~V}$, no estado sólido em modo estático, as amostras de catalisador incorporadas com $\mathrm{V}$ e passivadores de TR por meio dos complexos e submetidas à $\mathrm{DH}$. Os deslocamentos químicos nos espectros das amostras de catalisador foram comparados com os espectros dos respectivos $\mathrm{TRVO}_{4}$ sintetizados conforme descrito no Capítulo 4. Para efeito de caracterização, o espectro de $\mathrm{RMN}$ de ${ }^{51} \mathrm{~V}$ de $\mathrm{V}_{2} \mathrm{O}_{5}$ no estado sólido também foi registrado. Por meio deste conjunto de experimentos se 
pretendeu estabelecer o produto da interação entre os passivadores de TR e o V quando submetidos à DH.

Da série das TR empregada como passivadores nas amostras CdVTR (TR $=\mathrm{La}, \mathrm{Ce}$, $\mathrm{Nd}$, Gd, Dy, Yb e Y), não foi possível analisar os espectros de $R M N{ }^{51} \mathrm{~V}$ das amostras contendo as $\mathrm{TR} \mathrm{Gd}, \mathrm{Yb}$ e Dy em virtude de suas propriedades paramagnéticas. Os espectros das amostras registrados estão ilustrados entre as Figuras 5.19 e 5.23.

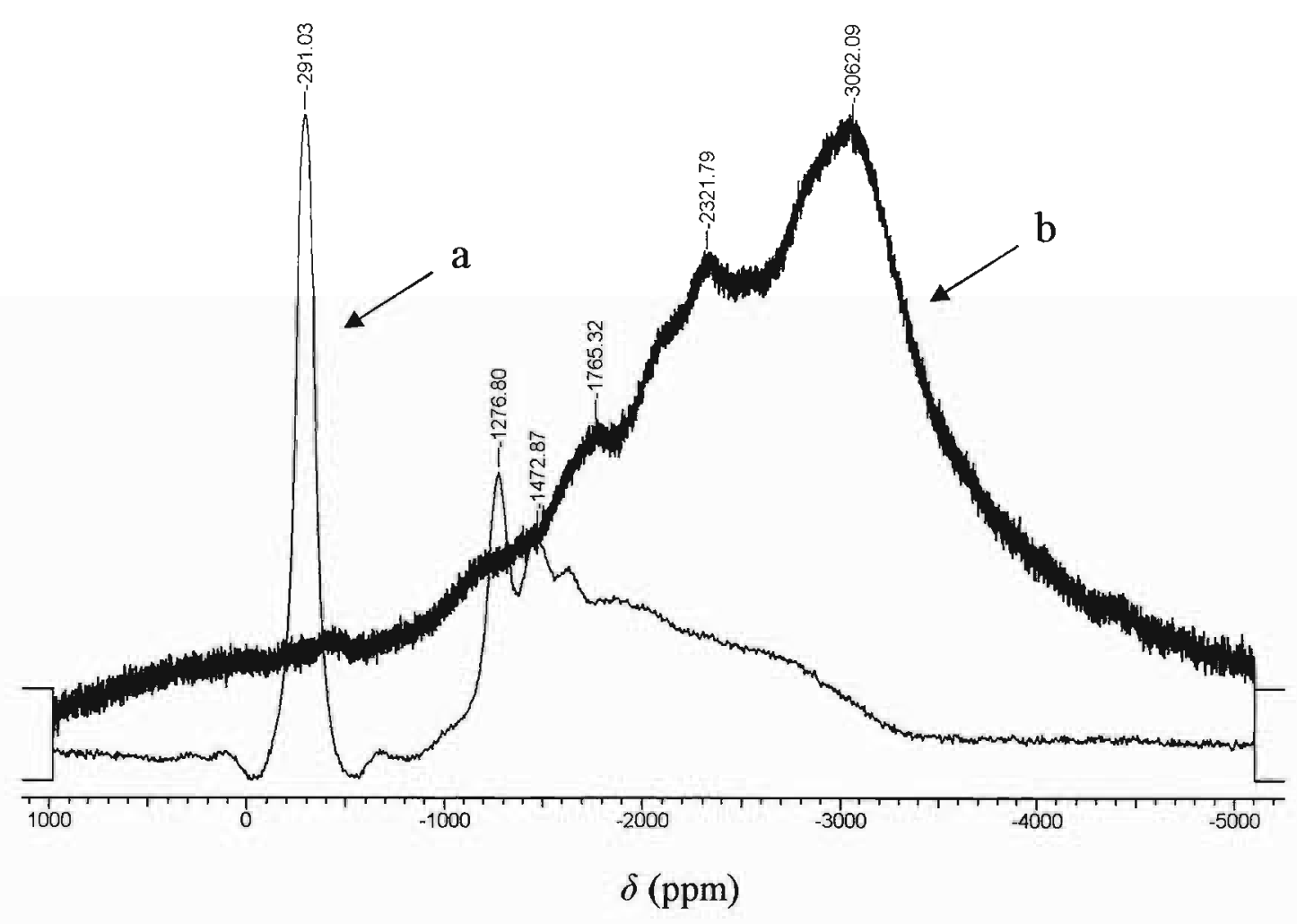

Figura 5.19. Espetro de $\mathrm{RMN}^{51} V$ das amostras (a) CdV após $\mathrm{DH}$ e (b) $\mathrm{V}_{2} \mathrm{O}_{5}$. 


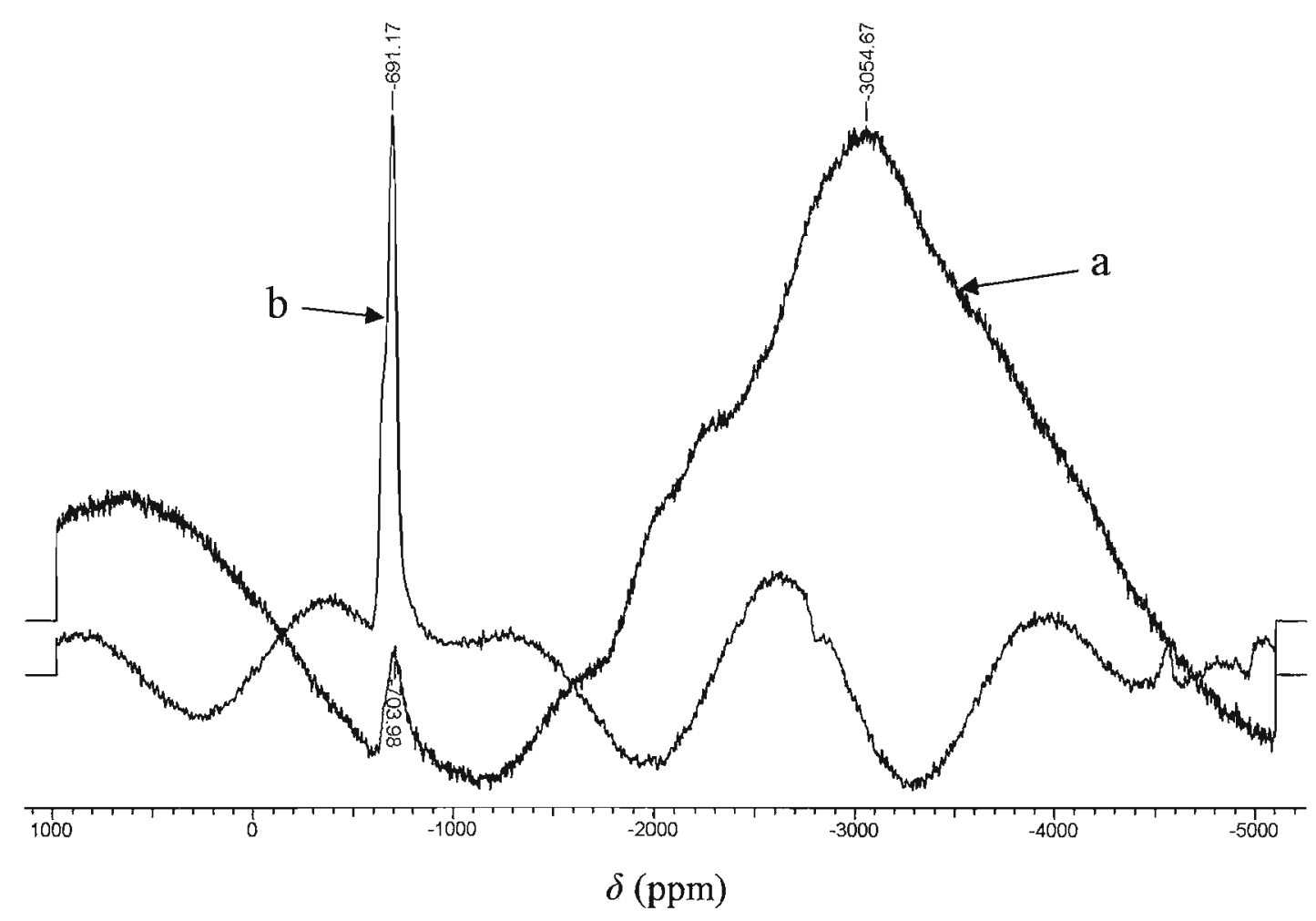

Figura 5.20. Espetro de $R M N^{5 l} V$ das amostras (a) CdVY após DH e (b) YVO

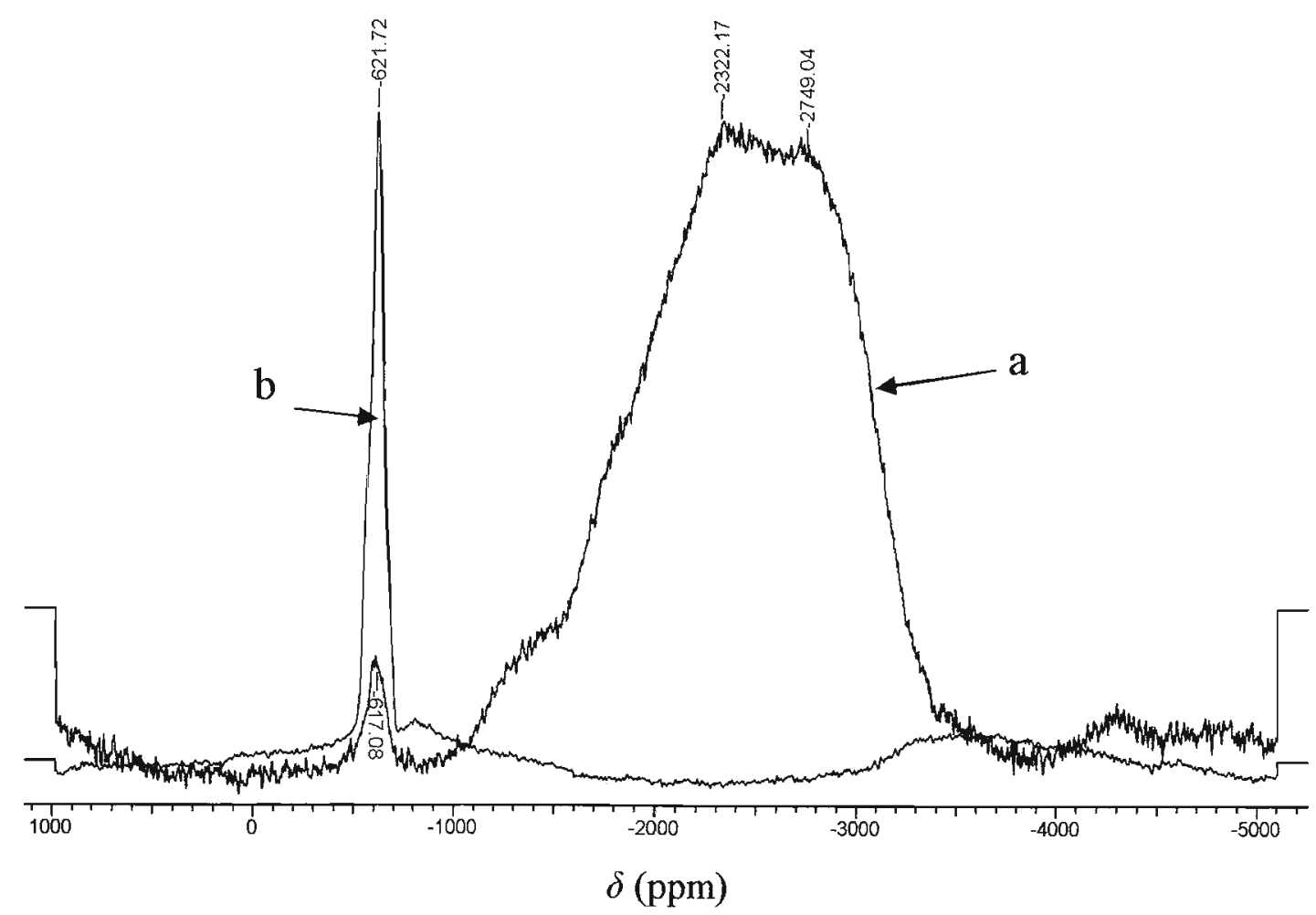

Figura 5.21. Espetro de $R M N^{51} V$ das amostras (a) CdVLa após DH e (b) LaVO $\mathrm{L}_{4}$ 


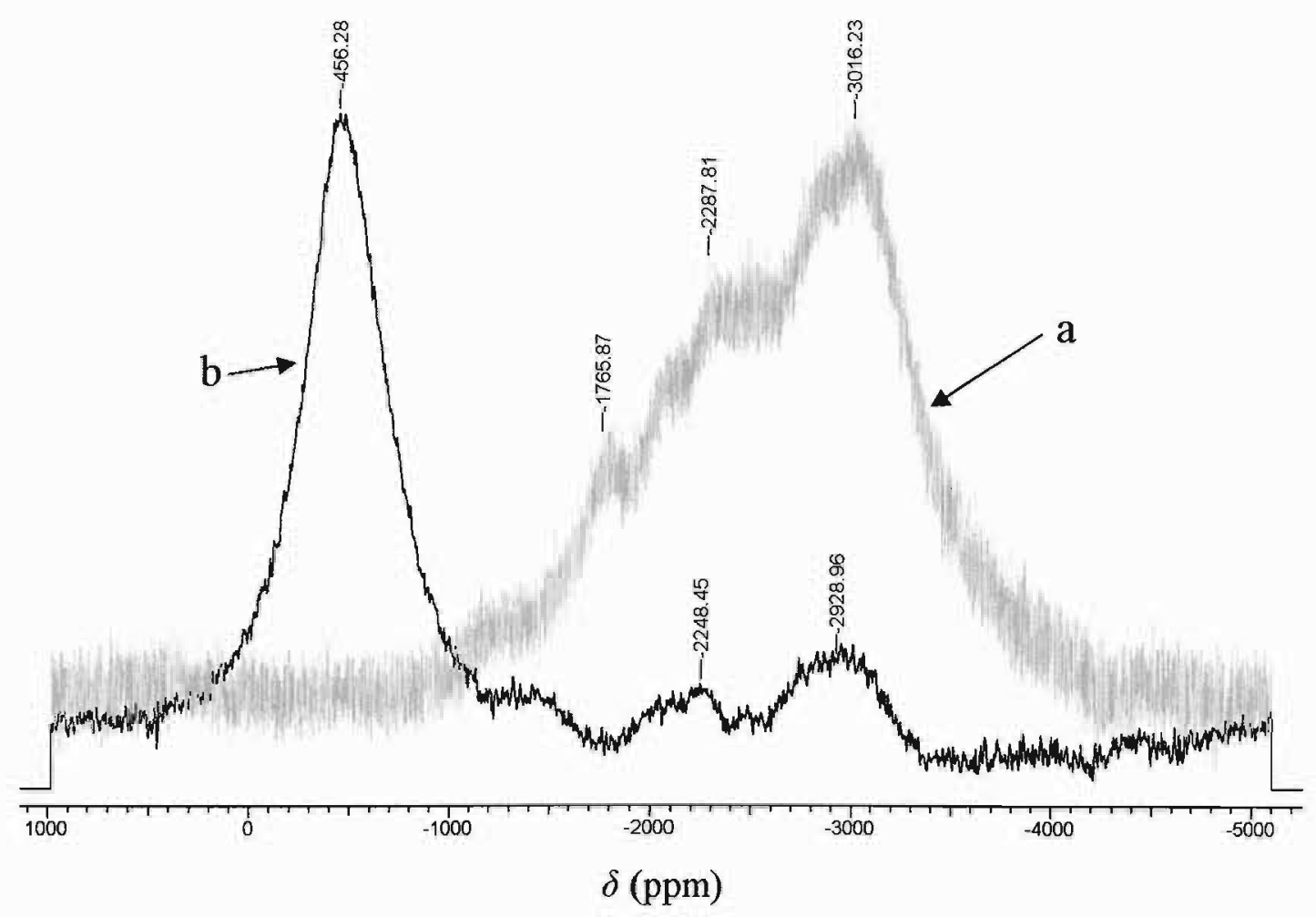

Figura 5.22. Espetro de $R M N^{5 I} V$ das amostras (a) CdVCe após $\mathrm{DH}$ e (b) $\mathrm{CeVO}_{4}$.

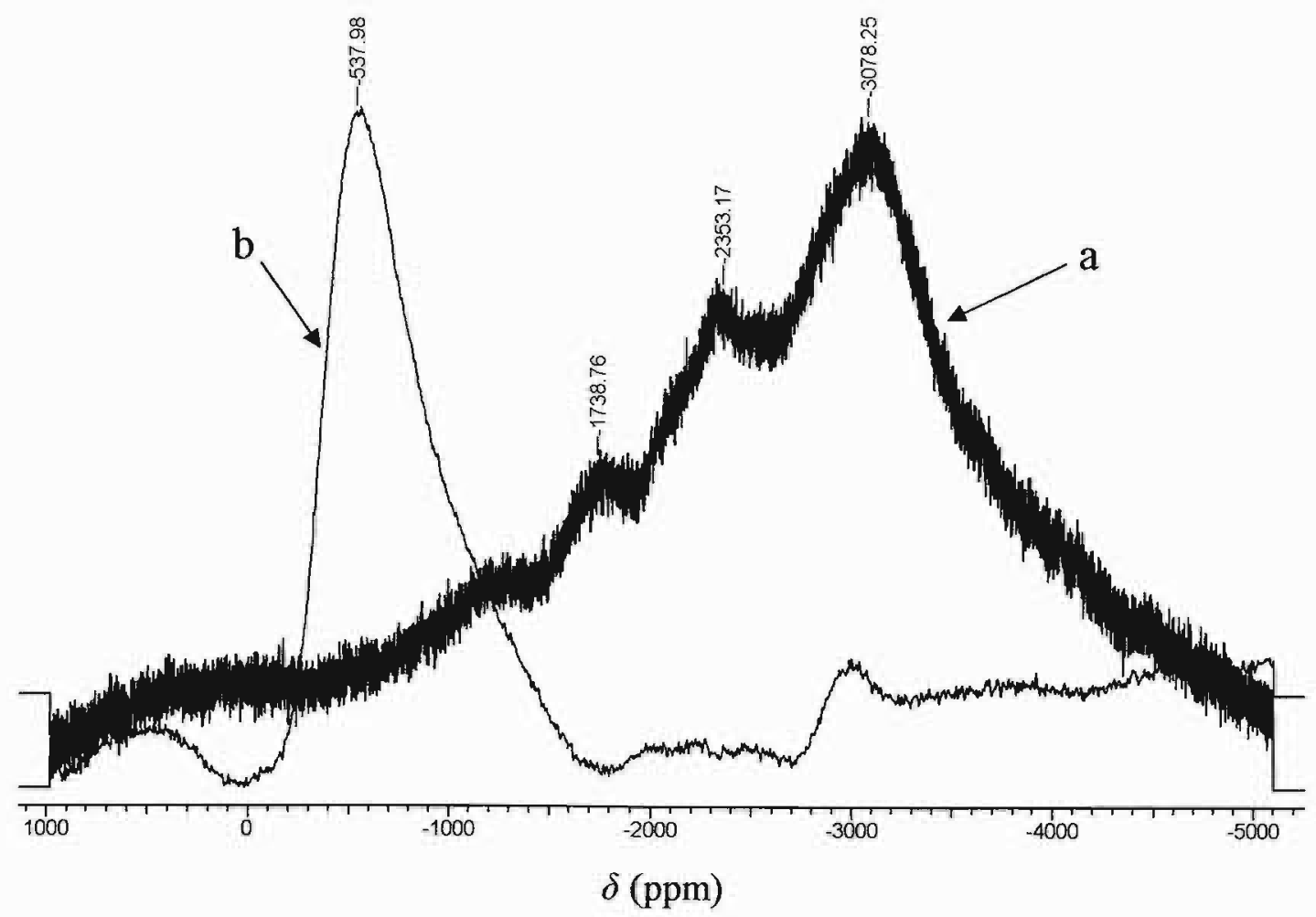

Figura 5.23. Espetro de $\mathrm{RMN}^{5 l} V$ das amostras (a) CdVNd após $\mathrm{DH}$ e (b) $\mathrm{NdVO}_{4}$. 
A Tabela 5.10 apresenta os deslocamentos químicos $(\delta)$ notados a partir dos espectros com as amostras. Através dos deslocamentos químicos, pôde ser comprovada a formação dos $\mathrm{TRVO}_{4}$ nas amostras. Verificou-se que as amostras de $\mathrm{LaVO}_{4}$ e $\mathrm{YVO}_{4}$ apresentaram um deslocamento químico caracterizado por uma banda intensa e definido entre -400 e $-700 \mathrm{ppm}$. Todas as amostras de catalisador, por sua vez, apresentaram uma banda larga entre -2800 e $-3080 \mathrm{ppm}$. As amostras CdVLa e CdVY apresentaram um pico definido, devido ao deslocamento químico coincidente com os respectivos $\mathrm{TRVO}_{4}$. As amostras CdVNd e CdVCe não apresentaram este deslocamento químico correspondente, entretanto, convém observar que a intensidade da banda nos espectros de $\mathrm{CeVO}_{4} \mathrm{e} \mathrm{NdVO}_{4}$ é menor que $\mathrm{LaVO}_{4}$ e $\mathrm{YVO}_{4}$. Talvez por isso, o $\mathrm{CeVO}_{4}$ e $\mathrm{NdVO}_{4}$ não tenham sido notados nos respectivos espectros das amostras CdVTR.

Tabela 5.10. Deslocamentos químicos das amostras sólidas analisadas por $R M N$ de ${ }^{5 l} V$, em ppm.

\begin{tabular}{lccccc}
\hline & $\mathrm{La}$ & $\mathrm{Ce}$ & $\mathrm{Nd}$ & $\mathrm{Y}$ & $\mathrm{V}$ \\
\hline TRVO $_{4}$ & -622 & ${ }^{(1)}-456$ & ${ }^{(1)}-538$ & -691 & ${ }^{(2)}-291,-1277,-1473$ \\
$\mathrm{CdVTR}$ & $-617,-2322,-2749$ & $-2250,-2928$ & $-1739,-2353,-3078$ & $-704,-3055$ & $(3)-1765,-2322,-3062$ \\
\hline $\begin{array}{l}\text { (1) } \\
\text { picos com baixa intensidade } \\
\text { deslocamentos do } \mathrm{V}_{2} \mathrm{O}_{5}\end{array}$ & & & & \\
(3) deslocamentos da amostra CdV & & & &
\end{tabular}

$\mathrm{O} \mathrm{V}_{2} \mathrm{O}_{5}$ apresentou uma banda nítida referente ao deslocamento químico por volta de -291 ppm. As amostras de catalisador incorporadas com V, por sua vez, não apresentaram este deslocamento químico. Portanto, é presumível que as espécies de V ocorram de forma isolada associadas à superficie das partículas.

\subsection{Espectroscopia foto-eletrônica de raios-X}

A principal característica desta técnica é a sensibilidade à superfície dos materiais estudados. O processo fundamental envolvido é o efeito foto-elétrico, em que o material é excitado com raios- $X$ de energia conhecida, e se mede a energia cinética de elétrons característicos produzidos pela interação dos fótons com o material estudado. Os fotoelétrons detectados durante a análise EFX têm sua origem nas últimas camadas da superfície, numa região entre 5 e $50 \AA$, dependendo das características do material e das condições de análise. Cada elemento possui um espectro particular cujos picos, com sua 
intensidade e energia características, estão diretamente associados à distribuição e densidade de elétrons nos seus orbitais. No espectro geral de uma amostra complexa aparece o conjunto completo de picos de cada um dos elementos presentes na superfície. A intensidade dos picos dos elementos que compõem a superficie está associada à composição e dispersão e sua energia de ligação e forma de linha ao seu estado químico [20].

A Figura 5.24 apresenta o espectro geral da amostra $\mathrm{Cd}$, destacando as linhas $\mathrm{O} 1 s$, $\mathrm{Al} 2 p$ e Si2 $p$. A Figura 5.25 apresenta o espectro geral da amostra CdVCe com destaque para as linhas $\mathrm{Ce} 3 d_{5}$ e V $2 p_{3}$ do espectro.

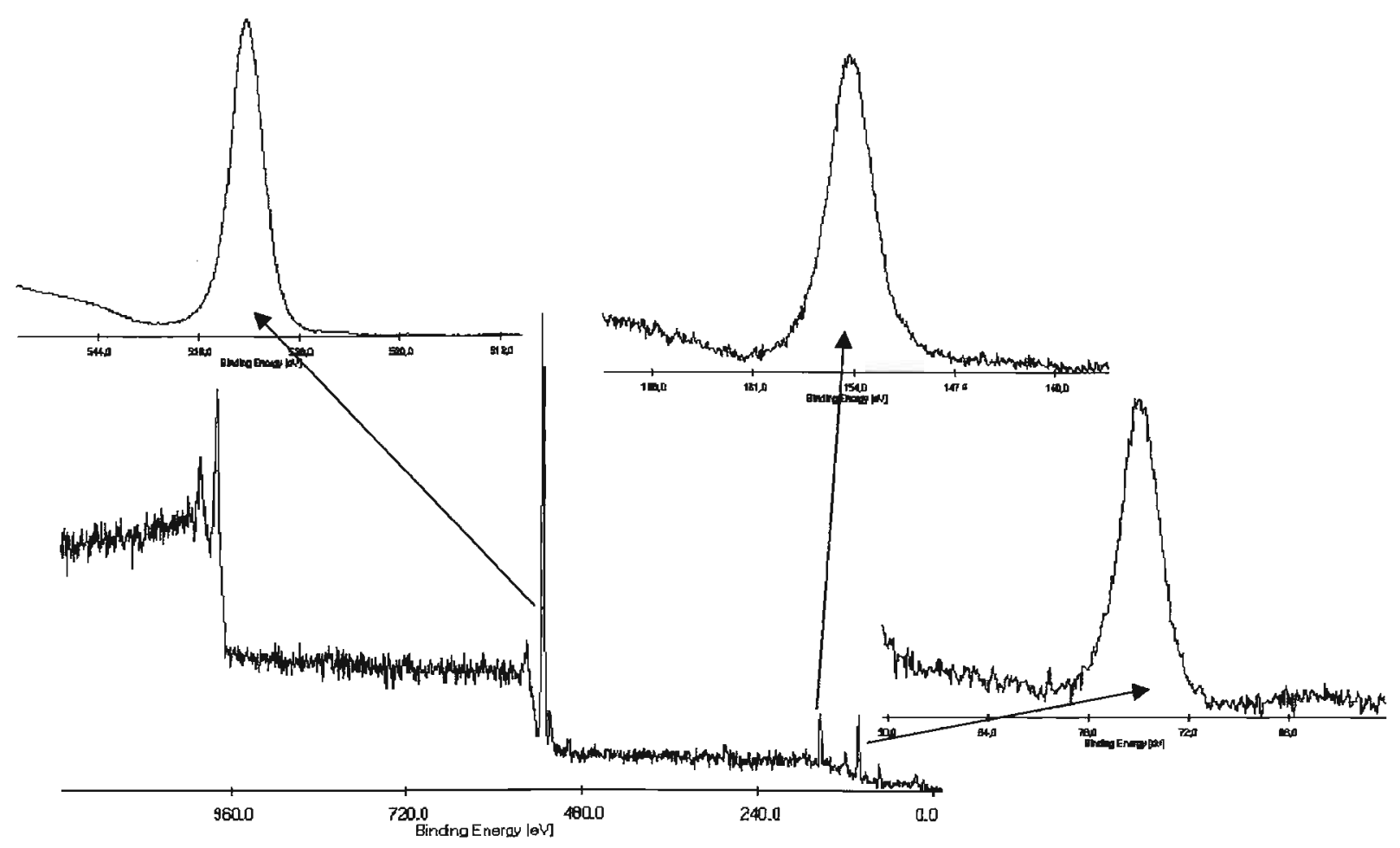

Figura 5.24. Espectros de EFX da amostra CaV. 


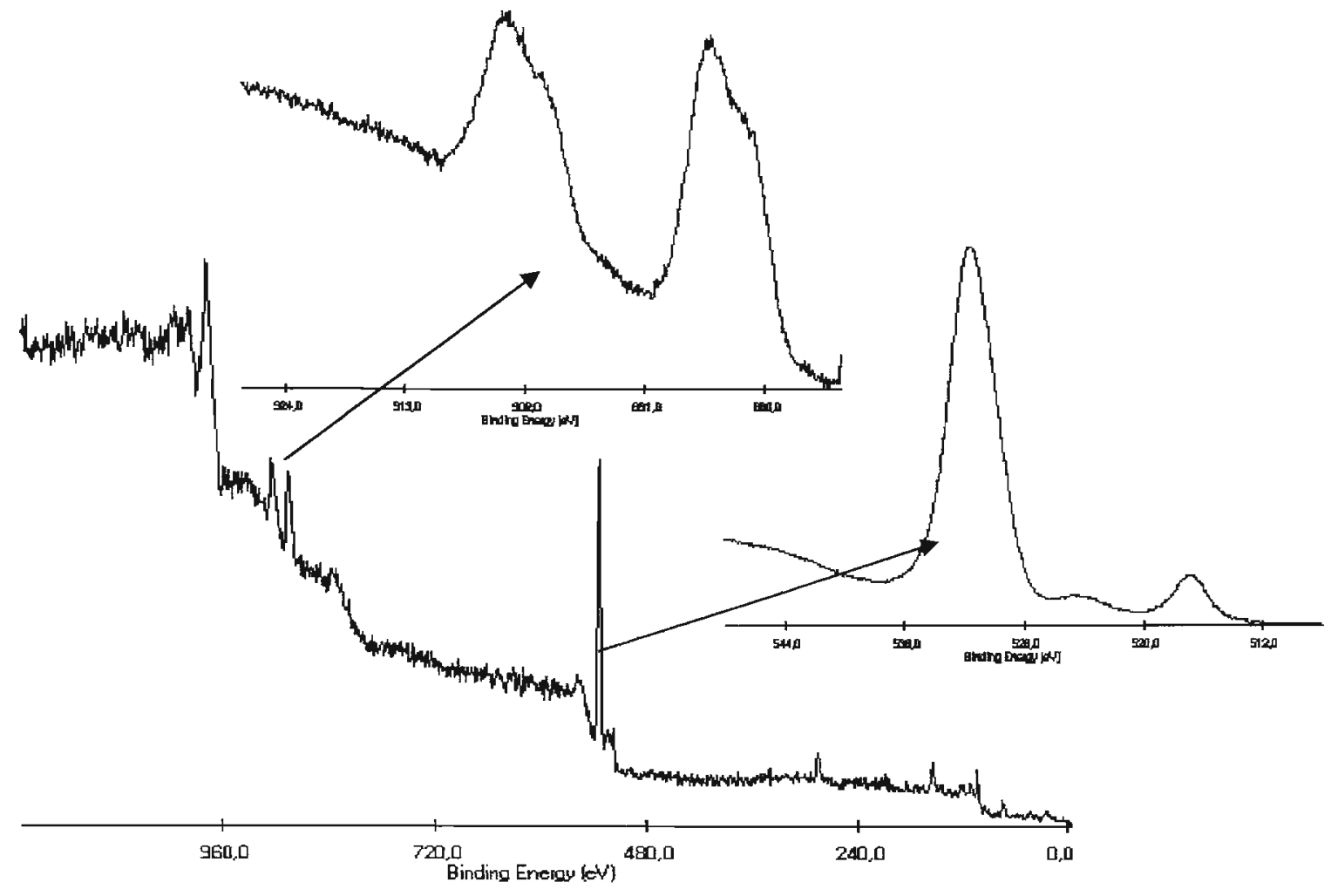

Figura 5.25. Espectros de EFX da amostra CdVCe.

A Tabela 5.11. mostra a concentração das espécies determinadas através da análise quantitativa de superfície. A concentração das amostras foi determinada integrando o pico referente à linha característica no espectro. Nota-se que as amostras CdVLa e CdVCe apresentaram a maior concentração de TR na superficie. Estas amostras foram as que estiveram mais concentradas de $\mathrm{V}$ também. A análise da amostra CdVNd encontrou uma quantidade desprezível de TR na superfície. As concentrações muito diferentes de TR e V notadas nas superficies das partículas por EFX são devidas às próprias condições experimentais da técnica, uma vez que a análise está restrita à uma determinada região aleatória que pode compreender espécies em concentrações distintas. A Figura 5.26 ilustra os limites da análise de EFX. 
Tabela 5.11. Concentrações atômicas (at) e mássicas (m) das superfícies das partículas analisadas por EFX.

\begin{tabular}{ccccccccccc}
\hline & \multicolumn{2}{c}{$\mathrm{O}$} & \multicolumn{2}{c}{$\mathrm{Si}$} & \multicolumn{2}{c}{$\mathrm{Al}$} & \multicolumn{2}{c}{$\mathrm{Y}$} & \multicolumn{2}{c}{ TR } \\
\hline & $a t$ & $m$ & $a t$ & $m$ & $a t$ & $m$ & $a t$ & $m$ & $a t$ & $m$ \\
\cline { 2 - 10 } Cd & 63,4 & 49,9 & 24,3 & 33,6 & 12,2 & 16,3 & - & - & - & - \\
CdV & 62,6 & 48,7 & 25,0 & 34,1 & 11,8 & 15,5 & 0,7 & 1,8 & - & - \\
CdVLa & 63,2 & 50,6 & 21,9 & 30,8 & 11,4 & 15,5 & 1,2 & 3,2 & 2,2 & 15,3 \\
CdVDy & 61,0 & 47,3 & 25,7 & 34,9 & 12,2 & 15,9 & 0,8 & 1,9 & 0,4 & 3,5 \\
CdVY & 57,5 & 44,1 & 29,3 & 39,4 & 11,8 & 15,3 & 0,5 & 1,2 & 0,9 & 3,8 \\
CdVCe & 62,7 & 50,1 & 19,0 & 26,7 & 12,5 & 16,9 & 2,5 & 6,3 & 3,3 & 23,1 \\
CdVYb & 64,1 & 50,8 & 23,4 & 32,5 & 11,2 & 15,0 & 0,7 & 1,7 & 0,5 & 4,6 \\
CdVGd & 64,0 & 50,8 & 20,9 & 29,1 & 13,9 & 18,6 & 0,6 & 1,4 & 0,7 & 5,4 \\
CdVNd & 62,7 & 48,8 & 23,6 & 32,2 & 12,9 & 16,9 & 0,8 & 2,1 & 0,0 & 0,0 \\
\hline
\end{tabular}

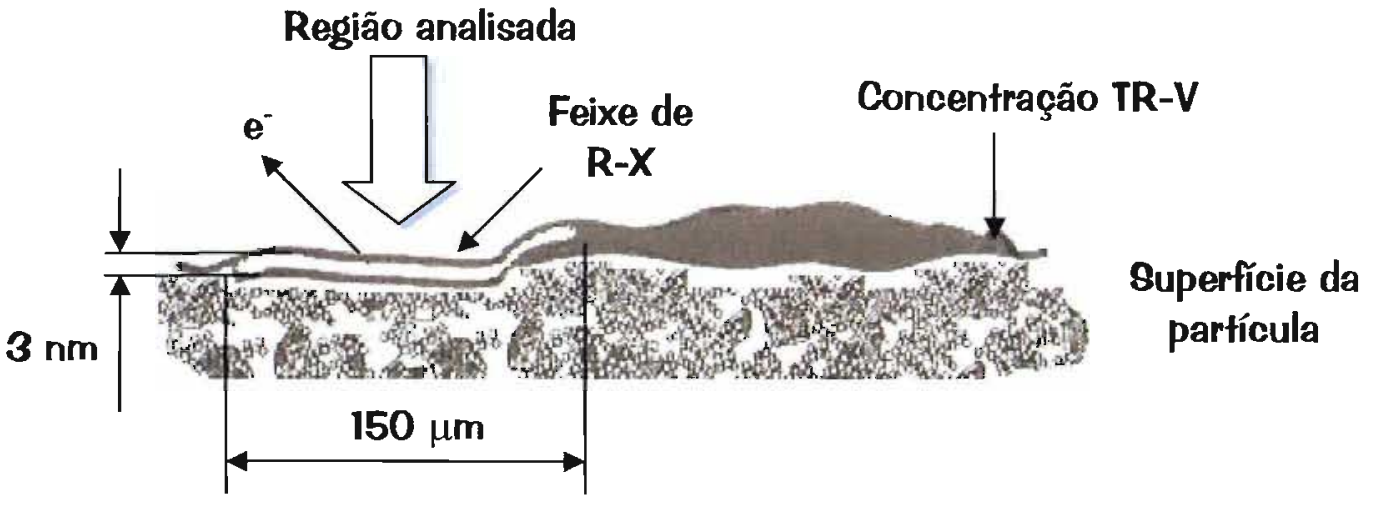

Figura 5.26. Limites da análise por $E F X$.

A Tabela 5.12 apresenta a relação $\mathrm{Si} / \mathrm{Al}$ das amostras analisadas. Verifica-se que as amostras incorporadas de $\mathrm{V}$ apresentam uma concentração de $\mathrm{Al}$ alta na superfície, tal como observado com os ensaios de MEV/EED. A Tabela 5.13 apresenta as energias de ligação características das linhas comuns entre as amostras estudadas no espectro de EFX, corrigidas com referência interna à linha $\mathrm{Al} 2 p=75 \mathrm{eV}$. 
Tabela 5.12. Relações atômicas Si/Al da superfície das partículas analisadas por EFX.

\begin{tabular}{cccccccccc}
\hline Amostra & $\mathrm{Cd}$ & $\mathrm{CdV}$ & $\mathrm{CdVLa}$ & CdVDy & CdVY & CdVCe & CdVYb & CdVGd & CdVNd \\
\hline SAR & 4,0 & 4,2 & 3,8 & 4,2 & 5,0 & 3,0 & 4,2 & 3,0 & 3,7 \\
\hline
\end{tabular}

Tabela 5.13. Energia de ligação das amostras de catalisador, em eV.

\begin{tabular}{ccccc}
\hline \multirow{2}{*}{ Amostra } & \multicolumn{3}{c}{ Linhas } \\
\cline { 2 - 4 } & $\mathrm{O} 1 s$ & $\mathrm{C} 1 s$ & $\mathrm{Si} 2 s$ & $\mathrm{~V} 2 p_{3}$ \\
\hline $\mathrm{Cd}$ & 532,3 & 284,6 & 154,3 & - \\
$\mathrm{CdV}$ & 534,4 & 285,1 & 154,5 & 517,6 \\
$\mathrm{CdVLa}$ & 532,1 & 284,9 & 154,2 & 517,6 \\
$\mathrm{CdVDy}$ & 532,2 & 284,4 & 154,3 & 517,3 \\
$\mathrm{CdVY}$ & 532,3 & 284,9 & 154,3 & 517,2 \\
$\mathrm{CdVCe}$ & 532,2 & 285,1 & 154,3 & 517,4 \\
$\mathrm{CdVYb}$ & 532,3 & 284,7 & 154,4 & 517,4 \\
$\mathrm{CdVGd}$ & 532,3 & 285,0 & 154,5 & 517,5 \\
CdVNd & 532,4 & 285,2 & 154,4 & 517,4 \\
\hline
\end{tabular}

A energia de ligação do elemento em determinado ambiente químico pode ser relacionada com o próprio estado químico da amostra. Para um determinado elemento, quanto menor a energia de ligação, menor o estado de oxidação correspondente [20]. A análise de EFX demonstrou que todo o $\mathrm{V}$ encontrado na superficie das partículas do catalisador encontrava-se como $\mathrm{V}^{5+}$. A Tabela 5.14 apresenta os valores de energia de ligação do orbital V2 $p_{3 / 2}$ do $\mathrm{V}$ e de alguns de seus óxidos obtidas da literatura [21-22]

Tabela 5.14. Energia de ligação de espécies de $V$, em eV.

\begin{tabular}{cc}
\hline Composto/Elemento & $\mathrm{V} 2 p_{3 / 2}$ \\
\hline $\mathrm{V}$ & 512,5 \\
$\mathrm{VO}^{+}$ & 513,5 \\
$\mathrm{~V}_{2} \mathrm{O}_{2}$ & 515,1 \\
$\mathrm{~V}_{2} \mathrm{O}_{3}$ & 515,7 \\
$\mathrm{VO}^{2+}$ & 516,3 \\
$\mathrm{~V}_{2} \mathrm{O}_{5}$ & 517,5 \\
\hline
\end{tabular}


A Tabela 5.15 apresenta as energias de ligação das TR analisadas nas amostras de catalisador. Através da análise das energias de ligação dos espectros com as amostras contendo TR, verifica-se que todas estas apresentam estado de oxidação (III). Não se observa Ce no estado de oxidação (IV). A quantificação de Ce (IV) em sistemas conjugados à alumina e atmosfera oxi-redutora foi caracterizada em trabalhos anteriores pela ocorrência de um pico no espectro com energia de ligação bem definida em $915 \mathrm{eV}$, não observado no presente trabalho (Figura 5.26) [23-24].

Tabela 5.15. Energia de ligação das linhas respectivas às TR das amostras incorporadas com os passivadores, em $\mathrm{eV}$.

\begin{tabular}{|c|c|c|c|}
\hline Amostra & \multicolumn{3}{|c|}{ Linha/energia de ligação } \\
\hline \multirow[t]{2}{*}{$\mathrm{CdVLa}$} & ${\mathrm{La} 3 d_{3}}$ & $\mathrm{La} 3 d_{5}$ & \\
\hline & 852,0 & 835,3 & \\
\hline \multirow[t]{2}{*}{ CdVDy } & Dy $3 d_{3}$ & Dy $3 d_{5}$ & \\
\hline & 1334,5 & 1296,0 & \\
\hline \multirow[t]{2}{*}{$\mathrm{CdVY}$} & $\mathrm{Y} 3 p_{1}$ & $\mathrm{Y} 3 p_{3}$ & \\
\hline & 313,2 & 301,4 & \\
\hline \multirow[t]{2}{*}{$\mathrm{CdVCe}$} & $\mathrm{Ce} 3 d_{3}$ & $\mathrm{Ce} 3 d_{5}$ & \\
\hline & 904,1 & 885,6 & \\
\hline \multirow[t]{2}{*}{$\mathrm{CdVYb}$} & ${\mathrm{Yb} 4 d_{3}}$ & $\mathrm{Yb} 4 d_{5}$ & \\
\hline & 200,0 & 185,8 & \\
\hline \multirow[t]{2}{*}{$\overline{\mathrm{CdVGd}}$} & $\mathrm{Gd} 3 d_{3}$ & $\mathrm{Gd} 3 d_{5}$ & $\mathrm{Gd} 4 d_{7}$ \\
\hline & 1219,3 & 1187,3 & 142,7 \\
\hline
\end{tabular}

\subsection{Atividade Catalítica}

A Tabela 5.16 apresenta os resultados do teste de atividade catalítica conduzido conforme condições descritas no item 4.2. A conversão mássica $\eta$, foi determinada conforme expressão [25]: 


$$
\eta(\%)=\frac{F-\left(\sum \text { não }- \text { convertidos }\right)}{F} \times 100
$$

onde: $F=$ massa de carga (gasóleo de petróleo) empregada.

Tabela 5.16. Rendimentos no teste de micro atividade das amostras após DH, em \%.

\begin{tabular}{cccccc}
\hline & Conversão & $\mathrm{C}_{3}-\mathrm{C}_{4}$ & $\mathrm{C}_{5}-\mathrm{C}_{12}$ & $\mathrm{H}_{2}$ & Coque \\
\cline { 2 - 4 } $\mathrm{Cd}$ & 49,2 & 7,8 & 34,2 & 0,01 & 2,2 \\
$\mathrm{CdV}$ & 15,2 & 1,8 & 8,9 & 0,31 & 2,4 \\
$\mathrm{CdVY}$ & 28,3 & 3,2 & 18,7 & 0,30 & 2,7 \\
$\mathrm{CdVLa}$ & 24,5 & 3,4 & 15,5 & 0,37 & 2,5 \\
$\mathrm{CdVCe}$ & 27,1 & 3,4 & 17,1 & 0,32 & 2,7 \\
$\mathrm{CdVNd}$ & 26,7 & 3,9 & 16,7 & 0,39 & 2,6 \\
$\mathrm{CdVGd}$ & 25,4 & 2,0 & 17,6 & 0,33 & 2,5 \\
$\mathrm{CdVDy}$ & 28,5 & 4,2 & 19,2 & 0,36 & 2,7 \\
$\mathrm{CdVYb}$ & 28,5 & 3,4 & 18,6 & 0,25 & 2,4 \\
$\mathrm{CdNd}$ & 63,5 & 12,9 & 42,4 & 0,12 & 5,6 \\
\hline
\end{tabular}

Observa-se que a conversão foi muito diminuída após a inserção de V seguida de $\mathrm{DH}$, indicando que o ataque à estrutura do catalisador compromete sobremodo o desempenho catalítico do material. O emprego dos complexos de TR como passivadores preservou a conversão, em alguma extensão. Entretanto, corroborando os resultados de outros trabalhos [26], não foram notadas mudanças expressivas na seletividade aos produtos do catalisador em função da TR ora empregada. A amostra $\mathrm{CdNd}$ incorporada exclusivamente do passivador $\mathrm{Nd}$ (na ausência de $\mathrm{V}$ ) e submetida à $\mathrm{DH}$ apresentou maior conversão que o catalisador original $\mathrm{Cd}$. Isso ocorre em função das propriedades das TR que incrementam as reações de craqueamento por intermédio do aumento da acidez no meio e das reações de transferência de hidrogênio $(\mathrm{TH})$. Em conseqüência destes efeitos promovidos pela $\mathrm{TR}$, o teor de coque de $\mathrm{CdNd}$ também se apresentou maior que todas as amostras incorporadas de $\mathrm{V}$. 
$\mathrm{O}$ rendimento de $\mathrm{H}_{2}$ não foi minimizado na presença dos passivadores. De fato, além de promover ataque à estrutura cristalina do catalisador, o $\mathrm{V}$ promove um efeito desidrogenante, porém em menor proporção que o Ni. O teor de coque gerado foi similar em todas as amostras, menos em CdNd. Ao mesmo tempo em que a redução da conversão diminui o rendimento de coque, a presença de TR produz mais coque em virtude do aumento das reações de transferência de hidrogênio. 


\section{Referências Bibliográficas}

[1] J. Scherzer, “Octane-Enhancing, Zeolite FCC Catalysts: Scientific and Technical Aspects”, Catal. Rev.-Sci. Eng., 31/3 (1989) 215.

[2] V.E. Karasev, N.I. Steblevskaya, E.T. Karaseva, "Thermal Decomposition of Hydrated Europium Acetylacetonate”, Russ. J. Inorg. Chem., 22 (1977) 1762.

[3] L.A. Pine, "Vanadium-Catalyzed Destruction of USY Zeolites", J. Catal., 125 (1990) 514.

[4] M. F. Hazenkamp, G. Blasse, "A Luminescence Spectroscopy Study on Supported Vanadium and Chromium Oxide Catalysts", J. Phys. Chem., 96 (1992) 3442.

[5] G. L. Baugis, H. F. Brito, W. Oliveira, F. R. Castro, E. F. Sousa-Aguiar, "The Luminescent Behavior of the Steamed EuY Zeolite Incorporated with Vanadium and Rare Earths Passivators" Microporous and Mesoporous Materials, 49 (2001) 179.

[6] S. Lee, H. Hwang, P. Kim, D.J. Jang, "Time-resolved Eu Luminescence Spectra and Kinetics at Various Y Zeolitic Enviroments”, Catalysis Letters 57 (1999) 221.

[7] J.-C. G. Bunzli, in: Lanthanide Probes in Life, Chemical and Earth Sciences, eds J.-C. G. Bunzli, and G.R. Choppin, Amsterdam, Elsevier, 1989, ch7.

[8] H.F. Brito, G.K. Liu, "Crystal field influence on the S-8(7/2) ground state splitting of $\mathrm{Bk}^{4+}$ in $\mathrm{CeF}_{4}$ ", J. Phys. Chem., 112 (2000) 4334.

[9] O.L. Malta, H.F. Brito, J.F.S. Menezes, F.R. Gonçalves e Silva, S. Alves Jr., F.S. Farias Jr. and A.V.M. de Andrade, "Spectroscopy Properties of a New Light-Converting Device Eu(thenoyltrifluoroacetonate) ${ }_{3}$ 2(Dibenzyl sulfoxide). A Theoretical Analysis Based on Structural Data Obtained from a Sparkle Model”, J. Luminescence, 75(3) (1997) 255.

[10] W.T. Carnall, H. Crosswhite and H.M. Crosswhite, "Energy Structure and Transition Probabilities of the Trivalent Lanthanides in $\mathrm{LaF}_{3}$ ", Argonne National Laboratory Report, relatório interno, 1977

[11] O.L. Malta, S.J.L. Ribeiro, M.Faucher and P. Porcher, "Theoretical Intensities of $4 f$ $4 f$ Transitions Between Stark Levels of the Eu3+ Iion in Crystal", J. Chem. Phys Solids, 52 (1991) 587.

[12] B.R. Judd, Phys Rev., "Optical Absorption Intensities of Rare Earth Ions", 127 (1962) 750 . 
[13] O.L. Malta, "Some Theoretical Investigations In Crystal Field Theory", Mol. Phys. 42 (1) (1981) 65 .

[14] I.L. Moudrakovski, A. Sayari, C.I. Ratcliffe, J.A. Ripmeester, K.F. Preston, "Vanadium-modified Zeolite with the Structure of ZSM-12: EPR and RMN Studies", J. Phys. Chem., 98 (1994) 10895.

[15] G. Catana, R.R. Rao, B.M. Weckhusyen, P. van der Voort, E. Vansant, R. A. Schoonheydt, "Supported Vanadium Oxide Catalysts: Quantitative Spectroscopy, Preferential Adsorption of $\mathrm{V}^{4+} \mathrm{V}^{5+}$, and $\mathrm{Al}_{2} \mathrm{O}_{3}$ Coating of Zeolite $\mathrm{Y}^{\prime \prime}$, J. Phys. Chem. B, 102 (1998) 8005.

[16] M.W. Anderson, M.L. Occelli, S.L. Suib, "Tin Passivation of Metal-Contaminated Fluid Cracking Catalysts: Electron Paramagnetic Resonance Studies”, J. Catal., 122 (1990) 374.

[17] C.A. Trujillo, "Desarrollo de Passivadores de Vanadio para Catalizadores de Ruptura Catalítica", Tese de Doutoramento, Facultad de Ciências, Universidad Nacional de Colombia, Santafé de Bogotá, 1996.

[18] A.A. Shubin, O.B. Lapina, D. Courcot, "Characterization by Solid State ${ }^{51} V$ RMN Spectroscopy”, Catal. Today 56 (2000) 379.

[19] Y.B. Taarit, J. Fraissard, in "Catalyst Characterization: Physical Techniques for Solid Materials", ed. B.Imelik and J.C. Vendrine, Plenum Press, New York (1994) p 91.

[20] M.J.B. Cardoso, "Fundamentos da Espectroscopia de Fotoelétrons", Comunicação Técnica - THPE N003/2001, Rio de Janeiro, Petrobrás, 2001.

[21] J.F. Moulder, "Handbook of X-ray Photoelectron Spectroscopy", J. Chastain ed, Philadelphia, Physical Electronics Inc., 1995.

[22] C.D.Wagner, "Standard Reference Database 20 - X-Ray Photoelectron Spectroscopy Database Version 1.01"; Gaithersburg, National Institute of Standards and Technology, NIST, MD 20899, 1989.

[23] J.Z. Shyu, W.H. Weber, H.S. Gandhi, "Surface Characterization of AluminaSupported Ceria", J. Phys. Chem., 9102 (1988) 4964.

[24] M. Romeo, K. bak, J.El Fallah, F.Le Normand, L. Hilarie, "XPS Syudy of Cerium Dioxide”, Surf. Interf. Anal., 20 (1993) 508.

[25] R. Sadeghbeigi, "Fluid Catalytic Cracking Handbook", Texas, Gulf Publishing Company, 1995, p138. 
[26] G. de la Puente, E.F Souza-Aguiar, F.M.Z. Zotin, V.L.D. Camorim, U. Sedran, "Influence of Different Rare Earth Ions on Hydrogen Transfer Over Y zeolite", Appl. Catal., 197 (2000) 41. 


\section{Análise e Discussão}

Os resultados das propriedades texturais indicaram que a presença de vapor durante a $\mathrm{DH}$ é fundamental no mecanismo de ataque do $\mathrm{V}$ à estrutura cristalina do catalisador. Através dos resultados obtidos por RPE e EFX verificou-se que a quantidade de V incorporada está quase totalmente no estado de oxidação (V), após a calcinação seguida de DH. Uma pequena fração está ainda preservada no estado de oxidação (IV), provavelmente, devido à troca iônica com outros cátions nos sítios mais internos da estrutura zeolítica, conforme verificado por Trujillo [1].

O V incorporado ao catalisador através do complexo apresenta geometria octaédrica. A adsorção preferencial de $\mathrm{V}$ na superficie do catalisador multicomponente, tal como o sistema aqui estudado, foi estabelecida por Catana et al., conforme a seqüência: $\mathrm{Al}_{2} \mathrm{O}_{3}>\mathrm{USY} \approx \mathrm{SiO}_{2}[2]$. A atração eletrostática entre o $\mathrm{V}^{4+}$ e a superfície da alumina $\left(\mathrm{AlO}_{4}{ }^{-}\right)$ é mais pronunciada entre as outras, em função do caráter ácido-base da interação. Além disso, um ligante oxigênio na superfície da alumina pode ser coordenado ao complexo estabilizando a geometria octaédrica da estrutura.

A oxidação $\left(\mathrm{V}^{4+} \rightarrow \mathrm{V}^{5+}+\mathrm{e}^{-}\right)$provocada no tratamento térmico leva o $\mathrm{V}^{5+}$ a uma geometria tetraédrica e o associa aos oxigênios da superficie dos componentes do catalisador. As unidades de $\mathrm{VO}_{4}{ }^{3-}$, assim formadas, na presença de água durante a $\mathrm{DH}$, dão origem ao $\mathrm{H}_{3} \mathrm{VO}_{4}$. $\mathrm{O}$ ácido formado neste ambiente é forte $\left(\mathrm{pKa}=0,05\right.$ a $25^{\circ} \mathrm{C}$ [3] $)$ e tem a propriedade de acelerar a destruição da estrutura por meio da lixiviação do $\mathrm{Al}$ da rede cristalina da zeólita ou da alumina matriz. O Al atacado pelo $\mathrm{V}$ concentra-se na superficie e é responsável pela sinterização entre as partículas, conforme visto nos ensaios por MEV/EED. Cheshnitskii et al. estudaram o equilíbrio de fase do sistema $\mathrm{Al}_{2} \mathrm{O}_{3}-\mathrm{V}_{2} \mathrm{O}_{5} \mathrm{e}$ verificaram que o $\mathrm{AlVO}_{4}$ formado desta interação se decompõe quando submetido a temperaturas superiores a $750^{\circ} \mathrm{C}$ [4]. É conhecido que o tempo empregado de $\mathrm{DH}$ na 
presença de $\mathrm{V}$ influencia diretamente a destruição da estrutura cristalina do catalisador [5]. Portanto, embora a reação entre $\mathrm{V}$ e $\mathrm{Al}$ ocorra sob as condições estudadas, esta interação não é suficiente para imobilizar completamente o $\mathrm{V}$ e proteger a zeólita, devido à instabilidade térmica dos compostos formados, conforme demonstra a Equação 6.1.

$$
2 \mathrm{AlVO}_{4} \rightleftharpoons \mathrm{Al}_{2} \mathrm{O}_{3}+\mathrm{V}_{2} \mathrm{O}_{5}
$$

A interação entre o $\mathrm{V}^{5+}$ e água, sob condições similares, foi caracterizada por Wormsbecher et al. [6] e Occelli [7], e se concluiu que ocorre a formação de espécies como $\mathrm{H}_{3} \mathrm{VO}_{4}$ e $\mathrm{H}_{4} \mathrm{~V}_{2} \mathrm{O}_{7}$ por hidratação do óxido $\left(\mathrm{V}_{2} \mathrm{O}_{5}\right)$ formado. Estes ácidos apresentariam uma alta mobilidade no meio, pois na temperatura de $\mathrm{DH}$ são voláteis, e assim potencializam a dispersão do V pelo meio.

Observa-se que o catalisador pré-desativado $(\mathrm{Cd})$ tem maior capacidade de resistir ao ataque por $\mathrm{V}$ que o catalisador fresco (C). Isto ocorre em função da presença do $\mathrm{Al}$ extra-estrutural (EFAl) gerado na $\mathrm{DH}$, que atenua o ataque promovido pelo $\mathrm{V}$ à estrutura cristalina. A Figura 6.1 apresenta o esquema pelo qual o ataque das espécies de $\mathrm{V}$ é mitigado pelo $\mathrm{Al}$ extra-estrutural coordenado à zeólita. Os passivadores de TR apresentam uma relativa capacidade de preservar a estrutura do catalisador pré-desativado, mas não foram efetivos com o catalisador fresco.

Quando incorporados por meio de soluções com os complexos tris-acetilacetonatos, os passivadores se distribuem melhor sobre a superficie das partículas, permitindo uma interação mais otimizada com o $\mathrm{V}$, embora sejam decompostos aos óxidos correspondentes na $\mathrm{DH}$. Quando os passivadores são incorporados por meio dos óxidos, por sua vez, o contato com o V é diminuído por possuírem sob tal forma determinado tamanho de partícula. Essas diferenças de contato e dispersão sobre a superficie influenciam em alguma extensão a capacidade de passivação dos elementos. A decomposição térmica dos complexos aos respectivos óxidos de TR sobre o catalisador não promove ataque à estrutura, mesmo produzindo compostos intermediários de caráter ácido. A deposição dos passivadores por meio dos complexos, entretanto, proporciona um ligeiro bloqueio dos poros do catalisador. 


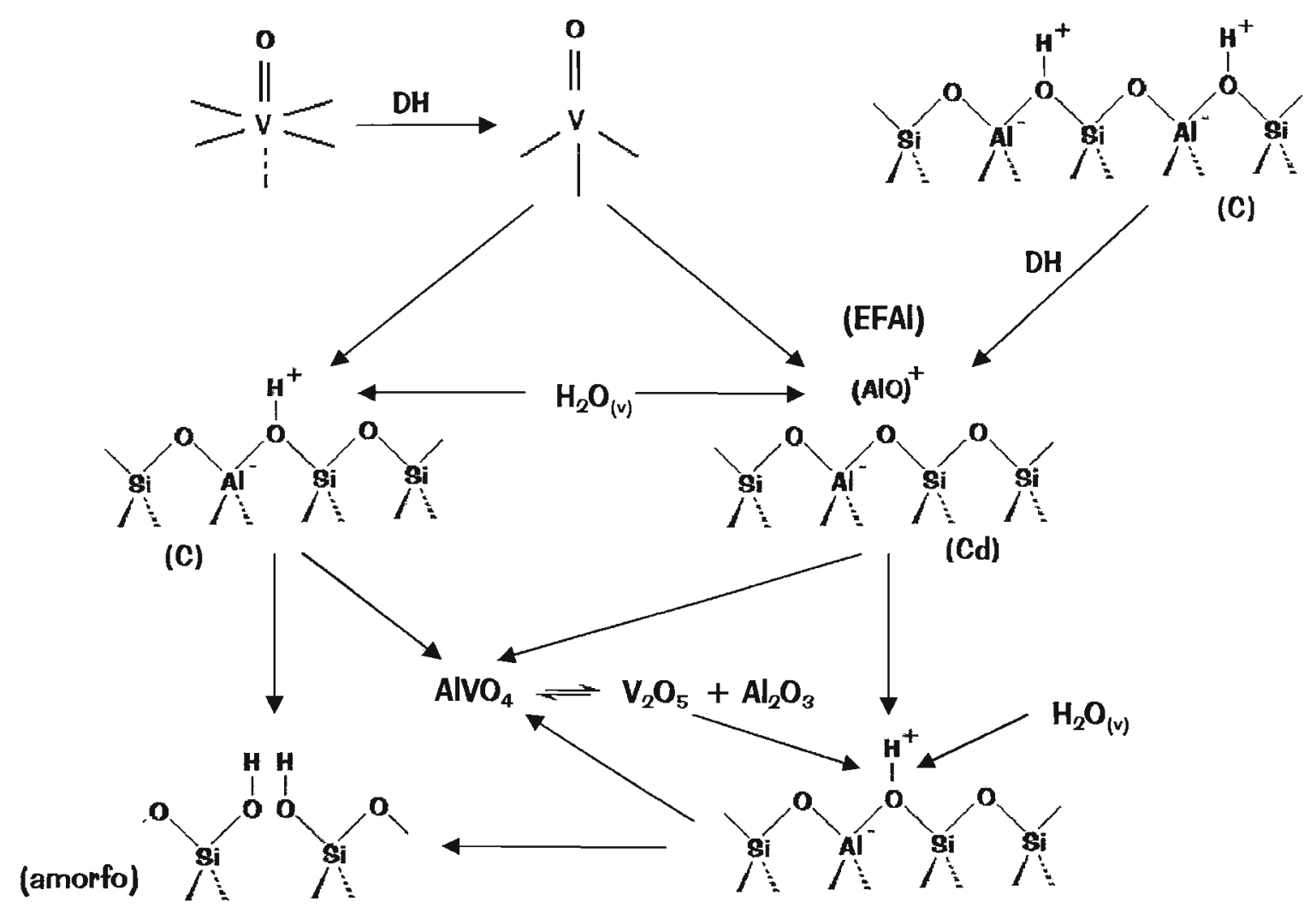

Figura 6.1. Ataque do $V$ à zeólita na presença o Al extra-estrutural gerado na DH.

Através dos ensaios de MEV/EED foi observado que os passivadores possuem uma reduzida permeabilidade ao interior das partículas do catalisador, mesmo quando incorporados através dos complexos, encontrando-se concentrados na superfície. De maneira distinta, o $\mathrm{V}$ proporciona uma distribuição quase homogênea entre o centro e a periferia das partículas. Assim, a interação entre TR e V ocorre principalmente na superfície externa da partícula. A Figura 6.2 ilustra a distribuição dos elementos sobre as partículas em função da diferença entre a mobilidades dos elementos. A decomposição dos complexos de TR e dos passivadores não ocorre simultaneamente, como se percebe através dos perfis de decomposição na análise térmica demonstrada no Capítulo 4 . O complexo de $\mathrm{V}$ empregado decompõe-se totalmente ao óxido em uma temperatura menor que os complexos de TR, fato este que contribui para o maior espalhamento do $\mathrm{V}$ sobre os componentes do sistema. A distribuição do $\mathrm{V}$ é ainda potencializada, uma vez que o $\mathrm{V}_{2} \mathrm{O}_{5}$ gerado se encontra líquido na temperatura dos testes, e também é transportado por meio das espécies ácidas hidrolisadas pelo vapor de água durante a $\mathrm{DH}$. 

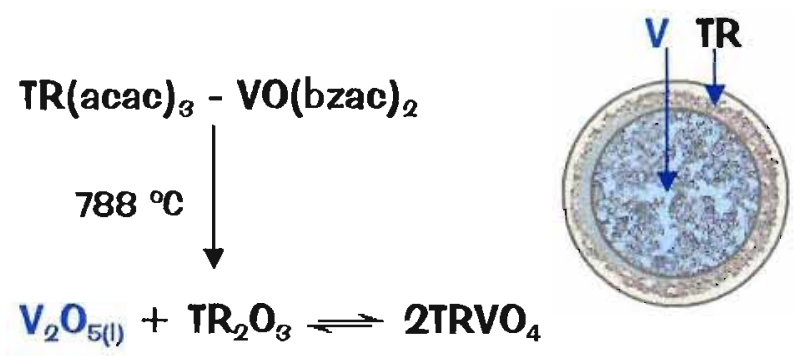

Figura 6.2. Permeação dos elementos de TR e V sob a estrutura do catalisador.

$\mathrm{O}$ emprego de TR, especialmente $\mathrm{Ce}$ e $\mathrm{Yb}$, como passivadores não influencia o estado de oxidação final de $\mathrm{V}$ após a $\mathrm{DH}$. Por meio dos ensaios de EFX, verificou-se que todas as TR apresentavam-se no estado (III). Moreira observou que sob condições similares ao estudo aqui conduzido, o $\mathrm{V}^{5+}$ seria reduzido na presença de $\mathrm{Ce}^{3+}$ conforme Equação 6.2 [8]. Contudo, nas condições propostas neste trabalho, tal efeito não foi verificado.

$$
\mathrm{Ce}^{3+}+\mathrm{VO}_{4}^{3-}+4 \mathrm{H}_{2} \mathrm{O} \rightarrow \mathrm{Ce}^{4+}+\mathrm{V}^{4+}+8 \mathrm{OH}^{-}
$$

Considerando os resultados das propriedades texturais (Tabela 5.2), verifica-se que as TR testadas proporcionam desempenhos ligeiramente diferentes, no que se refere à preservação da estrutura zeolítica frente ao ataque proporcionado pelo V. Avaliando-se estatisticamente os resultados, a um nível de significância de $95 \%$, pode-se afirmar que as áreas superficiais das amostras são diferentes. A tabela 6.1 apresenta a análise de variâncias do conjunto de amostras CdVTR, considerando o ensaio de análise de área superficial, $\operatorname{com} n=4$. Como $f_{0}>f$ crítico, conclui-se que a média das amostras são diferentes [9].

Tabela 6.1. Tabela de análise de variância (ANOVA) para o ensaio de análise de área superficial com as amostras CdVTR.

\begin{tabular}{ccccccc}
\hline Fonte da variação & $\Sigma \mathrm{Q}$ & $v$ & $\mathrm{MQ}$ & $f_{0}$ & valor-p & $f$ crítico \\
\hline Entre grupos & 3127 & 6 & 521 & 15,8 & $7,89 \mathrm{E}-07$ & 2,57 \\
Dentro dos grupos & 689 & 21 & 32,8 & & & \\
\hline Total & 3816 & 27 & & & & \\
\hline
\end{tabular}


A Figura 6.3 apresenta os intervalos para a média da área superficial das amostras com $95 \%$ de confiança. Observa-se que o resultado de CdVY é diferente de CdVLa e CdVYb, mas não pode ser considerado diferente dos demais. Excetuando o resultado da amostra CdVY, não se pode afirmar que os resultados das amostras sejam diferentes entre si.

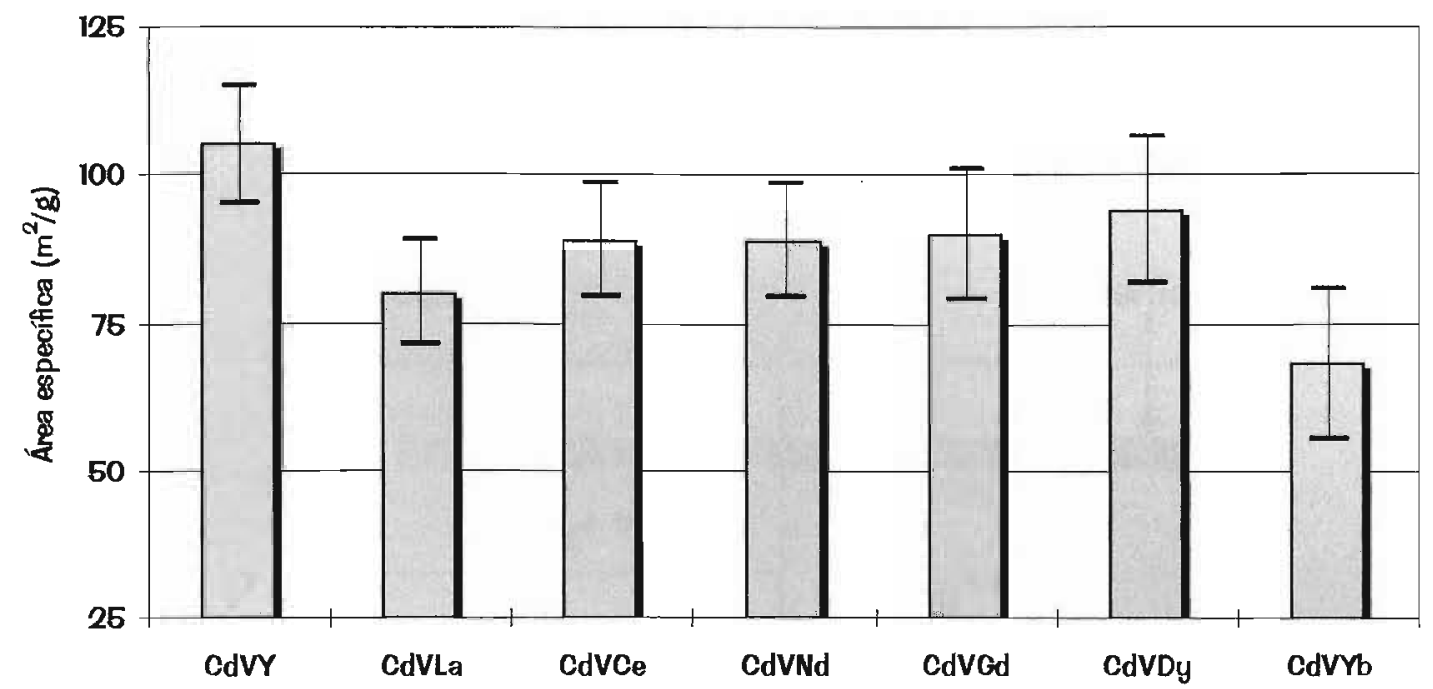

Figura 6.3. Resultados de área superficial BET das amostras submetidas à DH com os respectivos intervalos com $95 \%$ de confiança para média.

Os processos de calcinação e $\mathrm{DH}$ promovem a decomposição térmica dos complexos aos respectivos óxidos. De acordo com os diagramas de fases do sistema $\mathrm{TR}_{2} \mathrm{O}_{3}-\mathrm{V}_{2} \mathrm{O}_{5}$ estudados por Brusset et al. [10], a reação entre estes óxidos na temperatura da DH conduz a formação de ortovanadatos de TR em uma extensão determinada pelo elemento empregado. A presença de $\mathrm{TRVO}_{4}$ nos sistemas estudados neste trabalho foi comprovada através dos experimentos de $\mathrm{RMN}$ de ${ }^{51} \mathrm{~V}$. O TRVO $\mathrm{TR}_{4}$ produzido na reação tem alta estabilidade térmica e química, mantendo assim o $\mathrm{V}$ sob uma forma inócua no que concerne ao ataque à estrutura do catalisador. A Figura 6.4 apresenta os diagramas de fase para o sistema empregando $\mathrm{La}$ e $\mathrm{Nd}$. A região indicada no gráfico representa a temperatura alcançada nos experimentos e a provável concentração dos compostos entre o centro e a periferia das partículas. 

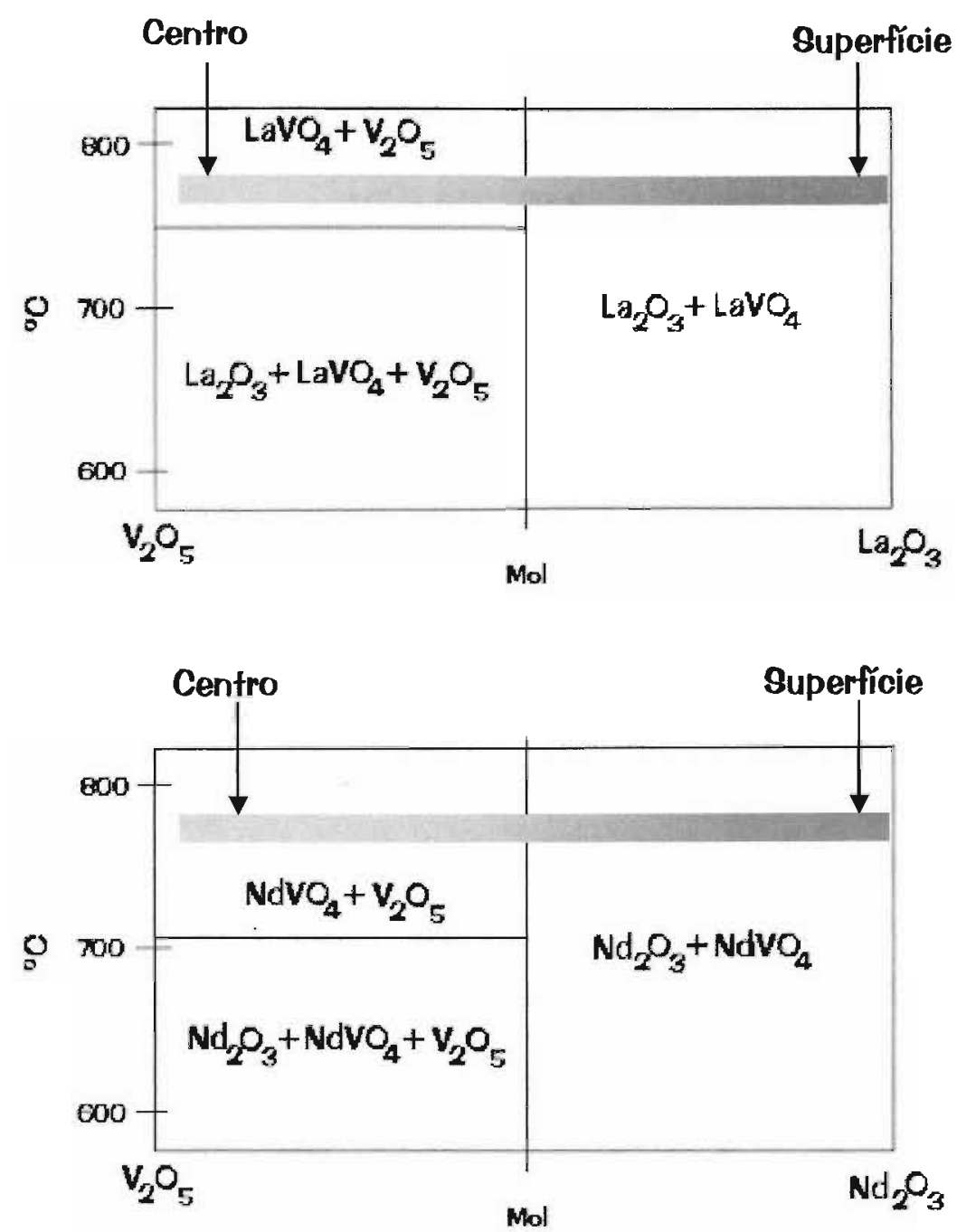

Figura 6.4. Diagramas de fases para o sistema $\mathrm{TR}_{2} \mathrm{O}_{3}-\mathrm{V}_{2} \mathrm{O}_{5}(\mathrm{TR}=L \mathrm{La}, \mathrm{Nd})[10]$.

Como pode ser verificada nos diagramas, a reação completa para a obtenção de $\mathrm{TRVO}_{4}$ é alcançada com temperaturas superiores a $700^{\circ} \mathrm{C}$ em um domínio com excesso de $\mathrm{V}_{2} \mathrm{O}_{5}$. Observa-se também que para o $\mathrm{LaVO}_{4}$ a temperatura requerida para reação completa é superior ao $\mathrm{NdVO}_{4}$. Convém ressaltar que a quantidade estequiométrica dosada dos passivadores foi desnecessária, posto que todo o conteúdo de TR incorporado ao sistema não esteve completamente em contato com o $\mathrm{V}$, devido às diferentes mobilidades pelo meio.

A magnitude do processo reacional: $\mathrm{TR}_{2} \mathrm{O}_{3}+\mathrm{V}_{2} \mathrm{O}_{5} \rightarrow 2 \mathrm{TRVO}_{4}$, pode ser descrita pelas relações fundamentais da termodinâmica clássica: 


$$
\begin{aligned}
& \ln K=-\frac{\Delta G}{R T} \\
& \Delta G=\Delta H-T \Delta S
\end{aligned}
$$

As Equações 6.3 e 6.4 estabelecem a relação entre a constante de equilíbrio $K$ da reação e a energia livre de Gibbs $(\Delta G)$ no processo. Esta energia, por sua vez, determina a extensão que as reações procedem em função das variações das propriedades termodinâmicas intrínsecas - entalpia $(\Delta H)$ e entropia $(\Delta S)$.

Mullica et al. estabeleceram a estrutura cristalográfica dos $\mathrm{TRVO}_{4}$ por meio de difração de raios-X e refinamento da análise pelo método de Rietveld [11]. A estrutura dos $\mathrm{TRVO}_{4}$ é tetragonal e assemelha-se a zirconita. $\mathrm{O}$ átomo de TR é circundado por oito átomos de oxigênio, 4 mais próximos que os outros. $\mathrm{O}$ átomo de $\mathrm{V}$ está inserido em um tetraedro de oxigênios. A Figura 6.5 mostra a estrutura. $O$ tamanho da célula unitária e a as distâncias interespaciais variam ligeiramente em função do raio iônico do elemento de TR.
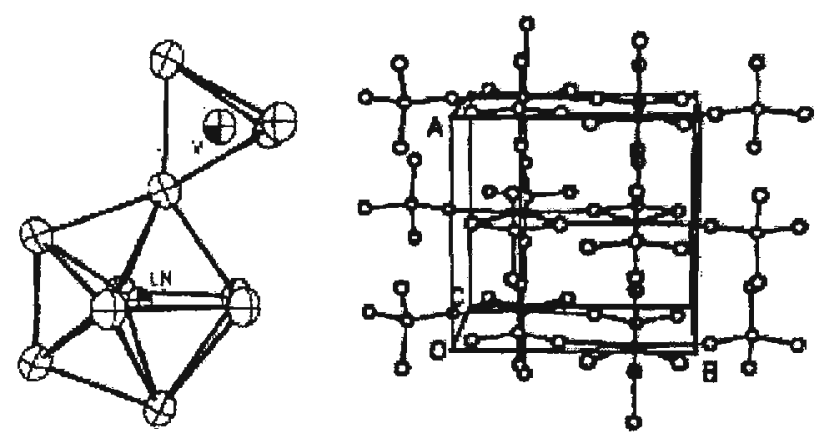

Figura 6.5. Disposição estrutural do $\mathrm{TRVO}_{4}[11]$.

A variação de entropia envolvida na reação de formação do $\mathrm{TRVO}_{4}$ pode ser considerada insignificante, uma vez que o processo se dá em estado sólido e a amplitude de vibração dos átomos em retículos cristalinos rígidos, como o caso, é pequena. Assim como nos ortovanadatos, Westrum descreveu como irrelevante a contribuição da componente entropia na energia livre de formação dos óxidos de TR, diante da magnitude da variação de entalpia [12]. 
A variação de entalpia na reação entre os óxidos de $\mathrm{TR}$ e $\mathrm{V}_{2} \mathrm{O}_{5}$ pode ser determinada experimentalmente, por meio de técnicas de análise térmica. A Tabela 6.2 apresenta $\Delta H f^{\circ}$ de alguns ortovanadatos de TR determinados nos trabalhos de Zielinski e Skupin [13] e Rykova et al. [14-15].

Tabela 6.2. $\Delta H f^{\circ}$ de $\mathrm{TRVO}_{4}$, em $-\mathrm{k} J . \mathrm{mol}^{l}$.

\begin{tabular}{lccccccccccc}
\hline $\mathrm{Y}^{(37)}$ & $\mathrm{La}^{(37)}$ & $\mathrm{Nd}^{(37)}$ & $\mathrm{Sm}^{(37)}$ & $\mathrm{Gd}^{(37)}$ & $\mathrm{Dy}^{(37)}$ & $\mathrm{Ho}^{(38)}$ & $\mathrm{Er}^{(38)}$ & $\overline{\mathrm{Tm}^{(38)}}$ & $\mathrm{Tb}^{(39)}$ & $\mathrm{Yb}^{(39)}$ & $\mathrm{Lu}^{(39)}$ \\
\hline 1800 & 1740 & 1770 & 1766 & 1782 & 1795 & 1800 & 1807 & 1779 & 1796 & 1754 & 1800 \\
\hline (ref) & & & & & & & & & & &
\end{tabular}

A Figura 6.6 apresenta um gráfico das $\Delta H f^{\circ}$ dos óxidos e ortovanadatos de TR. Observa-se que a entalpia de formação dos compostos varia gradualmente entre os lantanídeos $(\mathrm{La}-\mathrm{Lu})$ com um acentuado decréscimo com o Eu e $\mathrm{Yb}$. O raio iônico do $\mathrm{Y}^{3+}$ é aproximadamente o mesmo do $\mathrm{Ho}^{3+} \mathrm{e}$ vê-se de fato que os dois elementos apresentam praticamente a mesma entalpia de formação. Todos os lantanídeos trivalentes apresentam os orbitais $5 s$ e $5 p$ completos. A diferença em termos de configuração eletrônica baseia-se no preenchimento dos orbitais $4 f$, entre o La e Lu.

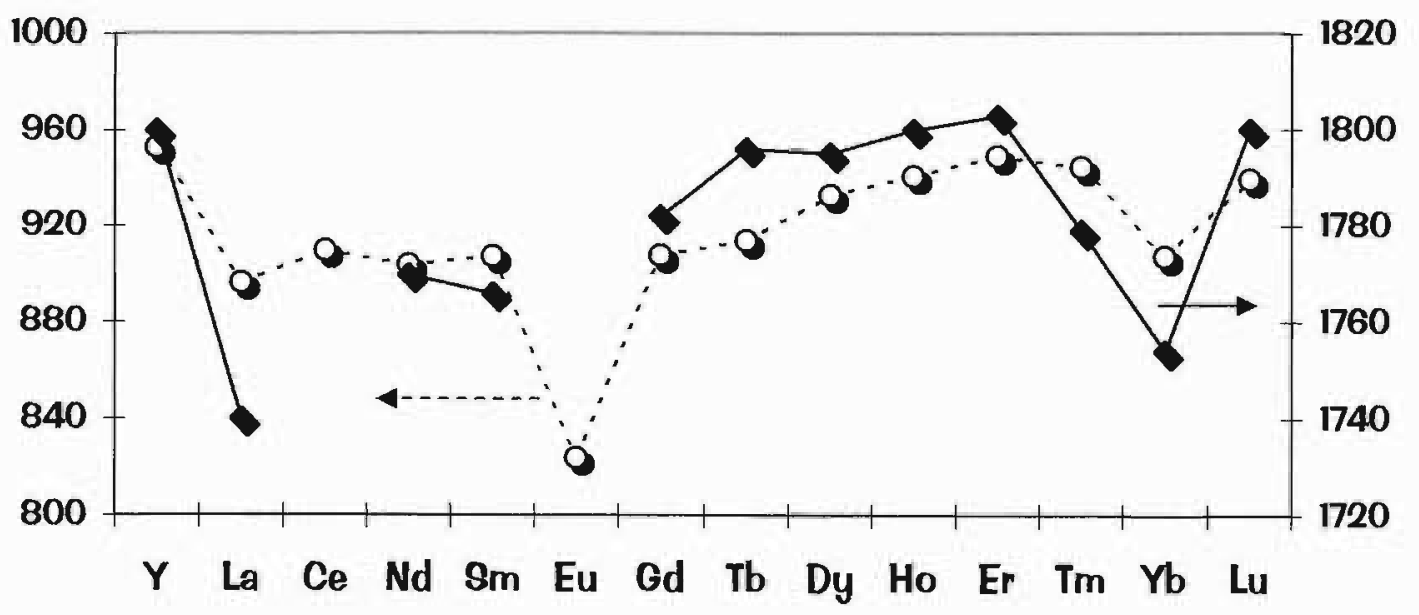

$$
\text { - O - Óxido } \longrightarrow \text { Ortovanadato }
$$

Figura 6.6. $\Delta H f^{\circ}$ de $\mathrm{TRVO}_{4}$ e $\mathrm{TR}_{2} \mathrm{O}_{3}, \mathrm{em}-\mathrm{kJ} . \mathrm{mol}^{I}$.

As variações e os desvios (no caso do $\mathrm{Eu} \mathrm{e} \mathrm{Yb}$ ) observados na entalpia de formação dos óxidos ocorrem em função da energia do retículo cristalino a partir da formação dos 
respectivos íons trivalentes gasosos. Uma clara explicação para a diferença do comportamento do Eu e Yb é obtida através da análise das configurações eletrônicas dos elementos. Para os íons trivalentes de lantanídeos, os elétrons de valência estão nos orbitais $4 f$, antes das camadas $5 s^{2}$ e $5 p^{6}$ completas, variando de $4 f^{1}$ para o $\mathrm{Ce}^{3+}$, até $4 f^{44}$ para o $\mathrm{Lu}^{3+}$. Especialmente no caso do $\mathrm{Eu}^{3+}$ e $\mathrm{Yb}^{3+}$, os elementos possuem configuração $4 f^{6}$ e $4 f^{13}$, respectivamente. A configuração eletrônica dos lantanídeos alcança maior estabilidade com os orbitais $4 f$ vazios, preenchidos totalmente $\left(f^{4}\right)$ ou pela metade $\left(f^{7}\right)$. Isto justifica a ocorrência de estados de oxidação além do (III), com ocorrem com o $\mathrm{Tb}^{4+}$ e o $\mathrm{Ce}^{4+}$. Assim, $\mathrm{Eu}^{3+} \mathrm{e} \mathrm{Yb}^{3+}$ tem a tendência de estabilizar um elétron de outras camadas no orbital $4 f$. Este elétron de menor energia participaria das ligações nos compostos formados, justificando a menor estabilidade [16-17].

O gráfico da Figura 6.7 apresenta a correlação entre a área específica das amostras de catalisadores pré-desativados incorporados com TR e a entalpia de formação padrão dos respectivos ortovanadatos [13-15]. Vê-se, portanto, que a preservação da estrutura cristalina do catalisador pode ser associada às propriedades termodinâmicas de formação dos $\mathrm{TRVO}_{4}$ envolvidas no processo com estimativa da interação TR-V.

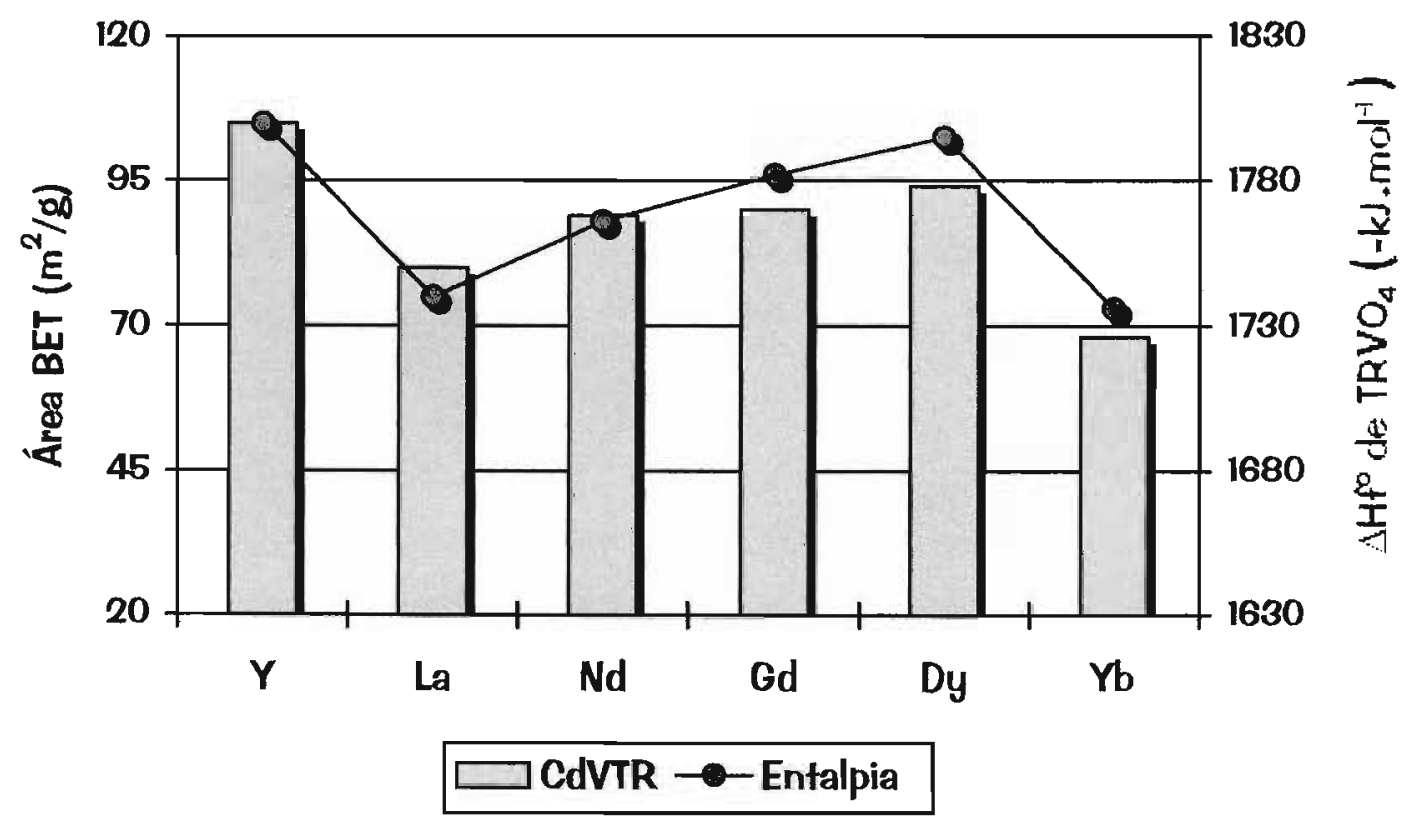

Figura 6.7. Relação entre a área BET das amostras submetidas à $\mathrm{DH}$ e $\mathrm{AHf}^{\circ}$ de $\mathrm{TRVO}_{4}$. 
A supressão da luminescência apresentada pelas amostras de zeólita Eu-Y pode também indicar a extensão do ataque do $\mathrm{V}$ à estrutura zeolítica e por conseguinte, a capacidade dos íons de TR em inibir tal reação. O parâmetro de intensidade $b$ também se correlaciona com as propriedades termodinâmicas dos $\mathrm{TRVO}_{4}$ (Figura 6.8). Ambas as propriedades podem ser consideradas para estimar o desempenho dos passivadores de TR nos sistemas estudados.

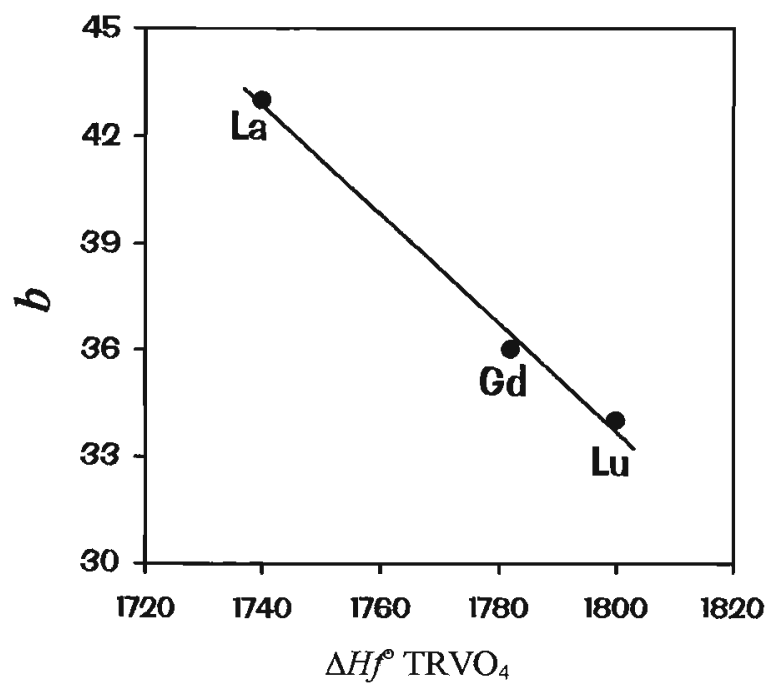

Figura 6.8. Relação entre o parâmetro de intensidade b e $\Delta H f^{\circ}$ de $\mathrm{TRVO}_{4}$, em -kJ.mol ${ }^{1}$. 


\section{Referências Bibliográficas}

[1] C.A. Trujillo, "Desarrollo de Passivadores de Vanadio para Catalizadores de Ruptura Catalítica", Tese de Doutoramento, Facultad de Ciências, Universidad Nacional de Colombia, Santafé de Bogotá, 1996.

[2] G. Catana, R.R. Rao, B.M. Weckhusyen, P. van der Voort, E. Vansant, R. A. Schoonheydt, "Supported Vanadium Oxide Catalysts: Quantitative Spectroscopy, Preferential Adsorption of $\mathrm{V}^{4+} \mathrm{N}^{5+}$, and $\mathrm{Al}_{2} \mathrm{O}_{3}$ Coating of Zeolite $Y^{\prime \prime}$, J. Phys. Chem. B, 102 (1998) 8005.

[3] M.T. Pope, in "Comprehensive Coordination Chemistry", G. Wilkinson ed., Oxford, Pergamon Press, 1987, p1026.

[4] S.M. Cheshnitskii, A.A. Fotiev, L.L. Surat, "The $\mathrm{Al}_{2} \mathrm{O}_{3}-\mathrm{V}_{2} \mathrm{O}_{5}$ System", Russ. J. Inorg. Chem., 28 (1983) 758.

[5] W.P. Hettinger Jr., "Catalysis Challenges in Fluid Catalytic Cracking”, Catal. Today, 53 (1999) 367

[6] R.F. Wormsbecher, A.W. Peter, J.M. Maselli, "Vanadium Poisoning of Cracking Catalysts: Mechanism of Poisoning and Design of Tolerant Catalyst System', J. Catal, 100 (1986) 130.

[7] M.L. Occelli, "Vanadium Resistant Fluid Cracking Catalysts", Stud. Surf. Sci. Catal., $100(1996) 27$

[8] C.R. Moreira, "Efeito do Método de introdução de Ce nas interações multicomponentes em sistemas V-Ce-USY”, Dissertação de Mestrado, Universidade Federal do Rio de Janeiro, Rio de Janeiro, 2001.

[9] D.C. Montgomery, G.C. Runger, "Estatística Aplicada e Probabilidade para Engenheiros", Rio de Janeiro, LTC ed., 2003, p214.

[10] H. Brusset, F. Madaule-Aubry, B. Blanck, J.P. Glaziou, J.P. Laude, "Etude des Oxydes Mixtes de Lanthanides et de Vanadium", Can. J. of Chemistry, 49 (1971) 3700.

[11] D.F. Mullica, E.L. Sappenfeld, M.M. Abraham, B.C. Chakoumakos, L.A. Boatner, "Structural Investigations of Several $\mathrm{LnVO}_{4}$ Compounds" Inorganica Chimica Acta, 248 (1996) 85 .

[12] E. F. Westrum Jr., "Developments in Chemical Thermodynamics of the Lanthanides", Adv. in Chem. Ser., 71 (1967) 25. 
[13] S. Zielinski, W. Skupin, "Détermination des Chaleurs de Formation des Orthovanadates de Certains Élements de Terres Rares par La Méthode D'analyse Thermique Différentielle", J. Thermal Anal., 19 (1980) 61.

[14] G.A. Rykova, O.N. Ustulova, M. Skorikov, I.V. Tananaev, "Interaction of Vanadium(V) Oxide with Dysprosium, Thulium, Yterbium and Lutetium Oxides", J. Russ. Inorg. Chem., 24 (1979) 183.

[15] G.A. Rykova, M. Skorikov, "Enthalpy of Formation and Heat capacity of Lanthanide Orthovanadate”, J. Russ. Inorg. Chem., 28 (1983) 644.

[16] L. Brewer, "Systematics of the Properties of the Lanthanides", in: Systematics of the Prorperties of the Lanthanides, S.P. Sinha, ed., New York, D. Riedel Publishing Company, $54,1983$.

[17] O. Johnson, "Role of Electros in chemical Bonding", J. Chem. Educ., 47 (1970) 431. 


\section{Conclusões}

As TR apresentam uma razoável capacidade de atenuar o ataque promovido pelo $\mathrm{V}$ ao catalisador quando submetido às condições próximas àquelas encontradas no regenerador. A inserção das TR por meio dos complexos em solventes orgânicos conforme protocolo de teste Mitchell proporciona maior capacidade de proteger o catalisador que os óxidos fisicamente misturados, uma vez que a distribuição sobre as partículas é mais uniforme e o contato com o V otimizado.

Quando adicionados sob quantidades estequiométricas, os passivadores de TR não são hábeis para capturar todo o V presente no meio, em função da diferença de mobilidade no sistema. Assim, o efeito proporcionado pelas TR na passivação do $\mathrm{V}$ se concentra preferencialmente na superfície das partículas.

Os resultados fornecidos pelas diferentes técnicas empregadas no trabalho indicam que o mecanismo de ataque à estrutura cristalina envolve, primeiramente, a coordenação do $\mathrm{V}$, via oxigênio, ao $\mathrm{Al}$ da zeólita ou da matriz. Os tratamentos térmicos provocam a mudança de geometria e estado de oxidação do $\mathrm{V}$. A presença de vapor de água é fundamental na formação das espécies que atuam no mecanismo de ataque do $\mathrm{V}$ à estrutura. Quando o catalisador possui Al extra-estrutural resultado da pré-desativação, o ataque é moderadamente suprimido.

A interação entre as TR e o V promove a formação de ortovanadatos de alta estabilidade térmica. A manutenção do $V$ em baixo estado de oxidação através das TR não é possível nas condições propostas no estudo.

As TR estudadas apresentam desempenhos ligeiramente diferentes, no que concerne a passivação de $\mathrm{V}$, quando adicionados em uma relação equimolar. Os 
lantanídeos são praticamente iguais entre si em termos de passivação. O Y apresenta o melhor desempenho da série estudada.

As diferenças observadas indicam que o melhor desempenho, no elenco das TR estudadas, pode ser indicado com base nas propriedades termodinâmicas da reação com o $\mathrm{V}$.

Dada a abundância na ocorrência em alguns minérios e a capacidade de preservação do catalisador a uma dada relação mássica TR/V, vemos que quando Y é usado como TR há maior potencialidade em termos de emprego comercial, quer seja através de complexos ou de trapas metálicas, como demonstra a Figura 7.1.

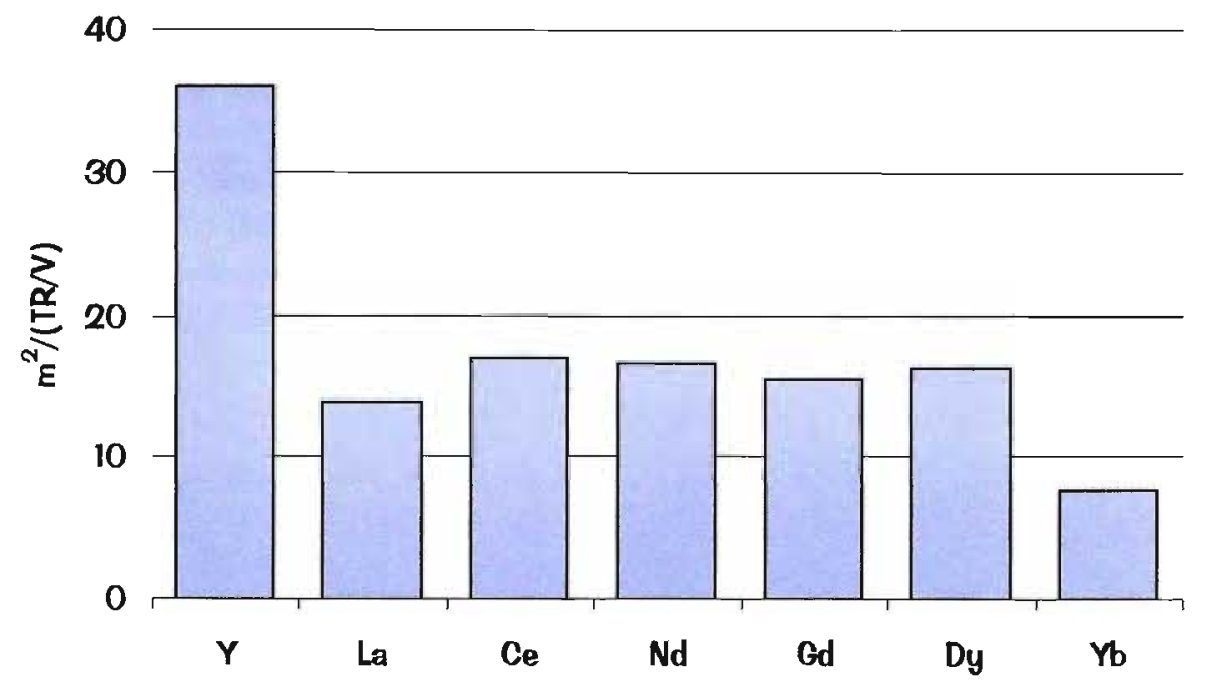

Figura 7.1. Área do catalisador preservada em função da relação mássica de TR/V por elemento nas amostras de catalisador pré-desativado. 